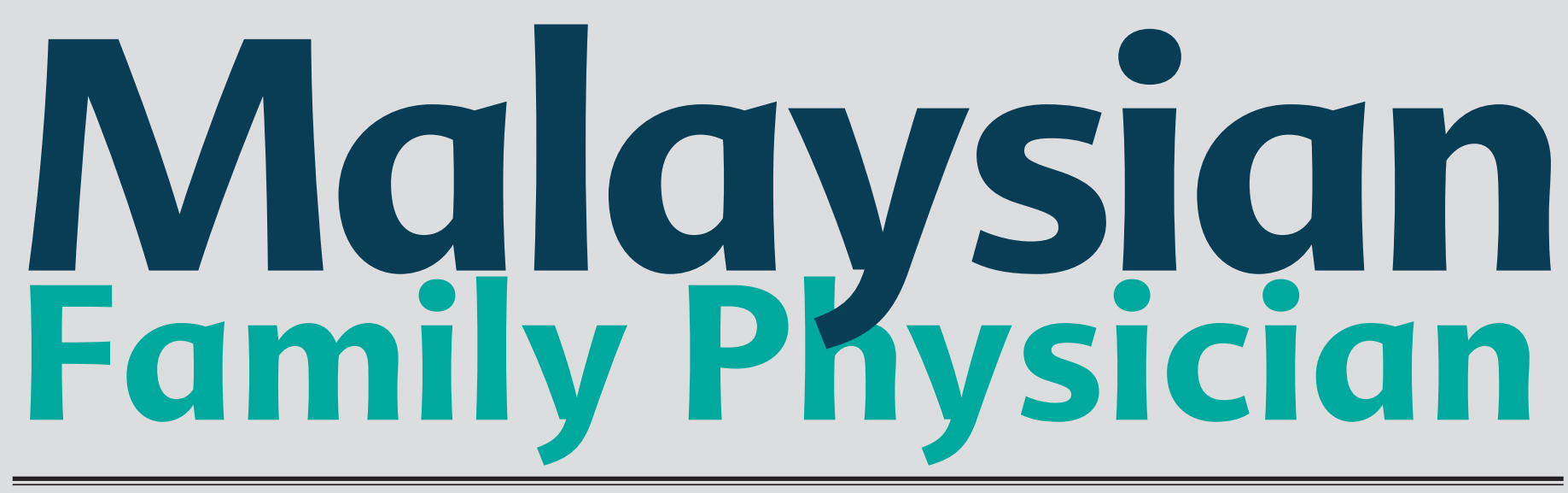

www.e-mfp.org

Official Journal of the Academy of Family Physicians of Malaysia and Family Medicine Specialist Association

2021 Volume 16 No. 1

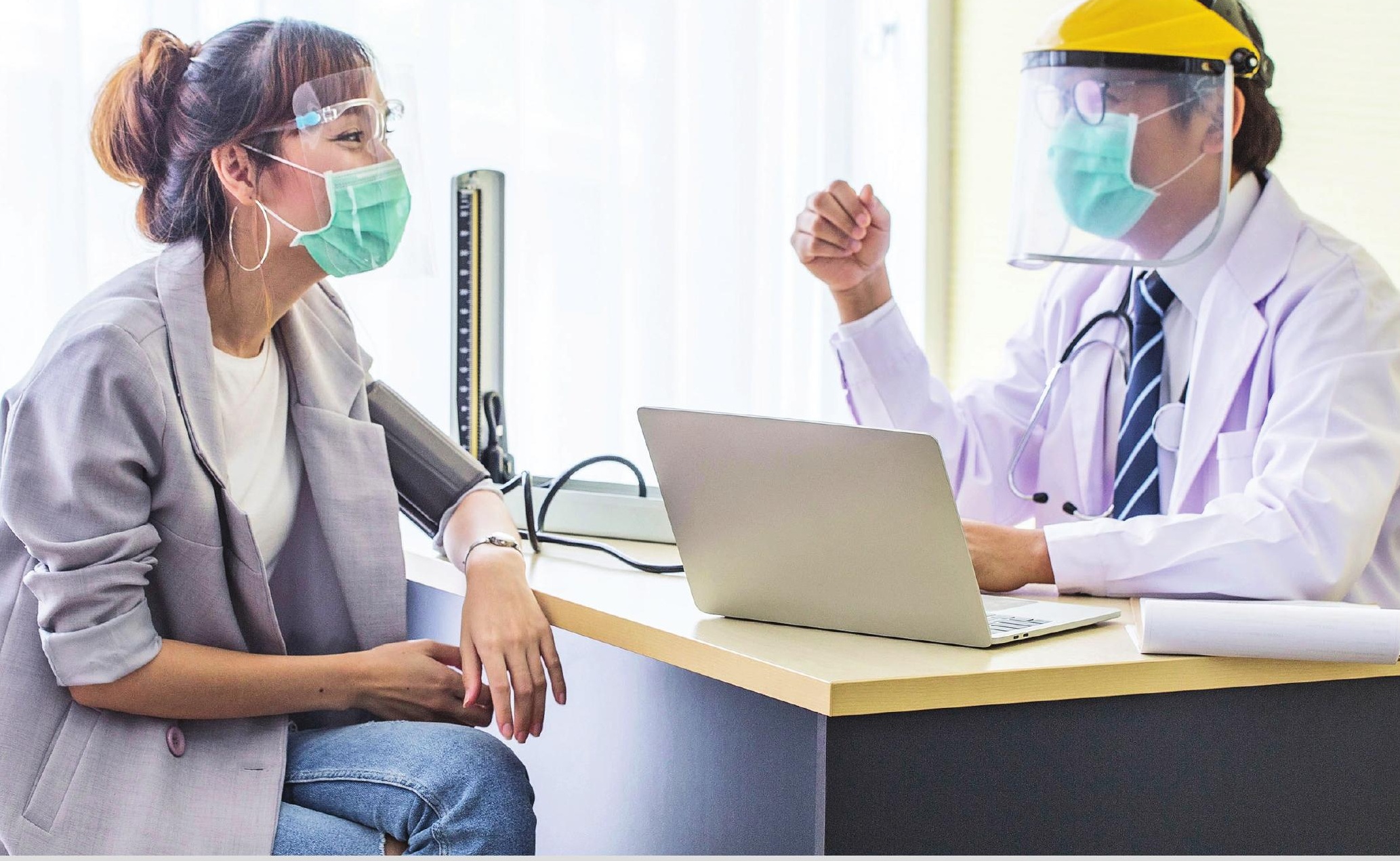

- Stigmatizing attitudes toward people living with HIV/AIDS (PLWHA) among primary health care providers in Kinta District, Perak

- Knowledge, attitude, and practice regarding atrial fibrillation among primary care physicians: the potential role of postgraduate training

- A single-centre experience of febuxostat as a second-line uratelowering therapy 


\section{About MFP}

The Malaysian Family Physician (MFP) is the official journal of the Academy of Family Physicians of Malaysia (AFPM). It is jointly published by the Family Medicine Specialist Association (FMSA) of Malaysia. The MFP is published three times a year. It also started an Online First section in January 2021, where accepted articles are published online ahead of the issue.

Goal: The MFP is an international journal that disseminates quality knowledge and clinical evidence relevant to primary care. The journal acts as the voice of family physicians, researchers and other members of the primary care team on clinical practice issues.

Scope: The MFP publishes:

i. Research - Original Articles and Reviews

ii. Education - Case Reports/Clinical Practice Guidelines/Test Your Knowledge. We only encourage case reports that have the following features:

1. Novel aspects

2. Important learning points

3. Relevant to family practice

iii. Invited debate, commentary, discussion, letters, online, comment, and editorial on topics relevant to primary care.

iv. A Moment in the Life of a Family Physician - We encourage submission of a short narrative to share perspectives, voice, views and opinions about a family physician's experience that has affected their practice or life. This moment should be a reflective piece of fewer than 500 words in length.

Strength: MFP is the only primary care research journal in Malaysia and one of very few in the region. It is open access and fully online. The journal is indexed in Scopus and has a relatively fast review time. The journal has a strong editorial team and an established pool of readers with increasing recognition both locally and internationally.

Circulation: The journal is freely available online.

\section{All correspondence should be addressed to:}

\section{Professor Dr. Su May Liew}

The Editor

The Malaysian Family Physician Journal

Academy of Family Physicians of Malaysia,

Unit 1-5, Level 1 Enterprise 3B Technology Park Malaysia (TPM)

Jalan Innovasi 1 Lebuhraya Puchong-Sungai Besi

Bukit Jalil, 57000 Kuala Lumpur.

Tel: $+603-89939176 / 9177$

Fax: $603-89939187$

Email: journal.mfp@gmail.com

Website: http://www.e-mfp.org

\section{Publication Ethics}

Ethics

Evidence of ethics approval and informed consent should be included in the manuscript for studies involving animal experiments or human participants.

Competing interests

MFP requires authors to declare all conflicts of interest in relation to their work. All submitted manuscripts must include a 'competing interests' section at the end of the manuscript (before references) listing all competing interests.

\section{Ethical Guidelines for Authors}

Authorship credit should be based only on:

1. Substantial contributions to conception and design, or acquisition of data, or analysis and interpretation of data;

2. Drafting the article or revising it critically for important intellectual content; and

3. Final approval of the version to be published.

4. Agreement to be accountable for all aspects of the work ensuring that questions related to the accuracy or integrity of any part of the work are appropriately investigated and resolved.

\section{Plagiarism Policy}

The journal takes a serious view on cases of plagiarism and research misconduct. All submitted articles are checked for plagiarism. If plagiarism or research misconduct is suspected, a thorough investigation will be carried out and action taken according to COPE guidance found at https://publicationethics.org/resources/flowcharts.

Open Access Policy

Upon acceptance, all articles in the Malaysian Family Physician are immediately and permanently free for everyone to read and download.

Disclaimer: Although an official publication, the Malaysian Family Physician provides a forum for free expression and exchange of views among those in the profession. Therefore, views expressed in published articles are not necessarily those of the Journal, AFPM or FMSA. The views of the editor need not reflect the views of the Academy. No portion of any matter appearing in the Malaysian Family Physician may be quoted or republished in any form without the prior written consent of the author, editor and the AFPM. 


\section{Editorial Board}

\section{Chief Editor}

Professor DrSu-May Liew (su_mayliew@um.edu.my)

\section{Deputy Chief Editor}

Professor Dr Ping Yein Lee (pylee@medic.upm.edu.my)

\section{Associate Editors}

Associate Professor Dr Adina Binti Abdullah (adinabdullah@um.edu.my)

Associate Professor Dr Ai Theng Cheong (caitheng@gmail.com)

Associate Professor Dr Boon How Chew (chewboonhow@gmail.com)

Professor Dr Ee Ming Khoo (khooem@um.edu.my)

Professor Dr Harmy Bin Mohamed Yusoff (harmyusoff@unisza.edu.my)

Dr Irmi Zarina Binti Ismail (irmiismail@upm.edu.my)

Associate Professor Dr Nik Sherina Haidi Binti Hanafi (sherina@ummc.edu.my)

Dr Ping Foo Wong (pingfoo@hotmail.com)

Dr Say Hien Keah (richardkeah8282@gmail.com)

Professor Dr Sazlina Binti Shariff Ghazali (drsazsg@gmail.com)

Associate Professor Dr Siew Mooi Ching (sm_ching@upm.edu.my)

Dr Sylvia McCarthy (sylvia@hospismalaysia.org)

DrV Paranthaman P Vengadasalam (drparan@gmail.com)

Dr Wai Khew Lee (leewaikhew@hotmail.com)

Dr Zainal Fitri Bin Zakaria (drzainalfitri@moh.gov.my)

\section{Local Advisors}

Professor Dr Chirk Jenn Ng (ngcj@um.edu.my)

Professor Datin Dr Yook Chin Chia (chiayc@um.edu.my)

Professor DrWah Yun Low (lowwy@um.edu.my)

Associate Professor Datuk Dr DM Thuraiappah (dmthuraiappah@gmail.com)

\section{International Advisors}

Professor Dr Cindy Lo-Kuen Lam (Hong Kong)

Professor Dr John W Beasle (USA)

Professor Dr Julia Blitz (South Africa)

Associate Professor Dr Lee Gan Goh (Singapore)

Professor Dr Michael Kidd (Australia)

Professor Dr Moyez Jiwa (Australia)

Professor Dr Nigel J Mathers (United Kingdom) 


\section{Information for Authors}

The Malaysian Family Physician welcomes articles on all aspects of family medicine in the form of original research papers, review articles, CPG review, case reports, test your knowledge and letters to the editor. The journal also publishes invited debate, commentary, discussion, letters, comment, and editorials on topics relevant to primary care.

Articles are accepted for publication on condition that they are contributed solely to the Malaysian Family Physician. Neither the Editorial Board nor the Publisher accepts responsibility for the views and statements of authors expressed in their contributions. All papers will be subjected to peer review. The Editorial Board further reserves the right to edit and reject papers. Authors are advised to adhere closely to the instructions given below to avoid delays in publication.

All manuscripts must be submitted through the Open Journal System (OJS) at http://e-mfp.org/ojs

\section{SUBMISSION REQUIREMENTS}

1. The author must declare that the manuscript has not been previously published, nor is it being considered for publication in another journal concurrently.

2. The Main Manuscript should be submitted in electronic form only and in Microsoft Word.

- The manuscript contains all the sub-headings required for the article type (refer below).

- The manuscript uses a single-spaced, 12-point font and uses italics rather than underlining (except URL addresses).

- All figures, tables and illustrations are placed at the appropriate sections in the manuscript file rather than at the end of the manuscript or submitted separately.

- Use left-aligned paragraph formatting rather than full justification.

- Follow the instructions in Ensuring a Blind Review (refer below).

- Follow the referencing style provided in the References section below.

- Provide URLs for references where available.

- Where available, URLs for the references have been provided.

3. The Title Page must be uploaded separately from the main manuscript file in Microsoft Word. Please refer to the required sub-headings in the Title Page section below.

4. A Cover Letter must be signed by the corresponding author on behalf of all authors. This letter must include this statement "this manuscript is my (our) own work, it is not under consideration by another journal, and this material has not been previously published."

5. All authors must sign the Declaration Form and submit it together with the manuscript and cover letter. Please download the form here.

6. Please enter all authors' name and email address in the submission portal.

7. When preparation your manuscript, please follow the Uniform Requirements for Manuscripts Submitted to Biomedical Journals recommended by the International Committee of Medical Journal Editors (http://www.icmje.org/icmje-recommendations.pdf).

\section{TITLE PAGE}

For all types of manuscript, please include all the sub-headings below in the Title Page:

- Article Type: Original Research / Review / CPG Review / Case Report / Test Your Knowledge / Letter To Editor

- Title: Please state the title in detail to include the study design, particularly for original research.

- Author(s): The full names, professional qualifications (limited to two only) and institutions of all authors.

- Shortened name of author(s): should be written in the style of surname or preferred name followed by initials, e.g. Abdullah KS, Rajakumar MK, Tan WJ, for future indexing.

- Corresponding Author: Corresponding author's mailing address, designation, institution and contact details (email, telephone and fax numbers)

- Funding: Please state if the study was funded; if so, by which institution and the funding ID.

- Ethical Approval: Please state if the study was approved; if so, by which institution and the approval ID.

- Conflicts of interest: Please state if any author has a conflict of interest.

\section{MAIN MANUSCRIPT}

For every article submitted, please follow the requirements according to the type of article.

\section{Original Research (Including Clinical Audit Article)}

The original research (including clinical audit) should be conducted in the primary care setting on a topic of relevance to family practice. Both qualitative and quantitative studies are welcome. The length should not exceed 3000 words with a maximum of 5 tables or figures and 30 references. Please include the following sub-headings in the manuscript:

1. Title: State the title based on PICO, including study design.

2. Abstract: Structured abstract (Introduction, Methods, Results and Conclusion) of no more than 250 words.

3. Keywords: 3-5 keywords, preferably MeSH terms.

4. Introduction: Clearly state the purpose of the article with strictly pertinent references. Do not review the subject extensively.

5. Methods: Describe the study in sufficient detail to allow others to replicate the results. Provide references to established methods, including statistical methods; provide references and brief descriptions of methods that have been published but are not well known; describe new or substantially modified methods, give reasons for using them, and evaluate their limitations. When mentioning drugs, generic names are preferred (proprietary names can be provided in brackets). Do not use patients' names or hospital numbers. Include numbers of observation and the statistical significance of the findings. When appropriate, state clearly that the research project has received the approval of the relevant ethical committee. For an RCT article, please include the trial registration number) and follow the CONSORT checklist. Other study designs must also follow a reporting checklist, which can be found at https://www.equator-network.org/.

6. Results: Present your results in logical sequence in the text, tables and figures. Tables and figures may be left at the respective location within the text. These should be numbered using Arabic numerals only. Table style should be "Simple" (as in Microsoft Word). Do not repeat table or figure data in the text.

7. Discussion: Emphasise the new and important aspects of the study and conclusions that follow from them. Do not repeat data given in the Results section. The discussion should state the implications of the findings and their limitations and relate the observations to the other relevant studies. Link the conclusions with the aims of the study but avoid unqualified statements and conclusions not completely supported by your data. Recommendations, when appropriate, may be included.

8. Acknowledgements: Acknowledge grants awarded in aid of the study and people who have contributed significantly to the study (but do not qualify for authorship).

9. Conflicts of interest: All authors must declare any conflicts of interest.

10. How does this paper make a difference in general practice?: This section should be written in bullet points (up to five points) and must not exceed 100 words.

11. References: Refer to the References section below for more details. 
All types of review articles, including narrative review, scoping reviews and systematic reviews are accepted for publication in MFP. A comprehensive review of the literature with a synthesis of practical information for practising doctors is expected. For a systematic review, the PRISMA checklist (https://www.equator-network.org/reporting-guidelines/prisma/) must be followed. For a scoping review, the PRISMA-ScR checklist (https:// www.equator-network.org/reporting-guidelines/prisma-scr/) should be followed. The length should not exceed 4000 words with a maximum of 5 tables or figures and 40 references. Please include the following sub-headings in the manuscript:

1. Title: Include the topic and type of review in the title.

2. Abstract: Structured abstract (Introduction, Methods, Results and Conclusion) of no more than 250 words.

3. Keywords: $3-5$ keywords, preferably MeSH terms.

4. Introduction: Describe the topic and objective of the review.

5. Methods: All types of review articles (including narrative review) must report the search strategy, database and keywords used to obtain the literature. The PRISMA and PRISMA-ScR checklists should be followed for systematic and scoping reviews, respectively.

6. Results ( ${ }^{*}$ for systematic and scoping reviews): This section is required for systematic and scoping reviews. Please follow the guideline in the PRISMA and PRISMA-ScR checklists.

7. Discussion (*for systematic and scoping reviews): This section is required for systematic and scoping reviews. Please follow the guideline in the PRISMA and PRISMA-ScR checklists.

8. Any relevant subheadings ( ${ }^{*}$ for narrative review): A narrative review may have any other relevant sub-headings according to needs.

9. Conclusion: Provide a conclusion by linking to the objective of the review.

10. Acknowledgements: Acknowledge grants awarded in aid of the study and people who have contributed significantly to the study (but do not qualify for authorship).

11. Conflicts of interest: All authors must declare any conflicts of interest.

12. How does this paper make a difference in general practice?: This section should be written in bullet points (up to five points) and must not exceed 100 words.

13. References: Refer to the References section below for more details.

\section{Case Report}

Case reports should preferably be less-commonly seen cases that have an educational value for practising doctors. Only case reports that are novel, have important learning points and relevant to family practice will be accepted for publication in this journal. The case report must be written in a patient-centred manner instead of a disease-centred focus. The length should not exceed 1500 words and cite no more than 20 references. Before submitting the case report, the authors must ensure that the patient's identity is protected both in the text and pictures. Please include the following sub-headings in the manuscript:

1. Title: Use an interesting title to show the new learning points and include the term "case report" in the title.

2. Abstract: Unstructured abstract between 100-250 words.

3. Keywords: $3-5$ keywords, preferably $\mathrm{MeSH}$ terms.

4. Introduction: Describe the condition and aim of the case report.

5. Case Presentation: Describe the case in detail.

6. Discussion: Discuss the case with existing literature.

7. Conclusion: Provide the key learning point from the case report.

8. Acknowledgements: Acknowledge grants awarded in aid of the study and people who have contributed significantly to the study (but do not qualify for authorship).

9. Conflicts of interest: All authors must declare any conflicts of interest.

10. Patients' consent for the use of images and content for publication: Was consent obtained from the patient(s)? Was the consent written or verbal?

11. What is new in this case report compared to the previous literature?: This section should be written in bullet points (up to five points) and must not exceed 100 words.

12. What is the implication to patients?: Describe any potential implication to patients based on the learning points from this case report.

13. References: Refer to the References section below for more details.

\section{CPG Review}

The CPG should be relevant to primary care. Its length should not exceed $\mathbf{4 0 0 0}$ words and $\mathbf{4 0}$ references. An abstract is required (no more than 300 words) together with the keywords. The CPG review should be written with case vignettes to illustrate its application in primary care practice.

1. Title: State the scope of the CPG, include the latest version or year for revised CPGs.

2. Abstract: Unstructured abstract between 100-250 words.

3. Keywords: 3-5 keywords, preferably MeSH terms.

4. Introduction: Describe the condition and aim of the CPG review.

5. Development process of the CPG: Describe the development process of the CPG, e.g.: who are the team members involved, what methodology was used, how was the evidence gathered, how was the decision made on the recommendations, was the outcomes validated, how was the CPG disseminate and implementation, etc. Follow the AGREE Reporting Checklist (https://www.equator-network.org/wp-content/ uploads/2016/03/AGREE-Reporting-Checklist.pdf) wherever possible.

6. Key recommendations of the CPG: Describe the key recommendations primary care doctors should know.

7. Key changes in the CPG (only applicable for revised CPGs): Describe the key changes or updates from the previous CPG.

8. How to apply the CPG into practice in primary care? Explain how the CPG can be used in primary care practice.

9. Case vignettes as examples of application: Use case vignettes to illustrate the application of the CPG.

10. Conclusion: Summarise the key learning points.

11. Acknowledgements: Acknowledge grants awarded in aid of the study and people who have contributed significantly to the study (but do not qualify for authorship).

12. Conflicts of interest: All authors must declare any conflicts of interest.

13. How does this paper make a difference in general practice?: This section should be written in bullet points (up to five points) and must not exceed 100 words.

14. References: Refer to the References section below for more details. 


\section{Test Your Knowledge}

A Test Your Knowledge article should be relevant to primary care and preferably be about less-commonly seen cases that have an educational value for practising doctors. The length should not exceed 1000 words and no more than 20 references. Please include the following sub-headings in the manuscript:

1. Title: State the title in a question format.

2. Abstract: Unstructured abstract between 100-250 words.

3. Keywords: 3-5 keywords, preferably MeSH terms.

4. Case Summary: Describe the case.

5. Questions: State the questions.

6. Answers with discussion: Provide the answers and discuss them with support from the literature.

7. Acknowledgements: Acknowledge grants awarded in aid of the study and people who have contributed significantly to the study (but do not qualify for authorship).

8. Conflicts of interest: All authors must declare any conflicts of interest.

9. How does this paper make a difference in general practice?: This section should be written in bullet points (up to five points) and must not exceed 100 words.

10. References: Refer to the References section below for more details.

\section{Letter to Editor}

A letter to the editor should be of relevance to primary care and in response to an article or topic published in previous issues of this journal. The length should not exceed 1000 words and cite no more than 20 references. Please include the following sub-headings in the manuscript:

1. Title: State the title clearly.

2. Keywords: 3-5 keywords, preferably MeSH terms.

3. Main text: Start the manuscript with "Dear editor:" There is no specific required heading. Authors can create any sub-headings as necessary.

4. References: Refer to the References section below for more details.

\section{REFERENCES}

Number references consecutively in the order in which they are first mentioned in the text. Identify references in text, tables and legends by Arabic numerals (in superscript). Please use the citation style adopted by the National Library of Medicine, Maryland, USA, (http://www.pubmed.gov), some examples are given below. For indexed journals, the short forms for the journal names can be accessed at the PubMed website (search within Journal Database). Where possible, avoid citing abstracts, personal communication or unpublished data as references. Include among the references manuscripts accepted but not yet published and designate the journal followed by "in press" (in parenthesis). When referencing a website, please include the full title and accessed date. Notice article titles are capitalised in sentence case; book and journal titles are capitalised in title case. Some examples of reference list entries:

- Standard journal article: List up to three authors only; when four or more, list only the first three and add et al. Connor EM, Sperling RS, Gelber R, et al. Reduction of maternal-infant transmission of human immunodeficiency virus type 1 with zidovudine treatment. Pediatric AIDS Clinical Trials Group Protocol 076 Study Group. N Engl J Med. 1994 Nov 3;331(18):1173-80.

- Standard journal article: Corporate Author International Committee of Medical Journal Editors. Uniform requirements for manuscripts submitted to biomedical journals. N Engl J Med.1997 Jan 23; 336(4):309-16.

- Books and other monographs: Personal Author(s) Stewart M, Brown JB, Weston WW, et al. Patient-Centered Medicine: Transforming the Clinical Method. Thousand Oaks, California: Sage Publications; 1995.

- Books and other monographs: Corporate Author Wonca International Classification Committee. International Classification of Primary Care, ICPC-2. 2nd ed. Oxford: Oxford University Press; 1998.

\section{ENSURING A BLIND REVIEW}

To ensure the integrity of the blind peer-review for submission to this press, every effort should be made to prevent the identities of the authors and reviewers from being known to each other. This involves the authors, editors, and reviewers (who upload documents as part of their review) checking to see if the following steps have been taken with regard to the text and the file properties:

- The authors of the document have deleted their names from the text, with "Author" and year used in the references and footnotes, instead of the authors' name, article title, etc.

- With Microsoft Office documents, author identification should also be removed from the properties for the file (see under File in Word), by clicking on the following, beginning with File on the main menu of the Microsoft application: File > Save As > Tools (or Options with a Mac) > Security $>$ Remove personal information from file properties on save $>$ Save.

- With PDFs, the authors' names should also be removed from Document Properties found under File on Adobe Acrobat's main menu.

\section{POLICY FOR USING ANY PUBLISHED MATERIALS}

Authors must seek approval from and acknowledge the MFP if they wish to use any published materials from this journal. Write to the Editorial Manager at email: editor.mfp@afpm.org.my

\section{ARTICLE PROCESSING CHARGES}

The Malaysian Family Physician does not charge submission, article processing, page or colour charges presently. The costs for services provided are funded by the Academy of Family Physicians of Malaysia and the Family Medicine Specialist Association. We retain the right to change this policy in the future, but this will only be done with due notice to all stakeholders.

\section{COPYRIGHT}

If the article is accepted for publication, the author agrees to transfer the copyright to AFPM. 
ii Editorial board

iii Information for authors

Editorial

Commentary

Review

8 Basic technology and proper usage of home health monitoring devices Himel Mondal, Shaikat Mondal

15 Sane and safe: Forced social distancing to prevent human-to-human transmission of COVID-19

Firdous Jahan

18 Experiences of women who underwent induced lactation: A literature review Shahirah Mohd Hassan, Zaharah Sulaiman, Tengku Alina Tengku Ismail

Original Article

31 Stigmatizing attitudes toward people living with HIV/AIDS (PLWHA) among primary health care providers in Kinta District, Perak

Chan Yuen Ching, Maliza Mawardi, Adibah Hanim Ismail@Daud

39 Knowledge, attitude, and practice regarding atrial fibrillation among primary care physicians: the potential role of postgraduate training

Phaik Choo Ooi, Gogilavendan Ramayah, Syahril Rizwan B. Omar, Vilasini Rajadorai, Thatsheila Nadarajah, Chung Hui Ting, Cheong Lieng Teng

50 A single-centre experience of febuxostat as a second-line urate-lowering therapy Swee Gaik Ong, Hui Jen Ding

56 Effectiveness of an intervention to increase the knowledge, attitude, and practice regarding the return and disposal of unused medications

Pauline Siew Mei Lai, Kit Mun Tan, Hong Gee Lee, Yin Yen Wong, Nur Azrida Azhari Wasi, Si Mui Sim

64 Development and validation of the maternal blues scale through bonding attachments in predicting postpartum blues

Suryani Manurung, S. Setyowati

75 The feasibility of a public-private mix program on pulmonary tuberculosis screening in Penang: A pilot study

Wei Shuong Tang, Mei Wai Chan, Fei Ping Kow, Ranjini A/P Ambigapathy, Justen Han Wei Wong, Vasantha Thiruvengadam, Umarazina bt Abd Kadir, Anita Jain, Ramesvari Pararajasingam Pillai

84 Exploring women's perceptions and experiences of menopause among East Coast Malaysian women

Nurul Najmi Mohamad Ishak, Nurjasmine Aida Jamani, Siti Roshaidai Mohd Arifin, Azwanis Abdul Hadi, Karimah Hanim Abd Aziz

93 Prevalence of musculoskeletal pain in two primary care clinics in a mid-sized town's urban population in Malaysia

Esha Dasgupta, Jasmine Li Lin Yap, K. Kirosa Kunjunee, Xin Ying Choong, Wan Wen Soh, Meroshini Sundaran, Swan Sim Yeap, Keen Sang Tai 

the primary care physician

Tharumaraja Thiruselvam, Aminudin Che-Ahmad, Ping Foo Wong, Afiza Hanun Ahmad@ Hamid, Mohd Idham Hasan, Mohd Yazid Bajuri, Gurmeet Singh Sewa Singh, Vijiya Mala Valayatham, Siti Norzalilah Abdul Majid, Hafizan Mohd Tajri, Masfiza Abdul Hamid, Ainol Haniza Kherul Anuwar, Mohd Aminuddin Mohd Yusof

Case Report
114 A rare cause of acute urinary retention in a young man: A median raphe penile cyst Mohd. Nazli Kamarulzaman, Azhani Chik, Hamid Ghazali

117 Facial nerve palsy in otitis externa: A red flag?

Aliyya Badaruddin, May May Choo

121 A life-threatening condition-ruptured ectopic pregnancy with negative urine pregnancy test: A case report

Fadzilah Mohamad, Ahmad Shuib Yahya, Aneesa Abdul Rashid, Navin Kumar Devaraj, Abdul Hadi Abdul Manap

124 Type 2 diabetes remission: How does it work?

Mohd Shahriman bin Ahmad Fuat, Faridah binti Mohd Zin, Zainab binti Mat Yudin

129 Late-Onset Mirror Syndrome

Erinna Mohamad Zon, Nik Ahmad Zuky Nik Lah, Pek Sung Hoo

133 Aural polyp with facial asymmetry in an unfortunate infant Farah Syahida Zubir, Jeyasakthy Saniasiaya, Haslinda Abdul Gani

136 Acute ptosis as a presentation of preseptal cellulitis leading to cerebral abscess in a patient with uncontrolled diabetes

Nor Roziah Razali, Yao Mun Choo 


\title{
EDITORIAL
}

\section{Changes to manuscript requirements and website}

\author{
Liew Su May \\ Chief Editor of MFP
}

\begin{abstract}
On behalf of the Board of Editors, Malaysian Family Physician, I am pleased to announce the latest changes to our journal. These changes are in line with the journal's ongoing efforts to improve the quality of the journal, increase visibility and readership, and fulfil our overall aim, which is to act as the voice of family physicians, researchers and other members of the primary care team on clinical practice issues and research.
\end{abstract}

The first change is that we are now publishing articles online prior to the publication of the journal issue. This is our Online First section that can be seen at our website https://e-mfp.org/. We hope to improve our time to publication through this method as the journal only publishes three issues in a year. I will take this opportunity to assure authors that the board of editors will continue to work on our time to publication to ensure that your work is shared in a timely manner. However, this will require the help of all members of our fraternity as it is challenging to find reviewers for the articles.

Secondly, we have revised the content of the Information for Authors page. An article may not be able to pass screening or peer review if it does not fulfil journal requirements. We ask authors to carefully go through these guidelines so that their submitted manuscripts will be more likely to pass review. You will see that we have made this section more detailed and emphasized ethical requirements, a patient-centred focus and reporting checklists according to study design.

Our aim is not to make it more difficult to publish in the Malaysian Family Physician! We hope to make it easier for authors to publish their research by stating the requirements clearly from the start. Thank you for helping us in our efforts to improve our journal. 


\title{
Practising shared decision making in primary care
}

\author{
Ping Yein Lee, Chirk Jenn Ng
}

Lee PY, Ng CJ. Practising shared decision making in primary care. Malays Fam Physician. 2021;16(1);2-7. https://doi.org/10.51866/cm0001

\section{Keywords:}

Shared decision making,

primary care, patient decision

aids, implementation.

\section{Authors:}

$\mathrm{Ng}$ Chirk Jenn

(Corresponding author) MBBS, MMed Family Med, PhD

Department of Primary Care

Medicine, Faculty of Medicine

University of Malaya, Kuala Lumpur

Malaysia

Email: ngcj@um.edu.my

\section{Lee Ping Yein}

MBBS, MMed Family Med

Department of Family Medicine Faculty of Medicine and Health

Sciences, Universiti Putra

Malaysia, Serdang, Malaysia

\section{Abstract}

Making healthcare decisions collaboratively between patients and doctors can be challenging in primary care, as clinical encounters are often short. Conflicts between patients and doctors during the decision-making process may affect both patient and doctor satisfaction and result in medicolegal consequences. With the increasing recognition of the importance of patient empowerment, shared decision making (SDM) can serve as a practical consultation model for primary care doctors (PCDs) to guide patients in making informed healthcare choices. Although more research is needed to find effective ways to implement SDM in the real world, the 6-step approach presented in this paper can guide PCDs to practise SDM in their daily practice. Implementation of SDM can be further enhanced by incorporating SDM training into undergraduate and postgraduate curricula and using evidence-based tools such as patient decision aids.

\section{Box 1. Case Study 1: Making a decision about starting insulin in a patient with type 2 diabetes}

Sally, a 68-year-old woman, has been diagnosed with type 2 diabetes mellitus for the past 15 years. She attends the Health Clinic nearby every 4 months for her diabetes check. Sally was able to achieve good control initially for the first few years; more recently, her doctor had to increase the dosage of her oral medications and add new medications to keep her diabetes under control.

During this clinic visit, Sally meets Dr Jon, a newly graduated family medicine specialist, who advises her to consider starting insulin. Dr Jon explains to Sally that her blood glucose control has deteriorated over the past 1 year (Hbalc : 8-9\%) despite taking three oral medications. Sally is surprised as she has been taking her medications regularly without fail and is extremely careful with her diet and exercise routine. She is not keen to start insulin as she is fearful of needles and pain with injections.

Dr Jon patiently explains to Sally that insulin will lower her blood glucose level and with good control, she is less likely to develop complications such as blindness, kidney failure and heart attacks. Sally is in a dilemma; while she does not like the idea of having diabetes complications (she has seen her mother suffering from kidney failure), she cannot bear the thought of having to inject herself daily. Moreover, she has been living alone since her husband's death 2 years ago, and her only son is living abroad. She is worried that she may have 'hypos' at home.

Issues to consider:

1. Sally is conflicted. She wants the best of both worlds; she wants to avoid diabetes complications but also to avoid the side effects of insulin.

2. Dr Jon is frustrated. He wants to help Sally to manage her diabetes better, and insulin is the obvious choice, but Sally is not accepting his advice.

3. Is there a way that Sally and Dr Jon can come to decision that both of them are happy with?

Box 2. Case study 2: Practising shared decision making with a man who requests prostate cancer screening

Richard, a 70-year-old man, requests his general practitioner, Dr Ian, screen him for prostate cancer. Richard is worried because his friend has just died of prostate cancer.

Dr Ian asks about Richard's risk of getting prostate cancer; fortunately, Richard does not have any family history of prostate cancer. Dr Ian then explains to him about the screening option, 
which is doing a prostate specific antigen (PSA) test. He explains that the other screening option, performing a digital rectal examination, is not as accurate as PSA test. That said, a PSA test is not very accurate as a screening tool; it may lead to 'false positive' (PSA level is high even though Richard does not have prostate cancer) and 'false negative' (PSA level is normal but Richard actually has prostate cancer) result. Richard begins to understand that the PSA test is not foolproof.

Dr Ian goes on to inform Richard about the implication of doing a PSA test. If the PSA test returns as high, Richard might be referred to a urologist for further assessment, where either a biopsy or MRI will be done to find out whether Richard indeed has prostate cancer. Richard asks questions about what a prostate biopsy entails, and Dr Ian explains the procedure, including the potential side effects such as pain, bleeding and infection. In addition, there may be risk of complication of incontinence and erectile dysfunction when prostate cancer is treated with prostatectomy.

Dr Ian then talks about how detecting prostate cancer early can potentially cure the cancer and save lives; however, some prostate cancers are slow-growing and may not need surgery or other treatments. The urologist will have to assess each patient individually and not to treat every patient the same way. Richard understands that the PSA test is not absolutely accurate, and there are consequences to doing it. He also realises that some prostate cancer takes a long time to grow and may not cause death immediately. He now has the choice of whether to go for PSA test, and not every man of his age must go for prostate cancer screening.

After making sure that Richard understands the information, Dr Ian guides Richard to make a decision by finding out what is important to Richard personally: is it the concern of having a prostate cancer, or not wanting to experience the consequences of a high PSA test. Richard values good quality of life and is concern about the complications of prostate biopsy and treatment. Richard decides that he can live with the uncertainty of having a prostate cancer as his risk is not high. He will return if he starts to experience any urinary symptoms so that an early diagnosis can be made. He decides not to have PSA test for now.

\section{Introduction}

Making healthcare decisions collaboratively between patients and doctors can be challenging, especially in primary care, where clinical encounters are often short. ${ }^{1}$ While most healthcare decisions are easy to make, some can be challenging, especially when patients' values differ from those of their doctors, such as whether to initiate insulin (Box 1). On the one hand, patients tend to find it difficult to make a decision as they must bear the consequences, including change in the lifestyle, financial burden and health outcomes. On the other hand, primary care doctors (PCD), who struggle to 'convince' patients to make a decision, may feel frustrated and dissatisfied with the consultation. Conflicts between patients and doctors during the decision-making process may affect both patient and doctor satisfaction and may, in some instances, result in medico-legal consequences. ${ }^{2}$ This warrants a decision-making approach that provides a platform for patients and PCDs to talk openly about their priorities and concerns to reach a consensus on the healthcare decision.
Historically, paternalism dominates healthcare consultations. ${ }^{3}$ Doctors tend to make decisions 'in the best interest of patients', often without involving them in the decision-making process. Clinical paternalism occurs when patients rely heavily on doctors' expertise and experience to decide for them, especially in societies where doctors are highly regarded in the social scale. Patients are also fearful of making a 'wrong' decision that may adversely affect their health; hence, they tend to delegate the decision-making task to the expert (doctor). ${ }^{4}$ However, with an increase in overall literacy and health literacy, and easy access to health information via the Internet, patients are now more empowered to acquire health information independently. ${ }^{5}$ This has shifted the power dynamic between the doctor and patient towards a more balanced partnership.

In primary care, where multiple healthcare decisions are made in each clinical encounter, there is an even more urgent need for PCDs to equip themselves with the skill to guide patients to make informed decisions, especially those with clinical equipoise. ${ }^{6}$ A practical and effective decision-making model, such as SDM, is needed for this to happen. 


\section{Shared Decision Making}

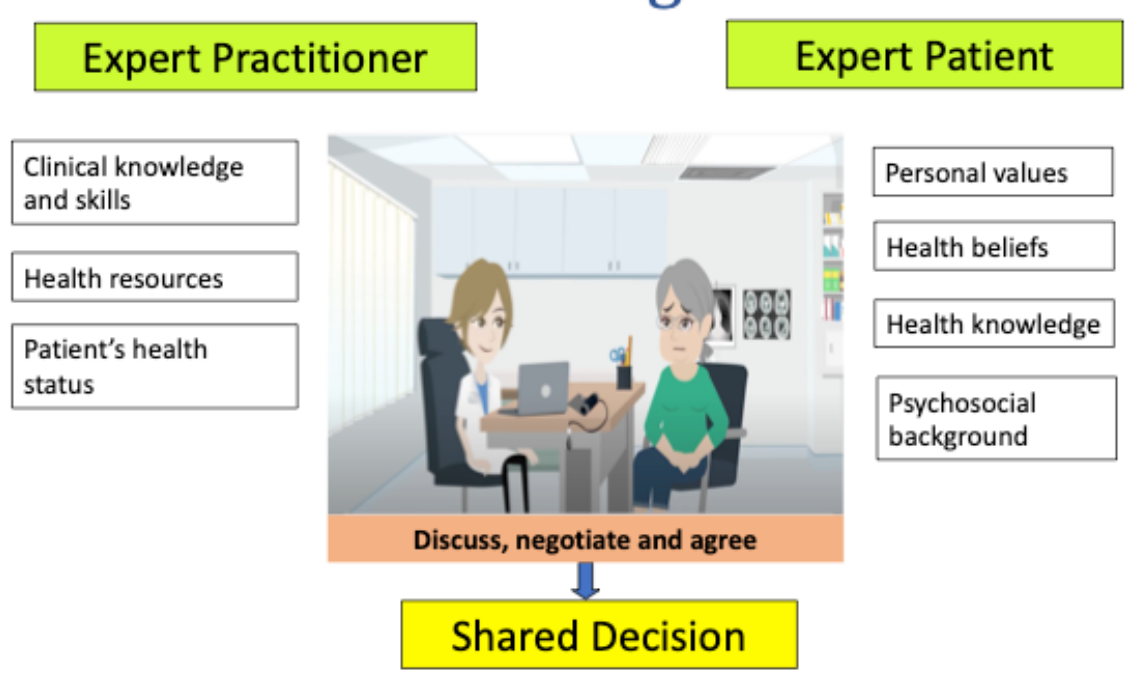

Figure 1: Shared decision-making model $^{7-9}$

\section{Shared Decision Making}

The concept of SDM was developed in the 1980 s out of the need to implement 'informed consent' in the healthcare setting. ${ }^{7}$ A huge practice variation existed within and across healthcare systems; for example, prescribing patterns and uptake of surgical procedures for the same health condition varied significantly. One of the key influencing factors was variation in how healthcare providers made decisions, often independently without patients' involvement and sometimes not following the recommended clinical practice guidelines. While some healthcare decisions are relatively straightforward, when benefits outweigh the risks (e.g. antibiotic use in pneumonia), some decisions are more challenging, especially those with clinical equipoise (e.g. the insulin initiation example described in Box $\mathbf{1}$ and the prostate cancer screening example described in Box 2). SDM requires patients and doctors to communicate their concerns and priorities openly during the clinical encounter.

SDM is a clinical consultation process where a patient and a doctor discuss, negotiate and agree on the final decision. ${ }^{8}$ SDM is usually conducted under the premise that both patients and doctors recognise that both parties' views must be respected. While doctors have clinical expertise and experience, patients are 'experts' in their own values (i.e. the patient knows what is important to them). ${ }^{\text {? }}$ Both patients and doctors have 'equal power' during the decision-making process, which requires building a good rapport between both parties, and a trusting professional relationship is critical. The success of the SDM implementation depends on how well and to what extent 'discussion', 'negotiation' and 'agreement' processes are done. Therefore, SDM requires doctors to embrace patientcentred care, have good communication skills, and recognise the clinical context in which SDM can be used to guide patients in making a decision.

Table 1: Six Steps in Practising Shared Decision Making (SDM)

\begin{tabular}{|l|l|}
\hline Steps & Key Questions \\
\hline 1. Identify the decision & What is the decision? \\
\hline 2. List the available options & What screening, diagnostic or treatment options are available? \\
\hline $\begin{array}{l}\text { 3. Discuss the pros and cons of } \\
\text { each option }\end{array}$ & $\begin{array}{l}\text { What are the advantages and disadvantages of each option? } \\
\text { What is the evidence? }\end{array}$ \\
\hline 4. Elicit patient values & What is important to the patient? \\
\hline 5. Provide support & What further support does the patient need to make this decision? \\
\hline 6. Make a decision & Is the patient ready to make a decision? \\
\hline
\end{tabular}




\section{Step-by-step approach to practising SDM}

Six steps can be used to guide patients to make an informed and value-based decision (Table 1) in SDM. ${ }^{10}$ The following step-by-step approach will use Case Study 2 (Box 2) as an exemplar to demonstrate how SDM can be practised during a primary care consultation.

\section{Step 1: Identify the decision}

It is important to establish what decision needs to be made before discussing SDM with patients. Decisions may be about screening, diagnostic tests or treatment options. In Case Study 1 , the decision is whether to start insulin as a treatment option (other options could be 'status quo' or 'add another medication'); in Case Study 2, the decision is whether to undergo prostate cancer screening by doing a PSA test.

\section{Step 2: List the available options}

After establishing what the decision is, the next step to inform the patient is about the available healthcare options. This step will ensure that the patient is aware of the range of options and that there is no 'right' or 'wrong' option. The final decision depends on how the patient views the options after considering their personal preference and values. In Case Study 2 , the options are to screen or not screen for prostate cancer using the PSA test.

\section{Step 3: Discuss the pros and cons of each option}

A PCD needs to discuss the pros and cons of each of the available options in an unbiased manner. In some instances, the options may include 'do nothing' and 'using complementary and alternative medicine'. All the information should be based on scientific evidence and explained to the patient in simple language.

In Case Study 2, Dr Ian informs Richard about the accuracy of the PSA test (false positives and false negatives) and that a biopsy would be required if the PSA is elevated. In discussing the benefit of screening, Dr Ian explains that early detection of prostate cancer may save lives; however, the doctor can never be sure whether the cancer will be slowgrowing or aggressive. He also talks about the potential harms of screening, including the complications of a prostate biopsy (e.g. bleeding and infection) and prostatectomy (e.g. incontinence and erectile dysfunction).
In communicating the pros and cons of the available options, the PCD should use 'numbers' (e.g. out of 100 patients like you, 20 experience headache) rather than 'percentages' (e.g. 20\%) to present the risks and benefits. ${ }^{11,12,13}$ In addition, to avoid the 'framing effect' (presenting the information positively or negatively to sway decision), it is important to present the chances of getting and not getting complications from the illness or treatment. $^{14}$

\section{Step 4: Elicit patient values}

Identifying the patient's values can be a challenging step in a consultation. ${ }^{10}$ Different individuals have different personal views, concerns and values of what is important to them. Values are an important element that may influence how a patient chooses the treatment or screening option. Patient values often relate to their psychosocial background, health beliefs and health knowledge. Therefore, it is essential to explore patient values before guiding them to make a decision.

In Case Study 2, Richard values good quality of life and is concerned about the complications of prostate biopsy and treatment. He decides not to go for prostate cancer screening as he prioritises the avoidance of the potential consequences of screening over the potential reassurance of a negative prostate cancer screening result.

\section{Step 5: Provide support}

Sometimes, the information provided by the PCD during a consultation may not be adequate. Patients may need more support in terms of health information or family and peer support. Open-ended questions, such as: 'Is there anything else you would like to know?' or 'Is there anyone else you would like to talk to before making a decision?’ may be useful.

\section{Step 6: Make a decision}

The last step is to establish whether the patient is ready to make a decision. Some patients may want to take time to think through the options or discuss with their family or peers before making a decision. In this case, the decision will need to be revisited in the next consultation. PCDs should explore further what other concerns the patient may have and address them accordingly. Patients should not be pressured to make a decision when they are 
not ready. PCDs must accept the possibility of 'no decision' when guiding the patient in making decisions during a consultation.

\section{Using Patient Decision Aids in SDM}

Patient decision aids (PDAs) are evidencebased tools used to help people make informed choices about treatment, diagnostic or screening options. ${ }^{15}$ PDAs provide information about the health condition and decision, list available options, present evidence of the benefits and risks of each option and explore patient values and preferences. PDAs are used as a tool in the SDM process to facilitate active discussion between patients and healthcare providers, leading them to informed decisions. ${ }^{15}$ The use of PDAs must consider the patient's social and cultural context, such as language, family involvement, and use of complementary and alternative medicine. ${ }^{16}$

A Cochrane systematic review confirmed the benefits of using a PDA in healthcare decision making; ${ }^{17}$ it increases patients' knowledge about treatment choices and their pros and cons. With increased knowledge, patients are more empowered to make an informed decision. They are also more satisfied with the treatment decision made and increase their treatment adherence. Using PDAs helps health care providers enhance their ability to provide information to patients and facilitate the decision-making process during a consultation. PDA use has a positive effect on patient-doctor communication, increases job satisfaction and reduces emotional exhaustion. Patients who have used a PDA before a consultation are more likely to be equipped with the necessary knowledge to make a decision and more aware of their concerns and values, ${ }^{17}$ hence allowing healthcare providers to focus on discussing what is relevant to the patient.

Several PDAs have been developed for Malaysian patients. These PDAs include, among others, 1) insulin initiation for type 2 diabetes, 2) early breast cancer treatment, 3) metastatic breast cancer treatment, 4) early prostate cancer treatment, 5) bladder management for spinal cord injury patients. These PDAs are written in different languages (English, Malays, Mandarin and Tamil) to ensure that they are tailored for patients of different ethnicities.

\section{Implementation of SDM in clinical practice}

Despite the increasing evidence to support the use of SDM in clinical practice, implementing SDM and PDAs remain a challenge, particularly in developing countries such as Malaysia, where the concepts of SDM and PDAs are still unfamiliar to policy makers, healthcare providers and patients. ${ }^{18}$ The main challenge is the lack of SDM culture. Doctors' paternalistic attitude, patients' passivity and lack of (or too much) trust in doctors make implementing SDM challenging. ${ }^{19}$ In addition, distinct role boundaries between the doctors and nurses are also a potential barrier. In many primary care clinics, doctors would not expect nurses to be able to deliver PDA information to patients. Furthermore, the lack of continuity of care makes it difficult for doctors to follow up on PDA use with their patients. ${ }^{19}$

To facilitate the implementation of SDM and PDAs, doctors need to be trained on how to practice SDM with their patients and use tools such as PDAs to facilitate decision making during a consultation. ${ }^{19}$ Doctors' communication style and commitment to patient-centred care are likely to influence the implementation outcomes of PDAs. ${ }^{20}$ While time is the most commonly cited barrier to practice SDM, ${ }^{21}$ PDAs may reduce cumulative consultation time as patients are less likely to delay a decision. In addition, a reminder network among the healthcare providers may be useful to address the issue of forgetfulness and trigger interest in using the PDA to encourage SDM. ${ }^{19}$ Health care authorities should create a conducive environment and provide patients with free access to PDAs to promote effective implementation of SDM. ${ }^{20}$

\section{Conclusion}

With the increasing recognition of the importance of patient empowerment, SDM can serve as a practical consultation model for PCDs to guide patients in making informed healthcare choices. Although more research is needed to find effective ways to implement SDM in the real world, the 6-step approach presented in this paper can guide a PCD to begin practising SDM in their daily practice. This practice can be further enhanced by strategies such as including incorporating SDM training into undergraduate and postgraduate training, using evidence-based tools such as PDAs and delivering those tools using technology. ${ }^{18}$ 


\section{References}

1. Irving G, Neves AL, Dambha-Miller H, et al. International variations in primary care physician consultation time: a systematic review of 67 countries. BMJ Open. 2017;7(10):e017902. doi:10.1136/ bmjopen-2017-017902

2. Elwyn G, Edwards A, Kinnersley P. Shared decision-making in primary care: the neglected second half of the consultation. Br J Gen Pract. 1999;49(443):477-482.

3. Sm G. Paternalism in healthcare decision making. Ostomy Wound Manage. 1998;44(4):22, 24-25.

4. Say R, Murtagh M, Thomson R. Patients' preference for involvement in medical decision making: A narrative review. Patient Educ Couns. 2006;60(2):102-114. doi:10.1016/j. pec. 2005.02 .003

5. Aydın GÖ, Kaya N, Turan N. The role of health literacy in access to online health information. Procedia - Soc Behav Sci. 2015;195:1683-1687. doi:10.1016/j. sbspro.2015.06.252

6. Elwyn G, Edwards A, Kinnersley P, Grol R. Shared decision making and the concept of equipoise: the competences of involving patients in healthcare choices. Br J Gen Pract. 2000;50(460):892-899.

7. President's Commission. President's Commission for the Study of Ethical Problems in Medicine and Biomedical and Behavioral Research. Making health care decisions. The ethical and legal implications of informed consent in the patientpractitioner relationship. Washington DC: 1982. Accessed February 18, 2021. https:// repository.library.georgetown.edu/bitstream/ handle/10822/559354/making_health_care_ decisions.pdf
8. Charles C, Gafni A, Whelan T. Shared decision-making in the medical encounter: what does it mean? (or it takes at least two to tango). Soc Sci Med. 1997;44(5):681-692. doi:10.1016/S0277-9536(96)00221-3

9. Murray E, Charles C, Gafni A. Shared decision-making in primary care: tailoring the Charles et al. model to fit the context of general practice. Patient Educ Couns. 2006;62(2):205-211. doi:10.1016/j. pec. 2005.07 .003

10. Schrager SB, Phillips G, Burnside E. A simple approach to shared decision making in cancer screening. Fam Pract Manag. 2017;24(3):5-10.

11. Fagerlin A, Zikmund-Fisher BJ, Ubel PA. Helping patients decide: ten steps to better risk communication. JNCI J Natl Cancer Inst. 2011;103(19):1436-1443. doi:10.1093/jnci/ djr318

12. Zipkin DA, Umscheid CA, Keating NL, et al. Evidence-based risk communication: a systematic review. Ann Intern Med. 2014;161(4):270-280. doi:10.7326/M140295

13. Sinayev A, Peters E, Tusler M, Fraenkel L. Presenting numeric information with percentages and descriptive risk labels: a randomized trial. Med Decis Mak Int J Soc Med Decis Mak. 2015;35(8):937-947. doi:10.1177/0272989X15584922

14. Joseph-Williams N, Newcombe R, Politi $\mathrm{M}$, et al. Toward minimum standards for certifying patient decision aids: a modified Delphi consensus process. Med Decis Mak Int J Soc Med Decis Mak. 2014;34(6):699-710. doi:10.1177/0272989X13501721
15. Patient Decision Aids - Ottawa Hospital Research Institute. Accessed February 17, 2021. https://decisionaid.ohri.ca/

16. Chenel V, Mortenson WB, Guay M, Jutai JW, Auger C. Cultural adaptation and validation of patient decision aids: a scoping review. Patient Prefer Adherence. 2018;12:321-332. doi:10.2147/PPA.S151833

17. Stacey D, Légaré $\mathrm{F}$, Lewis $\mathrm{K}$, et al. Decision aids for people facing health treatment or screening decisions. Cochrane Database Syst Rev. 2017;4:CD001431. doi:10.1002/14651858.CD001431.pub5

18. Ng CJ, Lee PY, Lee YK, et al. An overview of patient involvement in healthcare decisionmaking: a situational analysis of the Malaysian context. BMC Health Serv Res. 2013;13:408. doi:10.1186/1472-6963-13-408

19. Tong WT, Lee YK, Ng CJ, Lee PY. Factors influencing implementation of a patient decision aid in a developing country: an exploratory study. Implement Sci. 2017;12(1):40. doi:10.1186/s13012-0170569-9

20. Tong WT, Ng CJ, Lee YK, Lee PY. What will make patients use a patient decision aid? A qualitative study on patients' perspectives on implementation barriers and facilitators. J Eval Clin Pract. 2020;26(3):755-764. doi:10.1111/ jep. 13161

21. Légaré F, Ratté S, Gravel K, Graham ID. Barriers and facilitators to implementing shared decision-making in clinical practice: update of a systematic review of health professionals' perceptions. Patient Educ Couns. 2008;73(3):526-535. doi:10.1016/j. pec. 2008.07 .018 


\title{
Basic technology and proper usage of home health monitoring devices
}

\author{
Himel Mondal, Shaikat Mondal
}

Mondal H, Mondal S. Basic technology and proper usage of home health monitoring devices. Malays Fam Physician. 2021;16(1);8-14. https://doi.org/10.51866/rv1097

\section{Keywords:}

COVID-19, Blood Glucose,

Blood Pressure Monitors,

Primary Health Care, Remote

Consultation

\section{Authors:}

\section{Himel Mondal}

(Corresponding author)

MBBS, MD

Department of Physiology

Bhima Bhoi Medical College and Hospital Balangir, Odisha, India.

Email: himelmkcg@gmail.com

\section{Shaikat Mondal}

MBBS, MD

Department of Physiology

Raiganj Government Medical College and Hospital, West Bengal, India.

\section{Abstract}

Home health monitoring devices are consumer-grade devices that help to monitor the health of individuals at home. These devices are usually low-cost and easily procurable, and they can be operated by patients or their caretakers with minimal training. However, improper usage of these devices may provide erroneous results, which can lead to an unnecessary hospital visit or teleconsultation. In this article, we discuss the basic technology and proper usage of some of these devices, namely automatic blood pressure monitors, blood glucose monitors, body fat monitors, pulse oximeters, electrocardiographs, digital thermometers, and infrared thermometers. This brief document intends to help primary health care professionals and their patients use these devices.

\section{Introduction}

Home health monitoring devices are consumer-grade devices that help to monitor and track the health of individuals outside of clinics. ${ }^{1}$ Patients or their caretakers can monitor health status from their homes with these devices. ${ }^{2}$ The costs of these devices are usually lower than those of hospital-grade devices, and home devices can be operated easily by patients. ${ }^{3}$ Measured parameters can be recorded for self-monitoring purposes or consultation with doctors. ${ }^{4}$ Proper usage of these devices is imperative for credible results. Faulty handling of home devices or improper self-preparation may lead to erroneous results. If patients or their caretakers do not follow proper measurement techniques, 5,6 they could make unnecessary visits to medical facilities or consult superfluously with doctors via telemedicine channels. In this article, we present the basic technology (i.e., fundamental principles upon which the equipment works) and proper usage of some home health monitoring devices, namely automatic blood pressure monitors, blood glucose monitors, body fat monitors, pulse oximeters, electrocardiographs, digital thermometers, and infrared thermometers.

\section{Automatic blood pressure monitor}

\section{Technology}

Upper arm and wrist type automatic blood pressure monitors are popular for monitoring blood pressure. ${ }^{7}$ Both of the devices use the oscillometric method to detect blood pressure. Figure 1a demonstrates the basic principles of blood pressure measurement. When the cuff pressure exceeds systolic blood pressure, the artery becomes occluded and blood does not flow below the cuff, thus generating no sound or vibrations [Figure 1a]. When the cuff pressure is reduced gradually and becomes lower than systolic pressure, turbulent blood flow occurs beyond the cuff, and Korotkoff sounds and vibrations form [Figure 1a]. This vibration is detected by the pressure sensor present in the automatic blood pressure monitor. When the cuff pressure sinks below the diastolic pressure, minimal vibrations and sounds are produced [Figure 1a]. ${ }^{8}$ Sensors in the monitor use a fixed algorithm to calculate the diastolic blood pressure from this point. Most blood pressure monitors have fully automated the inflation and deflation of the cuff. When the monitor inflates the cuff, "fuzzy logic" (logic in which values of variables may be any number between 0 and 1) is used to estimate systolic blood pressure. The monitor then inflates the cuff above this level and then deflates to measure blood pressure.' Although the underlying technologies are similar in devices manufactured by different companies, one must always ensure that individual devices have been approved by the appropriate authority (e.g., FDA, ISO). Furthermore, the device should be calibrated at frequent intervals. ${ }^{10}$ 


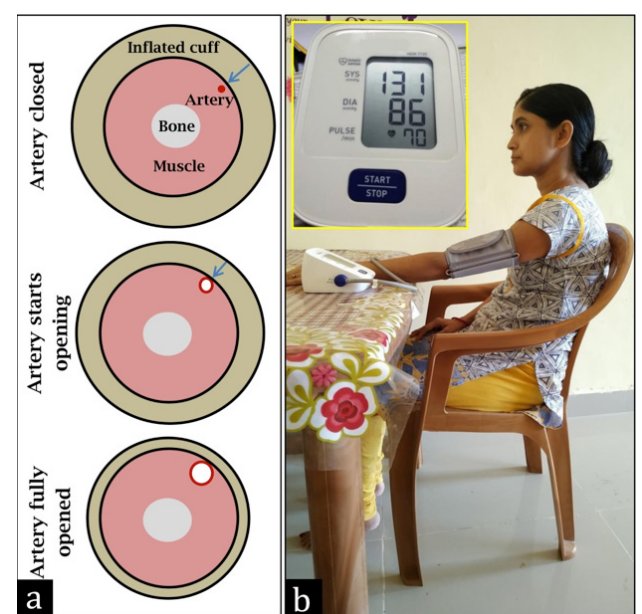

Figure 1. (a) Basic principle of oscillometric blood pressure measurement (b) A person measuring blood pressure using an automatic blood pressure monitor (inset: blood pressure reading)

\section{Usage}

Before measurement, the operator must ensure that the patient has avoided tea, coffee, caffeinated drinks, smoking, and any mode of exercise in the preceding 30 minutes. ${ }^{11,12}$ Any constricting clothes should be removed. After voiding the bladder, the patient sits quietly with uncrossed legs on a chair with back support and feet flat on the floor without shoes. The arm is supported on a flat surface, preferably on a table at the heart level. The patient rests for five minutes in this position. Nearby electronics gadgets should be kept away. The operator must then fasten the cuff on a bare arm and start recording the blood pressure [Figure $\mathbf{1 b}$ ]. The patient must not move or talk during the measurement. The operator measures twice with a gap of one minute in between, then takes the average of these measurements. ${ }^{13}$ The accuracy of this figure may be further enhanced by measuring thrice and taking the average as the final reading. ${ }^{14}$ However, these guidelines may vary among different countries. The final reading should always be noted in a logbook (i.e., a book where patients keep a record of their measurement) or health application in order to track changes over time. ${ }^{15}$

\section{Blood glucose monitor}

\section{Technology}

A blood glucose monitor and test strip are the basic components of a biosensor. Test strips contain a bioreceptor that receives a specific analyte and a transducer. Blood with various analytes [Figure 2a] comes into contact with the capillary space of the test strip. A bioreceptor in the strip specifically accepts glucose. This reaction generates a physiochemical signal that is converted to an electrical signal via a transducer and sent from the strip to the monitor. The monitor acts as the processing module and displays the result in a readable format. ${ }^{16}$ The monitor may also use predefined factors to convert the whole blood glucose reading to its plasma equivalent value (e.g., whole blood glucose $\times 1.11) .{ }^{17} \mathrm{~A}$ few monitors utilize a reaction in which glucose reacts with an enzyme and the product acts on a dye to change the color proportional to glucose concentration. ${ }^{18}$

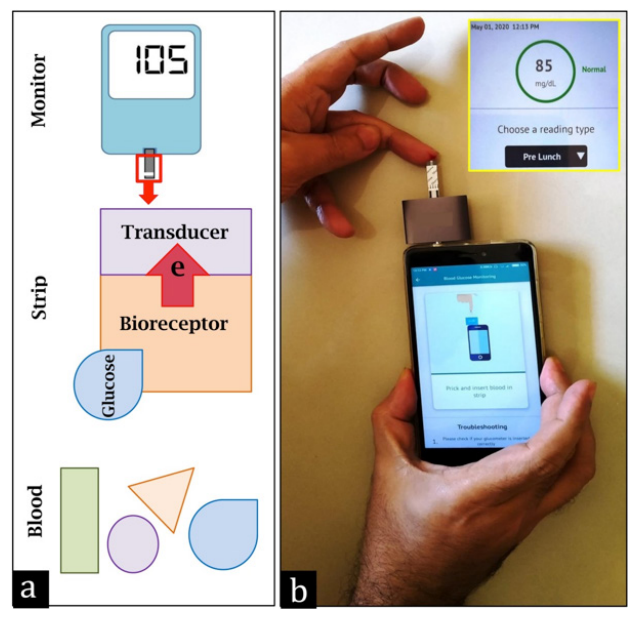

Figure 2. (a) Basic principle of a glucose monitor (b) A person measuring blood glucose on a smartphone-dependent glucose monitor (inset: blood sugar reading on a smartphone screen)

\section{Usage}

Operators should handle strips with dry and clean hands and keep the container of strips closed after extracting a single strip. Before measurement, checking the expiry date of the strip is mandatory. A new lancet should be used for each measurement. The lancet should be placed in the appropriate slot of the lancing device, and the depth of the prick should be set according to previous experience or skin thickness. The hand should be washed with mild soap and must be dry before pricking. After spring-loading the pricking device, a finger is pricked (preferably the ring or middle finger). Gentle milking may be necessary to produce an adequate drop of blood. The meter will take some time to perform the reaction after the blood makes contact with the strip capillary space. ${ }^{19}$ The reading will be displayed on the device screen or smartphone according to the type of device. Figure $\mathbf{2 b}$ illustrates the process 
of measuring blood glucose on a smartphonedependent glucose monitor by pricking the ring finger, and the result is shown in the inset. After the measurement, the lancet is disposed of in a sharp-materials container and strips in a biohazardous material container. Some patients may need to press the finger with cotton in order to stop the blood. After use, the tip of the lancet may be cleansed with an alcohol swab. The blood glucose reading should be entered into a logbook immediately after measurement.

\section{Body fat monitor}

\section{Technology}

Consumer-grade body fat monitors may come in either a two-electrode type without a weighing scale or a four-electrode type combined with a weighing scale. ${ }^{6}$ Figure 3a shows four electrodes placed on the hands and feet of a bioelectrical impedance analysis body fat monitor. The body fat monitor uses a low-frequency current that passes through the body easily via the watery medium and is impeded by fat. One electrode sends the current and another electrode receives the signal. This principle is used to estimate total body water and fat-free mass. Fat-free mass is subtracted from the measured body weight to calculate fat mass. ${ }^{20}$ This calculation is programmed into the monitor software and varies between different human ethnicities. Thus, it is important to check if individual monitors have been recommended by a regional licensing authority. ${ }^{21}$ In two-electrode body fat monitors (either hands or feet), the weight of the person is manually entered. By comparison, four-electrode body fat monitors simultaneously measure and provide body fat readings.

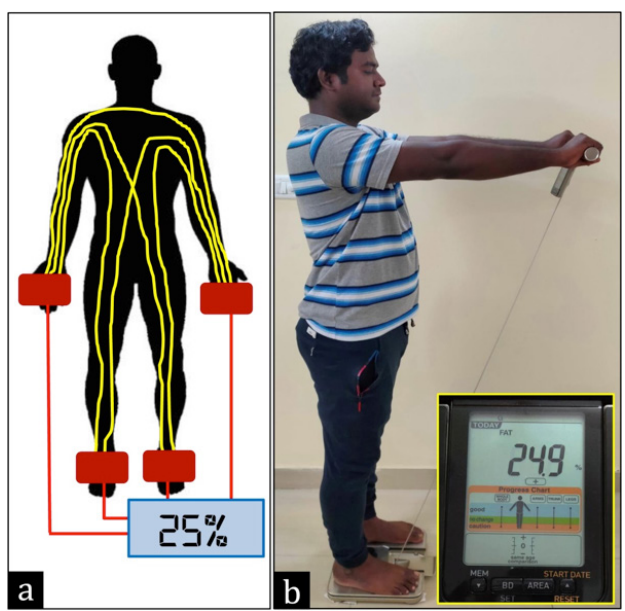

Figure 3. (a) Basic principle of bioelectric impedance analysis (b) A person measuring body fat on a four-electrode monitor (inset: body fat percentage reading)

\section{Usage}

Random measurement of body fat may lead to erroneous results. Patients should take premeasurement precautions when measuring body fat, including refraining from alcohol for 48 hours; avoiding coffee, chocolate, or any other diuretics for 12 hours; and abstaining from food and drink for four hours. Exercise should be avoided for 12 hours. Measurement during any illness that may affect body hydration such as fever and diarrhea should be avoided. The bladder should be voided within 30 minutes of measurement. During measurement, precise demographic data such as age, sex, and height should be entered on the monitor. ${ }^{22,23}$ All of these are used in the prediction equation. Proper contact with electrodes and proper body position should be maintained [Figure $\mathbf{3 b}$ ]. If hands and feet are extremely dry, these should be moistened with a wet handkerchief. Movement during measurement should be avoided. Commonly, body fat is expressed as a percentage [Figure $\mathbf{3 b}$ inset]. However, a single measurement should not be taken as final; instead, the average of three consecutive measurements should be calculated and recorded in a logbook or heath application.

\section{Electrocardiograph}

\section{Technology}

Single-lead consumer-grade electrocardiographs are now available at affordable prices. These devices work on the same principles as hospitalgrade electrocardiographs. The electrical activity of the heart is conducted to the body surface and captured by the electrodes placed on the skin [Figure 4a]. As this signal is very weak, the device amplifies it, and a simple galvanometer detects changes in voltages. This signal is processed by a computer, and the wave pattern is either shown on the device screen or on a connected smartphone [Figure $\mathbf{4 b}$ inset]. The computer also analyses the rate and rhythm of the heartbeats to detect any gross abnormalities. ${ }^{24,25}$ Typically, these devices have two electrodes placed on the surface of the casing. These two electrodes are either touched by two hands or touched by the right hand and the left side of the abdomen [Figure $\mathbf{4 b}$ ]. 


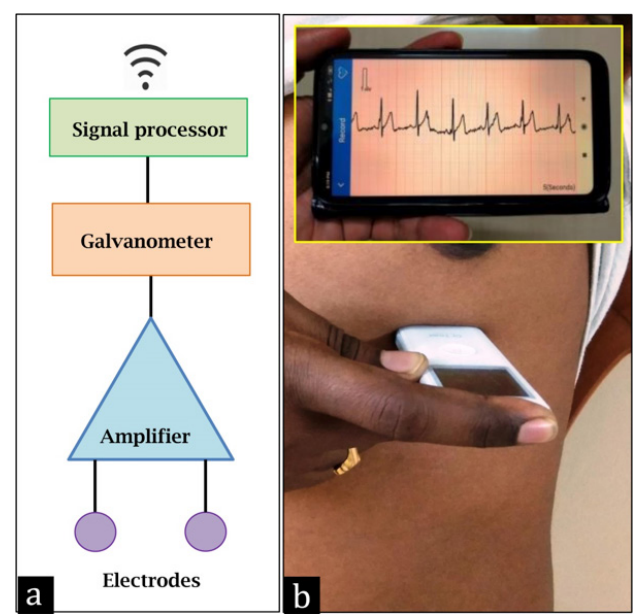

Figure 4. (a) Basic principle of an electrocardiograph (b) A person measuring a single-lead electrocardiogram using a consumer-grade electrocardiograph (inset: an electrocardiogram on a smartphone screen)

\section{Usage}

Electronic gadgets, metallic substances, and magnetic materials should be kept away from the device during measurement. A five-minute rest in a quiet sitting position is recommended before measurement. The person being measured should not move or talk during measurement. Optimum contact with the electrodes of the device should be ensured; if the hands are dry, moisten them by wiping them with a wet handkerchief. According to the manufacturer's instructions, place the electrodes properly to obtain credible ECG tracing (e.g., in Figure $\mathbf{4 b}$, the subject is holding the device with one electrode on the right index finger and another electrode on the left abdomen for a typical lead II measurement). After measurement, the report should be reviewed by a doctor. $^{26}$

\section{Pulse oximeter}

\section{Technology}

Pulse oximeters are commonly used in critical care settings and in anesthesia for monitoring the oxygen saturation of blood. However, handheld devices are available for use at home. These devices are battery-operated, standalone devices that can show pulse rates and oxygen saturation. The probe combines two light-emitting diodes (LED), red LED and infrared LED, which emit red and infrared light. The infrared light is not visible. Thus, we can only see red light from one side of the probe. On the opposite side of the probe, there is a light detector [Figure 5a]. When red and infrared light waves pass through the finger, some light is absorbed by the tissue and some is absorbed by the pulsating blood. The sensor removes the static signal (absorbed by the tissue) and only takes pulsatile signals. Oxyhemoglobin and deoxyhemoglobin display different patterns of absorption of red and infrared light. This absorption pattern is analyzed via the signal processing unit, and the result is displayed in a readable form. ${ }^{27,28}$

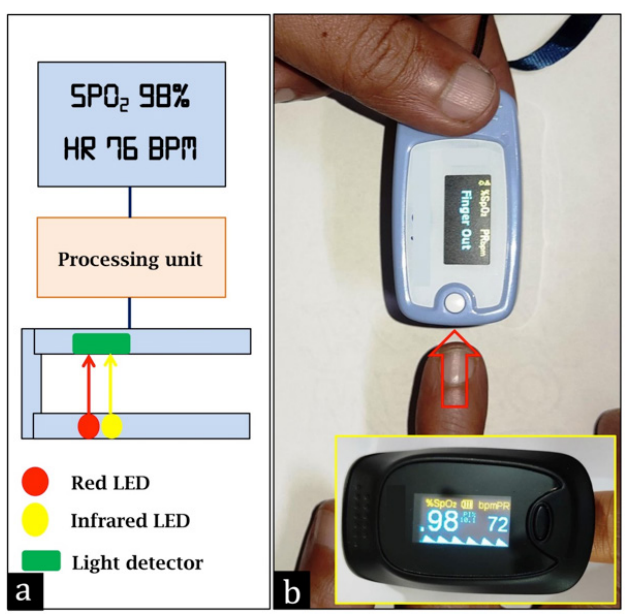

Figure 5. (a) Basic principle of a pulse oximeter (b) A person inserting finger into the pulse oximeter probe (inset: oxygen saturation and pulse rate reading)

\section{Usage}

Visible dirty hands should be washed, and tattooed or colored fingers (e.g., temporary henna designs) should be avoided. Nail color may be removed on the specific finger used for measurement. The probe should be placed on an appropriate finger so that it is neither too loose nor too tight. Figure $\mathbf{5 b}$ shows a person inserting a finger into the pulse oximeter probe. Care should be taken to check if the finger is covering the LEDs and the sensor on the opposite side. Pulse oximeters should not be used under bright sunlight or lighting, as interference from bright light may result in errors in estimation. If bright light cannot be avoided, a cloth can be used to cover the oximeter and finger. The person being measured should not move the finger during measurement. After using the device for several days, the LED and sensors can be cleaned with an alcohol swab as dirt may impair results. ${ }^{29}$

\section{Digital thermometer}

\section{Technology}

The digital thermometer uses the property of a thermistor (i.e., heating decreases resistance and 
cooling increases it). The thermometer has a tiny battery that sends a current through a wire towards the tip where the thermistor is present [Figure 6a]. According to the temperature of the thermistor, the current is impeded and received on the other end of the processing unit. This signal is then processed and the temperature is shown on the screen. ${ }^{30}$

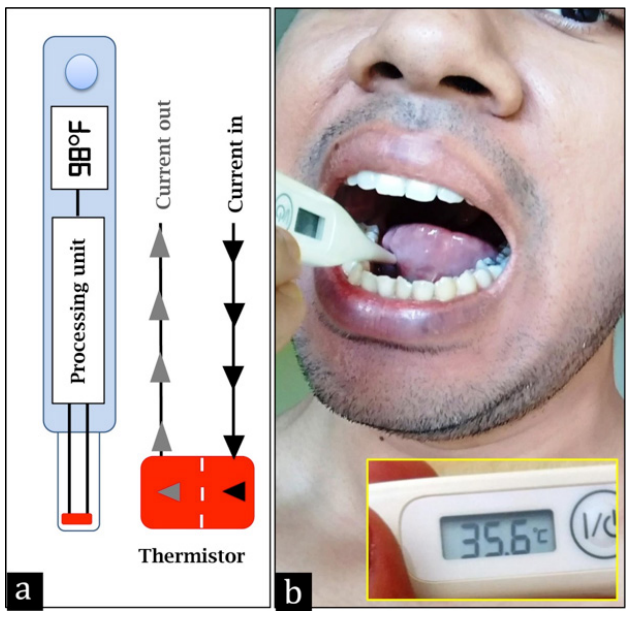

Figure 6. (a) Basic principle of a digital thermometer (b) A person placing the thermometer tip under the tongue (inset: temperature reading)

\section{Usage}

Digital thermometers can be used to safely record the temperature of all common sitesunder the tongue, armpit, and rectum. The thermometer should be handled with clean washed hands. The thermometer should also be cleaned with an alcohol swab or with soap and water after use. However, care should be taken not to dip the thermometer into water or liquid, which may damage the circuit inside. When measuring oral temperature, a person should not eat or drink within 30 minutes of measurement. After switching on the thermometer, it should be kept under the tongue [Figure $\mathbf{6 b}$ ], and the user should close his or her mouth firmly. The majority of thermometers beep after the measurement is recorded. Thus, wait until a beep sounds. The temperature should be immediately recorded in a logbook. For armpit measurement, the thermometer tip should come into contact with the skin. For rectal temperature measurement, the thermometer used should be designated specifically for the measurement of rectal temperature, and strict disinfection procedures should be followed. ${ }^{31}$

\section{Infrared thermometer}

\section{Technology}

Non-contact infrared thermometers can be used from a distance to measure temperature. These devices are larger in size than digital thermometers. The working principle is also different from that of a digital thermometer. Infrared thermometers receive infrared light emitted from a subject or an object-the warmer the subject or object, the greater its emissions of infrared radiation. These light rays are condensed via a lens in the device that focuses it on a thermopile (i.e., the sensor). The thermopile converts the infrared to heat, and the heat is converted to electricity using a processor. Finally, the electricity is processed and the reading is displayed [Figure 7a] ${ }^{32}$ Noncontact thermometers are often equipped with laser light. This is used to aim the thermometer at the desired point of interest. In Figure $\mathbf{7 b}$, the laser is seen on the middle of the forehead. This is simply for aiming the thermometer and has no connection to the heat sensing technology. Thus, many non-contact thermometers do not involve laser light. Both physicians and patients must be careful when selecting thermometers for measuring body temperature. Many available thermometers are for industrial usage. Care must be taken to confirm the temperature ranges that can be measured by the device as well as the device's certification according to local guidelines (e.g., FDA, ISO).

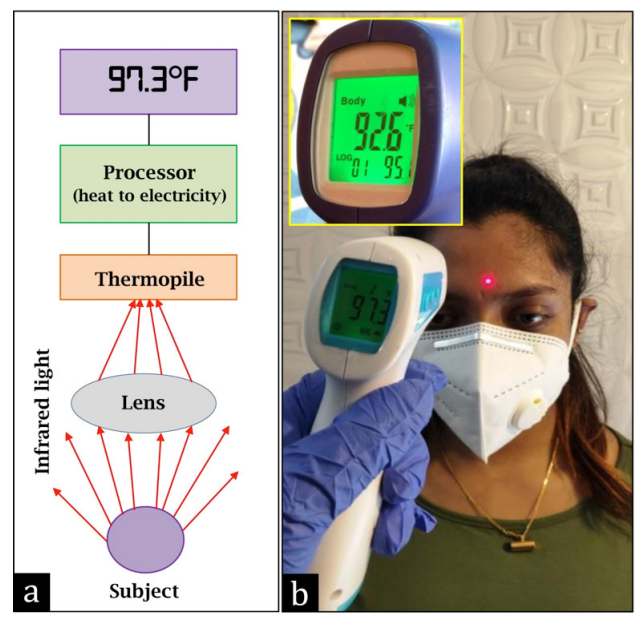

Figure 7. (a) Basic principle of an infrared thermometer (b) A person pointing the thermometer at the forehead of a subject from a distance (inset: temperature reading) 


\section{Usage}

The usage of non-contact thermometers has increased throughout the current COVID-19 pandemic. These devices are not only used in healthcare facilities but are being used in other non-healthcare facilities such as airports, shopping malls, banks, and so on. The device can also be used by family members to measure temperature from a distance when any one of the family members is in home quarantine. Care must be taken to obtain the proper temperature. The area of interest (e.g., forehead) should be cleaned and made dry before measurement. However, cosmetic wipes should be avoided, as these may increase the recorded temperature. Any additional clothing on the head should be removed, as this may increase the forehead temperature as well. The subject should not stand or sit under direct sunlight or near any heat source. The temperature of the environment should be between 16 to $40^{\circ} \mathrm{C}$, and the humidity should be below $85 \%$. The thermometer should be kept in the environment of measurement for 10 to 30 minutes so that the device adjusts to the ambient temperature. After taking these precautions, the thermometer must be held with the sensing part perpendicular to the measurement site, and the device must be switched on. ${ }^{33}$ Typically, it takes one to two seconds for the reading to show. These devices are easy to use and, being non-contact, help to prevent diseases that spread via contaminated surfaces. The lens of the device should be kept clean with a clean cloth, and the surfaces may be disinfected with a swab. However, the device should not be put into any disinfectant fluid.

\section{Conclusion}

This article compiled brief information on the technology and proper usage of the six most commonly used home health monitoring devices_automatic blood pressure monitors, blood glucose monitors, body fat monitors, pulse oximeter, electrocardiographs, digital thermometers, and infrared thermometers. This would help a busy physician to understand the basic working principles of the devices at a glance. However, this is a very basic guide. For an in-depth understanding, one may refer to the literature cited in this article. This guide would also help to disseminate knowledge amongst patients on the proper usage of the devices.

\section{Acknowledgments}

We thank the Head of the Department of Physiology, the Head of the Department of Anaesthesia, Dr. Sairavi Kiran Biri, Dr. Debasish Das, Dr. Dhananjay Soren of Fakir Mohan Medical College, Balasore, Odisha, Mr. Abhijit Roy of Roy Tech Tips, Ms. Smita Biswas of Smita's Boutique, and Ms. Shireen Sheikh, Barasat, West Bengal, India for their encouragement and help in the preparation of this manuscript. We also thank all the participants who volunteered as models in the figures.

\section{Funding}

No funding received for this work

\section{Ethical clearance}

Ethical clearance is not required

\section{Conflict of interest}

All authors declared there were no conflicts of interest

\section{How does this paper make a difference to general practice?}

- It informs primary care physicians on the working principles and correct handling of common home health monitoring devices.

- These physicians will then be able to train their patients to perform proper measurements.

- This guide can be shared with patients as well for the sake of their education.

- During or after a pandemic, when visiting a clinic is difficult, proper usage of home health monitoring devices can help patients and practitioners of telemedicine. 


\section{References}

1. Home Health Monitoring Devices. Somnology. 2016 July 26. Accessed 09 July 2020 at https:// www.somnologymd.com/2016/07/homehealth-monitoring-devices.

2. Story MF. Medical Devices in Home Health Care. National Academies Press (US). 2010. Accessed 09 July 2020 at https://www.ncbi. nlm.nih.gov/books/NBK210047.

3. Dias D, Paulo Silva Cunha J. Wearable Health Devices-Vital Sign Monitoring, Systems and Technologies. Sensors (Basel) 2018;18(8):2414.

4. Togawa T. Home health monitoring. J Med Dent Sci 1998;45(3):151-60.

5. Mondal S, Mondal H, Dutta R, Pal A, Acharya SS, Baidya C. Competency in Home Blood Pressure Monitoring and Effect of Training Program on Competency. Journal of Clinical and Diagnostic Research 2018;12:OC10-OC14.

6. Mondal H, Mondal S, Baidya C. Competency in home body fat monitoring by portable devices based on bioelectrical impedance analysis: A pilot study. J Educ Health Promot 2019;8:223.

7. Beevers G, Lip GY, O’Brien E. ABC of hypertension. Blood pressure measurement. Part I-sphygmomanometry: Factors common to all techniques. BMJ. 2001;322(7292):981-985.

8. Berger A. Oscillatory Blood

Pressure Monitoring Devices. BMJ 2001;323(7318):919.

9. Lin CT, Liu SH, Wang JJ, Wen ZC. Reduction of interference in oscillometric arterial blood pressure measurement using fuzzy logic. IEEE Trans Biomed Eng 2003;50(4):432-41.

10. Calibration, Maintenance, and Use of Blood Pressure Devices. National High Blood Pressure Education Program. 2004 August. Accessed on 09 July 2020 at https://www.ncbi.nlm.nih.gov/ books/NBK9622.

11. Ogedegbe G, Pickering T. Principles and techniques of blood pressure measurement. Cardiol Clin. 2010;28(4):571-586.

12. George J, MacDonald T. Home Blood Pressure Monitoring. Eur Cardiol. 2015;10(2):95-101.
13. Things you need to know about blood pressure and hypertension. Can J Cardiol. 2006;22(7):601-602.

14. Jose AP, Awasthi A, Kondal D, Kapoor M, Roy A, Prabhakaran D. Impact of repeated blood pressure measurement on blood pressure categorization in a population-based study from India. J Hum Hypertens 2019;33:594-601.

15. Monitoring Your Blood Pressure at Home [Internet]. USA: American Heart Association; 2017. Available from: https://www.heart. org/en/health-topics/high-blood-pressure/ understanding-blood-pressure-readings/ monitoring-your-blood-pressure-at-home. Accessed on 28 April 2020.

16. Wang J. Electrochemical glucose biosensors. Chem Rev 2008;108:814-25.

17. Kim HS. Blood Glucose Measurement: Is Serum Equal to Plasma?. Diabetes Metab J 2016;40(5):365-6.

18. Villena Gonzales W, Mobashsher AT, Abbosh A. The Progress of Glucose Monitoring-A Review of Invasive to Minimally and NonInvasive Techniques, Devices and Sensors. Sensors (Basel) 2019;19(4):800

19. Kirk JK, Stegner J. Self-monitoring of blood glucose: practical aspects. J Diabetes Sci Technol 2010;4:435-9.

20. Kyle UG, Bosaeus I, De Lorenzo AD, Deurenberg P, Elia M, Gómez JM, et al. Bioelectrical impedance analysis--part I: review of principles and methods. Clin Nutr 2004;23(5):1226-43.

21. Duren DL, Sherwood RJ, Czerwinski SA, et al. Body composition methods: comparisons and interpretation. J Diabetes Sci Technol 2008;2(6):1139-46.

22. Ricciardi R, Talbot LA. Use of bioelectrical impedance analysis in the evaluation, treatment, and prevention of overweight and obesity. J Am Acad Nurse Pract 2007;19:235-41.

23. Guedes DP. Clinical procedures used for analysis of the body composition. Rev Bras Cineantropom Desempenho Hum 2013;15:113-29.
24. Bansal A, Joshi R. Portable out-of-hospital electrocardiography: A review of current technologies. J Arrhythm 2018;34(2):129-38.

25. Garvey JL. ECG techniques and technologies. Emerg Med Clin North Am 2006;24(1):209-25.

26. AliveCor Heart Monitor and AliveECG app (Kardia Mobile) for detecting atrial fibrillation [Internet]. UK: National Institute for Health and Care Excellence; 2015. Available from: https://www.nice.org.uk/advice/mib35/chapter/ technology-overview. Accessed 28 April 2020.

27. Jubran A. Pulse oximetry. Crit Care 2015;19(1):272.

28. Singh S, Khan SZ, Singh D, Verma S, Talwar A. The uses of overnight pulse oximetry. Lung India 2020;37(2):151-7.

29. Using the Pulse Oximeter [Internet]. Switzerland: World Health Organization; 2011. Available from: https:/www.who.int/ patientsafety/safesurgery/pulse_oximetry/ who_ps_pulse_oxymetry_tutorial2_advanced_ en.pdf. Accessed 28 April 2020.

30. Gallagher JE. Inspection, Testing, Verification, Calibration, and Certification. In: Inspection, Testing, Verification, Calibration, and Certification. USA: Gulf Publishing Company; 2006.

31. Thermometers: How to Take your Temperature [Internet]. USA: Cleveland Clinic; 2020. Available from: https://my.clevelandclinic.org/ health/articles/9959-thermometers-how-totake-your-temperature. Accessed 28 April 2020.

32. How do infrared thermometers work? Generaltools. 2016 February 15. Accessed on 09 July 2020 at https://www.generaltools.com/ blog/how-do-infrared-thermometers-work.

33. Non-contact Infrared Thermometers. U.S. Food and Drug. 2020 April 23. Accessed on 09 July 2020 at https://www.fda.gov/medicaldevices/general-hospital-devices-and-supplies/ non-contact-infrared-thermometers.

34. Infrared thermometers: Cleaning and Storing. Temperature Blog. 2018 August 17. Accessed on 09 July 2020 at https://temperature.co.uk/ infrared-thermometers-cleaning-storing. 


\title{
Sane and safe: Forced social distancing to prevent human-to-human transmission of COVID-19
}

\author{
Firdous Jahan
}

Jahan F. Sane and Safe: Forced Social Distancing to Prevent Human-to-Human Transmission of COVID-19. Malays Fam Physician. 2021;16(1);15-17. https://doi.org/10.51866/rv0001

\section{Keywords:}

Social distancing, Covid-19, transmission of COVID-19,

Prevention

\section{Authors:}

\section{Firdous Jahan}

(Corresponding author)

Associate professor/ Head of the

Department Family Medicine, College

of Medicine and Health Sciences

Sohar, National University Oman Email: firdousjahan@nu.edu.om

\begin{abstract}
The current outbreak of COVID-19, originating from the city of Wuhan in China and ultimately involving over 200 countries, is now a global concern. Evidence indicates that COVID-19 spread to humans from wild animals, causing severe respiratory tract infections in humans; the typical symptoms of COVID include cough, high-grade fever, sore throat, and difficulty in breathing. The infection spreads from human to human via droplets. Therefore, social or physical distancing can reduce spread within communities. Asymptomatic spread can also occur during family gatherings or in the workplace; thus, we must enforce physical distancing as much as possible to reduce the spread of cases.
\end{abstract}

\section{Introduction}

COVID-19 is believed to spread mostly via close contact between individuals within communities. The coronavirus, which causes the COVID-19 disease, is a type of RNA virus that can result in symptoms ranging from those of a mild common cold to those of severe pneumonia.

Droplet transmission occurs when respiratory droplets generated via coughing, sneezing, or talking come into contact with susceptible mucosal surfaces, such as the eyes, nose, and mouth. ${ }^{1}$ Transmission may also occur indirectly via contact between contaminated fomites, hands, and mucosal surfaces. Respiratory droplets are large and unable to remain suspended in the air; thus, they are usually only dispersed over short distances. ${ }^{2}$ There are general principles that can help prevent the spread of the coronavirus, which include washing hands often with soap and water for at least 20 seconds, using an alcohol-based hand sanitizer, and cleaning and disinfecting frequently touched objects and surfaces in the home. It is imperative to cover one's nose and mouth when coughing or sneezing with a tissue and to then throw the tissue into a bin and washing one's hands. Many countries are now adopting measures such as "stay-home days," public health emergencies, family preparedness plans, and rapid medical response to control the pandemic. Currently, scientists are attempting to develop rapid diagnostic methods. To date, the most effective methods of control appear to be self-isolation, contact tracing, quarantining of exposed persons, workplace measures, closing borders to travelers, and social distancing. ${ }^{3}$ Because this virus spreads via close contact between individuals within communities, lowering overall morbidity and mortality rates will reduce burdens on the health care system.

\section{Social Distancing}

Coronavirus is primarily transmitted via droplets from the mouths and noses of infected people when they cough or sneeze, which can land on surfaces and the hands of others. Measures such as isolation and quarantine can break the cycle of spread, and social distancing measures have served as essential components of public health responses to influenza pandemics in the past. ${ }^{4}$

High-risk groups include individuals over 70 years old; those who have underlying health conditions such as diabetes, hypertension, asthma, heart disease, kidney or liver disease, and cancer; patients on steroids or undergoing chemotherapy; and those who are pregnant. These high-risk groups should limit face-toface interactions with friends and family. Social distancing is an essential infection control measure for reducing transmissions from infected people to susceptible individuals. It involves increasing physical distances between people and reducing the frequency of community gatherings, such as attending schools and universities as well as overcrowding in the workplace. ${ }^{5}$ 
Social and physical distancing is one of the primary components of public health response to the coronavirus pandemic. Precautionary measures should be taken to prevent the virus from entering closed communities, which can result in mass outbreaks. China has demonstrated this effectively by establishing a lockdown in the city of Wuhan, which has controlled the spread of coronavirus, whereas Italy delayed this measure and is now facing high morbidity and mortality rates.

Singapore has also shown promising results in combatting the H1N1 pandemic. Social distancing along with other efforts such as disease surveillance, symptomatic treatment, home quarantine, and infection control all worked to reduce the impact of the pandemic. ${ }^{6}$

Forced social distancing is required for public compliance and cooperation to ensure the effective implementation of safety measures. As mentioned previously, people can catch the coronavirus if they breathe in droplets from an infected person. These droplets can land on objects and surfaces from which a person can become infected by touching these objects or surfaces and subsequently touching their eyes, nose, or mouth. People visiting patients in hospitals are at high risk as well, as these droplets exist on many surfaces. Thus, it is imperative to restrict visitors in hospitals and primary health care facilities to reduce and delay the magnitude of the outbreak. ${ }^{7,8}$

Social distancing practices can help prevent the spread of the virus, as reducing social contact, refraining from handshakes and hugs, maintaining a distance of 1 meter from one another, closing schools and public places, and avoiding mass gatherings (such as weddings and funerals) can delay transmission and reduce the extent of an outbreak. Literature has reported that workplace social distancing has previously reduced influenza transmissions. ${ }^{9}$ Other sources of spread in communities should be closed as well, including shopping malls, entertainment outlets, sports and religious centers, restaurants, and supermarkets. Avoidance of public transport and altering travel times to avoid rush hour can also help. Additional places that should take precautionary measures include nursing homes, prisons, and drug rehabilitation centers. ${ }^{10}$

Social distancing measures can help reduce the transmission of coronavirus (COVID-19). Contact with someone who is displaying symptoms of coronavirus (COVID-19) should be avoided. These symptoms include highgrade fever, cough, and shortness of breath. One should stay at home and call a health helpline for further advice if one develops these symptoms. Various studies prove that these methods have displayed efficacy in preventing influenza pandemics. ${ }^{11}$

Responsible citizens should follow Ministry of Health guidelines, avoid overcrowding in public areas, and refrain from attending unnecessary social gatherings, especially events with large numbers of people or crowds. Separation from people one lives with is recommended to the extent to which it is possible. ${ }^{12}$ Social distancing may cause anxiety and depression. To combat this, people should take time to focus on personal health training, raise physical activity levels, and maintain healthy dietary habits. Literature on the coronavirus has also reported asymptomatic spreading of the disease in communities. ${ }^{13}$ Technology can be used to finish work, attend meetings, and engage with co-workers online. However, social distancing can lead to the spread of unhealthy rumors, misinformation, and myths via social media.

Physical distancing of at least one meter is the first step to preventing the coronavirus, followed by isolation if required. Self-isolation is mandatory when a person experiences fever, cough, or other COVID-19 symptoms. Staying at home even when someone is asymptomatic will reduce the chance of virus spread. These measures secure physical distance between people and reduce contact with contaminated surfaces. ${ }^{14}$

Many countries are now practicing a combination of social distancing of the entire population, home isolation of cases, household quarantine of family members, and possible school and university closures. ${ }^{15,16}$ The civic duty of individuals is to understand the gravity of the situation and its effects on politics, business, and public health while facing the coronavirus pandemic. Health care professionals must follow evidence-based management guidelines and update their knowledge frequently. Community support for health officials is effective and mandatory to break the cycle of infection; however, this may lead to economic shutdowns or lockdowns across the entire country. ${ }^{17,18}$

This paper's recommendation is to watch, read, 
or listen to national news for updates on the spread of COVID-19 in one's community. Infection control measures among health care professionals and educational programs on isolation precautions can further enhance citizens' levels of knowledge and practices to reduce infection transmission risks. Health care professionals should always practice proper selfcare to ensure their own safety and prevent the spread of infection within their communities.

\section{References}

1. WHO. Report on the burden of endemic health care associated infection worldwide. A Systematic review of the literature. Available from: http://whqlibdoc.who.int/ publications/2011/9789241501507 eng.pdf.

2. Tian X, Li C, Huang A, et al. Potent binding of 2019 novel coronavirus spike protein by a SARS coronavirus-specific human monoclonal antibody. Emerg Microbes Infect. 2020;9(1):382-385. doi:10.1080/22221751.20 20.1729069

3. Pang J, Wang MX, Ang IYH, et al. Potential Rapid Diagnostics, Vaccine and Therapeutics for 2019 Novel Coronavirus (2019-nCoV): A Systematic Review. J Clin Med. 2020;9(3):E623. 110 Published 2020 Feb 26. doi:10.3390/ jcm9030623

4. Liu J, Zheng X, Tong Q, et al. Overlapping and discrete aspects of the pathology and pathogenesis of the emerging human pathogenic coronaviruses SARS-CoV, MERS-CoV, and 2019-nCoV. J Med Virol. 2020;10.1002/jmv.25709. doi:10.1002/ jmv.25709

5. Wilder-Smith A, Freedman DO. Isolation, quarantine, social distancing and community containment: Pivotal role for old-style public health measures in the novel coronavirus (2019-nCoV) outbreak. J Travel Med. 2020;27(2):taaa020. doi:10.1093/jtm/taaa020.
6. Meo SA, Alhowikan AM, Al-Khlaiwi T, et al. Novel coronavirus 2019-nCoV: Prevalence, biological and clinical characteristics comparison with SARS-CoV and MERS-CoV. Eur Rev Med Pharmacol Sci. 2020;24(4):2012-2019. doi:10.26355/ eurrev_202002_20379.

7. Lake MA. What we know so far: COVID-19 current clinical knowledge and research (Lond). 2020;clinmed.2019-coron. doi:10.7861/ clinmed.2019-corona.

8. Centers for Disease Control and Prevention. Pandemic influenza, 2019 [cited 2019 Jul 7]. https://www.cdc.gov/flu/pandemic-resources/ index.htm.

9. Ahmed F, Zviedrite N, Uzicanin A Effectiveness of workplace social distancing measures in reducing influenza transmission: A systematic review. BMC Public Health. 2018;18:518.

10. European Centre for Disease Prevention and Control. Guide to public health measures to reduce the impact of influenza pandemics in Europe: The ECDC Menu. Stockholm: The Centre; 2009.

11. Ahmed et al. Effectiveness of workplace social distancing measures in reducing influenza transmission: a systematic review BMC Public Health (2018) 18:518 https://doi.org/10.1186/ s12889-018-5446-1.
12. Qualls N, Levitt A, Kanade N, Wright-Jegede N, Dopson S, Biggerstaff M, et al.; CDC Community Mitigation Guidelines Work Group. Community mitigation guidelines to prevent pandemic influenza-United States, 2017. MMWR Recomm Rep. 2017;66:1-34.

13. Jackson C, Vynnycky E, Hawker J, Olowokure B, Mangtani P. School closures and influenza: Systematic review of epidemiological studies. BMJ Open. 2013;3:e002149

14. Leung NH, Xu C, Ip DK, Cowling BJ. The fraction of influenza virus infections that are asymptomatic: A systematic review and metaanalysis. Epidemiology. 2015;26:862-72.

15. Hatchett RJ, Mecher CE, Lipsitch M. Public health interventions and epidemic intensity during the 1918 influenza pandemic. Proc Natl Acad Sci U S A. 2007;104:7582-7.

16. Ferguson NM, Laydon D, Nedjati-Gilani G, et al. Report 9: Impact of non-pharmaceutical interventions (NPIs) to reduce COVID-19 mortality and healthcare demand. Imperial College London. 16 Mar 2020.

17. Hisham R, Ng CJ , Liew SM, et al. Why is there variation in the practice of evidence-based medicine in primary care? A qualitative study. BMJ Open 2016;6:e010565.

18. Su May Liew. We have to write and share valid and reliable information on COVID-19 Malaysian Family Physician 2020; 15;1. 


\title{
Experiences of women who underwent induced lactation: A literature review
}

\author{
Shahirah Mohd Hassan, Zaharah Sulaiman, Tengku Alina Tengku Ismail \\ Mohd Hassan S, Sulaiman Z, Tengku Ismail TA. Experiences of Women Who Underwent Induced Lactation: A Literature Review. Malays Fam \\ Physician. 2021;16(1);18-30. https://doi.org/10.51866/rv0997
}

\section{Keywords:}

adoptive breastfeeding,

induced lactation, milk kinship

\section{Authors:}

Zaharah Sulaiman

(Corresponding author) MBBS (Adelaide), MMed (Comm Med) (USM), PhD (La Trobe), IBCLC Women's Health Development Unit School of Medical Sciences Universiti Sains Malaysia Kelantan, Malaysia Email: zaharah@usm.my

zaharahsulaiman@yahoo.com

\section{Shahirah Mohd Hassan} MBBS (University Malaya), IBCLC Women's Health Development Unit School of Medical Sciences Universiti Sains Malaysia Kelantan, Malaysia

Tengku Alina Tengku Ismail MD (USM), MMed (Comm. Med) (USM), PhD (USM)

Department of Community Medicine School of Medical Sciences Universiti Sains Malaysia Kelantan, Malaysia

\section{Abstract}

Objective: This article aims to review the literature published over the past five decades related to the experiences of women who have undergone induced lactation.

Methods: A comprehensive electronic search was conducted using PubMed, the Library of Congress, Google Scholar, SAGE, and ScienceDirect. The following search keywords were used: adoptive breastfeeding, induced lactation, non-puerperal lactation, extraordinary breastfeeding, and milk kinship. The search was restricted to articles written in English and published from 1956 to 2019. All study designs were included except for practice protocols.

Results: A total of 50 articles about induced lactation were retrieved. Of these, 17 articles identified the experiences of women who underwent induced lactation. The articles included original papers $(n=7)$, reviews $(n=5)$, and case reports $(n=5)$. Four articles were specifically related to Malaysia, and the others were international. These 17 articles concerning the experiences of women who induced lactation will be reviewed based on four themes related to inducing lactation: (a) understanding women's perception of satisfaction, (b) emotional aspects, (c) enabling factors, and (d) challenges.

Conclusion: Identifying a total of only 17 articles on induced lactation published over the last 53 years suggests that the subject is understudied. This review provides emerging knowledge regarding the experiences of women who have induced lactation in terms of satisfaction, emotions, enabling factors and challenges related to inducing lactation.

\section{Introduction}

Adoptive breastfeeding, referred to as induced lactation, is relevant in non-puerperal cases. Induced lactation is the process by which a non-puerperal woman is stimulated to lactate; more simply, the term refers to breastfeeding without prior pregnancy. ${ }^{1,2}$ Induced lactation has been described as the process of breastmilk production in a mammal (woman) without recent pregnancy and/or birth and may involve the use of herbs, supplements, medications, mechanical stimulation, and/or the infant to facilitate breastmilk production. ${ }^{2}$

Healthcare practitioners must comprehend the experiences of women who induce lactation to be able to provide unique, customized support for each individual. ${ }^{3}$ The American Academy of Pediatrics (AAP) supports this stance in its policy statement on "Breastfeeding and the Use of Human Milk," noting that pediatricians should provide counseling to adoptive mothers who decide to breastfeed through induced lactation, a process that requires professional support and encouragement. ${ }^{4}$
Malaysia is a Muslim country, which has a bearing on the topic as a motivating factor for Muslim adoptive parents to induce lactation is to establish religious milk kinship. Saari et al. reported a lack of research on induced lactation in Malaysia, particularly involving the Muslim community, regarding why women might induce lactation and the factors that motivate them to do so. ${ }^{5}$ Rahim et al. recommended that future investigations develop a practical model for induced lactation in Malaysia to explore maternal views related to the mothers' needs, obstacles, experiences, perceptions, and motivations. $^{6}$

The objective of this article is to review the literature that has been published over the past five decades regarding the experiences of women who have undergone induced lactation. Therefore, this review covers perceptions of satisfaction, emotional aspects, enabling factors, and the challenges that women who underwent induced lactation have experienced. It is hoped that this review will provide healthcare professionals insight into women's experience of induced lactation and acknowledge the vital role they play in assisting women in this process. 


\section{Methods}

A comprehensive electronic search was conducted using PubMed, the Library of Congress, Google Scholar, SAGE, and ScienceDirect. The inclusion criteria were articles written in English, published from 1956 to 2019, and reporting outcomes related to satisfaction, emotions, enablers, and challenges in induced lactation. The search included the following study designs: reviews, original papers, and case reports. The exclusion criteria were articles in languages other than English, articles without access to the full paper, and outcomes not related to satisfaction, emotions, enablers, and challenges in induced lactation. Studies with a practice protocol design were also excluded. The following search keywords were used: adoptive breastfeeding, induced lactation, non-puerperal lactation, extraordinary breastfeeding, and milk kinship. The retrieved articles were compiled and managed using EndNote X8 software according to the respective topics. The search was conducted with multiple databases, which resulted in retrieving some duplicate citations, which were deleted using the EndNote X8 software. After deduplication, the search results were screened by title and abstract, followed by reading the full texts and removing the articles that did not meet the inclusion criteria. Based on the repetition of the themes that emerged when reading the full texts, four aspects were chosen for consideration: satisfaction, emotions, enablers, and challenges in inducing lactation. Figure $\mathbf{1}$ shows the flowchart of the screening and reviewing process.

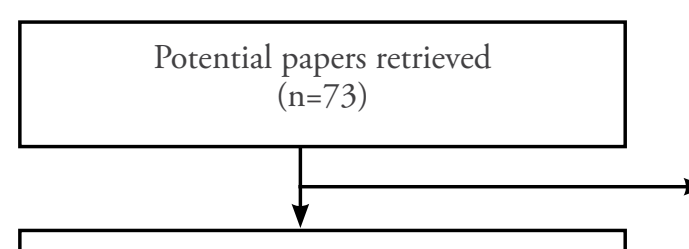

Full-text papers assessed for eligibility $(\mathrm{n}=50)$

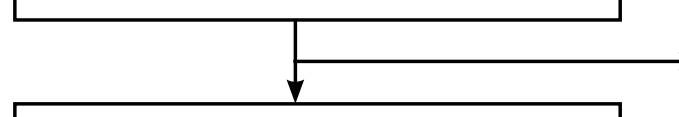

Papers included in the review $(\mathrm{n}=17)$
Papers with no access to full text excluded $(n=4)$

$$
\text { Duplicate excluded ( } \mathrm{n}=7)
$$

Articles excluded after screening the titles and abstracts $(n=12)$

Full-text papers excluded due to no outcome of interest $(n=33)$

Figure 1: Screening process for the literature review

\section{Results}

A total of 73 potential papers about induced lactation were retrieved. During the screening process, papers that were excluded were those lacking access to the full text $(n=4)$, duplicates $(\mathrm{n}=7)$, and articles with titles and abstracts that did not match the review's objective $(n=12)$. Consequently, 50 full-text papers were assessed for eligibility, from which full-text papers with no outcome of interest $(n=33)$ were excluded. The content of the papers that offered no outcome of interest included folklore, religious views, and using galactogogues to induce lactation. Finally, 17 papers were included in the review. Four articles were specifically related to Malaysia, and the others were international. The resulting studies comprised seven original papers, five reviews, and five case reports. Based on the themes that repeatedly emerged when reading the full-text papers, the women's experiences were reviewed based on the following topics related to inducing lactation: (a) understanding women's perception of satisfaction, (b) emotional aspects, (c) enabling factors, and (d) challenges.

\section{Understanding Women's Perception of Satisfaction in Inducing Lactation}

Auerbach et al. conducted a study in which 240 women who experienced adoptive nursing were asked about the parameters that led to success in a self-report questionnaire comprising closed-ended questions. ${ }^{7}$ The study reported that most of the women were satisfied with their experiences. ${ }^{7}$ Along the same lines, Goldfarb asked 228 participants how satisfied they were with their efforts to induce lactation. In this case, most of the women who induced lactation reported being satisfied with the overall experience and, given the opportunity, $83 \%$ said they would repeat the process. ${ }^{2}$ 
Most of the participants in Saari et al.'s study did not experience pregnancy or childbirth, yet they expressed the desire to enjoy motherhood by breastfeeding their adopted child. ${ }^{5}$ In that study, $67 \%$ of the mothers claimed that they enjoyed breastfeeding their child. The researchers noted repeated mentions of the words "satisfied," "relieved," "enjoy," "pleasure," and "indescribable feeling." In contrast to the papers that focused on understanding the mothers' perspectives, Bryant ${ }^{8}$ and Wittig et $\mathrm{al}^{3}$ published systematic reviews focusing on pharmacological and non-pharmacological methods to induce lactation. Both reviews reported that the maternal-infant bonding that resulted from induced lactation was the main source of satisfaction among the participants despite the rigorous process and their inability to produce an adequate milk supply to breastfeed exclusively. ${ }^{3,8}$

Table 1 summarizes the findings on understanding women's perception of satisfaction in inducing lactation in chronological order by year of publication. Based on the publications mentioned above, it is evident that the satisfaction of inducing lactation helps establish the maternal-infant bond, which is promoted by the process of inducing lactation.

Table 1: Findings on the perceptions of satisfaction in inducing lactation

\begin{tabular}{|c|c|c|}
\hline $\begin{array}{l}\text { Author } \\
\text { (Year) }\end{array}$ & $\begin{array}{c}\text { Study design } \\
\text { Number of participants/articles }\end{array}$ & $\begin{array}{l}\text { Summary of the findings on the } \\
\text { perceptions of satisfaction } \\
\text { in inducing lactation }\end{array}$ \\
\hline $\begin{array}{l}\text { Auerbach et al. } \\
\text { (1981) }\end{array}$ & $\begin{array}{l}\text { Original paper (quantitative design) } \\
240 \text { participants }\end{array}$ & $\begin{array}{l}\text { Most of the participants felt that the mother- } \\
\text { infant relationship was important, and } 76 \% \\
\text { evaluated adoptive nursing "positively." } \\
\text { No clarification of the term "positively." }\end{array}$ \\
\hline $\begin{array}{l}\text { Bryant }^{8} \\
(2006)\end{array}$ & $\begin{array}{c}\text { Review } \\
26 \text { articles as references }\end{array}$ & $\begin{array}{l}\text { The primary goal was not milk production } \\
\text { but establishing an emotional bond with the } \\
\text { infant. }\end{array}$ \\
\hline $\begin{array}{l}\text { Wittig et al. }{ }^{3} \\
\text { (2008) }\end{array}$ & $\begin{array}{c}\text { Review } \\
18 \text { articles as references }\end{array}$ & $\begin{array}{l}\text { Based on information drawn from the articles } \\
\text { in the review, it can be concluded that most } \\
\text { women who induce lactation cannot produce } \\
\text { enough breastmilk to exclusively breastfeed } \\
\text { their infant, but they find satisfaction in } \\
\text { this process because of the maternal-infant } \\
\text { bonding it promotes. }\end{array}$ \\
\hline $\begin{array}{l}\text { Goldfarb }^{2} \\
(2010)\end{array}$ & $\begin{array}{l}\text { Original paper } \\
\text { (mixed qualitative and } \\
\text { quantitative design) } \\
228 \text { participants }\end{array}$ & $\begin{array}{l}\text { The author reported that } 76 \% \text { of the women } \\
\text { were "satisfied" with no clarification of the } \\
\text { term "satisfied" because that part of the study } \\
\text { was quantitative. }\end{array}$ \\
\hline $\begin{array}{l}\text { Saari et al. }{ }^{5} \\
\quad(2015)\end{array}$ & $\begin{array}{l}\text { Original paper } \\
\text { (qualitative design) } \\
12 \text { participants }\end{array}$ & $\begin{array}{l}\text { The findings showed that } 67 \% \text { of the } \\
\text { mothers enjoyed breastfeeding their child, } \\
\text { with repeated mentions of the words } \\
\text { "satisfied," "relieved," "enjoy," "pleasure," and } \\
\text { "indescribable feeling." }\end{array}$ \\
\hline
\end{tabular}

\section{Emotional Aspects of Inducing Lactation}

Gribble reviewed the evidence in physiological and behavioral research studies regarding how breastfeeding plays a significant role in developing the attachment relationship between an adopted child and mother.' The results revealed that breastfeeding an adopted child is an attempt to ensure the quality of attachment between the mother and baby, whereby physical contact between them through breastfeeding enables a baby suffering from the trauma of separation from his/her birth mother to feel secure. ${ }^{?}$

In the qualitative section of Goldfarb's paper, the participants were asked to describe how they felt during the process of inducing lactation ${ }^{2}$ The text was analyzed for repeated words, phrases, and themes. The prevalent comments were feelings of awe, wonder, and amazement, followed by love. Mothers reported healing from grief due to infertility as an essential motivation for inducing lactation. ${ }^{2}$ 
Saari et al. asserted that induced lactation undertaken by participants elicited maternal instincts in adoptive mothers. ${ }^{5}$ After experiencing induced lactation, all participants agreed that the process prepared them to be mothers and that breastfeeding was a pleasurable experience. All the participants also agreed that breastfeeding entailed affection and touch, exerting a positive impact on the adoptive mothers and the babies they were nursing. ${ }^{5}$
Table 2 presents a summary of the findings on the emotional aspects of inducing lactation in chronological order by year of publication. Both positive and negative emotions were associated with induced lactation, as addressed by Goldfarb. ${ }^{2}$ Positive emotions were viewed as a source of motivation to induce lactation, and negative emotions were associated with challenges to inducing lactation. ${ }^{2}$

Table 2: Findings on the emotional aspects of inducing lactation

\begin{tabular}{|c|c|c|}
\hline $\begin{array}{l}\text { Author } \\
\text { (Year) }\end{array}$ & $\begin{array}{c}\text { Study design } \\
\text { Number of participants/articles }\end{array}$ & $\begin{array}{l}\text { Summary of the findings on the } \\
\text { perceptions of satisfaction } \\
\text { in inducing lactation }\end{array}$ \\
\hline $\begin{array}{l}\text { Gribble }^{9} \\
(2006)\end{array}$ & $\begin{array}{c}\text { Review } \\
163 \text { articles as references }\end{array}$ & $\begin{array}{l}\text { Breastfeeding an adopted child was an } \\
\text { attempt to ensure the quality of attachment } \\
\text { between the mother and baby. } \\
\text { Physical contact between the mother and } \\
\text { baby through breastfeeding helped a baby } \\
\text { suffering from the trauma of separation from } \\
\text { his/her birth mother feel secure. }\end{array}$ \\
\hline $\begin{array}{l}\text { Saari et al. }{ }^{5} \\
\quad(2015)\end{array}$ & $\begin{array}{l}\text { Original paper } \\
\text { (qualitative design) } \\
12 \text { participants }\end{array}$ & $\begin{array}{l}\text { Induced lactation led to a unique feeling, i.e., } \\
\text { maternal instinct in adoptive mothers. } \\
\text { All the participants agreed that breastfeeding } \\
\text { prepared them to be mothers and was a } \\
\text { pleasurable experience. } \\
\text { All the participants also agreed that } \\
\text { the affection and touch associated with } \\
\text { breastfeeding had a positive impact. }\end{array}$ \\
\hline $\begin{array}{l}\text { Goldfarb }^{2} \\
(2010)\end{array}$ & $\begin{array}{l}\text { Original paper } \\
\text { (mixed qualitative and } \\
\text { quantitative design) } \\
228 \text { participants }\end{array}$ & $\begin{array}{l}\text { Mothers reported that healing from grief } \\
\text { due to infertility was the most significant } \\
\text { motivation to induce lactation. } \\
\text { Positive emotions were related to the } \\
\text { mother-infant relationship, whereas negative } \\
\text { emotions were related to technical challenges } \\
\text { in inducing lactation, such as concerns about } \\
\text { breastmilk supply, finding time to pump, and } \\
\text { issues related to breast pumps. }\end{array}$ \\
\hline
\end{tabular}

\section{Enabling Factors in Inducing Lactation}

In this paper, enabling factors make it possible (or easier) for a woman to induce lactation. Based on an international article, this subtopic is divided into psychosocial and technical factors, including the regimes and tools used to induce lactation. ${ }^{3}$

\section{Psychosocial Factors Enabling Induced Lactation}

Szucs et al. published a case report of premature twins whose adoptive mother induced lactation. ${ }^{10}$ Both infants received their adoptive mother's milk exclusively at the age of two months. This approach reflects careful planning by the adoptive mother beginning in the prenatal period, her active role during the infants' hospital stay, and the support she received from healthcare personnel and family members. ${ }^{10}$

Lakhkar $^{11}$ and Nemba ${ }^{12}$ maintained that the mothers' motivation was the primary factor that enabled them to induce lactation, followed by family support. The researchers concluded that a mother who was motivated, confident, and knowledgeable about induced lactation had the best chance to succeed. ${ }^{11,12}$ Goldfarb $^{2}$ 
and Auerbach et al. ${ }^{7}$ found that enhancing the bond between the mother and baby was a key factor in breastfeeding an adopted child.

Women in Malaysia are driven to breastfeed their adopted babies through cultural exposure and religious beliefs to obtain milk kinship. ${ }^{5}$ Saari et al. developed a model for adoptive breastfeeding that integrated both the Figh and scientific perspectives of adoptive breastfeeding. ${ }^{5}$ Research has reported that the psychosocial enablers to induce lactation help fulfill religious milk kinship (Shariah-based) and, from a humanitarian perspective, foster compassion (sciencebased). ${ }^{13}$ Table 3 presents a summary of the findings on the psychosocial factors enabling induce lactation in chronological order by year of publication.

Table 3: Findings on the psychosocial factors enabling induced lactation

\begin{tabular}{|c|c|c|}
\hline $\begin{array}{l}\text { Author } \\
\text { (Year) }\end{array}$ & $\begin{array}{c}\text { Study design } \\
\text { Number of participants/articles }\end{array}$ & $\begin{array}{l}\text { Summary of the findings on the } \\
\text { perceptions of satisfaction } \\
\text { in inducing lactation }\end{array}$ \\
\hline $\begin{array}{l}\text { Auerbach et al. }{ }^{7} \\
\qquad(1981)\end{array}$ & $\begin{array}{l}\text { Original paper } \\
\text { (quantitative design) } \\
240 \text { participants }\end{array}$ & $\begin{array}{l}\text { Factors reported as psychosocial enablers } \\
\text { for inducing lactation: } \\
\text { i. Mother-infant bonding } \\
\text { ii. Fulfilling emotional needs of babies } \\
\text { iii. Body contact with baby } \\
\text { iv. Nutritional benefits of infants } \\
\text { v. Care by the mother } \\
\text { vi. Ability to produce breastmilk } \\
\text { vii. Breastfeeding as a reflection of femininity } \\
\text { viii. Mother's physical changes }\end{array}$ \\
\hline $\begin{array}{l}\mathrm{Nemba}^{12} \\
(1994)\end{array}$ & $\begin{array}{l}\text { Case report } \\
37 \text { participants }\end{array}$ & $\begin{array}{l}\text { A mother who was motivated, confident, and } \\
\text { knowledgeable on the topic experienced the } \\
\text { best chance of successfully inducing lactation. }\end{array}$ \\
\hline $\begin{array}{l}\text { Lakhkar }^{11} \\
(2000)\end{array}$ & $\begin{array}{c}\text { Case report } \\
23 \text { participants }\end{array}$ & $\begin{array}{l}\text { A mother's motivation and family support } \\
\text { acted as psychosocial enablers to induce } \\
\text { lactation. }\end{array}$ \\
\hline $\begin{array}{l}\text { Gribble }^{14} \\
(2003)\end{array}$ & $\begin{array}{c}\text { Review } \\
87 \text { articles as references }\end{array}$ & $\begin{array}{l}\text { Suggested that adoptive mothers in } \\
\text { developing countries might have greater } \\
\text { milk production than mothers in Western } \\
\text { countries because the former were more } \\
\text { knowledgeable about breastfeeding, practiced } \\
\text { frequent breastfeeding, had close physical } \\
\text { contact with children, and lived in cultures } \\
\text { that supported breastfeeding. }\end{array}$ \\
\hline $\begin{array}{l}\text { Goldfarb }^{2} \\
(2010)\end{array}$ & $\begin{array}{c}\text { Original paper } \\
\text { (qualitative and quantitative design) } \\
228 \text { participants }\end{array}$ & $\begin{array}{l}\text { Inducing lactation fulfilled the emotional } \\
\text { needs of babies and healed the mothers' grief } \\
\text { due to infertility. }\end{array}$ \\
\hline $\begin{array}{l}\text { Szucs et al. }{ }^{10} \\
\quad(2010)\end{array}$ & $\begin{array}{l}\text { Case report } \\
1 \text { participant }\end{array}$ & $\begin{array}{l}\text { Support from healthcare professionals and } \\
\text { family members played a role in ensuring } \\
\text { that premature twins received their adoptive } \\
\text { mother's milk exclusively at the age of } 2 \\
\text { months. }\end{array}$ \\
\hline
\end{tabular}




\begin{tabular}{|c|c|c|}
\hline $\begin{array}{c}\text { Saari et al. }{ }^{5} \\
(2015)\end{array}$ & $\begin{array}{c}\text { Original paper } \\
\text { (qualitative design) } \\
12 \text { participants }\end{array}$ & $\begin{array}{l}\text { The themes outlined with regard to these } \\
\text { psychosocial factors included "mahram," } \\
\text { "maternal instinct," "psychology," "offspring," } \\
\text { and "obligation." These themes are briefly } \\
\text { summarized as follows: } \\
\text { i. "Mahram" and "Obligation": To establish } \\
\text { religious milk kinship } \\
\text { ii. "Maternal instinct": To satisfy the } \\
\text { maternal instincts of adoptive mothers } \\
\text { who have not experienced childbirth } \\
\text { iii. "Psychology": Fulfill the desire to establish } \\
\text { a bond between the adoptive mother and } \\
\text { child } \\
\text { iv. "Offspring": To overcome grief from not } \\
\text { being able to conceive }\end{array}$ \\
\hline $\begin{array}{c}\text { Saari et al. }{ }^{13} \\
\quad(2017)\end{array}$ & $\begin{array}{c}\text { Original paper } \\
\text { (qualitative design) } \\
12 \text { participants }\end{array}$ & $\begin{array}{l}\text { This study developed a Guideline Model of } \\
\text { Breastfeeding Adopted Child alligned with } \\
\text { the Fiqh and science perspective. Psychosocial } \\
\text { enablers for inducing lactation included } \\
\text { obligation to fulfill religious milk-kinship } \\
\text { (shariah-based) and compassion (science- } \\
\text { based). }\end{array}$ \\
\hline
\end{tabular}

\section{Technical Factors: Different Regimes that Enable Inducing Lactation}

Common approaches to inducing lactation include pharmacologic (hormonal stimulation) and non-pharmacologic (breast stimulation) methods, often used in combination. ${ }^{3}$ Non-pharmacologic methods may involve women inducing lactation via breast stimulation through hand expression, using a breast pump, via direct suckling at the breast, or using a supplemental nursing system. ${ }^{2.3,7,15}$

Table 4 summarizes the reported technical factors, including pharmacologic and nonpharmacologic approaches, that enable women to induce lactation in chronological order by year of publication. Auerbach et al. ${ }^{7}$ and Goldfarb ${ }^{2}$ described various regimes used to induce lactation. Patel also demonstrated that a back massage is a simple method that can be implemented in a regime to induce lactation without straining resources. ${ }^{16}$ Cheales-Siebenaler et al. described an adoptive mother who produced breastmilk for her infant via various regimes, which resulted in adequate weight gain for her infant. ${ }^{17}$

Table 4: Technical factors enabling induced lactation

\begin{tabular}{|c|c|c|}
\hline $\begin{array}{l}\text { Author } \\
\text { (Year) }\end{array}$ & $\begin{array}{c}\text { Study design } \\
\text { Number of participants/articles }\end{array}$ & $\begin{array}{l}\text { Summary of the findings on the } \\
\text { perceptions of satisfaction } \\
\text { in inducing lactation }\end{array}$ \\
\hline $\begin{array}{l}\text { Wittig et al. }{ }^{3} \\
\text { (2008) }\end{array}$ & $\begin{array}{c}\text { Review } \\
18 \text { articles as references }\end{array}$ & $\begin{array}{l}\text { Procedures commonly used to induce } \\
\text { lactation include pharmacologic (hormonal } \\
\text { stimulation) and non-pharmacologic (breast } \\
\text { stimulation) methods, often in combination. }\end{array}$ \\
\hline $\begin{array}{l}\text { Goldfarb }^{2} \\
(2010)\end{array}$ & $\begin{array}{c}\text { Original paper } \\
\text { (mixed-methods design) } \\
228 \text { participants }\end{array}$ & $\begin{array}{l}\text { This paper described various regimes and } \\
\text { their popularity (by percentage) in terms of } \\
\text { being used to induce lactation, summarized } \\
\text { below: } \\
\text { i. Domperidone }(92 \%) \\
\text { ii. Fenugreek }(78 \%) \\
\text { iii. Birth control pill }(63 \%) \\
\text { iv. Blessed thistle }(68 \%) \\
\text { v. Nothing }(6 \%)\end{array}$ \\
\hline
\end{tabular}




\begin{tabular}{|c|c|c|}
\hline & & $\begin{array}{ll}\text { vi. } & \text { Metoclopramide (4\%) } \\
\text { vii. } & \begin{array}{l}\text { Expressed breastmilk before infant's } \\
\text { arrival via pumping }(75 \%) \text { or hand } \\
\text { expression (14\%) }\end{array} \\
\text { viii. } & \begin{array}{l}\text { Pumped after most feeds for } 10 \text { minutes } \\
(40 \%)\end{array} \\
\text { ix. } \quad \begin{array}{l}\text { Pumped after baby arrived, but not yet } \\
\text { suckling on the breast (32\%) }\end{array} \\
\text { x. } \quad \begin{array}{l}\text { Put baby to the breast with a } \\
\text { supplemental nursing system ( } 51 \%)\end{array} \\
\text { Maximum milk supply was reported by the } \\
\text { participants using the following protocols: } \\
\text { i. } \quad \begin{array}{l}\text { Domperidone, birth control, and } \\
\text { pumping ( } 45 \%)\end{array} \\
\text { ii. } \quad \begin{array}{l}\text { Domperidone and pumping (12\%) } \\
\text { iii. }\end{array} \\
\begin{array}{l}\text { Domperidone and supplemental } \\
\text { nursing system (12\%) }\end{array}\end{array}$ \\
\hline $\begin{array}{l}\text { Rahim et al. }{ }^{6} \\
\text { (2017) }\end{array}$ & $\begin{array}{c}\text { Review } \\
19 \text { articles as references }\end{array}$ & $\begin{array}{l}\text { No previous research has revealed any } \\
\text { effective guidelines in place for induced } \\
\text { lactation in Malaysia. } \\
\text { Establishing these guidelines is essential } \\
\text { in Malaysia, given the recent expansion } \\
\text { in Malaysians' awareness of breastfeeding } \\
\text { adopted children. }\end{array}$ \\
\hline $\begin{array}{l}\text { Auerbach et al. }{ }^{7} \\
\qquad(1981)\end{array}$ & $\begin{array}{c}\text { Original paper (quantitative design) } \\
240 \text { participants }\end{array}$ & $\begin{array}{l}\text { This paper reported that most of the } \\
\text { respondents practiced one or more of the } \\
\text { following to induce lactation: } \\
\text { i. Read three or four books about } \\
\text { breastfeeding or two or more articles on } \\
\text { adoptive nursing before the arrival of } \\
\text { their adopted infant } \\
\text { ii. Improved or supplemented maternal } \\
\text { diet } \\
\text { iii. Practiced nipple stimulation before or } \\
\text { after infant's arrival } \\
\text { iv. Occasionally used hormone } \\
\text { preparations to simulate pregnancy or } \\
\text { increase milk ejection reflex }\end{array}$ \\
\hline $\begin{array}{l}\text { Abejide et al. }{ }^{15} \\
\quad(1997)\end{array}$ & $\begin{array}{l}\text { Case report } \\
6 \text { participants }\end{array}$ & $\begin{array}{l}\text { All six women in the case study produced } \\
\text { breastmilk by breast-suckling alone; however, } \\
\text { no details were included indicating how long } \\
\text { they breastfed. }\end{array}$ \\
\hline $\begin{array}{l}\text { Cheales- } \\
\text { Siebenaler } \\
\text { et al. }{ }^{17} \\
(1999)\end{array}$ & $\begin{array}{l}\text { Case report } \\
1 \text { participant }\end{array}$ & $\begin{array}{l}\text { An adoptive mother induced lactation by } \\
\text { bilateral pumping, metoclopramide, and } \\
\text { oxytocin nasal spray. She did not use oral or } \\
\text { parenteral hormones to induce lactation. } \\
\text { She supplemented her adopted infant at } \\
\text { the breast with the help of a supplementary } \\
\text { feeding-tube device. She began to produce } \\
\text { breastmilk when the infant was } 4 \text { months } \\
\text { old (suddenly began to express four ounces } \\
\text { of breastmilk per breast). The mother } \\
\text { stopped her protocol at this time (stopped } \\
\text { pumping and taking medications) and } \\
\text { proceeded to direct-feed her infant without } \\
\text { supplementation throughout the fourth } \\
\text { and fifth months, with the infant gaining } \\
\text { adequate weight. }\end{array}$ \\
\hline
\end{tabular}




\begin{tabular}{|c|c|l|}
$\begin{array}{c}\text { Patel et al. }{ }^{16} \\
(2013)\end{array}$ & $\begin{array}{l}\text { Original paper } \\
\text { (quantitative design) } \\
220 \text { participants }\end{array}$ & $\begin{array}{l}\text { Back massage was effective in improving } \\
\text { lactation in all the parameters assessed } \\
\text { regarding the baby's well-being, which was } \\
\text { significantly progressive in the study group in } \\
\text { comparison to the control group. }\end{array}$ \\
\hline
\end{tabular}

\section{Challenges in Inducing Lactation}

In 2015, Saari et al. described the challenges of breastfeeding an adopted child in Malaysia. ${ }^{5}$ For example, some people may remain skeptical about breastfeeding an adopted child and consider the practice to be against human nature. ${ }^{5}$ Four years later, Cazorla et al. reported the challenges faced by mothers inducing lactation and divided them into three categories: challenges during induction of lactation, challenges during breastfeeding, and difficulties during breastfeeding cessation. ${ }^{18}$

Nemba conducted a study in Africa with 37 non-puerperal women ranging in age from 19 to $55 .^{12}$ A total of 27 women completed the lactation induction program, 24 (89\%) of whom successfully breastfed their well-nourished children. All the women who had never previously lactated were successful. Of the three mothers in whom induction was unsuccessful, two obtained a bottle from other sources; their children were malnourished. This study indicates that given a high degree of motivation combined with medication, support, and encouragement, lactation induction is likely to be highly successful and a critical factor in child survival. ${ }^{12}$

Table 5 presents a summary of the findings on the challenges in inducing lactation in chronological order by year of publication.

Table 5: Challenges in inducing lactation

\begin{tabular}{|c|c|c|}
\hline $\begin{array}{l}\text { Author } \\
\text { (Year) }\end{array}$ & $\begin{array}{c}\text { Study design } \\
\text { Number of participants/articles }\end{array}$ & $\begin{array}{l}\text { Summary of the findings on the } \\
\text { perceptions of satisfaction } \\
\text { in inducing lactation }\end{array}$ \\
\hline $\begin{array}{l}\mathrm{Nemba}^{12} \\
(1994)\end{array}$ & $\begin{array}{l}\text { Case report } \\
37 \text { participants }\end{array}$ & $\begin{array}{l}\text { Internal factor: } \\
\text { i. Demotivated } \\
\text { External factor: } \\
\text { i. Lack of support and encouragement }\end{array}$ \\
\hline $\begin{array}{l}\text { Gribble }^{9} \\
(2006)\end{array}$ & $\begin{array}{c}\text { Review } \\
163 \text { articles as references }\end{array}$ & $\begin{array}{l}\text { Internal factor: } \\
\text { i. Emotional instability in adoptive } \\
\text { infants characterized by the cycle of } \\
\text { progression-regression-progression of } \\
\text { trying to directly breastfeed an adopted } \\
\text { child. }\end{array}$ \\
\hline $\begin{array}{l}\text { Bryant }^{8} \\
(2006)\end{array}$ & $\begin{array}{c}\text { Review } \\
26 \text { articles as references }\end{array}$ & $\begin{array}{l}\text { Internal factor: } \\
\text { i. Difficulty in committing time to } \\
\text { frequently pump or breastfeed } \\
\text { External factor: } \\
\text { i. Lack of support from the public, which } \\
\text { views inducing lactation as odd or not } \\
\text { worth the effort }\end{array}$ \\
\hline $\begin{array}{l}\text { Goldfarb }^{2} \\
(2010)\end{array}$ & $\begin{array}{l}\text { Original paper (qualitative } \\
\text { and quantitative design) } \\
228 \text { participants }\end{array}$ & $\begin{array}{l}\text { Internal factors: } \\
\text { i. Worrying about the baby getting } \\
\text { enough milk } \\
\text { ii. Sore nipples/breasts } \\
\text { iii. Fatigue } \\
\text { iv. Getting baby to breastfeed } \\
\text { v. Lack of preparation time } \\
\text { External factor: } \\
\text { i. Equipment difficulties }\end{array}$ \\
\hline
\end{tabular}




\begin{tabular}{|c|c|c|}
\hline $\begin{array}{c}\text { Saari et al. }{ }^{5} \\
(2015)\end{array}$ & $\begin{array}{c}\text { Original paper } \\
\text { (qualitative design) } \\
12 \text { participants }\end{array}$ & $\begin{array}{l}\text { Internal factors: } \\
\text { i. Lack of commitment } \\
\text { ii. } \quad \text { Health problems } \\
\text { External factors: } \\
\text { i. } \quad \text { Misconceptions } \\
\text { ii. } \quad \text { Lack of support } \\
\text { iii. } \quad \text { Non-conducive work environment } \\
\text { iv. } \quad \text { Career setback }\end{array}$ \\
\hline $\begin{array}{c}\text { Cazorla-Ortiz }{ }^{18} \\
(2019)\end{array}$ & $\begin{array}{c}\text { Original paper } \\
\text { (qualitative design) } \\
9 \text { participants }\end{array}$ & $\begin{array}{l}\text { Internal factors: } \\
\text { i. } \\
\text { Hardship to endure induced-lactation } \\
\text { ii. } \quad \begin{array}{l}\text { Doubtocols } \\
\text { lactation, such as not being able }\end{array} \\
\text { to produce milk or producing an } \\
\text { insufficient amount of milk } \\
\text { iii. } \begin{array}{l}\text { Problems with breasts, such as cracked } \\
\text { nipples, nipple blebs, blocked ducts, }\end{array} \\
\text { pain, and suction problems } \\
\text { iv. } \quad \begin{array}{l}\text { Doubts if amount of milk supplied was } \\
\text { sufficient during breastfeeding period }\end{array} \\
\text { v. The end of shared responsibility for } \\
\text { breastfeeding with the partner during } \\
\text { breastfeeding cessation } \\
\text { vi. Reduced feeling of closeness to the } \\
\text { child during breastfeeding cessation } \\
\text { External factor: } \\
\text { i. } \quad \begin{array}{l}\text { Difficulty obtaining information from } \\
\text { health professionals }\end{array}\end{array}$ \\
\hline
\end{tabular}

\section{Discussion}

\section{Understanding Women's Perception of Satisfaction in Inducing Lactation}

An adoptive mother seeking to induce lactation is a unique client in need of customized and personalized care. Although understanding the perception of satisfaction in inducing lactation is vital, ${ }^{3}$ the studies reviewed on this subject failed to clarify the term "satisfaction" in inducing lactation. , 3,5,7,8 $^{-1}$

Saari et al. ${ }^{5}$ and Goldfarb $^{2}$ produced original papers that reported the outcome of experiences of induced lactation. For their part, Wittig et al. ${ }^{3}$ and Bryant $^{8}$ presented reviews that reported conclusions drawn by reviewing previous studies. Several studies reported that satisfaction in women who induced lactation arose from the bond the practice established between the mother and the infant. ${ }^{3,5,7,8}$

In light of this factor, healthcare professionals helping mothers induce lactation should ask the mothers beforehand about their perceptions of satisfaction in inducing lactation. Practicing this approach will allow healthcare professionals to work with these mothers to achieve their goals. ${ }^{7}$ Because inducing lactation is an ongoing process, the perception of satisfaction might change as the process unfolds. It is recommended that healthcare professionals continually ask women who are inducing lactation about how they perceive satisfaction before they induce lactation and during follow-up visits. Such ongoing communication will enable professionals to develop the most realistic plan for an individual woman to achieve lactation. ${ }^{3}$

\section{Emotional Aspects of Inducing Lactation}

The studies that mentioned positive emotions associated with inducing lactation reported that the practice healed grief due to infertility, increased a woman's maternal instincts, and benefited the adopted babies by ensuring a secure feeling after the trauma of being separated from their birth mother. In support of this idea, Goldfarb ${ }^{2}$ and Saari et al $^{5}$ wrote original papers that reported on the outcome of experiences of induced lactation, and Gribble $^{9}$ published a review based on the conclusions reported in previous studies.

The emotions reported from the studies mentioned above correlate with a recommendation rooted in dependency theory (Attachment Theory), which was developed by 
John Bowlby and Mary Ainsworth in 1950. According to this theory, a baby's dependency on the mother or mother figure is predicated on acceptance, protection, security, and caring. ${ }^{19}$ Based on these phenomena, love between a mother and child can be nurtured as early as the birth of the baby through such acts as breastfeeding. The positive effects that inducing lactation can have on women's emotions support the recommendation that healthcare professionals should always take time to ask the women they are assisting about their emotional well-being during different phases of the lactation-inducing process. This approach provides healthcare professionals with both an opportunity to document the emotional changes that mothers go through when inducing lactation and additional insight about how women feel during different phases of that process. Thus, healthcare professionals will be better able to understand how to assist mothers in inducing lactation. The importance of this recommendation is underlined by the fact that over the course of 53 years, only three studies have addressed this subject, suggesting that more research on this topic is needed. ${ }^{2,5,9}$

Women who induce lactation may experience both positive and negative emotions. The negative emotions are related to the technical challenges, such as being concerned about breastmilk supply, finding time to pump, and issues related to breast pumps. ${ }^{2}$ Healthcare professionals can assist women with these aspects by offering regular follow-ups to identify the triggers that lead to negative emotions and discuss a plan to avoid those triggers and reduce or eliminate those emotions. Women going through induced lactation should be well supported emotionally because negative emotions will impair the autocrine process of lactation. ${ }^{20}$ Consultation sessions should also be attended by family members, a friend, a spouse, or a partner so that they can form a support system for the women inducing lactation to help them avoid emotional breakdowns.

\section{Psychosocial and Technical Factors that Enable Inducing Lactation}

Information regarding the social norms that positively affect a woman's ability to induce lactation in developing countries is somewhat similar to breastfeeding in general. In developing countries, mothers are knowledgeable about breastfeeding because they have observed the practice from a young age. ${ }^{14,21}$ This familiarity results in increased confidence in breastfeeding and fewer breastfeeding problems. ${ }^{22,23}$ Some women also have beliefs about child care that optimize breastfeeding. For example, they allow unrestricted breastfeeding and keep their babies in close physical contact, day and night. ${ }^{24,25}$ This technique maximizes prolactin secretion and breast emptying, accelerating breast development and increasing milk production. ${ }^{26}$

The participants in the studies by Goldfarb ${ }^{2}$ and Auerbach et al. $^{7}$ highly valued the development of love and an affectionate relationship between an adoptive mother and her adopted child because the adoptive woman did not carry the child in her womb. Efforts to establish a bond between an adoptive mother and her adopted child are unequivocally important as a Muslim in a local community in order to establish a mahram relationship. Both motivations act as psychosocial enablers to induce lactation, albeit from different perspectives. The goals are similar, involving an attempt to accept an adopted child as a part of one's family to avoid any issue of segregation despite the lack of a biological connection. 2,5,7 It is recommended that healthcare professionals understand the psychosocial factors that help women to induce lactation. While the reports regarding these psychosocial factors acknowledged their role in enabling induced lactation, it is recommended that healthcare professionals seek more in-depth information on this subject throughout the different phases of inducing lactation and during follow-ups. Each adoptive mother and breastfeeding baby has their own unique experience, and the psychosocial aspect has received less priority than the nutritional and immunity-enhancing aspects of breastfeeding. ' Seven articles on this subject over the past 53 years suggests that this topic is severely understudied and deserves further investigation. Gaining insight into the psychosocial enablers in inducing lactation will help healthcare professionals assist women in making practical management plans and managing their expectations. ${ }^{8}$

Moreover, many technical factors should be considered in induced lactation programs due to variations in the adoptive mothers' religious and ethnic backgrounds, health status, and financial and environmental

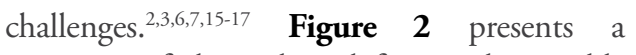
summary of the technical factors that enable women to induce lactation. 


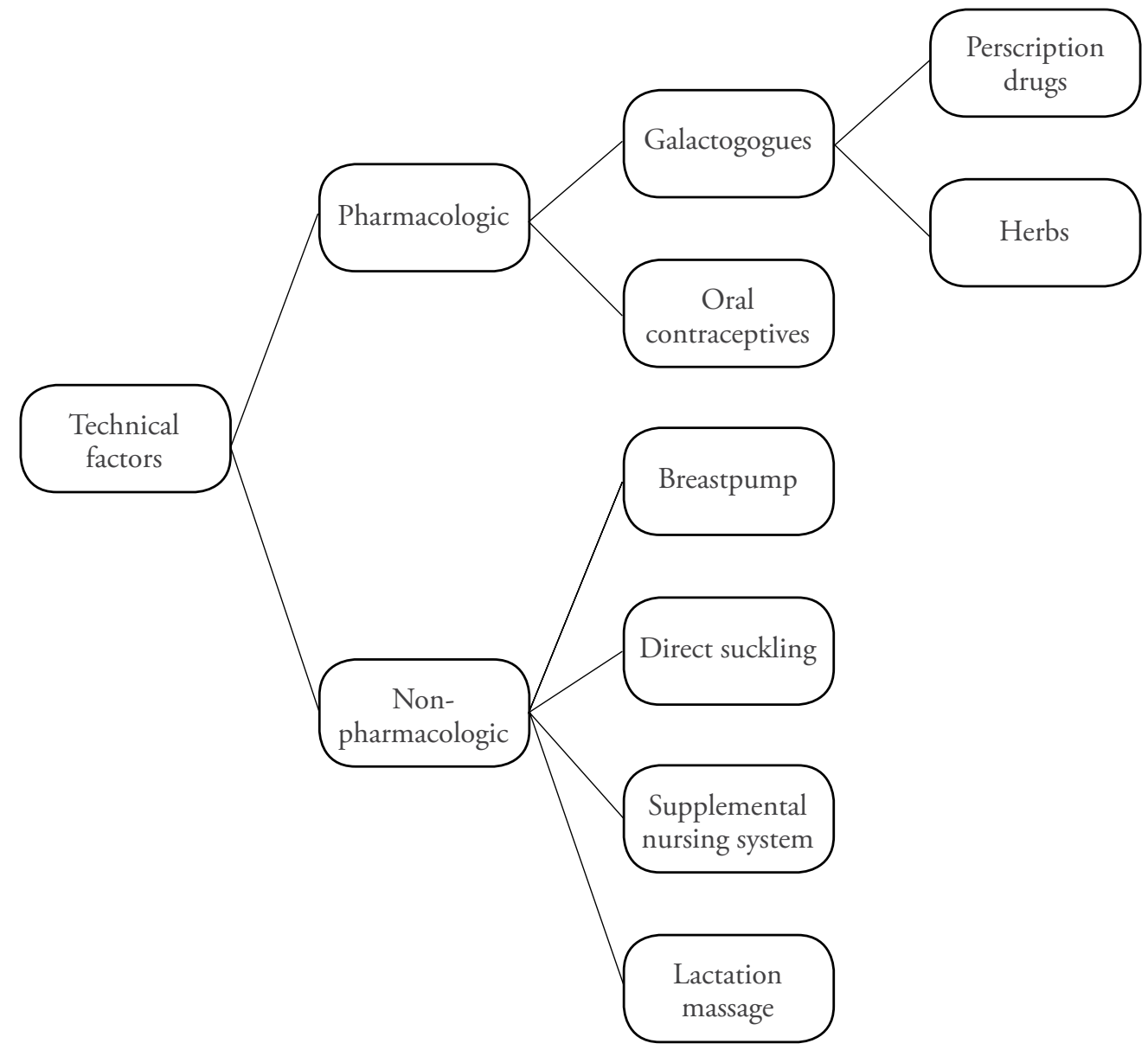

Figure 2: Summary of the technical factors that enable a woman to induce lactation

\section{Challenges in Inducing Lactation}

Although a review of the challenges to inducing lactation is limited in light of the lack of previous research in this area, women who induce lactation face internal challenges and external challenges. In general, internal challenges include a mother's lack of motivation, difficulty maintaining the stimulation protocol while inducing lactation, encountering breast problems while pumping or breastfeeding, and the lack of confidence in the ability to produce breastmilk. ${ }^{2,5,8,12,13,18}$ External challenges are the lack of support from people, the lack of efficient tools for stimulation, and the emotional instability of the adopted child causing latching difficulties. ${ }^{5,9,12,18}$

Bandura's $^{27}$ social cognitive theory serves to summarize the challenges women go through when inducing lactation. Social cognitive theory is founded on a model of causation involving triadic reciprocal determinism. In reciprocal causation, behavior, cognition, personal factors, and environmental influences are interacting determinants that influence each other bidirectionally. ${ }^{27}$ Figure 3 describes how social cognitive theory can be incorporated into the results from the review considering the challenges of inducing lactation. As an elaboration of the theory, consider an example from the results that demonstrates the role of environmental factors, personal factors, and behavioral factors. A woman who lacks support from the people around her may be demotivated to induce lactation and have difficulty adhering to the stimulation schedule. For example, breastfeeding equipment difficulties (environmental factor) could lead her to have difficulty adhering to the stimulation schedule (behavioral factor) and cause her to worry about the quantity of breastmilk production (personal factor). 


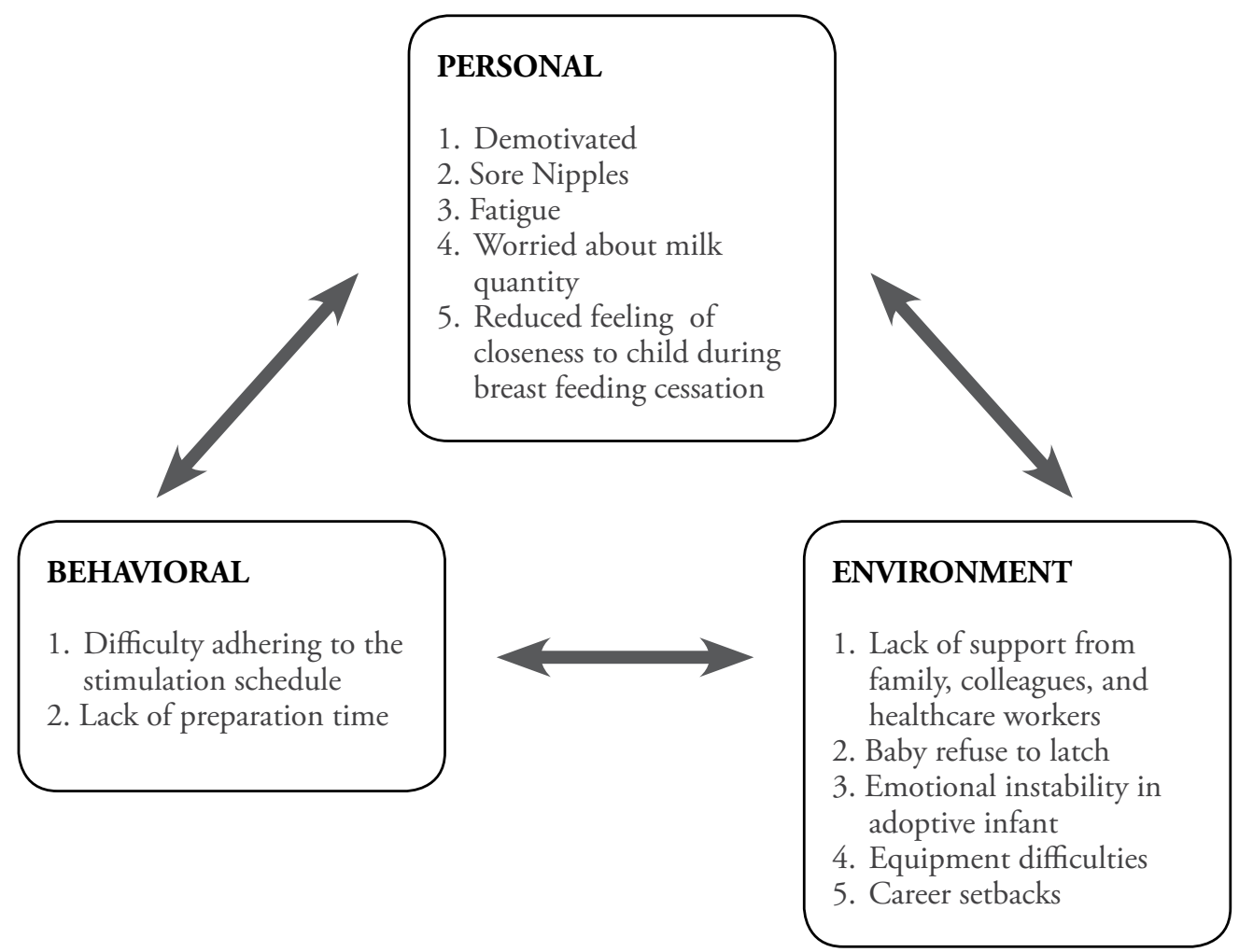

Figure 3: Social cognitive theory used to summarize the challenges faced when inducing lactation

\section{Conclusion}

The review presented in this paper summarized the experiences of women who have induced lactation. The discussion enables a better understanding of participants' perception of satisfaction, their emotions when inducing lactation, the enablers to inducing lactation, and the challenges in doing so. The information gathered from the articles on induced lactation in the past 53 years supports the conclusion that women seeking to induce lactation perceive satisfaction in terms of the maternal-infant bonding that develops as the process unfolds. ${ }^{3,8}$ Women who induced lactation also experienced positive and negative emotions. Positive emotions were related to the mother-infant relationship, while negative emotions stemmed from the technical challenges faced when inducing lactation, such as concerns about the breastmilk supply, finding time to pump, and issues related to breast pumps. ${ }^{2,5,9}$

Enablers for inducing lactation can be psychosocial or technical. Psychosocial enablers are related to bonding, nutritional benefits, feelings of self-competency when producing breastmilk, support from people in one's surroundings, and the obligation to fulfill religious milk kinship. ${ }^{2,5,711,12}$ Technical enablers include pharmacologic (hormonal stimulation) and non-pharmacologic (breast stimulation) methods. ${ }^{3,6,7,15-17}$ used to induce lactation. The challenges associated with induced lactation encompass a variety of internal and external factors, reciprocally influenced by personal, behavioral, and environmental factors (one's surroundings). ${ }^{2,5,8,9,12,18}$

\section{Conflict of interest}

The authors declare that they have no conflicts of interest regarding this manuscript.

\section{Ethical approval}

The study was approved by the Human Research Ethics Committee, Universiti Sains Malaysia (USM/JEPeM/18040194).

\section{Informed consent}

The writing of this manuscript did not involve any respondents; therefore, informed consent was not required. 


\section{References}

1. Biervliet FP, Atkin SL. Lactation by a commissioning mother in surrogacy. Human Reprod. 2012;16(3):412-4.

2. Goldfarb L. Results of a survey to assess the experiences of women who induced lactation J Hum Lact. 2010;26(4):432-3.

3. Wittig SL, Spatz DL. Induced lactation: Gaining a better understanding. Matern Child Health J. 2008;33(2):76-81.

4. AAP Policy Statement: Breastfeeding and the use of human milk [Internet]. 2005. Available from: http://pediatrics.aappublications.org/cgi/ doi/10.1542/peds.2004-2491.

5. Saari Z, Yusof FM. Motivating factors to breastfeed an adopted child in a Muslim community in Malaysia. Jurnal Teknologi. 2015;74(1):211-20

6. Rahim NCA, Sulaiman Z, Ismail TAT. The availability of information on induced lactation in Malaysia. Malays J Med Sci. 2017;24(4):5.

7. Auerbach KG, Avery JL. Induced Lactation: A study of adoptive nursing by 240 women. Am J Dis Child. 1981;135(4):340-3.

8. Bryant CA. Nursing the adopted infant. J Am Board Fam Med. 2006;19(4):374-9.

9. Gribble KD. Mental health, attachment and breastfeeding: Implications for adopted children and their mothers. Int Breastfeed J. 2006;1(1):5.

10. Szucs KA, Axline SE, Rosenman MB. Induced lactation and exclusive breast milk feeding of adopted premature Twins. J Hum Lact. 2010;26(3):309-13.

11. Lakhkar BB. Breastfeeding in adopted babies. Indian Pediatr. 2000;37(10):1114-6.
12. Nemba K. Induced lactation: A study of 37 non-puerperal mothers. J Trop Pediatr. 1994;40(4):240-2.

13. Saari Z, Yusof FM. Guideline model of adoptive breastfeeding for Muslim foster mothers in the Malay community in Malaysia. Int J of Islamic Studies. 2017;8(5):42-51.

14. Gribble KD. The influence of context on the success of adoptive breastfeeding:developing countries and the west. Breastfeeding review. 2003;12(1):5-13.

15. Abejide OR, Tadese MA, Babajide DE, Torimiro SEA, Davies-Adetugbo AA, Makanjuola ROA. Non-puerperal induced lactation in a Nigerian community: Case reports. Ann Trop Pediatr. 1997;17(2):109-14.

16. Patel U, Ds G. Effect of back massage on lactation among postnatal mothers. Int J of Med Research and Review. 2013;1(1):5-13.

17. Cheales-Siebenaler NJ. Induced lactation in an adoptive mother. J Hum Lact. 1999;15(1):41-3.

18. Cazorla-Ortiz G, Galbany-Estragués P, Obregón-Gutiérrez N, Goberna-Tricas J. Understanding the challenges of induction of lactation and relactation for non-gestating Spanish mothers. J Hum Lact. 2020;36(3):528-36.

19. Bowlby J. The nature of the child's tie to his mother. Int J Psychoanal. 1958;39(5):350-73.

20. McManaman JL, Neville MC. Lactation: Physiology, nutrition and breastfeeding: Springer Nature; 2012. Available from: https:// books.google.com.my/books?hl=en \&lr=\&id $=\mathrm{hNvTBwAAQBAJ \& oi=fnd \& pg=PA3 \& dq}$ =lactation+physiology\&ots=H3Ld6nJfkM\& sig=eQdTofjzV2DYSVTG0uZkI1mGNPE \&redir_esc=y\#v=onepage $\& \mathrm{q}=$ lactation $\% 20$ physiology $\& \mathrm{f}=$ false.
21. Jelliffe DB, Jelliffe EP. Non-puerperal induced lactation. Pediatrics. 1972;50(1):170-1.

22. Hill PD, Aldag J. Potential indicators of insufficient milk supply syndrome. Research in Nursing \& Health. 1991;14(1):11-9.

23. McCarter-Spaulding DE, Kearney MH. Parenting self-efficacy and perception of insufficient breast milk. J Obstet Gynecol Neonatal Nurs. 2001;30(5):515-22.

24. Stuart-Macadam P. Breastfeeding: Bioculturual perspectives: Routledge; 2017. Available from: https://books.google.com.my/books?hl=en \&lr=\&id=SGZQDwAAQBAJ\&oi=fnd\&pg $=$ PA $1 \& d q=$ stuart + macadam $\&$ ots $=$ a $1 \mathrm{r} 5 \mathrm{PnS}$ 4My\&sig=ftBnaL6gQPe0g8Nmilla5gOIq Ek\&redir_esc $=y \# \mathrm{v}=$ onepage $\& \mathrm{q}=$ stuart $\% 20$ macadam $\& \mathrm{f}=$ false.

25. Lozoff B, Brittenham G. Infant care: Cache or carry. J Pediatr. 1979;95(3):478-83.

26. Daly SEJ, Kent JC, Owens RA, Hartmann PE. Frequency and degree of milk removal and the short-term control of human milk synthesis. Exp Physiol. 1996;81(5):861-75.

27. Smith K, Hitt M. Great minds in management: The process of theory development: Emerald Group Publishing Limited; 2006. Available from: https://books.google.com.my/books/ about/Great_Minds_in_Management. html?id=P8kSDAAAQBAJ\&source=kp_book_ description\&redir_esc $=y$. 


\title{
Stigmatizing attitudes toward people living with HIV/AIDS (PLWHA) among primary health care providers in Kinta District, Perak
}

\author{
Chan Yuen Ching, Maliza Mawardi, Adibah Hanim Ismail@Daud
}

Chan YC, Mawardi M, Adibah HI. Stigmatizing attitudes toward people living with HIV/AIDS (PLWHA) among primary health care providers in Kinta District, Perak. Malays Fam Physician. 2021;16(1);31-38. https://doi.org/10.51866/oa0001

\section{Keywords:}

Stigmatizing attitudes,

primary health care

providers, HIV, AIDS

\section{Authors:}

Maliza binti Mawardi

(Corresponding author)

MBBS (Malaya), MFamMed (Malaya)

Faculty of Medicine and Health

Science, Universiti Putra Malaysia

Malaysia

Email: maliza_mawardi@upm.edu.my

\section{Chan Yuen Ching}

MD (UPM) MMed FamMed (UPM)

Klinik Kesihatan Greentown

Ministry of Health, Malaysia.

\section{Adibah Hanim binti Ismail@}

Daud

MD (USM), MMed FamMed (USM)

Faculty of Medicine and Health

Science, Universiti Putra Malaysia

Malaysia

\section{Abstract}

Background: Stigmatizing attitudes expressed by health care providers prevent some members of at-risk populations from accessing human immunodeficiency virus (HIV) screening and care. This attitude contributes to the continuity of the infection dissemination within our community, which gives an impact on the healthcare service and the curtailment of the global HIV/acquired immunodeficiency syndrome (AIDS) pandemic.

Objective: This study was conducted to identify stigmatizing attitudes toward people living with HIV/AIDS (PLWHA) and their determinants among primary health care providers in Kinta District, Perak.

Methodology: A cross-sectional study was conducted in 36 primary care clinics in Kinta District, Perak. Using stratified random sampling, 365 primary health care providers were recruited into the study. A validated self-administered questionnaire was used to obtain sociodemographic data as well as information on the healthcare experiences of healthcare providers, their knowledge of HIV/AIDS, and attitudes toward PLWHA. Determinants were identified using multiple linear regression.

Results: More than half of the respondents (54.1\%) had never provided care to HIV/AIDS patients. A minority (29.9\%) had received training on HIV/AIDS. This study shows that doctors (Coef. $=-9.50,95 \% \mathrm{CI}:-18.93,-0.07, \mathrm{p}=0.048$ ), respondents with HIV-positive relatives, (Coef. $=-5.61,95 \% \mathrm{CI}:-10.57,-0.65, \mathrm{p}=0.027)$, those who had provided care to HIV/AIDS patients (Coef. $=-2.38,95 \%$ CI: $-4.31,-0.45, \mathrm{p}=0.016$ ), and those with a higher knowledge score on HIV/AIDS (Coef. $=-0.86,95 \% \mathrm{CI}:-1.59,-0.13, \mathrm{p}=0.021$ ) were less likely to show stigmatizing attitudes toward PLWHA.

Conclusion: The issue of stigmatizing attitudes toward PLWHA among primary health care providers needs to be addressed. This study finds that knowledge, profession, experiences with caring for PLWHA, gender, and having HIV-positive relatives are significant predictors of stigmatizing attitudes toward PLWHA among primary health care providers in Kinta District, Perak. Interventional programs to improve knowledge and awareness, as well as decrease stigma toward PLWHA, should be implemented among all health care providers, especially those who have no opportunity to provide direct care.

\section{Introduction}

Since the onset of the human immunodeficiency virus (HIV) epidemic in 1981, 75 million people have been diagnosed with HIV, and more than one-third of them die from HIV/acquired immunodeficiency syndrome (AIDS). ${ }^{1}$ The Joint United Nations Program on HIV and AIDS (UNAIDS) and the World Health Organization (WHO) have found that the primary reason most people are hesitant to receive HIV testing, reveal their HIV status, and obtain treatment is a fear of stigma and discrimination. ${ }^{2}$ Additionally, the People Living with HIV (PLHIV) Stigma Index interviewed PLHIV and aggregated data from 50 countries, finding that about $12.5 \%$ of them are turned down from health care services due to stigma and discrimination. ${ }^{3}$

Many studies conducted worldwide have identified factors that are associated with stigmatizing attitudes toward people living with HIV/AIDS (PLWHA) among health care workers, especially in countries where HIV is highly prevalent, such as in Nigeria and South Africa. 4,5 These factors vary among countries. The stigmatizing attitudes of health care providers may also vary depending on the place of practice, as hospital settings differ from primary health care settings. 
In Malaysia, anonymous HIV screening and HIV care have been provided in all government health clinics since the year 2000. The Prevention of Mother-To-ChildTransmission (PMTCT) Programme that screens all pregnant women for HIV began even earlier, in 1998, involving government health clinics. This screening programme was extended into community clinics (Klinik Komuniti) in 2015. All family medicine specialists (FMS) nationwide have been trained in HIV care, and many mobile CD4 point-ofcare tests are available at primary care clinics as of December 2015.6 Therefore, the attitudes of primary health care professionals toward PLWHA are important, as the stigmatizing attitudes they express may prevent members of at-risk populations from accessing HIV screening and treatment. ${ }^{7-10}$

It is important to understand the attitudes of primary health care providers toward PLWHA, as HIV patients increasingly seek treatment and follow-ups from FMS in government health clinics. The results of this study will contribute to a better understanding of the determinants of stigmatizing attitudes among primary health care providers, which could further be used in the development of interventions to improve attitudes based on the factors that contribute to stigmatization. Thus, health care services for PLWHA would indirectly improve with improvements in attitudes toward sufferers among health care providers.

\section{Method}

A cross-sectional study was conducted from July to August 2019 in primary care clinics in Kinta District, Perak. All health care providers who have had direct or indirect contact with PLWHA or patients who were suspected to have HIV were recruited for this study. This included doctors, nurses, medical assistants, pharmacists, health care assistants, medical laboratory technologists (MLT), and radiographers. The calculated sample size was 365, using the formula for comparing means between two independent groups, in accordance with a study by Waluyo et al. ${ }^{8}$ There are a total of 36 primary health care clinics under the Kinta District Health Office. These clinics include 14 Klinik Kesihatan, 5 Klinik Komuniti, 12 Klinik Desa, and 5 Klinik Kesihatan Ibu \& Anak (KKIA). Samples were selected using stratified random sampling from a list of all health care providers registered under this district health office, which consists of 164 doctors, 411 nurses, 81 medical assistants, 95 pharmacists, 87 health care assistants (PPK), 42 medical laboratory technologists (MLT), and 13 radiographers. The eligible individuals were listed according to their job strata, namely 1 . doctor, 2 . nurse, 3. medical assistant, 4. pharmacist, 5. health care assistant (PPK), 6. medical laboratory technologist, and 7. radiographer. The requisite proportion of each stratum in the district was calculated. Samples were then randomly selected using a random number generator to meet the calculated proportion.

\section{Data collection}

Health care providers were approached individually by the researcher. They were given an explanation and written information regarding the study. Informed and written consent was obtained from those who were willing to participate. The pretested questionnaire was provided to the participants and collected by the end of the day by the researcher to ensure completeness. Participants were kept anonymous, as no personal information was required in the questionnaire. All consent forms containing personal information were kept separately from the questionnaire.

\section{Study instrument}

The questionnaire consisted of four sections: 1) sociodemographic profile, 2) health care experiences, 3) HIV/AIDS knowledge, and 4) attitudes toward PLWHA. The sections on HIV/AIDS knowledge and attitudes toward PLWHA were adopted from a validated questionnaire by Vorasane et al. ${ }^{10}$ Permission from the authors in both sections were obtained. ${ }^{11,12}$ The HIV/AIDS knowledge section consists of 10 items that had previously been used in many HIV studies in China. ${ }^{11}$ Attitudes toward PLWHA were measured using 17 items as well as a fivefactor multidimensional HIV-related stigma scale, which was developed and validated using both exploratory and confirmatory factor analysis. ${ }^{12}$ The fit of the final confirmatory factor model with five subscales displayed excellence in both development and validation samples. The result of the confirmatory analysis between the five subscales and each item in the subscales was significant $(p<0.01){ }^{12}$ The Cronbach's alpha coefficient was reported to be $0.81,{ }^{10}$ a higher score indicating more severe 
stigmatizing attitudes. The questionnaires were translated from English to Malay by two bilingual Malaysians who are well versed in both languages. Back translation from Malay to English was performed by a different pair of bilingual Malaysians who were also well versed in both languages. The discrepancies of the translation were then discussed among the translators and researchers in order to come to an agreement on the final translation as well as ensure semantic and content validity. A pilot study was conducted among 40 health care providers in Hospital Pengajar Universiti Putra Malaysia (HPUPM) to assess the face validity of the Malay questionnaire. One question each in Sections 1, 2, and 4 was revised by changing the wording without changing the meaning based on the feedback obtained during the pilot study. The questionnaire distributed to the respondents was bilingual.

\section{Data analysis}

Statistical Package for Social Sciences (SPSS) version 20.0 was used to analyze the data. Before conducting a descriptive analysis, normality testing was performed for all continuous data. The results were reported as medians and interquartile ranges (IQR), as the data was not normally distributed. Multiple linear regression (MLR) was applied to factors with $p<0.25$ in bivariate analysis. The results of the MLR were presented as coefficients and $95 \%$ confidence intervals. The significance level was set at $p<0.05$.

Ethical clearance was obtained from the Medical Research and Ethics Committee (MREC) of the Ministry of Health, Malaysia.

\section{Results}

Out of 365 selected primary health care providers in Kinta District, 355 of them agreed to participate in this study and returned completed questionnaires, creating a response rate of $97.3 \%$.

The median age of the respondents was 36.0 years, with an IQR of 8 . The majority of the respondents were female $(81.1 \%)$, Malay $(74.1 \%)$, married $(86.8 \%)$, and had completed at least tertiary education (91.8\%). A small percentage $(3.1 \%)$ of the respondents had relatives with HIV infection. Almost half of the respondents were nurses $(46.8 \%)$, which aligns with the proportion of health care providers in PKD Kinta. More than half of the respondents (54.1\%) had never provided care to HIV/ AIDS patients. A minority of respondents $(29.9 \%)$ had received training on HIV/AIDS.

Table 1: Sociodemographic profiles and health care experiences of respondents

\begin{tabular}{|l|c|c|}
\hline \multirow{2}{*}{ Variable } & \multicolumn{2}{|c|}{ N $=355$} \\
\cline { 2 - 3 } & Frequency (n) & \\
\hline Age (years) (median 36.0, IQR 8) & \multicolumn{2}{|c|}{} \\
\hline Gender & \multicolumn{2}{|c|}{} \\
Male & 67 & 18.9 \\
Female & 288 & 81.1 \\
\hline Ethnicity & & \\
Malay & 263 & 74.1 \\
Chinese & 31 & 8.7 \\
Indian & 58 & 0.9 \\
Others & 3 & 8.2 \\
\hline Educational level & & 44.8 \\
Secondary education & 29 & 15.8 \\
Certificate/diploma & 159 & 31.2 \\
Post-basic & 56 & \\
Degree & 111 & 86.8 \\
\hline Marital status & & 2.0 \\
Single & 38 & 0.5 \\
Married & 308 & \\
Divorced & 7 & \\
Widowed & 2 & \\
\hline
\end{tabular}




\begin{tabular}{|l|c|c|} 
Have relatives with HIV & & 3.1 \\
Yes & 11 & 96.9 \\
No & 344 & \\
\hline Profession & 63 & 17.7 \\
Doctor & 166 & 46.8 \\
Nurse & 33 & 9.3 \\
Medical assistant & 39 & 11.0 \\
Pharmacist & 32 & 9.0 \\
Health care assistant (PPK) & 17 & 4.8 \\
Medical laboratory technologist & 5 & 1.4 \\
Radiographer & & \\
Years of working experience (median 11.0, IQR 8) & & 45.9 \\
\hline Provided care to HIV/AIDS patients & 163 & 54.1 \\
Yes & 192 & \\
No & & 29.9 \\
\hline Training on HIV/AIDS & 106 & 70.1 \\
\hline Yes & 249 & \\
No & & \\
\hline
\end{tabular}

In this study, the minimum knowledge score was 2 and the maximum score was 10 . The median score was 9 with an IQR of 2 . The median score of stigmatizing attitudes was 45 with an IQR of 11, and scores ranged between 17 and 71.

\section{Factors associated with stigmatizing attitudes of primary health care providers toward PLWHA}

Bivariate analysis demonstrates that respondents with degrees (Coef. $=-8.43,95 \%$ confidence interval $[\mathrm{CI}]:-11.87,-4.99, p=<0.001$ ), health care providers who have HIV-positive relatives (Coef. $=-5.70,95 \%$ CI: $-11.05,-0.35$, $p=0.037)$, those who have provided care to HIV/AIDS patients (Coef. $=-4.90,95 \% \mathrm{CI}$ : $-6.70,-3.10, p=<0.001)$, and those with higher levels of HIV/AIDS knowledge (Coef. $=-1.51,95 \%$ CI: $-2.21,-0.81, p=<0.001)$ were less likely to display stigmatizing attitudes toward PLWHA. Furthermore, doctors (Coef. $=-15.58,95 \%$ CI: $-23.08,-8.09, p=<0.001)$, nurses (Coef. $=-7.45,95 \%$ CI: $-14.77,-0.13$, $\mathrm{p}=0.046$ ), medical assistants (Coef. $=-9.56$,
95\% CI: $-17.30,-1.82, p=0.016)$, and pharmacists (Coef. $=-10.38,95 \%$ CI: -18.04 , $-2.72, p=0.008)$ were less likely to demonstrate stigmatizing attitudes toward PLWHA. Female respondents were significantly associated with stigmatizing attitudes toward PLWHA (Coef. = 3.29, 95\% CI: 0.93, 5.65, $p=0.006$ ).

Multiple linear regression revealed that respondents who work as doctors (Coef. = $-9.50,95 \%$ CI: $-18.93,-0.07, p=0.048$ ), those who have HIV-positive relatives (Coef. = -5.61, 95\% CI: $-10.57,-0.65, p=0.027)$, those who have provided care to PLWHA (Coef. = $-2.38,95 \%$ CI: $-4.31,-0.45, p=0.016)$, and those with higher levels of knowledge on HIV/ AIDS (Coef. $=-0.86,95 \%$ CI: $-1.59,-0.13, p=$ $0.021)$ were less likely to manifest stigmatizing attitudes toward PLWHA. Female respondents were significantly associated with stigmatizing attitudes toward PLWHA (Coef. $=3.02$, 95\% CI: $0.34,5.71, p=0.028$ ). In this study, there was no multicollinearity found between the independent variables in which the tolerance values were more than 0.1 and variance inflation factor (VIF) values were less than 5 . 
Table 2: Factors associated with stigmatizing attitudes toward PLWHA among respondents (bivariate and multiple linear regression analysis)

\begin{tabular}{|c|c|c|c|c|c|c|}
\hline \multirow{2}{*}{ Characteristics } & \multicolumn{3}{|c|}{ Bivariate } & \multicolumn{3}{|c|}{ Multivariate } \\
\hline & Coef. & $95 \% \mathrm{CI}$ & $p$-value & Coef. & $95 \% \mathrm{CI}$ & $p$-value \\
\hline Age & 0.09 & $-0.05,0.23$ & 0.211 & $<0.001$ & $-0.34,0.34$ & 0.999 \\
\hline $\begin{array}{l}\text { Gender (Male as RC) } \\
\text { Female }\end{array}$ & 3.29 & $0.93,5.65$ & 0.006 & 3.02 & $0.34,5.71$ & 0.028 \\
\hline $\begin{array}{l}\text { Ethnicity } \\
\text { (Others as RC) } \\
\text { Malay } \\
\text { Chinese } \\
\text { Indian }\end{array}$ & $\begin{array}{l}1.52 \\
-2.16 \\
-3.64\end{array}$ & $\begin{array}{l}-8.44,11.48 \\
-12.53,8.21 \\
-13.79,6.52\end{array}$ & $\begin{array}{l}0.765 \\
0.682 \\
0.482\end{array}$ & & & \\
\hline $\begin{array}{l}\text { Educational level } \\
\text { (Secondary education as RC) } \\
\text { Certificate/diploma } \\
\text { Post-basic } \\
\text { Degree }\end{array}$ & $\begin{array}{l}-1.77 \\
-3.22 \\
-8.43\end{array}$ & $\begin{array}{l}-5.10,1.57 \\
-7.00,0.55 \\
-11.87,-4.99\end{array}$ & $\begin{array}{c}0.298 \\
0.094 \\
<\mathbf{0 . 0 0 1}\end{array}$ & $\begin{array}{c}0.02 \\
0.20 \\
-2.95\end{array}$ & $\begin{array}{l}-7.71,7.75 \\
-7.90,8.30 \\
-12.52,6.62\end{array}$ & $\begin{array}{l}0.996 \\
0.961 \\
0.544\end{array}$ \\
\hline $\begin{array}{l}\text { Marital status } \\
\text { (Widowed as RC) } \\
\text { Single } \\
\text { Married } \\
\text { Divorced }\end{array}$ & $\begin{array}{l}3.08 \\
5.04 \\
7.21\end{array}$ & $\begin{array}{l}-9.66,15.81 \\
-7.42,17.49 \\
-6.86,21.29\end{array}$ & $\begin{array}{l}0.635 \\
0.427 \\
0.314\end{array}$ & & & \\
\hline $\begin{array}{l}\text { Have HIV-positive relatives } \\
\text { (No as } \mathrm{RC} \text { ) } \\
\text { Yes }\end{array}$ & -5.70 & $-11.05,-0.35$ & 0.037 & -5.61 & $-10.57,-0.65$ & 0.027 \\
\hline $\begin{array}{l}\text { Profession } \\
\text { (Radiographer as RC) } \\
\text { Doctor } \\
\text { Nurse } \\
\text { Medical assistant } \\
\text { Pharmacist } \\
\text { Health care assistant } \\
\text { Medical lab technologist }\end{array}$ & $\begin{array}{l}-15.58 \\
-7.45 \\
-9.56 \\
-10.38 \\
-4.79 \\
-3.08\end{array}$ & $\begin{array}{l}-23.08,-8.09 \\
-14.77,-0.13 \\
-17.30,-1.82 \\
-18.04,-2.72 \\
-12.55,2.96 \\
-11.29,5.12\end{array}$ & $\begin{array}{l}<\mathbf{0 . 0 0 1} \\
\mathbf{0 . 0 4 6} \\
\mathbf{0 . 0 1 6} \\
\mathbf{0 . 0 0 8} \\
0.225 \\
0.461\end{array}$ & $\begin{array}{l}-9.50 \\
-6.34 \\
-5.74 \\
-5.66 \\
-4.45 \\
-3.39\end{array}$ & $\begin{array}{l}-18.93,-0.07 \\
-13.67,0.99 \\
-13.73,2.25 \\
-15.17,3.85 \\
-14.60,5.70 \\
-11.57,4.80\end{array}$ & $\begin{array}{l}\mathbf{0 . 0 4 8} \\
0.090 \\
0.158 \\
0.243 \\
0.389 \\
0.416\end{array}$ \\
\hline Years of working experience & 0.14 & $-0.002,0.28$ & 0.053 & 0.27 & $-0.32,0.37$ & 0.880 \\
\hline $\begin{array}{l}\text { Provided care to HIV/AIDS } \\
\text { patients (No as RC) } \\
\text { Yes }\end{array}$ & -4.90 & $-6.70,-3.10$ & $<0.001$ & -2.38 & $-4.31,-0.45$ & 0.016 \\
\hline $\begin{array}{l}\text { Training on HIV/AIDS } \\
\text { (No as RC) } \\
\text { Yes }\end{array}$ & -1.51 & $-3.54,0.52$ & 0.145 & -1.09 & $-3.03,0.85$ & 0.269 \\
\hline HIV/AIDS knowledge & -1.51 & $-2.21,-0.81$ & $<0.001$ & -0.86 & $-1.59,-0.13$ & 0.021 \\
\hline
\end{tabular}

$\mathrm{RC}=$ Reference category

\section{Discussion}

This study found that over half (54.1\%) of the respondents had never provided care to HIV/ AIDS patients. This finding aligns with those of similar studies conducted in Indonesia and Bangladesh, ${ }^{9,15}$ which could be due to the fact that all three studies included supporting staff in the study population, and only certain health care providers are directly involved in the management of HIV patients in a primary care setting. This includes FMS, medical officers, and nurses who are trained to handle HIV patients. This study demonstrates that only $29.9 \%$ of respondents had undergone training in terms of courses or workshops on HIV/AIDS. This contradicts the findings of another local study performed among nurses in a tertiary center, where $73.3 \%$ of respondents had been trained in HIV/AIDS. ${ }^{13}$ This reflects the inadequacy of training among primary health care providers in the Kinta 
district. The median knowledge score among the respondents was 9. This aligns with the findings of a study conducted in Lao PDR, where the same questionnaire on HIV/AIDS knowledge was used. ${ }^{10}$ However, the median knowledge score among the subgroup of health care assistants (PPK), medical lab technicians, and radiographers was lower (8), most likely because these professionals do not have direct contact with PLWHA and are not given the opportunity to attend courses related to HIV/ AIDS.

In this study, we aimed to determine the level of stigmatizing attitudes and their predictors among primary health care professionals toward PLWHA. Overall, the median score of stigmatizing attitudes in this study was high (45) and exceeded the score found in the study in Lao PDR, where the median score was $39 .{ }^{10}$ This signifies that primary health care providers in the Kinta district displayed greater stigmatizing attitudes toward PLWHA than those in Lao PDR. Factors associated with stigmatizing attitudes include gender, having HIV-positive relatives, profession, experiences with care of HIV patients, and HIV/AIDS knowledge.

Female respondents were more likely to display stigmatizing attitudes toward PLWHA, a finding that is consistent with those of a study conducted by Andrewin and Chien, who postulated that females tend to be more homophobic compared to their male counterparts. ${ }^{14}$ Women experience greater social consequences for behavior that is deemed to be sexually or morally deviant by the community. Most studies found that gender was not significantly associated with stigmatizing attitudes. ${ }^{8-10,15,16}$ However, all of these studies were conducted in a hospital setting.

Health care providers who have relatives with HIV displayed lesser stigmatizing attitudes toward PLWHA. This could be explained by their familiarity with the disease and low levels of perceived danger, as similarly shown in a study performed among relatives of patients with psychiatric illness. ${ }^{17}$ However, a study in Bangladesh showed that having relatives with HIV does not significantly influence stigmatizing attitudes among health care professionals. $^{9}$

In this study, it was found that doctors, compared to other health care providers, display lesser stigmatizing attitudes toward
PLWHA. Similar results have been found in other studies. ${ }^{9} 15,16,18$ Harapan et al. state that doctors have more HIV/AIDS knowledge compared to nurses and thus hold lesser stigmatizing attitudes toward PLWHA. ${ }^{15}$ In this study, doctors were also found to possess higher knowledge scores compared to other health care providers, thus displaying lesser stigmatizing attitudes toward PLWHA.

Health care providers who have provided care to PLWHA demonstrated lower stigma scores compared to those who have never cared for this group of patients. Other studies have also demonstrated that health care providers who have had direct physical contact with PLWHA display lesser stigmatizing attitudes. ${ }^{10,15,18}$ This could be due to contact with PLWHA mitigating stigmatizing attitudes and dispelling misconceptions regarding HIV infection and transmission. $^{18}$

Previous studies have shown that knowledge is one of the primary predictors of stigmatizing attitudes toward PLWHA. ${ }^{10,14-16,18}$ Our study illustrates that primary health care professionals with higher levels of HIV/AIDS knowledge displayed less stigma toward PLWHA. Greater education on HIV modes of transmission and universal precautions significantly contributes to the reduction of stigmatized attitudes toward PLWHA and instills more positive attitudes toward PLWHA in learners. ${ }^{15,19}$

This study has a few limitations. Firstly, this cross-sectional study was unable to demonstrate the causal relationship between the dependent variable and independent variables. Secondly, the results of the study cannot be generalized or applied to other settings, as they are confined to primary health care providers in one district in Perak. Moreover, the unequal gender ratio in this study affected the significance of the variable in the inferential analysis, which in turn resulted in female respondents being significantly associated with stigmatizing attitudes, a result that cannot be generalized. This ratio reflects a known scenario in health care settings in which females predominate most categories of health care personnel, especially among allied health staff professions, namely nurses and pharmacists. ${ }^{20}$ In terms of the study instrument, the knowledge and attitudes questionnaire used has yet to be validated locally. Therefore, it is recommended that future studies be carried out to develop a valid questionnaire determining the stigmatizing 
attitudes of health care providers toward PLWHA that could be used locally. Lastly, calculations regarding stigmatizing attitudes toward PLWHA reflect what the respondents reported. As some of the questions were deemed sensitive in nature, there is a possibility that answers provided by respondents were more socially acceptable than truthful. Hence, stigmatizing attitudes could be underreported in this study.

This study is the first to determine levels of stigmatizing attitudes toward PLWHA among primary health care providers in Malaysia. This study illustrates that lower levels of HIV/AIDS knowledge are associated with greater levels of stigmatizing attitudes toward PLWHA. Future studies may be conducted during the pre- and post-continuous medical education (CME) section on HIV/AIDS to demonstrate improvements in knowledge and attitudes. The CME session should target all levels of staff, not only doctors, nurses, and pharmacists but professionals that have indirect contact with HIV patients as well, including health care assistants, medical laboratory technicians, and radiographers. Furthermore, this study indicates that only $29.9 \%$ of health care providers have had training on HIV/AIDS. Another study suggests that attending a short course can improve knowledge, and thus, providing short courses on HIV/AIDS may able to improve the knowledge of health care providers and lower levels of stigma toward PLWHA. ${ }^{21}$

\section{Conclusion}

The issue of stigmatizing attitudes toward PLWHA among primary health care providers must be addressed. This study finds that knowledge, profession, experiences with care of PLWHA, gender, and having relatives with HIV are significant predictors of stigmatizing attitudes toward PLWHA among primary health care providers in Kinta District, Perak. Interventional programs to improve knowledge and awareness regarding stigma toward PLWHA should be implemented among all health care providers, especially those who have no opportunity to provide direct care.

\section{Acknowledgments}

We would like to acknowledge the Director General of Health Malaysia for his permission to publish this article. The authors wish to thank Pegawai Kesihatan Daerah Kinta and health care providers in Kinta District for providing support during data collection. We also express gratitude to Madam Premaa Supramaniam for her assistance in the statistical analysis of the study.

\section{Conflicts of interest}

The authors declared that they have no conflicts of interest.

\section{How does this paper make a difference to general practice?}

- The lack of training of primary health care providers in HIV/AIDS indicates that more training should be provided to improve their knowledge and thus improve attitudes toward PLWHA as well as those who come in for screening.

- The negative relationship between HIV/AIDS knowledge and stigmatizing attitudes toward PLWHA indicates that continuous medical education (CME) should be provided to all levels of primary health care providers, including health care assistants, medical lab technologists, and radiographers, as they have indirect contact with HIV patients as well.

\section{References}

1. WHO $\mid$ HIV/AIDS [Internet]. WHO. [cited 2019 Sept 25]. Available from: https://www. who.int/gho/hiv/en/
2. United Nations Development Programme (UNDP) US. 2014unaidsguidancenote_ stigma_en.pdf [Internet]. [cited 2018 Jul 19]. (Reduction of HIV-related stigma and discrimination). Available from: http:// www.unaids.org/sites/default/files/media_ asset/2014unaidsguidancenote_stigma_en.pdf
3. Developing tools and methods to measure HIV-related stigma and discrimination in health care settings in Thailand. International Health Policy Program Ministry of Public Health, Thailand, 2014. Available from: http:// pdf.usaid.gov/pdf_docs/PA00KHKM.pdf 
4. Umeh CN, Essien EJ, Ezedinachi EN, et al. Knowledge, Beliefs and Attitudes about HIV/AIDS related issues, and the Sources of Knowledge among Health Care Professionals in Southern Nigeria. J R Soc Promot Health. 2008 Sep;128(5):233-9

5. Okpala PU, Uwak R, Nwaneri AC, et al. Nurses' knowledge and attitude to the care of HIV/AIDS patients in South East, Nigeria. Int J Community Med Public Health. 2017 Jan 25;4(2):547-53.

6. HIV/STI Section of Ministry of Health Malaysia editorial team. Global AIDS Response Progress Report Malaysia 2016. 2016;40.

7. Wagner AC, Hart TA, McShane KE, et al. Health Care Provider Attitudes and Beliefs About People Living with HIV: Initial Validation of the Health Care Provider HIV/ AIDS Stigma Scale (HPASS). AIDS Behav. 2014 Dec 1;18(12):2397-408

8. Waluyo A, Culbert GJ, Levy J, et al. Understanding HIV-related stigma among Indonesian nurses. J Assoc Nurses AIDS Care JANAC. 2015;26(1):69-80.

9. Hossain MB, Kippax S. Stigmatized Attitudes Toward People Living With HIV in Bangladesh: Health Care Workers' Perspectives. Asia Pac J Public Health. 2011 Mar 1;23(2):171-82.
10. Vorasane S, Jimba M, Kikuchi K, et al. An investigation of stigmatizing attitudes toward people living with HIV/AIDS by doctors and nurses in Vientiane, Lao PDR. BMC Health Serv Res [Internet]. 2017 Feb 10 [cited 2018 Jan 28];17. Available from: https://www.ncbi. nlm.nih.gov/pmc/articles/PMC5301416/

11. Li L, Wu ZY, Wu S, et al. HIV-related stigma in health care settings: A survey of service providers in China. AIDS Patient Care STDs. 2007;21(10):753-62

12. Stein JA, Li L. Measuring HIV-related Stigma Among Chinese Service Providers. AIDS Behav. 2008 Sep;12(5):789-95.

13. Gulifeiya A, Rahmah MA. Nurses awareness and attitude toward HIV/AIDS and universal precautions: a cross-sectional study in UKMMC. J Kesihat Masy. 2008;14(2):36-45.

14. Andrewin A, Chien L-Y. Stigmatization of patients with HIV/AIDS among doctors and nurses in Belize. AIDS Patient Care STDs. 2008 Nov;22(11):897-906

15. Harapan H, Khalilullah SA, Anwar S, et al. Discriminatory attitudes toward people living with HIV among health care workers in Aceh, Indonesia: A vista from a very low HIV caseload region. Clin Epidemiol Glob Health. 2015 Apr 1;3(1):29-36.
16. Famoroti TO, Fernandes L, Chima SC. Stigmatization of people living with HIV/AIDS by healthcare workers at a tertiary hospital in KwaZulu-Natal, South Africa: a cross-sectional descriptive study. BMC Med Ethics. 2013 Dec 19;14(Suppl 1):S6.

17. Sousa S de, Marques A, Rosário C, et al. Stigmatizing attitudes in relatives of people with schizophrenia: a study using the Attribution Questionnaire AQ-27. Trends Psychiatry Psychother. 2012;34(4):186-97.

18. Librarian I. Evaluation of Knowledge, Attitudes, and Practices of Health Care Providers toward HIV-Positive Patients in Tanzania [Internet]. [cited 2018 May 21]. Available from: https://www.hrhresourcecenter. org/node/1747.html

19. Zarei N, Joulaei H, Darabi E, et al. Stigmatized Attitude of Healthcare Providers: A Barrier for Delivering Health Services to HIV Positive Patients. IJCBNM. 2015;3(4):292-300.

20. Planning Division, Ministry of Health, Malaysia. Human Resources for Health, Country Profiles 2015, Malaysia

21. Josep M.A, Gemma.F, Josep J, et al. Effectiveness of a short-course in improving knowledge and skills on evidence-based practice. BMC Family Practice volume 12, Article number: 64 (2011) 


\section{Knowledge, attitude, and practice regarding atrial fibrillation among primary care physicians: the potential role of postgraduate training}

Phaik Choo Ooi, Gogilavendan Ramayah, Syahril Rizwan B. Omar, Vilasini Rajadorai, Thatsheila Nadarajah, Chung Hui Ting, Cheong Lieng Teng

Ooi PC, Ramayah G, Syahril RO, et al. Knowledge, attitude, and practice regarding atrial fibrillation among primary care physicians: the potential role of postgraduate training. Malays Fam Physician. 2021;16(1);39-49. https://doi.org/10.51866/oa0002

\section{Keywords:}

Knowledge, attitude, and practice; primary care physicians; atrial fibrillation; anticoagulation

\section{Authors:}

\section{Ooi Phaik Choo}

(Corresponding author) MBBS (UM), MAFP/FRACGP

Community Based Department Universiti Kuala Lumpur, Royal College of Medicine Perak Ipoh, Perak, Malaysia email: Ivkopc@yahoo.com

Gogilavendan Ramayah MBBS, MAFP/FRACGP Buntong Health Clinic Ipoh, Perak, Malaysia

Syahril Rizwan B. Omar MBBS

Simee Health Clinic

Ipoh, Perak, Malaysia

Vilasini Rajadorai

MBBS

Ayer Tawar Health Clinic

Ayer Tawar, Perak, Malaysia

Thatsheila Nadarajah

$M D$

Menglembu Health Clinic

Ipoh, Perak, Malaysia

\section{Abstract}

Introduction: Atrial fibrillation (AF) is known to lead to stroke and thromboembolism, causing a five-fold increase in the risk of stroke and almost doubling the mortality rate. Optimal anticoagulant therapy is effective in reducing AF-related death. However, prescription of anticoagulants in $\mathrm{AF}$ in East Asian countries has been low, ranging from $0.5 \%$ to $28 \%$. This study aimed to determine whether vocational training in family medicine improves primary care physicians' knowledge, attitude, and practice in the management of AF.

Method: This investigation was a cross-sectional study carried out during centralized workshops for two groups of trainees using a validated questionnaire: (i) junior trainees were newly enrolled postgraduate trainees in the Graduate Certificate in Family Medicine (GCFM) program, and (ii) senior trainees were postgraduate trainees in Advance Training in Family Medicine (ATFM) programs of the Academy of Family Physicians of Malaysia (AFPM).

Results: A total of 223 trainees (127 junior and 96 senior) participated in this study. Only 55.2\% of the trainees passed the knowledge test; senior trainees were more likely to pass the knowledge test compared to junior trainees $(69.8 \%$ vs. $44.1 \%$, p < 0.001$)$. Female trainees were significantly more likely to pass the knowledge test than male trainees. While the attitude of senior and junior trainees was similar, more of the latter group worked in public clinic that provide better support where there is better support for outpatient anticoagulation treatment (e.g., same-day INR test, direct access echocardiogram, and warfarin in in-house pharmacy).

Conclusion: Vocational training in family medicine appears to improve primary care physicians' knowledge regarding the management of AF. Better knowledge will help vocationally trained primary care physicians to provide anticoagulation treatment for AF within primary care clinics. More optimal AF management within primary care can take place if the identified barriers are addressed and a shared care plan can be implemented.

\section{Introduction}

Atrial fibrillation (AF) is the commonest cardiac arrhythmia of clinical significance. ${ }^{1-3}$ It causes systemic thromboembolism and is associated with a five-fold increased risk of stroke. ${ }^{4,5}$ Moreover, $15 \%$ of all strokes are related to $\mathrm{AF}^{2}$ Ischemic strokes associated with $\mathrm{AF}$ are typically more severe than those from other causes, resulting in a doubled risk of death and higher morbidity. ${ }^{5}$

The prevalence of AF varies from one population to another. In the general population, the average prevalence of $\mathrm{AF}$ is between $1 \%$ to $2 \% .{ }^{1}$ However, the prevalence varies, progressively increasing with age, reaching $10 \%$ to $17 \%$ among those $>80$ years old. ${ }^{1}$ Furthermore, this figure is likely underestimated, as $10 \%$ to $40 \%$ of $\mathrm{AF}$ patients can be asymptomatic and undiagnosed. ${ }^{1}$ Asymptomatic AF patients have a similar or higher risk of stroke and death compared to symptomatic patients. ${ }^{1}$

In Malaysia, the AF prevalence among hospitalized patients was $2.8 \% .^{6,7}$ In UK primary care, the age-sex standardized prevalence of $\mathrm{AF}$ increased $50 \%$ from $2.14 \%$ in 2000 to $3.29 \%$ in $2016 .{ }^{4}$ This trend is in keeping with estimates that the prevalence of AF will at least double in the coming 50 years due to an aging population. $^{2}$

Oral anticoagulation (OAC) with vitamin $\mathrm{K}$ 


\author{
Ting Chung Hui \\ MD, MAFP/FRACGP \\ Gunung Rapat Health Clinic \\ Ipoh, Perak, Malaysia
}

\section{Teng Cheong Lieng}

MFamMed (UM), FRACGP, FAMM.

Professor

Department of Family Medicine

International Medical University

Seremban Campus, Seremban

Negeri Sembilan, Malaysia antagonist (VKAs) or novel oral anticoagulants (NOACs) can markedly reduce the risk of stroke by approximately two-thirds. ${ }^{4}$ In comparison, aspirin use is considerably inferior in preventing stroke while presenting a similar risk of major bleeding. ${ }^{4}$ Unfortunately, despite the availability of clinical practice guidelines and evidence of the effectiveness of anticoagulation therapy in stroke prevention, many studies have confirmed gross underuse of anticoagulant therapy in patients with $\mathrm{AF}^{6-8}$

In Asia, the reported prevalence of stroke related to $\mathrm{AF}$ in community- and hospital-based studies has ranged from $1.9 \%$ to $6.0 \%$ and $0.36 \%$ to $28.3 \%$, respectively. ${ }^{8}$ However, anticoagulation prescription in AF in East Asian countries has been low, ranging between $0.5 \%$ and $28 \%{ }^{7}$ Globally, most studies have shown treatment rates of $\leq 50 \%$, even in hospital-based studies. ${ }^{6,10}$

Freestone et al. $^{6}$ found that patients with $\mathrm{AF}$ were not adequately investigated. The researchers' findings also asserted that the use of anticoagulation therapy was suboptimal among acute medical admissions to a busy hospital in Malaysia. Only $20 \%$ of the patients were treated with warfarin; among them, none were aged $>65$ years. ${ }^{6}$

Studies have identified three general categories of barriers to the prescription of anticoagulants, especially warfarin: i) physician-related factors, ii) patient-related factors, and iii) healthcare system-related factors. ${ }^{9,10}$

The physician-related barriers include significant knowledge gaps $^{9-11}$ and physicians' perceptions regarding the risks and benefits of anticoagulation and practice characteristics, which determine their attitude and practice in the management of AF.9-13

In Malaysia, the Academy of Family Physicians of Malaysia (AFPM) offers a postgraduate program consisting of four years of vocational training in family medicine. The first two years comprise the Graduate Certificate in Family Medicine (GCFM), and the last two years involve Advanced Training in Family Medicine (ATFM). Both courses include a cardiovascular module.

AF imposes a substantial burden on the future cost of health care. ${ }^{5}$ Primary care physicians can potentially play a larger role in the management of patients with AF. Thus, both determining their knowledge regarding AF and assessing their readiness to manage $\mathrm{AF}$ are vital.

The primary objective of this study is to compare the knowledge, attitudes, and practices between senior ATFM trainees and junior (newly registered) GCFM trainees in the management of AF. In particular, we wish to identify specific knowledge gaps and suggest a focus for future educational intervention.

\section{Methods}

\section{Study participants and setting}

This cross-sectional study was conducted from May to August 2017. The study participants were postgraduate trainees of the Academy of Family Physicians Malaysia (AFPM). We regarded the first group as junior trainees (newly enrolled GCFM trainees who had not undergone the training) and the second group as senior trainees (having completed two cardiology modules, which included diagnosis and management of atrial fibrillation).

\section{Questionnaire development and standard- setting}

Self-administered validated structured questionnaires were used to collect data. The questionnaires comprised four sections.

Section A: Demographic data, including age, gender, ethnicity, years of working as a doctor, years of working in primary care, current workplace, location of practice (urban, suburban, or rural), and current level of training. Section B: Knowledge test comprised of ten single-best answer multiple-choice questions, based on Malaysian and international clinical practice guidelines and consisted of five clinical vignettes (Appendix 1).

Section C: Assessment of participants' attitude in the management of AF. This section presented five questions about the opinion of the doctors regarding the diagnosis and management of atrial fibrillation, to be answered on a Likert scale of 1 (strongly disagree) to 6 (strongly agree) Section D: Assessment of participants' practice in the management of AF. This part consisted of five questions regarding the current practice of the doctors in the diagnosis and management of AF, to be answered by choosing from three options: Yes, Not sure, or No.

Sections C \& D were developed based on a 
literature review. No formal validation was done. The content of the knowledge test was developed using the Delphi technique, and standard-setting was conducted using the Nedelsky method. The standard was set at the level of a practicing family physician. This process involved an expert panel of nine members, consisting of three academic family physicians, a family medicine specialist at a government health clinic, a general practitioner, three academic internists, and one general physician. The passing mark based on the standard setting was $55 \%$.

A pilot study was conducted with ten medical officers at various public primary care clinics in Perak. The above group completed the questionnaire within 20 minutes. Because they did not encounter any difficulty in answering, no amendment was necessary.

Data collection was conducted during the lunch or tea breaks of the centralized workshops (unrelated to the management of AF) organized by AFPM in July 2017 (GCFM intake 18 and ATFM intake 6) and August 2017 (ATFM intake 5) with AFPM approval. Informed consent was obtained from the participants before data collection, and a pen was distributed to each participant as a token of appreciation.

Contact email addresses were requested from study participants who wanted to receive feedback about their performance on the knowledge test. The email addresses were not recorded in the data file and were deleted from the sender's email account immediately after the knowledge test results were sent to the respective participants.

\section{Statistical analysis}

The collected data were analyzed using IBM SPSS Statistical Software version 25. The outcome variables comprised scores on the knowledge test and responses to the attitude and practice questions. The independent variables included trainee category (junior or senior), workplace, practice location, gender, age, and duration of working in primary care.

The knowledge score was calculated as a proportion of correct answers for the tenitem MCQs, in percentages. A passing score was defined as a score of $55 \%$ and above. The overall summative scores and the percentage of participants who answered correctly for individual questions were also tabulated.

Responses to the attitude questions were based on a 6-point Likert-type scale ranging from 1 (strongly disagree) to 6 (strongly agree). Median scores were computed for the responses to each question because the data were not normally distributed.

The responses to the practice questions were recoded as follows: a "Yes" response remained as it was, while "Not sure" and "No" were merged into another category. The percentages of the responses for each question were computed.

The proportion who passed the knowledge test was compared using a chi-square test. Logistic regression was performed to determine the variables independently associated with pass/fail in the knowledge test. The knowledge scores of the two groups of trainees were compared using the Mann-Whitney $U$ test. Furthermore, the Mann-Whitney $U$ test and chi-square test were used to compare differences in the responses of the two groups of trainees for the attitude and practice questions, respectively. Statistical significance was set at $\mathrm{p}<0.05$.

\section{Results}

Out of 265 eligible trainees, 223 (127 junior trainees and 96 senior trainees) participated, giving a response rate of $84.2 \%$. The sociodemographic characteristics of the study participants show a predominance of females, urban practice locations, and working in public primary care clinics (see Table 1). The mean ages of junior and senior trainees were 31.8 and 35.9 years, respectively. 
Table 1: Demographic data of study participants

\begin{tabular}{|l|c|c|c|}
\hline & Junior trainees (n, \%) & Senior trainees (n, \%) & P-value \\
\hline Gender & $36(28.3)$ & $27(28.1)$ & 0.971 \\
Fale & $91(71.7)$ & $69(71.9)$ & \\
\hline Ethnicity & & & \\
Malay & $49(38.6)$ & $29(30.2)$ & 0.265 \\
Chinese & $38(29.9)$ & $40(41.7)$ & \\
Indian & $33(26.0)$ & $24(25.0)$ & \\
Others & $7(5.5)$ & $3(3.1)$ & 0.022 \\
\hline Workplace & $103(81.1)$ & $65(67.7)$ & \\
Public clinic & $21(16.5)$ & $25(26.0)$ & \\
Private clinic & $3(2.4)$ & $6(6.2)$ & \\
Other clinics* & & & \\
\hline Practice location & $73(57.5 \%)$ & $60(62.5 \%)$ & \\
Urban & $37(29.1 \%)$ & $31(32.3 \%)$ & \\
Suburban & $17(13.4 \%)$ & $5(5.2 \%)$ & \\
Rural & & & \\
\hline Years working in & & $48(0 \%)$ & \\
primary care & $11(8.7 \%)$ & $4(45.8 \%)$ & \\
$<1$ & $8(6.3 \%)$ & 96001 \\
$1-5$ & $3(2.4 \%)$ & & \\
6-10 & 127 & & \\
$>10$ & & & \\
\hline Total & & & \\
\hline & & & \\
\hline
\end{tabular}

* Other clinics include primary care clinics at universities, military health facilities, etc.

\section{Knowledge of atrial fibrillation}

Overall, a total of $123(55.2 \%)$ out of 223 trainees passed the knowledge test; senior trainees were significantly more likely to pass than junior trainees $(69.8 \%$ vs. $44.1 \%, \mathrm{p}<0.001)$. In the univariate analysis, three other variables were found to be statistically associated with passing the knowledge test: female gender (59.4\% vs. $44.4 \%)$ and the number of years working as a doctor and in primary care (see unadjusted OR in Table 2).

No significant difference in the knowledge score was found between doctor's age and practice locations.

In our logistic regression model, which included four variables, only senior trainees and the female gender remained statistically significantly associated with passing the knowledge test. See Table $\mathbf{2}$.

For the summative scores of the knowledge test, the overall mean was $56.10 \%$ (Table 3). The mean score for the junior and senior trainees was $51.0 \%$ and $62.8 \%$, respectively $(\mathrm{p}=<0.001)$. Thus, the seniors performed significantly better than the juniors.

Table 2: Factors associated with passing atrial fibrillation knowledge test

\begin{tabular}{|l|c|c|}
\hline Variables & Unadjusted OR (95\%CI) & Adjusted OR (95\%CI) \\
\hline Category of trainees (senior vs. junior) & $2.93(1.68,5.12)$ & $2.59(1.35,5.00)$ \\
\hline Gender (female vs. male) & $1.83(1.01,3.29)$ & $2.01(1.07,3.75)$ \\
\hline Years working as a doctor & $1.08(1.01,1.16)$ & $1.04(0.94,1.15)$ \\
\hline Years working in primary care & $1.12(1.02,1.23)$ & $1.00(0.96,1.15)$ \\
\hline
\end{tabular}


For individual questions, the percentage of participants who answered correctly was tabulated (Table 3).

Table 3: Knowledge test: percentage of correct answers

\begin{tabular}{|l|c|c|c|c|}
\hline Knowledge questions & $\begin{array}{c}\text { Overall } \\
\mathbf{( \% )}\end{array}$ & $\begin{array}{c}\text { Junior } \\
\text { trainees } \\
\mathbf{( \% )}\end{array}$ & $\begin{array}{c}\text { Senior } \\
\text { trainees } \\
\mathbf{( \% )}\end{array}$ & P-value \\
\hline 1. Management of AF in valvular heart disease & $56.5 \%$ & $58.3 \%$ & $54.2 \%$ & 0.541 \\
\hline 2. Management of lone AF & $43.5 \%$ & $33.9 \%$ & $56.3 \%$ & 0.001 \\
\hline 3. CHA2DS2-VASc scoring & $58.7 \%$ & $49.6 \%$ & $70.8 \%$ & 0.001 \\
\hline 4. Patient with TIA on aspirin & $56.5 \%$ & $59.1 \%$ & $53.1 \%$ & 0.376 \\
\hline 5. Factors affecting bleeding risks & $74.0 \%$ & $69.3 \%$ & $80.2 \%$ & 0.066 \\
\hline 6. Target of INR & $76.2 \%$ & $72.4 \%$ & $81.3 \%$ & 0.126 \\
\hline 7. Dietary advice for warfarin & $48.9 \%$ & $36.2 \%$ & $65.6 \%$ & $<0.001$ \\
\hline 8. Investigations for AF & $74.9 \%$ & $68.9 \%$ & $83.3 \%$ & 0.011 \\
\hline 9. Management strategy in AF & $21.1 \%$ & $22.1 \%$ & $19.8 \%$ & 0.683 \\
\hline 10. Drug choice for rate control & $53.4 \%$ & $43.3 \%$ & $66.7 \%$ & 0.001 \\
\hline Total & $56.1 \%$ & $51.0 \%$ & $62.8 \%$ & $<0.001$ \\
\hline
\end{tabular}

The senior trainees showed better knowledge than junior trainees for almost all the questions, reaching statistical significance for five questions (Q2, Q3, Q7, Q8, Q10). We noted that the performance of both junior and senior trainees was relatively poor for Q9.

\section{Attitude}

Regarding the attitude toward the management of AF, no significant difference was notable between the two groups in the responses to 4 out of 5 questions asked (Table 4). However, junior trainees were significantly more likely to agree that "routine screening of AF in the elderly is useful."

Table 4: Median score of responses to attitude questions

\begin{tabular}{|l|c|c|c|}
\hline Attitude questions & Junior trainees & Senior trainees & P-value \\
\hline 1. Routine screening of AF in the elderly is useful. & 5 & 4 & $<0.001$ \\
\hline $\begin{array}{l}\text { 2. AF can be managed competently in primary } \\
\text { care setting. }\end{array}$ & 5 & 4 & 0.817 \\
\hline 3. Warfarin has too many diet-drug interactions. & 4 & 4 & 0.743 \\
\hline $\begin{array}{l}\text { 4. Warfarin causes more harm than good in } \\
\text { elderly aged }>75 \text { years. }\end{array}$ & 4 & 4 & 0.345 \\
\hline $\begin{array}{l}\text { 5. Patients with AF in primary care are not keen } \\
\text { on warfarin therapy. }\end{array}$ & 3 & 4 & 0.297 \\
\hline
\end{tabular}

\section{Practice}

Our study showed that the availability of resources for AF management was relatively low in primary care clinics (see Table 5). Interestingly, we found that junior trainees answered "yes" to four of the five practice questions compared to the senior trainees.
Significantly more junior trainees reported availability of direct access echocardiography, same-day INR within the clinic, and warfarin available in the clinic pharmacy. Regarding counseling of warfarin patients about fooddrug interactions, junior trainees were significantly more likely to perform this task than senior trainees (Table 5). 
Table 5: Responses to practice questions

\begin{tabular}{|l|c|c|c|c|}
\hline Questions & $\begin{array}{c}\text { Overall } \\
\mathbf{( \% )}\end{array}$ & $\begin{array}{c}\text { Junior } \\
\text { trainees } \\
\mathbf{( \% )}\end{array}$ & $\begin{array}{c}\text { Senior } \\
\text { trainees } \\
\mathbf{( \% )}\end{array}$ & P-value \\
\hline $\begin{array}{l}\text { 1. I can request echocardiography without going } \\
\text { through the specialist clinic. }\end{array}$ & 48.4 & 56.7 & 37.5 & 0.005 \\
\hline $\begin{array}{l}\text { 2. My clinic can perform INR within the same } \\
\text { day. }\end{array}$ & 29.6 & 38.6 & 17.7 & 0.001 \\
\hline 3. Warfarin is available in my clinic pharmacy. & 48.0 & 55.1 & 38.5 & 0.014 \\
\hline $\begin{array}{l}\text { 4. I would adjust warfarin dosage for AF patients } \\
\text { if needed. }\end{array}$ & 68.6 & 72.4 & 63.5 & 0.156 \\
\hline $\begin{array}{l}\text { 5. I routinely advise warfarin patients about diet } \\
\text { and drug interactions. }\end{array}$ & 71.7 & 81.1 & 59.4 & $<0.001$ \\
\hline
\end{tabular}

\section{Discussion}

The results of this study showed an overall pass rate of $55.2 \%$ in the knowledge test, indicating that a significant knowledge gap remains among both groups of postgraduate family medicine trainees regarding the management of AF. This finding concurs with previous studies that also identified a significant knowledge gap among physicians in relation to $\mathrm{AF}$ and stroke. ${ }^{11}$ In fact, educational gaps were found across the continuum of care for AF patients. ${ }^{14}$ This result could be due to physicians being unaware of the current literature ${ }^{9}$ or overestimating the efficacy of antiplatelet agents or overestimating the risk of hemorrhage from anticoagulation. ${ }^{11}$

Besides the above educational gaps, while factual content on AF might receive adequate coverage in the vocational training syllabus for the trainees, the knowledge was likely not reinforced in the trainees' daily clinical practices. Many of them do not treat AF patients regularly due to a lack of resources and the nature of their practices, as highlighted by our study. Interventions that include interdisciplinary case discussions and seminars focusing on $\mathrm{AF}$ management during the vocational training may be helpful in this aspect.

By comparing the two groups, our study identified specific knowledge gaps among the senior trainees from the questions where they performed worse or not significantly better than the junior trainees (Q1, Q4, Q5, Q6, \& Q9). These areas included the management of AF in valvular heart disease, a TIA patient on aspirin, factors affecting bleeding risk, the target INR, and the management strategy in AF.

In particular, Q9 (on the management strategy in $\mathrm{AF}$ ) performance reflected gaps in the knowledge of senior trainees, representing a crucial area that requires further education and/ or management in consultation with specialists.

Multiple previous studies have recommended educating physicians as a possible solution to improve the management of $\mathrm{AF}^{11,13}$ It is reassuring that senior trainees showed a higher pass rate on the AF knowledge test compared to the junior trainees. Future study is needed to demonstrate whether better knowledge of senior trainees will translate into better management of AF patients.

Both groups of trainees in our study had a similar attitude regarding the management of AF, except in their answers to Q1. Compared to the seniors, the junior trainees were significantly more likely to acknowledge the usefulness of screening for AF in the elderly (see Table 4) ( $<$ 0.001). This outcome was in contrast with the recommendation by the Malaysian Ministry of Health for opportunistic case finding for AF with radial pulse palpation $(\geq 20 \mathrm{sec})$ during BP screening ${ }^{15}$ and a similar recommendation by the 2016 ESC guidelines for the management of $\mathrm{AF}$ to screen patients aged $\geq 65$ years. $^{16}$

Our study showed that the senior trainees had less access to resources for the management of $\mathrm{AF}$ in their practices compared to the junior trainees. This scenario could be the barrier that contributed to the poorer attitude that the senior trainees exhibited. Due to the inconvenience of referral to a secondary care center for management, they might have underestimated a patient's ability to comply with the management ${ }^{11}$ in the event that the screening found AF in an elderly patient. Of 
course, this outcome could alternatively be due to unawareness of the current literature by the participants. However, it was also likely that despite their knowledge, they underestimated the benefits of anticoagulation for stroke prevention and overestimated the harm of major bleeding with anticoagulation. ${ }^{13}$ These factors could lead to the perception and attitude that screening for AF is not very useful. Thus, further studies are required to determine the fundamental factors that caused the physicians to not comply with the clinical management guidelines in local settings in order to address the barriers in physicians' attitudes effectively.

Unexpectedly, the junior trainees revealed significantly better practice in the management of AF compared to the senior trainees. This outcome could be due to the fact that significantly more junior trainees worked at public clinics compared to the senior trainees (see Table 1), offering greater availability of same-day INR testing, warfarin in the clinic pharmacy, and direct access to an echocardiogram in the public clinics. Practice factors (e.g., availability of the INR test, anticoagulants that can be prescribed by family physicians) present major barriers to upgrading AF management in Malaysian primary care clinics. This issue demands the attention of the relevant policymakers.

As in our study, numerous other studies have also recognized physicians' negative beliefs and attitudes as major obstacles against anticoagulations ${ }^{10-12}$ and acknowledged healthcare system barriers ${ }^{9,10}$ Patient-related barriers is another vital aspect that requires analysis. ${ }^{9,10}$

Further studies to assess the knowledge, attitude, and practice of the same subjects before and after vocational training should also be carried out to provide a better reflection of the effect of vocational training.

Many of the stable AF patients who presented at the emergency care of the Mayo Clinic in Rochester, MN (USA), were seen for long-term follow-up by the specialists at the secondary care level rather than at the primary care level. ${ }^{17}$ The situation is similar in Malaysia, leading to congestion at the specialists' clinics.

The 2016 European Society of Cardiology (ESC) guidelines on the management of AF have recommended an integrated approach as a solution to overcome the increasing burden of AF-related health care (Recommendation Class IIa, Level of evidence B). ${ }^{16}$ Along the same line, Gallagher et al. ${ }^{18}$ found that integrated care improved patient outcomes in the management of AF by reducing allcause mortality and hospitalization related to cardiovascular conditions.

The benefit of integrated care was reaffirmed by van den Dries et al. in a randomized controlled trial on integrated care for elderly AF patients in primary care that demonstrated a significant $45 \%$ decrease in all-cause mortality compared to conventional care. ${ }^{19}$ In their study, besides focusing on team-based integrated care involving general practitioners, nurses, and specialists, the authors also emphasized the importance of training providers. ${ }^{19}$

Therefore, to optimize the care of patients with AF, Malaysia should consider exploring the option of implementing integrated care that involves primary care providers, particularly trained family physicians.

The evaluation and management of AF are fairly complicated and frequently not straightforward. ${ }^{14}$ Thus, wider implementation of AF management in primary care settings requires careful consideration regarding the training of the primary care doctor (especially for many who are not trained in family medicine) as well as provision of supportive services (echocardiogram, INR tests, medications, and consultation with a specialist) to both the public and private primary care sectors.

It is also vital for educational intervention programs, including vocational training in family medicine, to incorporate activities that will help translate knowledge on AF into practice in the management of AF. ${ }^{14}$

\section{Conclusion}

Vocational training in family medicine may improve primary care physicians' knowledge of the management of AF. However, the currently available training has not improved their attitude and practices due to multiple obstacles. Our study identified barriers involving both physicians and the healthcare system to the provision of warfarin management for atrial fibrillation in 
Malaysian primary care settings. The study also identified specific areas of knowledge gaps and the need to translate knowledge into practice, which can comprise a focus for future educational intervention.

\section{Acknowledgements}

The authors would like to express their sincere gratitude and appreciation to the following:

1. Academy of Family Physicians of Malaysia and postgraduate trainees

2. The Medical Ethics Committee of the International Medical University for giving the ethics approval and a small grant for this study (Project ID: IMU 384/2017)

3. Members of the expert panel involved in the validation of the knowledge test:
Prof. Dr. Esha Das Gupta (Internist \& Rheumatologist, IMU Seremban), Dr. Lee Li Yuan (Head, Medical department and Clinical Research Centre, Hospital Sri Manjung), Prof. Dr. Rifdy Mohideen (Internist, IMU Batu Pahat), Assoc. Prof. Dr. Velayudhan Menon (Internist, IMU Batu Pahat), Dr. Lee Tong Weng (Family Physician, Ipoh), Prof. Dr. Tong Seng Fah (Family Physician, UKM), Dr. Stanley Chan (Family Physician, IMU Seremban), Assoc. Prof. Dr. Verna Lee Kar Mun (Family Physician, IMU Bukit Jalil), Dr. Jean-Li Lee (Family Medicine Specialist, KK Seremban)

\section{Conflicts of interest}

None.

\section{References}

1. Boriani G, Pettorelli D. Atrial fibrillation burden and atrial fibrillation type: Clinical significance and impact on the risk of stroke and decision making for long-term anticoagulation. Vascul Pharmacol. 2016;83:26-35.

2. Lip GYH, Brechin CM, Lane DA. The global burden of atrial fibrillation and stroke: A systematic review of the epidemiology of atrial fibrillation in regions outside North America and Europe. Chest. 2012;142(6):1489-1498.

3. Kodani E, Atarashi H. Prevalence of atrial fibrillation in Asia and the world. J Arrhythmia. 2012;28(6):330-7.

4. Adderley NJ, Ryan R, Nirantharakumar K, Marshall T. Prevalence and treatment of atrial fibrillation in UK general practice from 2000 to 2016. Heart. 2019;105(1):27-33.

5. Miller PS, Andersson FL, Kalra L. Are cost benefits of anticoagulation for stroke prevention in atrial fibrillation underestimated? Stroke. 2005;36(2):360-366.

6. Freestone B, Rajaratnam R, Hussain N, Lip GY. Admissions with atrial fibrillation in a multiracial population in Kuala Lumpur, Malaysia. Int J Cardiol. 2003;91(2-3):233-238.
7. Guo Y, Lip GYH, Apostolakis S. The unmet need of stroke prevention in atrial fibrillation in the Far East and South East Asia. Malays J Med Sci. 2012;19(3):1-7.

8. Bai Y, Wang YL, Shantsila A, et al. The global burden of atrial fibrillation and stroke: A systematic review of the clinical epidemiology of atrial fibrillation in Asia. Chest. 2017;152(4):810-820.

9. Bungard TJ, Ghali WA, Teo KK, et al. Why do patients with atrial fibrillation not receive warfarin? Arch Intern Med. 2000;160(1):41-6.

10. Buckingham TA, Hatala R. Anticoagulants for atrial fibrillation: Why is the treatment rate so low? Clin Cardiol. 2002;25(10):447-54.

11. Frankel DS, Parker SE, Rosenfeld LE, et al. HRS/NSA 2014 survey of atrial fibrillation and stroke: Gaps in knowledge and perspective, opportunities for improvement. Heart Rhythm. 2015;12(8):e105-e113.

12. Pugh D, Pugh J, Mead GE. Attitudes of physicians regarding anticoagulation for atrial fibrillation: A systematic review. Age Ageing. 2011;40(6):675-83.

13. Peterson G, Boom K, Jackson S, Vial J. Doctors' beliefs on the use of antithrombotic therapy in atrial fibrillation: Identifying barriers to stroke prevention. Intern Med J. 2002;32(1-2):15-23.
14. Murray S, Lazure P, Pullen C, et al. Atrial fibrillation care: challenges in clinical practice and educational needs assessment. Can J Cardiol. 2011;27(1):98-104.

15. Health Technology Assessment Unit. Clinical practice guideline on management of atrial fibrillation. Putrajaya: Ministry of Health Malaysia, 2012.

16. Kirchhof P, Benussi S, Kotecha D, et al. 2016 ESC guidelines for the management of atrial fibrillation developed in collaboration with EACTS. Eur Heart J. 2016;37(38):2893-2962.

17. Robelia P, Kopecky S, Thacher T. Atrial fibrillation care improvement collaborative. BMJ Open Quality. 2015;4:u208947.w3629.

18. Gallagher C, Elliott AD, Wong CX, et al. Integrated care in atrial fibrillation: A systematic review and meta-analysis. Heart. 2017;103(24):1947-1953.

19. van den Dries CJ, van Doorn S, Rutten FH, et al. Integrated management of atrial fibrillation in primary care: Results of the ALL-IN cluster randomized trial [published online ahead of print, 2020 Feb 29]. Eur Heart J. 2020; ehaa055. 


\section{APPENDIX 1}

\section{(A) Questions on knowledge}

Please circle your answers.

1. David Kanang, a 33-year-old Iban male, presents with occasional palpitation. He had rheumatic fever when he was a child. He has an early diastolic murmur with an opening snap that is low pitched at the cardiac apex. There is no late diastolic component to the murmur. He is found to have atrial fibrillation.

Which of the following is the most appropriate long-term drug therapy for him?
A. A novel anticoagulant such as dabigatran
B. Aspirin alone
C. Clopidogrel
D. No need for long-term drug therapy
E. Warfarin

\section{Answer: E}

2. Mr. Tan, a 55-year-old man, comes for a health screening. He is free of chronic disease and is currently asymptomatic. His blood test results are normal, but his ECG shows atrial fibrillation with a heart rate of $88 / \mathrm{min}$. His echocardiogram and thyroid function test done later are all normal.

Which one of the following would be your advice?
A. Aspirin
B. Aspirin plus clopidogrel
C. Clopidogrel
D. No thromboprophylaxis is required
E. Warfarin

\section{Answer: D}

\section{Questions 3 \& 4 are based on the following scenario:}

BK Lim, a 63-year-old man, presents with a history of atrial fibrillation, hypertension, and diabetes. His daughter, who accompanied the patient, states that yesterday, the patient had a period when he could not speak or understand words, and that approximately 4 weeks prior, he staggered against a wall and was unable to stand unaided because of weakness in his legs. She states that both instances lasted approximately half an hour. She was unable to persuade her father to go to the emergency room either time.

Past medical history: Hypertension for 15 years, well-controlled; type 2 diabetes for five years. Medications: Diltiazem CD $300 \mathrm{mg}$ daily; lisinopril $40 \mathrm{mg}$ daily; metformin $500 \mathrm{mg}$ bd; aspirin $75 \mathrm{mg}$ daily.

Tobacco history: Smoked 2 packs a day; quit when he was diagnosed with hypertension. Alcohol history: Drinks 1 beer a day.

Review of systems: Denies dyspnea, dizziness, or syncope; denies focal motor weakness or loss of sensation, except for the reported incident.

Physical exam: Body mass index 26.5kg/m2; BP $134 / 82 \mathrm{~mm} \mathrm{Hg}$; heart rate $88 \mathrm{bpm}$ at rest, irregularly irregular pattern. 
3. What is his CHA2DS2-VASc score?
A. 0
B. 1
C. 2
D. 3
E. 4

\section{Answer: E}

4. Based on his current clinical presentation, what will be your choice of next management strategy?
A. Add a beta-blocker for rate control
B. Add warfarin for thromboprophylaxis
C. Replace aspirin with warfarin for thromboprophylaxis
D. Rhythm control with pharmacological cardioversion
E. Rhythm control with electrical cardioversion

\section{Answer: C}

\section{Questions 5-7 are based on the following scenario:}

Meenachi is a 64-year-old woman with hypertension and a long history of poorly controlled hyperthyroidism who developed atrial fibrillation six months ago. The atrial fibrillation persisted despite treatment with radioactive iodine. There is no history of transient ischemic attack or stroke. She takes 1-2 units of alcohol per day. She is currently on the following medications: amlodipine $5 \mathrm{mg}$ daily, L-thyroxine $0.1 \mathrm{mg}$ daily. Clinically, she is euthyroid, with blood pressure $120 / 70 \mathrm{mmHg}$, heart rate $84 / \mathrm{min}$, BMI $25 \mathrm{~kg} / \mathrm{m} 2$. Her recent full blood count, renal profile, and liver function test are all normal.

5. Which of the following factors is unlikely to increase her bleeding risk if she were to be started on warfarin for thromboprophylaxis?
A. Alcohol intake 1-2 units per day
B. Her body mass index
C. Her systolic blood pressure exceeding $160 \mathrm{mmHg}$
D. Increasing age
E. Occurrence of renal impairment

\section{Answer: B}

6. Meenachi was started on warfarin. What is the target international normalization ratio (INR) that should be aimed for?
A. 0.5 to 1.0
B. 1.0 to 2.0
C. 1.5 to 2.5
D. 2.0 to 3.0
E. 2.5 to 3.5

Answer: D 
7. Which of the following pieces of dietary advice is appropriate for Meenachi?
A. Avoid all green leafy vegetables
B. Avoid all fruits with green skin
C. Can take liberal amounts of cranberry juice
D. Can take liberal amounts of dried prunes
E. Take a consistent amount of green leafy vegetables

\section{Answer: E}

\section{Questions 8-10 are based on the following scenario:}

Mr. JS, a 61-year-old bus driver, presents with a two-week history of mild palpitations associated with mild giddiness without any episodes of fainting. He has had no such episode before. There was no chest pain, orthopnea, or paroxysmal nocturnal dyspnoea.

PMH: No significant medical illness or history of recent bleeding. No past history of asthma or COPD.

Physical examination: Comfortable, not in distress. Pink. No edema is noted.

BP: $130 / 80 \mathrm{mmHg}$; PR 120/min, irregularly irregular, JVP is not raised.

No other abnormalities detected on examination of the peripheral pulses and the precordium. ECG confirms atrial fibrillation with a heart rate of $130 / \mathrm{min}$.

8. Which of the following investigations is least helpful for Mr. JS at this stage?
A. Echocardiogram
B. Exercise stress test
C. Full blood count
D. Serum electrolytes
E. Thyroid function test

\section{Answer: B}

9. Investigations failed to find a specific cause of his atrial fibrillation. What management strategy is appropriate for Mr. JS?
A. Rate control first, then long-term warfarin
B. Rate control plus short-term warfarin, then rhythm control
C. Rhythm control, no need for initial anticoagulant therapy
D. Rate control alone, no need for rhythm control
E. Rate control first, then antiplatelet therapy

\section{Answer: B}

10. What is the first-line drug you would choose to control Mr. JS's heart rate?
A. Amiodarone
B. Amlodipine
C. Digoxin
D. Metoprolol
E. Verapamil

\section{Answer: D}




\section{A single-centre experience of febuxostat as a second-line urate-lowering therapy}

\section{Swee Gaik Ong, Hui Jen Ding}

Ong SG, Ding HJ. A single-centre experience of febuxostat as a second-line urate-lowering therapy. Malays Fam Physician. 2021;16(1);50-55. https://doi.org/10.51866/oa0892

\section{Keywords:}

febuxostat, second-line,

urate-lowering therapy, gout

\section{Authors:}

Ong Swee Gaik

(Corresponding author)

$M D, M R C P$

Rheumatology Unit, Department of

Medicine, Kuala Lumpur Hospital

Kuala Lumpur, Malaysia

Email: ongsweeg@gmail.com

\section{Ding Hui Jen}

MBChB, MRCP

Rheumatology Unit, Department of Medicine, Kuala Lumpur Hospital Jalan Pahang, Kuala Lumpur Malaysia

\section{Abstract}

Introduction: The purpose of this study was to describe the local experience in terms of drug efficacy and safety using a new xanthine oxidase inhibitor, febuxostat, as a second-line urate-lowering therapy (ULT) in gout patients with normal renal function and chronic kidney disease.

Methods: This cross-sectional study included all gout patients who attended the rheumatology clinic from January 2013 to June 2018 and had received febuxostat as a second-line ULT. Analysis focused on the proportion of gout patients who achieved target serum urate $(\mathrm{sUA})$ of $<360 \mu \mathrm{mol} / \mathrm{L}$, duration taken to achieve target sUA, and febuxostat dosage at achievement of target sUA. Safety assessments included comparison of serum creatinine, estimated glomerular filtration rate (eGFR), and serum alanine aminotransferase (ALT) at baseline, at achievement of target sUA, and at 12-monthly intervals. Results: Majority (90.9\%) of patients achieved target sUA. Median duration required to achieve target sUA was 5.5 months with IQR (interquartile range) of 8.5. Five (22.7\%) patients achieved target sUA within one month of therapy with febuxostat $40 \mathrm{mg}$ per day. Eleven $(55 \%)$ patients achieved target sUA within six months and $16(80 \%)$ by 12 months. Equal proportion of patients achieved target sUA with febuxostat $40 \mathrm{mg}$ per day and $80 \mathrm{mg}$ per day, respectively. There was no significant difference in the changes in serum creatinine level, eGFR and ALT from baseline and at achievement of target sUA, nor at 12-monthly intervals throughout the duration of febuxostat therapy. Apart from three patients who developed hypersensitivity reactions to febuxostat, no other adverse events were reported.

Conclusion: A significant proportion of gout patients with $\mathrm{CKD}$ managed to achieve target sUA with a lower dose of febuxostat at $40 \mathrm{mg}$ per day and it is reasonable to maintain this dose for up to six months before considering dose escalation.

\section{Introduction}

Gout is the most common inflammatory arthritis in adults worldwide, and if left untreated can lead to joint deformities and a poor quality of life. ${ }^{1,2}$ Over the last several decades, the incidence of gout has risen substantially, mainly due to increased frequency of comorbidities that are related to hyperuricemia, including obesity, hypertension, diabetes mellitus, dyslipidemia and chronic kidney disease (CKD). ${ }^{3-}$ 6 The growing use of drugs that induce hyperuricemia, such as thiazide and loop diuretics, is further contributing to the rise in gout cases.

Gout is attributed to hyperuricemia, which is defined as serum urate (sUA) concentration exceeding $400 \mu \mathrm{mol} / \mathrm{L}$ - the limit of urate solubility. The recommendation in gout management is to lower and maintain sUA to a level below $360 \mu \mathrm{mol} / \mathrm{L}^{7}$ in order to avoid formation of monosodium urate crystals and deposition in joints and soft tissues, thus minimizing gout flares. This treat-totarget concept is key to quality management of gout. Most gout patients require uratelowering therapy (ULT), with allopurinol being the most frequently used agent. ${ }^{8}$ It is a xanthine oxidase inhibitor that reduces urate production. Allopurinol is generally safe and well tolerated. Nevertheless, it occasionally induces serious cutaneous adverse reactions which can be potentially fatal. Patients intolerant to allopurinol would then require an alternative urate-lowering agent and the currently available option is febuxostat.

Febuxostat is a novel selective xanthine oxidase inhibitor that is used in lowering serum urate levels primarily in patients who are intolerant and non-responders to allopurinol. This drug received regulatory approval by the Ministry of Health (MOH) Malaysia in 2017. Before 2017, febuxostat use in Malaysian public hospitals required prior approval from the $\mathrm{MOH}$. To date, there is limited data on febuxostat use in Malaysian gout patients. Hence, this study aims to describe our local 
experience in terms of drug efficacy and safety using a new urate-lowering therapy, febuxostat.

\section{Methods}

This is a cross-sectional study conducted at the Rheumatology Clinic of Hospital Kuala Lumpur involving patients who received treatment from January 2013 to June 2018. Gout patients who required second-line uratelowering therapy were included. Patients were not eligible if they had not previously used allopurinol as a first-line urate-lowering agent, had incomplete medical records, had coronary heart disease, or had chronic liver disease of Child-Pugh class C. Approval from the Medical Research Ethics Committee, Ministry of Health Malaysia was obtained and registration was completed in accordance with the National Medical Research Register Malaysia (NMRR-17-2273-37871).

The target sUA was $<360 \mu \mathrm{mol} / \mathrm{L}$. Management of hyperuricemia with uratelowering therapy (ULT) was according to standard of care wherein febuxostat was initiated at $40 \mathrm{mg}$ per day, and increased to $80 \mathrm{mg}$ per day when target SUA was not attained.

The study had several objectives: examination of the proportion of gout patients who received febuxostat and achieved target sUA; assessment of the time taken to achieve target sUA; analysis of febuxostat dosage at achievement of target sUA; comparison of serum creatinine, estimated glomerular filtration rate (eGFR) using the modification of diet in renal disease (MDRD) method, ${ }^{9}$ and serum alanine aminotransferase (ALT) at baseline and at achievement of target sUA after febuxostat use.

Body mass index (BMI) according to the World Health Organization ${ }^{10}$ classification was defined as the following: underweight corresponds to BMI of $<18.5 \mathrm{~kg} / \mathrm{m}^{2}$, normal BMI value is between 18.5 to $24.9 \mathrm{~kg} / \mathrm{m}^{2}$, overweight is between 25.0 to $29.9 \mathrm{~kg} / \mathrm{m}^{2}$, and obese is $\geq 30.0 \mathrm{~kg} / \mathrm{m}^{2}$.

The current classification of chronic kidney disease $(\mathrm{CKD})$ is based on the Kidney Disease: Improving Global Outcomes (KDIGO) 2012 Clinical Practice Guideline. ${ }^{11} \mathrm{CKD}$ is defined as structural or functional abnormalities of the kidney, present for $\geq 3$ months, with or without decreased GFR, that can lead to decreased GFR; or eGFR $<60 \mathrm{ml} / \mathrm{min} / 1.73 \mathrm{~m}^{2}$ that is present for $\geq 3$ months, with or without evidence of kidney damage.

Categorical variables were reported as frequency and percentage, while continuous data were expressed as the mean (standard deviation, $\mathrm{SD}$ ) or median (interquartile range, IQR). Levels of serum creatinine, eGFR and ALT between baseline and when target SUA was achieved were analyzed using independent $\mathrm{t}$-test. Values of $\mathrm{p}<0.05$ were considered to be statistically significant. Analyses were performed using SPSS version 20.0 (IBM SPSS Inc., Chicago, IL, USA).

\section{Results}

All gout patients who received febuxostat as a second-line urate-lowering agent were included in this study. Altogether there were 24 patients. Twenty-three patients had a history of hypersensitivity reaction to allopurinol, while one had inadequate response to allopurinol. Of the 24 patients who received febuxostat, three developed hypersensitivity reaction to febuxostat wherein they experienced generalized pruritic maculopapular rash. One patient underwent successful desensitization to febuxostat and continued to receive the drug. Therefore, final analysis was undertaken on 22 patients.

Mean age of patients was 62.7 (SD 13.3) years, and $16(72.7 \%)$ were men. Sixteen $(72.7 \%)$ patients were of Malay descent, five were Chinese and one was Indian. Mean age at the onset of gout was 48.5 (SD 15.1) years. The earliest age at the onset of gout was 21 years in men compared to women at 48 years. Median duration of gout was 10 with interquartile range (IQR) of 12.8 years. Mean baseline sUA concentration was 599.5 (SD 90.6) $\mu \mathrm{mol} / \mathrm{L}$.

Mean body mass index (BMI) of the patients was 26.8 (SD 3.5) kg/m². Six (27.3\%) patients had normal BMI, 11 (50\%) were overweight, and five $(22.7 \%)$ were obese. Fifteen $(68.2 \%)$ patients had CKD and all of them were in CKD stage 3 (Table $\mathbf{1}$ ).

With regard to the concomitant use of drugs that exerted contributory effects to hyperuricemia, two patients received hydrochlorothiazide for management of hypertension, one received frusemide for treatment of pulmonary arterial hypertension, and one patient who had renal transplant received cyclosporine. 
Patient characteristics and comorbidities are depicted in Table $\mathbf{1 .}$

Table 1. Baseline demographics, gout history and comorbidities of patients.

\begin{tabular}{|c|c|}
\hline Characteristics & Patients $(n=22)$ \\
\hline Age, years & $62.7(13.3)^{\mathrm{a}}$ \\
\hline BMI, $\mathrm{kg} / \mathrm{m}^{2}$ & $26.8(3.5)^{\mathrm{a}}$ \\
\hline $\begin{array}{l}\text { Gender } \\
\text { Men } \\
\text { Women }\end{array}$ & $\begin{array}{l}16(72.7 \%) \\
6 \quad(27.3 \%)\end{array}$ \\
\hline $\begin{array}{l}\text { Ethnicity } \\
\text { Malay } \\
\text { Chinese } \\
\text { Indian }\end{array}$ & $\begin{array}{lc}16 & (72.7 \%) \\
5 & (22.7 \%) \\
1 & (4.6 \%)\end{array}$ \\
\hline Duration with gout, years & $10(12.8)^{\mathrm{b}}$ \\
\hline $\begin{array}{l}\text { Earliest age at onset of gout, years } \\
\text { Men } \\
\text { Women }\end{array}$ & $\begin{array}{l}21 \\
48\end{array}$ \\
\hline Baseline $s \mathrm{UA}, \mu \mathrm{mol} / \mathrm{L}$ & $599.5(90.6)^{\mathrm{a}}$ \\
\hline Duration of febuxostat use, months & $33.5(26.3)^{\mathrm{b}}$ \\
\hline $\begin{array}{l}\text { eGFR (MDRD), } \mathbf{n}(\%) \\
\geq 90 \mathrm{ml} / \mathrm{min} \\
60-89 \mathrm{ml} / \mathrm{min} \\
45-59 \mathrm{ml} / \mathrm{min} \\
30-44 \mathrm{ml} / \mathrm{min} \\
15-29 \mathrm{ml} / \mathrm{min} \\
<15 \mathrm{ml} / \mathrm{min}\end{array}$ & $\begin{array}{l}1(4.5 \%) \\
6(27.3 \%) \\
9(40.9 \%) \\
6(27.3 \%) \\
0(0 \%) \\
0(0 \%)\end{array}$ \\
\hline $\begin{array}{l}\text { Metabolic syndrome } \\
\text { Hypertension } \\
\text { Diabetes mellitus } \\
\text { Dyslipidemia }\end{array}$ & $\begin{array}{l}19(86.4 \%) \\
7(31.8 \%) \\
14(63.6 \%)\end{array}$ \\
\hline Family history of gout & $5(22.7 \%)$ \\
\hline Smoking & $5(22.7 \%)$ \\
\hline Alcohol use & $2(9.1 \%)$ \\
\hline $\begin{array}{l}\text { Clinical manifestations of gout } \\
\text { Tophi } \\
\text { Radiographic bone erosion } \\
\text { Medullary nephrocalcinosis } \\
\text { Urate nephrolithiasis or urolithiasis }\end{array}$ & $\begin{array}{c}19(86.4 \%) \\
9(40.9 \%) \\
5(22.7 \%) \\
0(0 \%)\end{array}$ \\
\hline
\end{tabular}

${ }^{\mathrm{a}}$ mean $(\mathrm{SD}) ;{ }^{\mathrm{b}}$ median $(\mathrm{IQR})$

Twenty (90.9\%) of 22 patients achieved target SUA (Table 2). The two patients who did not achieve target sUA had CKD. One had CKD stage $3 \mathrm{a}$ while the other had stage $3 \mathrm{~b}$. Thirteen of the 15 patients with CKD achieved target sUA. Median duration to achieve target sUA was 5.5 (IQR 8.5) months. Eleven (50\%) patients achieved target sUA within six months of commencing febuxostat. By 12 months, 16 $(72.7 \%)$ patients managed to achieve target sUA.
Five $(22.7 \%)$ patients achieved target sUA within one month of therapy. Eleven (50\%) patients reached target sUA at 6 months, $72.7 \%$ at 12 months and $90.9 \%$ at the end of study period.

Patients who had not achieved target sUA by six months with febuxostat $40 \mathrm{mg}$ per day had dose escalation to $80 \mathrm{mg}$ per day. One patient was an exception as she was commenced on febuxostat $80 \mathrm{mg}$. Eight patients (36.4\%) achieved target sUA with febuxostat $80 \mathrm{mg}$. 
Table 1. Gout history, renal function and febuxostat dosages of all patients who tolerated febuxostat

\begin{tabular}{|c|c|c|c|c|c|c|c|c|c|c|}
\hline $\mathbf{P t}$ & $\begin{array}{c}\text { Age } \\
\text { (years) }\end{array}$ & Gender & $\begin{array}{l}\text { Ethnic } \\
\text { group }\end{array}$ & $\begin{array}{c}\text { Duration } \\
\text { of gout } \\
\text { (years) }\end{array}$ & $\begin{array}{c}\text { Age at } \\
\text { onset } \\
\text { of gout } \\
\text { (years) }\end{array}$ & $\begin{array}{c}\text { Baseline eGFR } \\
\text { (MDRD) } \\
\left(\mathrm{ml} / \mathrm{min} / 1.73 \mathrm{~m}^{2}\right)\end{array}$ & $\begin{array}{c}\text { Baseline } \\
\text { sUA } \\
(\mu \mathrm{mol} / \mathrm{L})\end{array}$ & $\begin{array}{c}\text { sUA after } \\
\text { treatment } \\
\text { with } \\
\text { febuxostat } \\
(\mu \mathrm{mol} / \mathrm{L})\end{array}$ & $\begin{array}{c}\text { Duration } \\
\text { to achieve } \\
\mathrm{sUA}<360 \\
\mu \mathrm{mol} / \mathrm{L} \\
\text { (months) }\end{array}$ & $\begin{array}{c}\text { Febuxostat } \\
\text { dose to } \\
\text { achieve sUA } \\
<360 \mu \mathrm{mol} / \mathrm{L} \\
\quad(\mathrm{mg})\end{array}$ \\
\hline 1 & 67 & M & $\mathrm{M}$ & 29 & 38 & 47 & 519 & 325 & 1 & 40 \\
\hline 2 & 77 & $\mathrm{~F}$ & $\mathrm{M}$ & 13 & 64 & 52 & 518 & 287 & 1 & 40 \\
\hline 3 & 54 & $\mathrm{M}$ & C & 6 & 48 & 81 & 608 & 294 & 1 & 40 \\
\hline 4 & 67 & $M$ & I & 21 & 46 & 41 & 561 & 301 & 1 & 40 \\
\hline 5 & 63 & $\mathrm{M}$ & $\mathrm{M}$ & 10 & 53 & 39 & 516 & 272 & 1 & 40 \\
\hline 6 & 46 & $\mathrm{M}$ & $\bar{M}$ & 10 & 36 & 58 & 619 & 331 & 3 & 40 \\
\hline 7 & 74 & $\mathrm{~F}$ & M & 5 & 69 & 61 & 410 & 325 & 3 & 40 \\
\hline 8 & 58 & $\mathrm{~F}$ & $\mathrm{M}$ & 7 & 51 & 74 & 612 & 348 & 4 & 40 \\
\hline 9 & 50 & $\mathrm{~F}$ & $\mathrm{M}$ & 2 & 48 & 56 & 805 & 350 & 5 & 80 \\
\hline 10 & 85 & $\bar{M}$ & $M$ & 14 & 61 & 32 & 638 & 359 & 5 & 40 \\
\hline 11 & 63 & $M$ & C & 19 & 44 & 93 & 550 & 353 & 6 & 40 \\
\hline 12 & 33 & $M$ & $\mathrm{M}$ & 8 & 25 & 69 & 612 & 322 & 8 & 80 \\
\hline 13 & 69 & F & $\mathrm{M}$ & 5 & 64 & 60 & 735 & 346 & 9 & 80 \\
\hline 14 & 69 & $\mathrm{M}$ & $\mathrm{M}$ & 3 & 66 & 82 & 478 & 323 & 9 & 40 \\
\hline 15 & 57 & $M$ & $M$ & 24 & 33 & 39 & 698 & 358 & 10 & 80 \\
\hline 16 & 59 & $M$ & $\mathrm{M}$ & 18 & 41 & 46 & 599 & 294 & 10 & 80 \\
\hline 17 & 77 & $M$ & $M$ & 10 & 67 & 54 & 605 & 343 & 13 & 40 \\
\hline 18 & 83 & $\mathrm{~F}$ & $\mathrm{M}$ & 10 & 73 & 40 & 591 & 357 & 17 & 80 \\
\hline 19 & 68 & $\mathrm{M}$ & $\bar{C}$ & 32 & 36 & 54 & 725 & 357 & 21 & 80 \\
\hline 20 & 67 & $M$ & C & 9 & 58 & 55 & 672 & 265 & 34 & 80 \\
\hline 21 & 35 & $\mathrm{M}$ & $\mathrm{C}$ & 10 & 25 & 32 & 625 & 420 & $\mathrm{NA}$ & $\mathrm{NA}$ \\
\hline 22 & 59 & $\bar{M}$ & $M$ & 38 & 21 & 53 & 492 & 439 & NA & NA \\
\hline
\end{tabular}

Pt: patient; Gender - M: male, F: female; Ethnic group - M: Malay, C: Chinese, I: Indian; sUA: serum uric acid; eGFR (MDRD): estimated glomerular filtration rate (modification of diet in renal disease); NA: not applicable

Among the 15 patients who had CKD, 13 (86.7\%) achieved target sUA. Seven (53.8\%) of the 13 patients achieved target sUA within six months of febuxostat treatment. Of note, four of them achieved target sUA by one month. Seven (53.8\%) patients achieved target sUA with febuxostat $40 \mathrm{mg}$ while the remaining six $(46.2 \%)$ required febuxostat $80 \mathrm{mg}$.

In terms of drug safety, comparison of serum creatinine, eGFR (MDRD) and ALT was made at baseline and at achievement of target sUA. Analysis of this set of data did not show any significant difference $(p>0.05)$. Given the median duration of febuxostat use was 33.5 (IQR 26.3) months, further analysis was undertaken with regard to the comparison of serum creatinine, eGFR (MDRD) and ALT at baseline, and at every subsequent 12 months. Evaluation of these patients at 12, 24, 36 and 48 months also did not demonstrate statistically significant changes $(p>0.05)$ when compared to baseline values. None of the patients had deranged ALT values throughout the course of treatment with febuxostat.

Febuxostat was generally well tolerated.
Majority of patients who were switched to febuxostat did not develop hypersensitivity reaction (23/24 were allergic to allopurinol, while $3 / 24$ were allergic to febuxostat). No other adverse effects were reported. Nonetheless, two patients were advised to discontinue febuxostat at seven months and 48 months of treatment. One of them was diagnosed to have coronary heart disease from coronary angiography several months after commencement of febuxostat. Coronary angiography was carried out during her workup for pulmonary arterial hypertension. The other patient was later found to have sonographically-confirmed liver cirrhosis given the history of chronic alcohol consumption.

\section{Discussion}

Even though allopurinol is recommended as the first-line ULT for the management of gout, ${ }^{12}$ its use has occasionally been hampered by the development of adverse events, in particular, serious cutaneous adverse reactions in certain patients. Studies have shown that a significant proportion of gout patients have concomitant $\mathrm{CKD},{ }^{13}$ which impacts the management of gout. Given the general 
understanding that allopurinol requires dose adjustment according to creatinine clearance, coupled with the fact that the safest and most effective dosing of allopurinol is still debatable, it is not unexpected for patients with gout and $\mathrm{CKD}$ to be prescribed suboptimal doses of allopurinol. ${ }^{14}$ This inevitably leads to failure in achieving target sUA, culminating in greater frequency of gout flares among CKD patients. With the advent of febuxostat, an alternative ULT can be offered to patients who are intolerant to, or have failed to respond to, allopurinol.

A vast majority of the patients in our cohort achieved target sUA, a finding which concurs with previous studies confirming the effectiveness of febuxostat. ${ }^{16-18}$ The fact that five of the 22 patients in our cohort achieved target sUA within one month of febuxostat therapy and seven achieved target sUA by three months of therapy proved that febuxostat is indeed a potent ULT. In addition, 10 of the 11 patients who achieved target sUA within six months of febuxostat treatment were in fact receiving a lower dose of febuxostat at $40 \mathrm{mg}$ per day. Among the CKD patients in our cohort, there was an almost equal proportion who responded to febuxostat $40 \mathrm{mg}$ and $80 \mathrm{mg}$ per day, respectively. This observation demonstrated that a lower dose of febuxostat can be effective in patients with CKD. Hence, it would be prudent to initiate febuxostat at $40 \mathrm{mg}$ per day instead of $80 \mathrm{mg}$ per day in patients with mild to moderate renal impairment. In the event the target sUA is not achieved by six months, febuxostat dose can be escalated to $80 \mathrm{mg}$ per day. Interestingly, the authors would like to highlight that two patients (Patients 14 and 17 in Table 2) who received febuxostat $40 \mathrm{mg}$ per day eventually achieved target sUA, albeit at 9 months and 13 months, respectively. The reason why both patients remained on febuxostat $40 \mathrm{mg}$ per day without dose escalation was because they encountered logistics issues, rendering them unable to attend clinic appointments at earlier dates. Of note, the usual dosing regime for febuxostat is $40 \mathrm{mg}$ per day with dose escalation to $80 \mathrm{mg}$ after two to four weeks.

With regard to drug safety, there were no major adverse events reported in our cohort. Liver and renal functions of our cohort were not significantly affected throughout the course of febuxostat therapy. Nevertheless, we had to discontinue febuxostat in one patient when sonographically-evident liver cirrhosis was detected, given the fact that febuxostat is predominantly metabolised in the liver. We concluded that the aetiology of liver cirrhosis was most likely attributed to alcohol and not febuxostat, as that patient had a longstanding history of alcohol consumption. ${ }^{19}$ Notwithstanding the fact that he had received febuxostat for 48 months, his ALT had remained within the normal range throughout this period. Upon further consideration, the decision to discontinue febuxostat may not be valid as our patient had chronic liver disease of Child-Pugh class A. According to Khosrawan et $\mathrm{al}^{20}$ the pharmacokinetics of febuxostat were unaffected in patients with mild-to-moderate hepatic impairment i.e. Child-Pugh classes A and $B$, thus suggesting that febuxostat is only contraindicated in Child-Pugh class C.

Another patient correspondingly had febuxostat terminated at the seventh month of therapy after she was diagnosed to have coronary heart disease in the course of investigation for pulmonary arterial hypertension. This decision was made based on the findings in the CARES (cardiovascular safety of febuxostat and allopurinol in patients with gout and cardiovascular morbidities) trial that demonstrated an adverse impact of febuxostat on all-cause mortality as well as cardiovascular mortality in gout patients with coexisting cardiovascular disease, although the mechanism underlying the mortality risk remains unclear. ${ }^{21}$

Despite the encouraging findings, this study has its limitations given the small sample size. Therefore, caution should be exercised in interpreting our findings as this study may be statistically underpowered. Given the fact that current gout guidelines recommend for febuxostat to be used as a second-line uratelowering agent, it is not unexpected that this would be the limiting factor in determining the sample size. We anticipate readers might question why other trials involving febuxostat had enormous sample sizes while our sample size was substantially smaller. We would therefore like to remind readers that those trials were comparative trials using allopurinol vs febuxostat as first-line urate-lowering agents. The second limitation is that this research did not compare the urate-lowering effect, safety and tolerability of febuxostat with allopurinol.

\section{Conclusion}

Our study showed that a significant proportion of gout patients with CKD managed to achieve 
target sUA with a lower dose of febuxostat at $40 \mathrm{mg}$ per day. We suggest that this dose be maintained for up to six months in the event that target sUA has not been achieved before considering dose escalation.

\section{Funding}

This research did not receive any funding from any agency.

\section{Conflict of interest statement}

The authors declared no potential conflicts of interest with respect to the research, authorship, and/or publication of this article.

\section{Acknowledgment:}

The authors would like to thank the DirectorGeneral of Health Malaysia for the permission to publish this paper.

\section{References}

1. Roddy E, Zhang W, Doherty M. Is gout associated with reduced quality of life? A casecontrol study. Rheumatology 2007;46(9):1441-4.

2. Singh JA, Strand V. Gout is associated with more comorbidities, poorer healthrelated quality of life and higher healthcare utilisation in US veterans. Ann Rheum Dis 2008;67(9):1310-6

3. Wallace KL, Riedel AA, Joseph-Ridge N, et al. Increasing prevalence of gout and hyperuricemia over 10 years among older adults in a managed care population. J Rheumatol 2004;31(8):1582-7.

4. Klemp P, Stansfield SA, Castle B, et al. Gout is on the increase in New Zealand. Ann Rheum Dis 1997;56(1):22-6.

5. Nan H, Qiao Q, Dong Y, et al. The prevalence of hyperuricemia in a population of the coastal city of Qingdao, China. J Rheumatol 2006;33(7):1346-50.

6. Miao Z, Li C, Chen Y, et al. Dietary and lifestyle changes associated with high prevalence of hyperuricaemia and gout in the Shandong coastal cities of Eastern China. J Rheumatol 2008;35(9):1859-64.

7. Bardin T. Hyperuricemia starts at 360 micromoles (6 mg/dL). Joint Bone Spine 2015; 82(3):141-3.

8. Khanna D, Fitzgerald JD, Khanna PP, et al. 2012 American College of Rheumatology guidelines for management of gout. Part 1: Systematic nonpharmacologic and pharmacologic therapeutic approaches to hyperuricemia. Arthritis Care Res (Hoboken) 2012;64(10):1431-46.
9. Stevens LA, Coresh J, Feldman HI, et al. Evaluation of the modification of diet in renal disease study equation in a large diverse population. J Am Soc Nephrol. 2007;18(10):2749-57.

10. International Obesity Task Force. Managing the Global Epidemic of Obesity. Report of the World Health Organization (WHO) Consultation on Obesity; June 5-7, 1997; Geneva, Switzerland.

11. Kidney disease: Improving global outcomes (KDIGO) CKD work group. KDIGO 2012 Clinical practice guideline for the evaluation and management of chronic kidney disease. Kidney Int Suppl. 2013(1):1-150.

12. Richette P, Doherty M, Pascual E, et al. 2016 updated EULAR evidence-based recommendations for the management of gout. Ann Rheum Dis 2017;76:29-42.

13. Fuldeore MJ, Riedel AA, Zarotsky V, et al. Chronic kidney disease in gout in a managed care setting. BMC Nephrol 2011;12:36.

14. Dalbeth N, Kumar S, Stamp L, et al. Dose adjustment of allopurinol according to creatinine clearance does not provide adequate control of hyperuricemia in patients with gout. J Rheumatol 2006;33(8):1646-50.

15. Becker MA, Schumacher HR, Wortmann RL, et al. Febuxostat compared with allopurinol in patients with hyperuricemia and gout. NEJM 2005;353(23):2450-61

16. Schumacher HR, Becker MA, Lloyd E, et al. Febuxostat in the treatment of gout: 5-yr findings of the FOCUS efficacy and safety study. Rheum 2009;48(2):188-94.
17. Becker MA, Schumacher HR, Espinoza LR, et al. The urate-lowering efficacy and safety of febuxostat in the treatment of the hyperuricemia of gout: the CONFIRMS trial. Arthritis Res Ther 2010;12(2):R63.

18. Saag KG, Whelton A, Becker MA, et al. Impact of febuxostat on renal function in gout patients with moderate-to-severe renal impairment. Arthritis Rheum 2016;68(8):2035-43.

19. Sorensen TI, Orholm M, Bentsen KD, et al Prospective evaluation of alcohol abuse and alcoholic liver injury in men as predictors of development of cirrhosis. Lancet. 1984:2:241-244.

20. Khosravan R, Grabowski BA, Mayer $\mathrm{MD}$, et al. The effect of mild and moderate hepatic impairment on pharmacokinetics, pharmacodynamics, and safety of febuxostat, a novel nonpurine selective inhibitor of xanthine oxidase, J Clin Pharmacol 2006;46(1):88-102.

21. White WB, Saag KG, Becker MA, Borer JS, et al. Cardiovascular safety of febuxostat or allopurinol in patients with gout. NEJM 2018; 378(13):1200-10. 


\section{Effectiveness of an intervention to increase the knowledge, attitude, and practice regarding the return and disposal of unused medications}

Pauline Siew Mei Lai, Kit Mun Tan, Hong Gee Lee, Yin Yen Wong, Nur Azrida Azhari Wasi, Si Mui Sim

Lai PSM, Tan KM, Lee HG, et al. Effectiveness of an intervention to increase the knowledge, attitude, and practice regarding the return and disposal of unused medications. Malays Fam Physician. 2021;16(1);56-63. https://doi.org/10.51866/oa1013

Keywords:

diabetes mellitus, risk factors,

cognitive disorders, general

practice

\section{Authors:}

Pauline Lai Siew Mei

(Corresponding author)

Associate Professor B Pharm, PhD

Department of Primary Care Medicine

(University of Malaya Primary Care

Research Group) Faculty of Medicine

University of Malaya, Kuala Lumpur

Malaysia

Email: plai@ummc.edu.my

\section{Tan Kit Mun}

Assoc Prof, MB BCh BaO (Hons), MRCP (UK)

Department of Medicine (Division

of Geriatric Medicine), Faculty of

Medicine, University of Malaya

Kuala Lumpur Malaysia

\section{Lee Hong Gee}

Senior Lecturer, B Pharm, M Pharm

Department of Pharmacy, Faculty of

Medicine, University of Malaya

Kuala Lumpur Malaysia

\section{Wong Yin Yen}

Pharmacist, B Pharm

Pharmacy Department, University

Malaya Medical Centre

Kuala Lumpur, Malaysia

\section{Abstract}

This study aimed to evaluate the effectiveness of an educational intervention (Safe D.U.M.P) to improve the knowledge, attitude, and practice regarding the return and disposal of unused medications. Community-dwelling adults in Malaysia who could understand English were recruited from two healthcare events. Participants were asked to fill out the validated Return and Disposal of Unused Medications (ReDiUM) questionnaire (pre-intervention), view six educational intervention posters on how to dispose of unused medications (Safe D.U.M.P), then answer the ReDiUM questionnaire immediately after viewing the posters (post-intervention). A total of 390 out of 456 participants participated (response rate $=85.5 \%$ ). Most were female $(71 \%)$ with a median age of 42 years. The overall knowledge of participants significantly increased from $60 \%$ to $80 \%$ ( $\mathrm{p}<0.001)$. However, no improvement was seen regarding their overall attitude and practice. This outcome was as expected as it may be more difficult to improve attitude and practice (when compared to knowledge) with a single educational session.

\section{Introduction}

In 2010, the Pharmaceutical Services Division, Ministry of Health (MOH) Malaysia implemented the "Return Your Medicines Program." This program aimed to encourage patients to return their unused or excess medications for safe disposal by the $\mathrm{MOH}$. In 2016, a conservative estimate of medications returned to three $\mathrm{MOH}$ hospitals in Malaysia (based on their value) were US\$6,670, US $\$ 12,854$, and US\$45,570, respectively. ${ }^{2}$ These figures represent an underestimation of medication wastage, considering that a total of 144 hospitals and special medical institutions as well as 2881 health clinics are under the administration of $\mathrm{MOH}$ Malaysia. $^{3}$

In 2017, approximately US\$12.67 million was allocated for medications in a 1,643-bed, tertiary public teaching hospital serving a population of over 1.5 million. ${ }^{4}$ An internal audit conducted from May 2016 to January 2017 found that US\$36,216 worth of unused medications were returned to this hospital's outpatient pharmacy. ${ }^{5}$ Common factors that led to excessive medications included a change or discontinuation of treatment regimen, non-compliance, adverse effects, or oversupply of medications. ${ }^{2}$ Unused medications represent a significant waste of healthcare resources and economic wastage, and improper disposal of unused medications has adverse consequences for the environment and public health. ${ }^{6}$

Ideally, unused medications should be returned to authorized collectors for proper disposal to reduce releasing unwanted active pharmaceutical ingredients into the environment. One study reported that more than $50 \%$ of Malaysian patients disposed of unused medications by throwing them away with normal garbage or by burning them. ${ }^{7}$ Another study found that $93 \%$ of university students in Malaysia were not aware of the "Return Your Medicines Program" and had flushed unused medications down the toilet or sink. ${ }^{8}$ Disposal of unused medications as household garbage (which ends up in a landfill) or flushing them down the toilet or sink (where they end up in the sewerage system) may contaminate soil or surface water.' Management of active pharmaceutical ingredients in the environment is both challenging and potentially costly. ${ }^{10}$

To date, no study has investigated the knowledge, attitude, and practice (KAP) of community-dwelling adults in Malaysia regarding the return and disposal of unused medications. Hence, we decided to develop an educational intervention (Safe D.U.M.P) to assess the KAP of community-dwelling adults to determine if this educational program would increase their KAP regarding medication 


\section{Nur Azrida Azhari Wasi \\ Pharmacist B Pharm \\ Pharmacy Department, University \\ Malaya Medical Centre \\ Kuala Lumpur, Malaysia}

\section{Sim Si Mui}

Professor B Sc, PhD

Department of Pharmacology, Faculty

of Medicine University of Malaya

Kuala Lumpur, Malaysia disposal. The aim of this study was to evaluate the effectiveness of this educational intervention (Safe D.U.M.P) to improve the KAP of communitydwelling adults toward the return and disposal of unused medications.

\section{Methods}

Recruitment was done during two events (at the World Pharmacist Day in September 2017 and Patient Safety Week in December 2017), considering that the safe D.U.M.P program consisted of 6 posters that could only be displayed using a poster board, usually only available at events. The aim of our study was to assess the KAP of community-dwelling adults. Hence, any adult $\geq 18$ years of age who could speak English was recruited. It was not necessary to recruit only adults who had chronic illness, as any adult could have had an acute or chronic illness and could have unused medications at home. Individuals exhibiting intellectual disability, defined as a disability characterized by significant limitations in both intellectual functioning (reasoning, learning, problem-solving) and adaptive behavior and covering a range of everyday social and practical skills, were also excluded. We did not use any tool to assess intellectual disability. We excluded these participants by not approaching them.

A search of the published literature found that no study had previously assessed the effectiveness of an intervention to improve knowledge regarding the disposal of unused medications. Hence, for the purpose of calculating the sample size for this study, we hypothesized that knowledge levels would improve by $10 \%$ from pre- to post-intervention. Accordingly, the sample size required for this study with a confidence level of $95 \%$ and $80 \%$ power was 349 participants. ${ }^{11}$

\section{The educational intervention (Safe D.U.M.P) provided}

As no instrument had been developed previously for this purpose, an educational intervention program (called Safe D.U.M.P) was newly created by the research team (consisting of one physician, four pharmacists, and one pharmacologist) to assess the KAP of community-dwelling adults regarding discarding unused medications. Our research team developed six A1 size graphic posters, each with a key question, focus points, and a take-home message, based on a literature review (Table 1).

Table 1: The Safe D.U.M.P. posters

\begin{tabular}{|c|c|c|c|}
\hline No. & Key questions & Focus points & Take-home message \\
\hline 1 & $\begin{array}{l}\text { Are you experiencing } \\
\text { unwanted effects from } \\
\text { your medications? }\end{array}$ & $\begin{array}{l}\text { If so, seek medical attention as } \\
\text { soon as possible and return the } \\
\text { unused medications to a pharmacy. }\end{array}$ & $\begin{array}{l}\text { Don't store medications "just in } \\
\text { case." }\end{array}$ \\
\hline 2 & $\begin{array}{l}\text { What is the impact of } \\
\text { unused medications? }\end{array}$ & $\begin{array}{l}\text { Unused medications may cause: } \\
\text { a) health hazard for people or } \\
\text { animals, b) waste of public } \\
\text { resources, and c) risk of global } \\
\text { warming and contaminated water. }\end{array}$ & $\begin{array}{l}\text { Return unused medications before } \\
\text { they cause harm or become a waste } \\
\text { of resources! }\end{array}$ \\
\hline 3 & $\begin{array}{l}\text { Why is safe disposal } \\
\text { of unused medications } \\
\text { important? }\end{array}$ & $\begin{array}{l}\text { Water treatment does not remove } \\
\text { medication residue in sewage; } \\
\text { discarded medications may end up } \\
\text { in landfills and appear in surface } \\
\text { water. }\end{array}$ & $\begin{array}{l}\text { Do not pour it down the drain, } \\
\text { toss it in the toilet, or throw it in } \\
\text { the garbage! }\end{array}$ \\
\hline 4 & $\begin{array}{l}\text { How to reduce } \\
\text { unused medications? }\end{array}$ & $\begin{array}{l}\text { Unused medications are a waste } \\
\text { of resources and a risk to the } \\
\text { environment. }\end{array}$ & $\begin{array}{l}\text { Don't keep medications } \\
\text { "just in case"; collect or buy } \\
\text { medications only when you } \\
\text { need them. }\end{array}$ \\
\hline 5 & $\begin{array}{l}\text { How to avoid } \\
\text { medication wastage? }\end{array}$ & $\begin{array}{l}\text { Store medications according } \\
\text { to instructions; check your } \\
\text { medications monthly for the } \\
\text { amount and expiration date. }\end{array}$ & $\begin{array}{l}\text { Return unused medications to } \\
\text { a pharmacy as soon as you can. }\end{array}$ \\
\hline 6 & $\begin{array}{l}\text { How do you dispose } \\
\text { of medications } \\
\text { safely? }\end{array}$ & $\begin{array}{l}\text { For tablets/capsules, syrups/ } \\
\text { mixtures, creams/ointments, } \\
\text { injections, dry powder inhalers, } \\
\text { and eye/nose drops, return to } \\
\text { a pharmacy, and they will send } \\
\text { your unused medications for } \\
\text { incineration. }\end{array}$ & $\begin{array}{l}\text { Pressurized medications such } \\
\text { as metered dose inhalers } \\
\text { cannot be incinerated; these } \\
\text { medications can be thrown as } \\
\text { normal waste in the garbage. }\end{array}$ \\
\hline
\end{tabular}




\section{Instruments used}

\section{Baseline demographic questionnaire}

A baseline demographic questionnaire was used to record the demographic characteristics of participants.

\section{The Return and Disposal of Unused Medications (ReDiUM) questionnaire}

The validated Return and Disposal of Unused Medications (ReDiUM) questionnaire consisted of 30 items with three domains: KAP. ${ }^{12}$ The knowledge domain consisted of 10 items, with each item having "true," "false," and "do not know" options. One point was given for correct answers, while zero points were given for incorrect or "don't know" answers. Scores were then converted to percentages. The attitude and practice domains each had 10 items, each having a 5-point Likert-scale response, where 1 represented "strongly disagree" and 5 represented "strongly agree." Only item 14 was reverse-scored, as this item was worded in a negative manner. Participants took 10-15 minutes to answer the questionnaire.

\section{Procedure}

Convenience sampling was used to recruit participants. The purpose of the study was explained to potential participants using a participant information sheet. For those who agreed to participate, written informed consent was obtained. Participants were first asked to fill out the baseline demographic questionnaire and the ReDiUM questionnaire (i.e., "pre-intervention"). Participants were then asked to read the six educational Safe D.U.M.P posters (i.e., the intervention) and then complete the ReDiUM questionnaire again (i.e., "post-intervention"). Participants had to answer all the questions in the ReDiUM. All questionnaires were checked by a researcher at the point of submission. If any missing items were found, the researcher asked the participant to complete the missing items. Coding by number was used to ensure matching of the same participant's pre- and post-intervention forms while maintaining his/her anonymity. Ethics approval was obtained prior to the study from the University of Malaya Medical Ethics Committee (approval no. 20161028-4450).

\section{Data analysis}

The data were analyzed using the Statistical Package for Social Sciences (SPSS) version 22. As normality could not be assumed, continuous data were presented as median and inter-quartile range, while categorical data were presented as number and frequency.

\section{Results}

A total of 390 out of 456 participants agreed to participate (response rate $=85.5 \%$ ). Most of the participants were female $(71 \%)$, with a median age of 42 years (Appendix 1).

All items in the knowledge domain were significantly different pre- and post-intervention. The overall knowledge of participants significantly increased from $60 \%$ (pre-intervention) to $80 \%$ (post-intervention, $\mathrm{p}<0.001$ ) [Table 2]. Prior to the intervention, the participants already scored well: More than $75 \%$ knew the correct answers for items 1 (the harmful effects of improper drug disposal on the environment), 7 (unsafe to discard needles in the garbage), and 8 (acceptable to return unused medicines to a local pharmacy or healthcare facility for disposal). Nonetheless, despite the high level of baseline knowledge, the percentage of correct answers increased significantly for these three items following the intervention. Pre-intervention knowledge was poor in items 2, 6, and 9, with less than $50 \%$ correct answers, and moderate in items $3,4,5$, and 10 , with a correct score in $50 \%-75 \%$ of the answers. All items with a low and moderate level of pre-intervention knowledge improved significantly after the intervention. 
Table 2: Knowledge of participants pre- and post-intervention

\begin{tabular}{|c|c|c|c|c|c|}
\hline \multirow[b]{2}{*}{$\begin{array}{c}\text { Item } \\
\text { no. }\end{array}$} & \multirow[b]{2}{*}{ Item } & Pre-intervention & Post-intervention & \multirow[b]{2}{*}{$\begin{array}{l}\text { Chi-square } \\
\text { or z-value }\end{array}$} & \multirow[b]{2}{*}{ p-value } \\
\hline & & $\begin{array}{c}\text { No. of } \\
\text { participants } \\
\text { who answered } \\
\text { the item correctly } \\
(\mathbf{n}=390) \mathbf{n}(\%)\end{array}$ & $\begin{array}{c}\text { No. of } \\
\text { participants } \\
\text { who answered } \\
\text { the item correctly } \\
(\mathrm{n}=390) \mathrm{n}(\%)\end{array}$ & & \\
\hline 1 & $\begin{array}{l}\text { Improper drug disposal } \\
\text { has harmful effects on the } \\
\text { environment and ecosystem. }\end{array}$ & 344 (88.2) & $370(94.9)$ & 16.1 & $<0.001^{*}$ \\
\hline 2 & $\begin{array}{l}\text { Wastewater treatment removes } \\
\text { most of the medicines from the } \\
\text { environment and ecosystem. }\end{array}$ & $112(28.7)$ & $236(60.5)$ & 30.8 & $<0.001^{*}$ \\
\hline 3 & $\begin{array}{l}\text { It is acceptable to dispose of } \\
\text { solid medicines (such as tablets, } \\
\text { capsules, and patches) in the } \\
\text { garbage. }\end{array}$ & $267(68.5)$ & 343 (87.9) & 7.5 & $0.006^{*}$ \\
\hline 4 & $\begin{array}{l}\text { It is acceptable to dispose of liquid } \\
\text { medicines by throwing them } \\
\text { down the sink. }\end{array}$ & $250(64.1)$ & $359(92.1)$ & 2.3 & $<0.001^{*}$ \\
\hline 5 & $\begin{array}{l}\text { It is acceptable to dispose of } \\
\text { medicines by flushing them down } \\
\text { the toilet. }\end{array}$ & $256(65.6)$ & $364(93.3)$ & 9.1 & $0.003^{*}$ \\
\hline 6 & $\begin{array}{l}\text { Incineration is the } \\
\text { environmentally sound way of } \\
\text { disposing of unwanted medicines. }\end{array}$ & $139(35.6)$ & $183(46.9)$ & 21.3 & $<0.001^{*}$ \\
\hline 7 & $\begin{array}{l}\text { It is acceptable to dispose of } \\
\text { needles and syringes in the } \\
\text { garbage. }\end{array}$ & $304(77.9)$ & $339(86.9)$ & 15.2 & $<0.001^{*}$ \\
\hline 8 & $\begin{array}{l}\text { It is acceptable to return or } \\
\text { dispose of unused medicines to } \\
\text { a local pharmacy or healthcare } \\
\text { facility. }\end{array}$ & $327(83.8)$ & $358(91.8)$ & 8.5 & $0.003^{*}$ \\
\hline 9 & $\begin{array}{l}\text { It is acceptable to dispose of } \\
\text { pressurized metered-dose inhalers } \\
\text { (like a Ventolin inhaler) in the } \\
\text { garbage. }\end{array}$ & $74(19.0)$ & $185(47.4)$ & 7.9 & $0.005^{*}$ \\
\hline 10 & $\begin{array}{l}\text { It is acceptable to dispose of } \\
\text { creams and ointments in the } \\
\text { garbage. }\end{array}$ & $215(55.1)$ & $313(80.3)$ & 5.8 & $0.016^{*}$ \\
\hline & $\begin{array}{l}\text { Total knowledge score: median } \\
\text { (IQR) }\end{array}$ & $60.0(40.0-70.0)$ & $80.0(70.0-90.0)$ & -13.3 & $<0.001^{*}$ \\
\hline
\end{tabular}

Chi-square test was used for all categorical variables, Wilcoxon Signed-Rank test was used for all continuous variables; *statistically significant at $\mathrm{p}<0.05$

The overall attitude of participants did not change significantly from pre- to post-intervention (Table 3). However, a significant change occurred from pre- to post-intervention for items 11 ("It is my responsibility to protect the environment even if others are unconcerned or irresponsible"), 15 ("Media reports and campaigns can influence my willingness to return unused medicines"), 19 ("If I have paid for my prescribed medicines, I expect a refund when I return my unused medicines"), and 20 ("If I have excess medicines, I will share my medicines with others").
Similarly, the participants' overall practice did not change significantly from pre- to postintervention (Table 3). However, a significant change occurred from pre- to post-intervention for items 22 ("I dispose of my medicines when the medicines have expired"), 27 ("I have unused medicines because I do not feel better after I take them"), and 30 ("I keep medicines that I no longer require just in case I will need them in the future"). 
Table 2: Attitude and practice of participants regarding the return and disposal of unused medications preand post-intervention

\begin{tabular}{|c|c|c|c|c|c|c|}
\hline \multirow{2}{*}{ Domain } & \multirow{2}{*}{ Item } & \multicolumn{2}{|c|}{ Pre-intervention } & \multicolumn{2}{|c|}{ Post-intervention } & \multirow{2}{*}{$\begin{array}{c}\begin{array}{c}\text { Wilcoxon } \\
\text { Signed- Rank test }\end{array} \\
\text { p-value }\end{array}$} \\
\hline & & Mean \pm SD & $\begin{array}{c}\text { Median } \\
\text { (IQR) }\end{array}$ & Mean \pm SD & $\begin{array}{l}\text { Median } \\
\text { (IQR) }\end{array}$ & \\
\hline \multirow[t]{11}{*}{ Attitude } & $\begin{array}{l}\text { 11. It is my responsibility to } \\
\text { protect the environment even } \\
\text { if others are unconcerned or } \\
\text { irresponsible. }\end{array}$ & $4.3 \pm 0.8$ & $4.0(4.0-5.0)$ & $4.4 \pm 0.9$ & $5.0(4.0-5.0)$ & $0.023^{*}$ \\
\hline & $\begin{array}{l}\text { 12. It is my responsibility to } \\
\text { ensure the safety of other } \\
\text { living species on earth. }\end{array}$ & $4.4 \pm 0.8$ & $5.0(4.0-5.0)$ & $4.4 \pm 0.9$ & $5.0(4.0-5.0)$ & 0.110 \\
\hline & $\begin{array}{l}\text { 13. It is my responsibility to } \\
\text { protect my household } \\
\text { members from unintended } \\
\text { harmful exposure to unused } \\
\text { medicines. }\end{array}$ & $4.4 \pm 0.8$ & $5.0(4.0-5.0)$ & $4.5 \pm 0.8$ & $5.0(4.0-5.0)$ & 0.443 \\
\hline & $\begin{array}{l}\text { 14. If medicines are free or } \\
\text { heavily subsidized by the } \\
\text { government, I will not } \\
\text { collect all the prescribed } \\
\text { medicines even if I have } \\
\text { sufficient amounts of the } \\
\text { medicines at home.\# }\end{array}$ & $3.7 \pm 1.2$ & $2.0(1.0-3.0)$ & $3.8 \pm 1.2$ & $2.0(1.0-3.0)$ & 0.192 \\
\hline & $\begin{array}{l}\text { 15. Media reports and campaigns } \\
\text { can influence my willingness } \\
\text { to return unused medicines. }\end{array}$ & $4.0 \pm 1.0$ & $4.0(4.0-5.0)$ & $4.1 \pm 1.0$ & $4.0(4.0-5.0)$ & $0.009^{*}$ \\
\hline & $\begin{array}{l}\text { 16. I believe discarding unused } \\
\text { medicines that are still in } \\
\text { good condition is a waste of } \\
\text { resources. }\end{array}$ & $3.8 \pm 1.2$ & $4.0(3.0-5.0)$ & $3.8 \pm 1.2$ & $4.0(3.0-5.0)$ & 0.995 \\
\hline & $\begin{array}{l}\text { 17. I am willing to donate my } \\
\text { unused medicines before } \\
\text { expiry to reduce wastage. }\end{array}$ & $3.9 \pm 1.1$ & $4.0(4.0-5.0)$ & $3.8 \pm 1.2$ & $4.0(4.0-5.0)$ & 0.196 \\
\hline & $\begin{array}{l}\text { 18. If there is a monetary } \\
\text { incentive for me to return } \\
\text { unused medicines, I am } \\
\text { more likely to do so. }\end{array}$ & $3.6 \pm 1.2$ & $4.0(3.0-4.0)$ & $3.5 \pm 1.2$ & $4.0(3.0-4.0)$ & 0.190 \\
\hline & $\begin{array}{l}\text { 19. If I have paid for my } \\
\text { prescribed medicines, I } \\
\text { expect a refund when I } \\
\text { return my unused medicines. }\end{array}$ & $3.2 \pm 1.1$ & $3.0(2.0-4.0)$ & $3.2 \pm 1.2$ & $3.0(2.0-4.0)$ & $0.005^{*}$ \\
\hline & $\begin{array}{l}\text { 20. If I have excess medicines. I } \\
\text { will share my medicines with } \\
\text { others. }\end{array}$ & $2.8 \pm 1.3$ & $3.0(2.0-4.0)$ & $2.6 \pm 1.3$ & $2.0(1.8-4.0)$ & $0.006^{*}$ \\
\hline & Total score (\%) & $76.1 \pm 10.9$ & 76 (72.0-84.0) & $75.8 \pm 11.9$ & $76(72.0-82.0)$ & 0.764 \\
\hline
\end{tabular}

\begin{tabular}{|c|l|c|c|c|c|c|}
\hline \multirow{2}{*}{ Domain } & \multirow{2}{*}{ Item } & \multicolumn{2}{|c|}{ Pre-intervention } & \multicolumn{2}{c|}{ Post-intervention } & $\begin{array}{c}\text { Wilcoxon } \\
\text { Signed- Rank test }\end{array}$ \\
\cline { 2 - 7 } & Mean \pm SD & $\begin{array}{c}\text { Median } \\
\text { (IQR) }\end{array}$ & Mean \pm SD & $\begin{array}{c}\text { Median } \\
\text { (IQR) }\end{array}$ & p-value \\
\hline Practice & $\begin{array}{l}21 . \text { I have unused medicines } \\
\text { because I stop taking the } \\
\text { medicines when I feel better. }\end{array}$ & $3.3 \pm 1.2$ & $4.0(2.0-4.0)$ & $3.2 \pm 1.3$ & $4.0(2.0-4.0)$ & 0.061 \\
\hline $\begin{array}{l}\text { 22. I dispose my medicines when } \\
\text { the medicines have expired. }\end{array}$ & $3.7 \pm 1.2$ & $4.0(3.0-4.0)$ & $3.5 \pm 1.3$ & $4.0(2.0-4.0)$ & $0.001^{*}$ \\
\hline $\begin{array}{l}\text { 23. I have unused medicines } \\
\text { because I experience } \\
\text { unwanted side effects. }\end{array}$ & $3.2 \pm 1.1$ & $3.0(2.0-4.0)$ & $3.3 \pm 1.2$ & $4.0(2.0-4.0)$ & 0.141 \\
\hline $\begin{array}{l}24 . \text { I dispose my medicines when } \\
\text { I experience unwanted side } \\
\text { effects. }\end{array}$ & $3.0 \pm 1.2$ & $3.0(2.0-4.0)$ & $3.0 \pm 1.2$ & $3.0(2.0-4.0)$ & 0.840 \\
\hline $\begin{array}{l}25 . \text { I have unused medicines } \\
\text { because my doctor has } \\
\text { changed my treatment. }\end{array}$ & $3.3 \pm 1.1$ & $4.0(2.0-4.0)$ & $3.3 \pm 1.1$ & $4.0(2.0-4.0)$ & 0.899 \\
\hline
\end{tabular}




\begin{tabular}{|c|c|c|c|c|c|}
\hline $\begin{array}{l}\text { 26. I dispose my medicines when } \\
\text { they smell bad, taste bad or } \\
\text { look bad. }\end{array}$ & $3.5 \pm 1.3$ & $4.0(2.0-4.0)$ & $3.4 \pm 1.3$ & $4.0(2.0-4.0)$ & 0.473 \\
\hline $\begin{array}{l}\text { 27. I have unused medicines } \\
\text { because I do not feel better } \\
\text { after I take them. }\end{array}$ & $3.1 \pm 1.2$ & $3.0(2.0-4.0)$ & $3.2 \pm 1.2$ & $4.0(2.0-4.0)$ & $0.024^{*}$ \\
\hline $\begin{array}{l}\text { 28. I dispose my medicines } \\
\text { when I have not stored them } \\
\text { correctly and my medicines } \\
\text { turned bad. }\end{array}$ & $3.5 \pm 1.2$ & $4.0(3.0-4.0)$ & $3.4 \pm 1.2$ & $4.0(2.0-4.0)$ & 0.175 \\
\hline $\begin{array}{l}\text { 29. I have unused medicines } \\
\text { because I have not taken } \\
\text { the medicines as instructed/ } \\
\text { prescribed. }\end{array}$ & $2.9 \pm 1.2$ & $3.0(2.0-4.0)$ & $2.9 \pm 1.2$ & $3.0(2.0-4.0)$ & 0.813 \\
\hline $\begin{array}{l}30 . \text { I keep medicines that I no } \\
\text { longer require just in case I } \\
\text { need them in the future. }\end{array}$ & $3.2 \pm 1.2$ & $4.0(2.0-4.0)$ & $2.8 \pm 1.3$ & $2.0(2.0-4.0)$ & $<0.001^{*}$ \\
\hline \begin{tabular}{l} 
Total score (\%) \\
\hline
\end{tabular} & $65.4 \pm 14.8$ & $\begin{array}{c}68.0 \\
(58.0-76.0)\end{array}$ & $64.2 \pm 17.7$ & $(52.0-76.0)$ & 6.183 \\
\hline
\end{tabular}

* significantly significant at $\mathrm{p}<0.05$; \#This item was reversed scored as it was worded in a negative manner.

\section{Discussion}

Our study found that the knowledge of communitydwelling Malaysians improved immediately after a poster-based education session. However, no improvement was seen regarding their attitude and practice.

In this study, the participants' overall knowledge regarding the safe disposal of unused medications increased by $20 \%$ (from $60 \%$ to $80 \%$ ) after the Safe D.U.M.P. educational intervention. This outcome was not unexpected since the posters contained information that specifically addressed issues relating to the wastage of unused medications, along with the harm on the environment or public health caused by the inappropriate disposal of these unused medications. We were, however, unable to compare our findings with prior studies as no studies had previously assessed the effectiveness of an educational intervention on this topic. Although knowledge increased significantly in all items, postintervention knowledge was still poor for item 6 ("Incineration is the environmentally sound way of disposing of unwanted medicines") and 9 ("It is acceptable to dispose of pressurized metered-dose inhalers (like Ventolin inhaler) in the garbage"), with fewer than $50 \%$ of the participants providing the correct answer. This result may be due to the deeply ingrained knowledge that burning (i.e., incineration), in general, causes the release of toxic gases into the environment. However, burning in an incinerator is carried out under highly controlled conditions and at an extremely high temperature of $>1100^{\circ} \mathrm{C}$, which can destroy pathogens and toxins, rendering the medicinal waste nontoxic to the environment. ${ }^{13}$ Therefore, in the case of medication disposal, incineration is the more environmentally sound method compared to disposal in the garbage or sewage system, which in turn contaminates surface water, possibly poisoning aquatic or land animals and entering the food chain., ${ }^{9,15}$ Furthermore, pharmaceuticals that enter the environment through inappropriate disposal methods can also contribute to antibiotic resistance $e^{14,16}$ and affect the human endocrine system. ${ }^{17}$ However, for medicinal items such as pressurized metered-dose inhalers, incineration may potentially cause an explosion due to the presence of chlorofluorocarbons, which can also release toxic gases into the environment. Hence, throwing a pressurized inhaler into the garbage is the better option as opposed to incineration. ${ }^{18}$ Future educational sessions should apply more emphasis on improving knowledge in these two items.

Knowledge is known to have an impact on attitude formation. One study found that both benefit and risk knowledge either directly contributes to attitude formation or indirectly affects attitudes through the mediating roles of benefit and risk perceptions. ${ }^{19}$ Therefore, it is not surprising that certain attitude items (items 11, 15, and 20) showed a significant (albeit small) change. An individual who is more aware of the hazard unused medications can pose on the environment and on his/her own health has a greater likelihood of feeling more responsible toward his own actions (item 11), more willing to return unused medicines (item 15), and less likely to want to share his excess medicines with others (item 20).

Similarly, we expected to see some change in practice resulting from increased knowledge of the adverse impact of inappropriate disposal of unused medications on the environment, human health, and healthcare resources. ${ }^{20}$ Our study found that post-intervention, the participants agreed that they were less likely to dispose of their medicines that have expired (item 22) or to keep medicines they no longer required in case they might need them in the future (item 30). This change in practice can be 
important, as it could potentially reduce the risk of accidental poisoning of vulnerable persons, including children, older persons, or the cognitively/visually impaired person. However, as the post-intervention questionnaire was administered immediately after the viewing of Safe D.U.M.P. posters, the participants' responses on the practice domain could only be interpreted as "perceived future practice" in light of their newfound knowledge.

Even though a few of the attitude and practice items showed favorable changes, the participants' overall attitude and practice did not change significantly immediately after the Safe D.U.M.P educational session. This outcome is likely because it is more difficult to improve attitude and practice (when compared to knowledge) with a single educational session. Our findings were consistent with a previous study that reported that mailed educational leaflets failed to increase the practice of returning unused medications to health authorities for safe disposal. ${ }^{21}$ However, when a face-to-face interview and educational material were included and physical assistance was provided to collect unused medications, the researchers reported a high yield of households returning unused medications. ${ }^{21}$ Notwithstanding the improved outcome, such a labor-intensive intervention may not be sustainable in the long run. Another study found that patient counseling was associated with an increase in the proportion of patients returning unused medications to a pharmacy or healthcare provider.22 All these studies highlight the need for continuous education, repeated counseling, and practical incentives to effect a change in the attitude and practice of the public.

The strengths of this study included the use of a validated questionnaire to assess the KAP and the inclusion of a sufficiently large sample size. However, the weakness of our study was that participants were assessed immediately after their educational intervention. We are aware that the second questionnaire, administered immediately post-intervention, was not able to assess practice but instead may have only assessed perceived future practice. The ReDiUM should ideally be administered two weeks later to determine whether any sustained change in knowledge, attitude, and practice has occurred. Therefore, we were unable to assess the long-term benefits of the Safe D.U.M.P. We also acknowledge that although a statistically significant difference in several items was evident in the attitude and practice section, it is uncertain whether this outcome translates to a meaningful difference overall in the participants' attitude and practice.

\section{Conclusion}

The Safe D.U.M.P. educational intervention regarding the safe disposal of unused medications significantly increased participants' overall knowledge level. However, no improvement was seen regarding their overall attitude and practice. Further studies can be conducted to develop an intervention with the aim of effecting a sustained change in the KAP of patients in a clinical setting, pre- and post-intervention. The study findings may help policymakers design appropriate interventions or educational sessions to raise public awareness regarding the safe disposal of unused medications. Facilities and logistics would also have to be in place for a sustained return of unused medications for safe disposal.

\section{Acknowledgments}

We would like to thank Bee Cheng GOON and Soo Chin WOON for their assistance in data collection. Our thanks also go to all the participants who took part in our study.

\section{Conflicts of interest}

None

\section{Funding}

Funding for this study was obtained from the University of Malaya Living Lab Grant no. LL03016SUS.

\section{How does this paper make a difference to general practice?}

- Ideally, unused medications should be returned to authorized collectors for proper disposal to reduce releasing unwanted active pharmaceutical ingredients into the environment.

- However, most community-dwelling adults dispose of unused medications by throwing them away with normal garbage or by burning them.

- Safe D.U.M.P (which consists of six educational posters) improved the knowledge, attitude, and practice of community-dwelling adults toward the return and disposal of unused medications.

- General practitioners and other healthcare professionals can use Safe D.U.M.P. to educate patients on the proper return and disposal of medications. 


\section{References}

1. Pharmaceutical Services Division Ministry of Health. Return your medicines program. 2013 [cited 201712 Nov]; Available from: https:// www.pharmacy.gov.my/v2/en/content/returnyour-medicines-program.html.

2. Suppiah, V.L. Malaysia's MOH: Excess medicines to be returned to government healthcare institutions. 2016 [cited 201828 Oct]; Available from: https://today.mims.com/malaysia-smoh--excess-medicines-to-be-returned-togovernment-healthcare-institutions.

3. Ministry of Health Malaysia. KKM health facts. 2017; Available from: http://www.moh.gov. my/images/gallery/publications/HEALTH\%20 FACTS\%202017.pdf.

4. Wong, Y.Y., Sim, S.M., Lai, P.S.M., Tan, K.M., Lee, H.G., and Sulaiman, C.Z.S. Safe Disposal of Unused Medications-working towards a green pharmacy in the University Malaya Medical Centre (poster presentationP13) in Diabetes Asia 2018 Conference, 26-29 July. 2018. BCCK, Kuching, Sarawak, Malaysia.

5. Lee, H.G., Tan, K.M., Sim, S.M., Sulaiman, C.Z.S., Wong, Y.Y., and Lai, P.S.M. Unused medications return to the hospital pharmacy in Malaysian Congress of Geriatric Medicine, Hospital Sultanah Bahiyah, Alor Setar, Kedah. 2-4 August 2018.

6. Haughey, C.W., Lawson, D., Roberts, K., Santos, M., and Spinosa, S., Safe Medication Disposal. Home Health Now, 2019. 37(2): p. 106-110.

7. Al-Nagar, R.A. and Adel, A., Patients' opinion and practice regarding unused medication disposal in Malaysia: a qualitative study. Thai J Pharm Sci, 2010. 34(3): p. 117.
8. Azad, M.A.K., Ansary, M.R.H., Akhter, M.A., Al-Mamun, S.M., and Uddin, M., Disposal practice for unused medications among the students of the International Islamic University Malaysia. J Appl Pharm Sci, 2012. 2.

9. Bound, J.P. and Voulvoulis, N., Household disposal of pharmaceuticals as a pathway for aquatic contamination in the United Kingdom. Environ Health Perspect, 2005. 113(12): p. 1705-11.

10. Sorell, T.L., Approaches to the development of human health toxicity values for active pharmaceutical ingredients in the environment. AAPS J, 2016. 18(1): p. 92-101.

11. Rosner, B., Fundamentals of Biostatistics. 1995, Duxbury Press. p. 221.

12. Sim, S.M., Lai, P.S.M., Tan, K.M., Lee, H.G., and Sulaiman, C.Z., Development and validation of the Return and Disposal of Unused Medications questionnaire (ReDiUM) in Malaysia. Asia Pac J Public Health, 2018. 30(8): p. 737-749.

13. Medical Waste, C., Medical Waste Disposal. Air \& Waste, 1994. 44(10): p. 1176-1179.

14. Beirens, T.M.J., van Beeck, E.F., Dekker, R., Brug, J., and Raat, H., Unsafe storage of poisons in homes with toddlers. Accident Analysis \& Prevention, 2006. 38(4): p. 772-776.

15. Ruhoy, I.S. and Daughton, C.G., Beyond the medicine cabinet: an analysis of where and why medications accumulate. Environ Int, 2008. 34.

16. Costanzo, S.D., Murby, J., and Bates, J., Ecosystem response to antibiotics entering the aquatic environment. Mar Pollut Bull, 2005. 51.
17. Hon, K.L., Ho, J.K., Leung, T.F., Wong, Y., Nelson, E.A., and Fok, T.F., Review of children hospitalised for ingestion and poisoning at a tertiary centre. Ann Acad Med Singapore, 2005. 34(5): p. 356-61.

18. Hassan, W.U., Henderson, A.F., and Keaney, N.P., Disposal of used metered dose inhalers. BMJ, 1992. 305(6851): p. 479-479.

19. Zhu, X. and Xie, X., Effects of Knowledge on Attitude Formation and Change Toward Genetically Modified Foods. Risk Analysis, 2015. 35(5): p. 790-810.

20. Beach, D.J., Professional knowledge and its impact on nursing practice. Nurse Education in Practice, 2002. 2(2): p. 80-86.

21. Abahussain, E.A. and Ball, D.E., Disposal of unwanted medicines from households in Kuwait. Pharm World Sci, 2007. 29.

22. Seehusen, D.A. and Edwards, J., Patient practices and beliefs concerning disposal of medications. J Am Board Fam Med, 2006. 19(6): p. 542-7. 


\title{
Development and validation of the maternal blues scale through bonding attachments in predicting postpartum blues
}

\author{
Suryani Manurung, S. Setyowati
}

Manurung S, Setyowati S. Development and Validation of the Maternal Blues Scale Through Bonding Attachments in Predicting Postpartum Blues. Malays Fam Physician. 2021;16(1);64-74. https://doi.org/10.51866/oa1037

\section{Keywords:}

Questionnaire development,

postpartum blues, internal

and external indicators,

Indonesia

\section{Authors:}

\section{S. Setyowati}

(Corresponding author)

Professor

Maternity Nursing Department

Faculty of Nursing Universitas

Indonesia

Email: wati123@ui.ac.id

\section{Suryani Manurung}

Lecturer

Maternity Nursing Department

Health Polytechnic Jakarta I

Indonesia

\section{Abstract}

Background: Postpartum blues in Indonesia has a high prevalence at 37\% to 67\%. Postpartum blues syndrome has been described as varying changes in the affective domain, such as feelings, behavior, or thoughts, that can be influenced by the roles and tasks of women, along with their social, cultural, and economic support. Instruments that measure maternal blues through bonding attachment behavior have never before been developed in Indonesia.

Objective: This study aimed to develop a maternal blues scale through bonding attachments to predict postpartum blues.

Method: The research design consisted of three stages: 1) phenomenology design and focus group discussion; 2) development and construction of the maternal blues scale, and 3) a cross-sectional study to measure validation of the scales. Respondents were postpartum mothers in the first week after birth. The sample comprised 501 participants. Sampling was done by consecutive sampling at the Public Health Center (PUSKESMAS) in the South Jakarta area. Data analysis used exploratory factor analysis (EFA) and confirmatory factor analysis (CFA), correlation, and a diagnostic testing .

Results: Item analysis produced 32 items consisting of 24 items regarding the mother's role and duties as internal factors and eight factors involving social, cultural, and economic support as external factors. Both factors were valid and reliable in predicting postpartum blues with indicators ( $\mathrm{t}$ loading factors $\geq 1.96$, standardized loading factor $(\mathrm{SLF}) \geq .50$, internal factors: construct reliability $(\mathrm{CR}) \geq .70$ and extraction variants $(\mathrm{VE}) \geq .50$ and external factors: $\mathrm{CR} \geq .74$ to $.83 \mathrm{VE} \geq .50$ to .63$)$. The relationship with Kennerley's maternity blues as a gold standard was significant. Internal factors had a score of 53 , with a sensitivity of $60.2 \%$. The external factors score was 19 , with a sensitivity of $77.3 \%$.

Conclusion: The new scale for postpartum blues prediction developed displayed internal consistency and validity of each indicator (internal and external factors) that was good ( $\mathrm{CR} \geq .70$; VE $\geq .50$ ). This scale provides a feasible tool to predict postpartum blues.

\section{Introduction}

Depression, a change in the affective domain that describes mental and emotional conditions, most often occurs in general population especially during postpartum period. ${ }^{1}$ Changes in mental and emotional conditions take place from an early phase after birth (postpartum blues) and put mothers at risk of beginning in the early stage with post partum blues and progressing with time to post partum depression and psychosis. ${ }^{2} 80 \%$ of new mothers experience postpartum blues, and $10-15 \%$ of those cases progress to postpartum depression. ${ }^{1}$ The prevalence of postpartum blues in Indonesia is quite high, at $37 \%$ to $67 \%$. $^{3,4}$ Postpartum blues are likely to be predictors of postpartum depression by $15 \%$ to $20 \%{ }^{1}$ The progression of postpartum blues to major depression must be prevented due to the risk that mothers might become triggered to engage in self-injury, suicide, or abandoning their babies. $^{5}$

Depressive symptoms are found in most of the postpartum women that describe changes in the affective domain and may vary from person to person in such areas as feelings, behavior, and thoughts, from mild to severe intensity. ${ }^{6}$ This syndrome takes place during the transition phase in the perinatal period. Changes in affective domains may worsen, for example, displayed in such reactions as disliking pregnancy and the birth of the baby or patterns of maternal interaction with infants. ${ }^{7-9}$ Previous researchers have also suggested that postpartum depression is related to the affective domain of bonding attachments. This concept was tested on the maternal postnatal attachment scale (MPAS) 
scale and Edinburgh postnatal depression scale (EPDS) scale, revealing a correlation between both postpartum depression and bonding attachments. ${ }^{10,11}$

Based on a literature review and previous research, several factors emerged that influence postpartum depression and the failure of bonding attachments, including roles and tasks as mothers during the transition phase as well as social, cultural, and economic support. ${ }^{12,13}$ Symptoms of postnatal depression include the inability to carry out mothering tasks, becoming angry with continuing tasks, poor self care, and finding a mother's work burdensome. ${ }^{14,15}$

Cultural tradition was another factor that some researchers found could trigger depression and bonding attachment failure. ${ }^{16}$ Local community and family values that prioritize one sex of children over the other can significantly trigger domestic violence and influence behavior involving rejecting the presence of babies. ${ }^{17}$ Other traditional behaviors in caring for mothers after childbirth include restricted activities, staying at home for a month, or forbidding certain foods. Such restrictions can exert an influence on mothers' emotions, especially in terms of interacting with their baby, causing them to blame the baby for such restrictions. ${ }^{16}$

Economic factors (especially family income) have been found to relate to depressive symptoms and bonding attachment failure. ${ }^{18}$ Economic status can cause low interest or desire to interact with infants and increased stress. ${ }^{18,19}$ The results of the literature review illustrate that postpartum blues can be detected through the affective domain in observing mothers' interactions with their infants (bonding attachment). ${ }^{1,6}$ Studies investigating postpartum blues have previously been carried out using a scale developed by Pitt, Stein, and Kennerley. ${ }^{20}$ The measuring instrument was originally developed in a different culture from that in Indonesia, based on factors such as depression, anxiety, somatic abnormalities, and personality to describe the condition of the affective domain in measuring postpartum blues.

This study aimed to develop a maternal blues scale related to the affective domain in interacting with infants (bonding attachment) to predict postpartum blues. Measuring instruments were developed based on factors involving mothers' roles and tasks along with social, cultural, and economic support in accordance with Indonesian culture. The scale was validated to measure its validity and reliability in predicting postpartum blues. The purpose of developing this scale measuring maternal blues through the affective domain of interacting with infants (bonding attachment) was to maximize maternal care and infant welfare. $^{1}$

\section{Methods}

\section{Research design}

The study design consisted of three stages. Stage one used a qualitative method, a phenomenology design that employed indepth interviews and focus group discussion. ${ }^{16}$ The study population included pregnant women and women who had already experienced motherhood in Depok Sawangan West Java and the South Tanggerang District. Stage two involved constructing the maternal blues scale through the affective domain of interacting with infants (bonding attachment), which was carried out through an item generation process that reflected information gathered in the previous qualitative study. Item generation produced 65 items in the form of statements, developed from the factors of mothers' roles and duties as well as social, cultural, and economic support.

Stage three was a cross-sectional study designed to validate the scales. ${ }^{21}$ The development and validation processes included the following steps: 1$)$ assessing the validity and reliability of 65 items from the draft item statement on the factors of mothers' roles and duties and social, cultural, and economic support; 2) assessing the validity and reliability of maternal roles and tasks as well as social, cultural, and economic support for the postpartum blues construct; 3) conducting parallel tests between the maternal blues scale based on Kennerley's maternity blues 3) measuring the sensitivity of the developed maternal blues scale in predicting postpartum blues.

The following flowchart illustrates the research process used to develop the postpartum blues scale. 


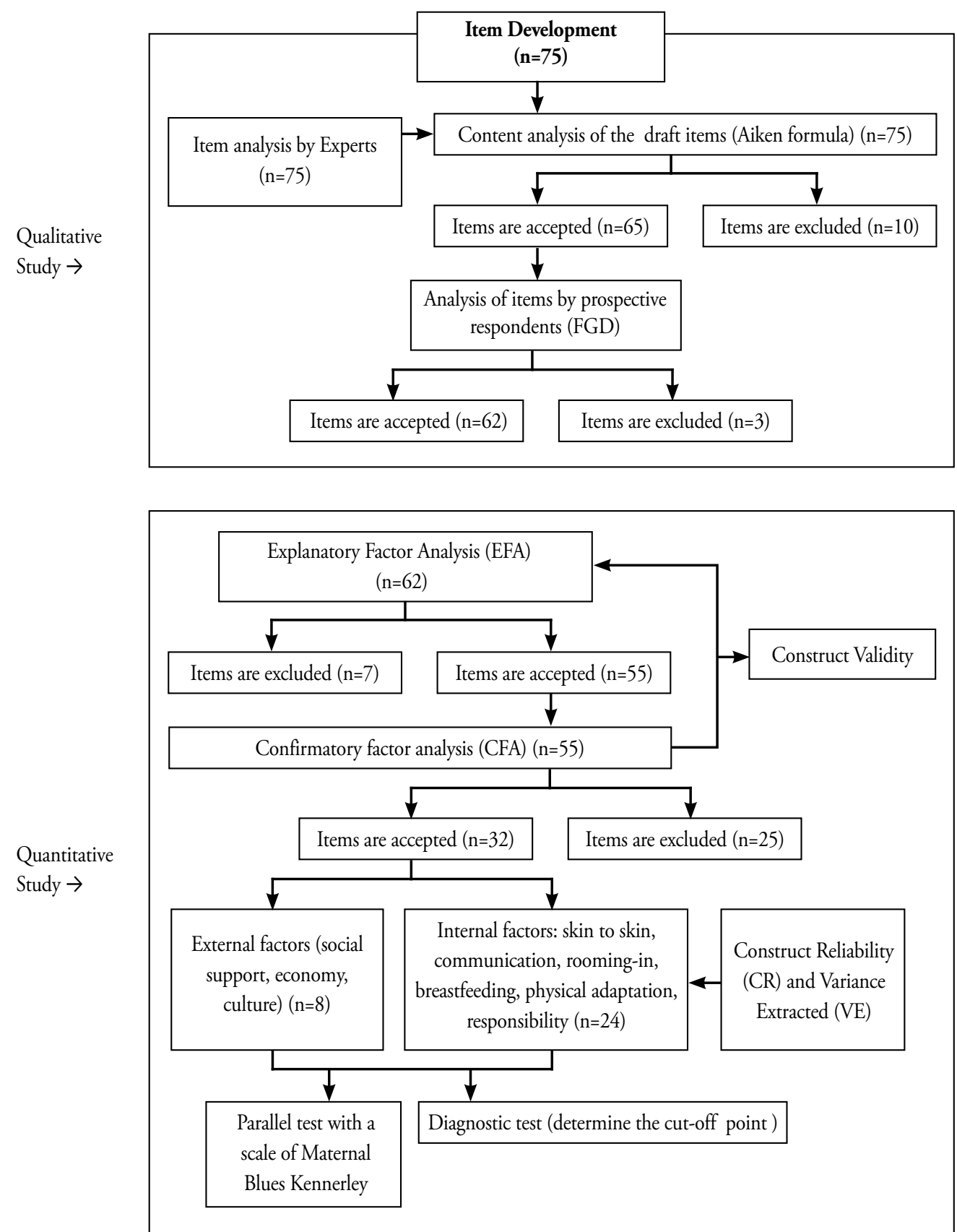

Figure 1: Flowchart of the process of developing the maternal blues scale.

\section{Setting and sample}

The study was conducted in five public health centers (Puskesmas) in South Jakarta that had a relatively high delivery rate ( \pm 50 deliveries/ month). Randomly selected Puskesmas were Jagakarsa, Pasar Minggu, Tebet, Cilandak Barat, and Kebayoran Lama. Data collection used the maternal blues scale questionnaire and Kennerley's maternity blues scale, which was translated into Indonesia. Data were gathered by data collectors in each Puskesmas from January to June 2017. Data collectors were trained and familirized with the new maternal blues scale and Kennerley maternity blues scale questionnaires. Parallel tests was conducted on the maternal blues scale and were constructed with the Kennerley model's maternal blues scale. This test is to see the correlation of the two scales in measuring postpartum blues. The results obtained illustrate the two scales have a significant relationship $(\mathrm{P}<.01)$. This data illustrates that the two scales represent the same data. Correlation of two scales was significant (.30). The magnitude of the correlation reflects the difference between the two scales in showing the occurrence of postpartum blues. The maternal blues scale that is constructed describes the affective domain in interacting with infants (bonding attachment) while 
the Kennerley model's maternal blues scale describes the condition of the affective domain.

Then a correlation test was conducted between internal factors: the role and task of mothers with external factors, namely supporting sources: culture, social and economic support from the maternal blues scale that was built. The results obtained that these two factors have a significant relationship $(\mathrm{P}<.01)$. The correlation between internal and external factors is strong (>.6).

The new maternal blues scale draft questionnaire was designed as a Likert scale with positive and negative statements. The answer options included very appropriate, appropriate, ordinary, inappropriate, and very inappropriate.

The participants in the study sample came from the postpartum maternal population. The sample inclusion criteria included normal labor, live birth, and no complications after childbirth. Sampling was carried out using a consecutive sampling technique. Study participants selected in accordance with the inclusion criteria numbered 501 mothers.

\section{Data collection and analysis}

Data were obtained from participants who were in the health center, in a ward postpartum, or who came in for a checkup on the fifth or seventh day postpartum. Data collection was done one time using one measurement. The data were processed using several measurement methods to produce fix items that were formulated to predict postpartum blues. The software packages used to analyze the data were the Lisrel program (2006) and SPSS version 19.

The selection of the maternal blues scale items was carried out by analysis of structural equation modeling (SEM). The initial analysis involved exploratory factor analysis (EFA), which tested the feasibility of the draft item as part of the initial modeling. Confirmatory factor analysis (CFA) was used to match the item (goodness of fit) based on the value of validity and reliability to predict postpartum blues. Some indicators of validity and reliability included $t$ value, standardized loading factor (SLE), extracted variance (VE), and construct reliability (CR). ${ }^{22}$

Parallel test analysis compared the maternal blues scale with Kennerley's maternity blues scale model. The comparison between the two measuring instruments was analyzed to arrive at a tool that could predict postpartum blues. ${ }^{23}$

The new maternal postpartum blues scale has been developed as a screening tool. The sensitivity tests were carried out by using the receiver operating characteristic (ROC) method. ${ }^{23}$

\section{Principles of Ethics}

The ethical principle applied during the research was the principle of beneficence, which involves respect for human dignity and justice. Before the questionnaire was distributed to the participants, informed consent was obtained by providing information about the research activities, followed by signing the agreement. Participants were given the opportunity to refuse or indicate their willingness to participate. The research activities satisfied ethical requirements and received approval from the ethics committee of the Faculty of Nursing University of Indonesia.

\section{Results}

Respondents selected in accordance with the inclusion criteria numbered 501 people. The number of respondents who were surveyed in the process of developing the scale has been fulfilled according to the criteria. The respondents completed filling out the draft scale of the maternal blues questionnaire with 65 items in the form of statements and the maternity blues scale from Kennerley's model. The average age of respondents was $28.98 \pm$ SD 5.98 years (aged between 16 to 46 years). The minimum number of maternal parity was one, and the maximum was seven children.

\section{Item analysis}

Preliminary modeling was carried out using due diligence with EFA analysis. The item statements selected in the initial modeling included 54 items, consisting of groups: maternal role and task factors (41 items), social support (six items), and culture and economy (seven items). The indicator criteria of the results of the feasibility test produced included the value of the Bartlett test of sphericity with a chi-square with p-value $<.001$. This indicator reveals a significant correlation between the observed variables. The value of Kaiser-MeyerOlkin (KMO) was equal to .908 with a p-value 
$<.05$; internal consistency (Alpha Cronbach's was .45 to .91). Based on the above indicators, 54 statement items were feasible for a model match test with CFA analysis.

The model suitability measurement for the 54 items aimed to measure the validity and reliability of 1) the relationship between item with factors of mothers' roles and tasks, along with social, cultural, and economic support and 2) the relationship between the factors of mothers' roles and tasks as well as social, cultural and economic support and the postpartum blues construct. The results of the model suitability measurements on the 54 items indicated seven factors, with 32 items having statements suitable for describing postpartum blues. Analysis of the seven factors in the 32 statement items is shown in Tables $\mathbf{1}$ to 3 .

Table 1: Measurement of Items Statement of Internal Factors: Role and Tasks of Mother in Interacting with Infants (Bonding Attachment) to Predict Postpartum Blues ( $\mathrm{n}=501)$.

\begin{tabular}{|c|c|c|c|c|c|}
\hline $\begin{array}{l}\text { Latent variable } \\
\text { Mother's roles } \\
\text { and duties }\end{array}$ & $\begin{array}{l}\text { Indicator variable (item statement) } \\
\text { and item statement number }\end{array}$ & $\begin{array}{l}\text { Standardized } \\
\text { Loading Factor } \\
\text { (SLF) } \geq \mathbf{0 . 5 0}\end{array}$ & $\begin{array}{c}T \\
\text { value }\end{array}$ & $\begin{array}{l}\mathrm{CR} \geq \\
0.70\end{array}$ & $\begin{array}{l}\mathrm{VE} \geq \\
0.50\end{array}$ \\
\hline \multirow{10}{*}{$\begin{array}{l}\text { F1: } \\
\text { skin to skin, } \\
\text { communication, } \\
\text { rooming in }\end{array}$} & Happy when in contact with baby's skin (4). & .74 & 15.3 & \multirow{10}{*}{.95} & \multirow{10}{*}{.61} \\
\hline & Happy when I see baby comfortable when hugged (3). & .70 & 9.9 & & \\
\hline & $\begin{array}{l}\text { Happy when baby found comforted by hearing my } \\
\text { voice (6). }\end{array}$ & .74 & 10.29 & & \\
\hline & Happy when the baby is in my arms (9). & .75 & 10.23 & & \\
\hline & Pray for baby's health (7). & .69 & 9.94 & & \\
\hline & Happy when baby with me all day (20). & .71 & 10.00 & & \\
\hline & Tired of giving birth lost when hugging a baby (1). & .48 & 15.38 & & \\
\hline & Families give confidence to care for babies (56). & .63 & 9.44 & & \\
\hline & Feels convenient to talk with my baby (44). & .62 & 9.37 & & \\
\hline & I feel that caring for a baby all day is a burden (23). & .64 & 9.55 & & \\
\hline \multirow{8}{*}{$\begin{array}{l}\text { F2: } \\
\text { breastfeeding }\end{array}$} & Tired of nursing their baby (14). & .71 & 11.06 & \multirow{8}{*}{.87} & \multirow{8}{*}{.50} \\
\hline & Hate because of time wasted on breastfeeding (17). & .72 & 11.13 & & \\
\hline & $\begin{array}{l}\text { Hate because the baby does not want to stop } \\
\text { breastfeeding (19). }\end{array}$ & .66 & 10.66 & & \\
\hline & Tired of caring for babies throughout the day (21). & .73 & 11.24 & & \\
\hline & Breastfeeding a baby for a long time is fun (18). & .67 & 10.13 & & \\
\hline & Baby presence interferes with family needs (50). & .66 & 10.59 & & \\
\hline & Whenever I give breastfeed, I do it happily (15). & .63 & 9.51 & & \\
\hline & Hope the baby does not interfere while resting (10). & .53 & 15.04 & & \\
\hline \multirow{3}{*}{$\begin{array}{l}\text { F3: } \\
\text { physical } \\
\text { adaptation }\end{array}$} & $\begin{array}{l}\text { Worried, my husband doesn't accept my body changes } \\
\text { (34). }\end{array}$ & .75 & 15.49 & \multirow{3}{*}{.81} & \multirow{3}{*}{.50} \\
\hline & $\begin{array}{l}\text { Hate heart because I don't have time to take care of } \\
\text { myself (32). }\end{array}$ & .74 & 12.16 & & \\
\hline & I stress doing family advice in caring for babies (35). & .76 & 13.04 & & \\
\hline \multirow{3}{*}{$\begin{array}{l}\text { F4: } \\
\text { responsibility }\end{array}$} & Worried, I can't take care of the baby. (27) & .50 & 7.86 & \multirow{3}{*}{.65} & \multirow{3}{*}{.69} \\
\hline & I cry every time the baby cries (26). & .58 & 12.41 & & \\
\hline & Worried about a mother's resposibilities (30). & .67 & 9.02 & & \\
\hline
\end{tabular}

Table 1 illustrates the compatibility of internal factor models for predicting postpartum blues. Confirmatory analysis produced 24 items suitable for predicting postpartum blues through the affective domain (feelings, attitudes, and behaviors through the role and tasks of the mother in interacting with the baby). The item was developed from six factors: skin-to-skin contact, rooming in, communication, breastfeeding, physical adaptation, and responsibility. 
Table 2: Measurement of Statement Item External factors: Culture, Social Support, Economic for Predicting Postpartum Blues $(\mathrm{n}=501)$

\begin{tabular}{|c|c|c|c|c|c|}
\hline $\begin{array}{l}\text { Supporting } \\
\text { Resources: culture, } \\
\text { social support, } \\
\text { economy }\end{array}$ & $\begin{array}{l}\text { Indicator variable (item statement) } \\
\text { and item statement number }\end{array}$ & $\begin{array}{l}\text { Standardized } \\
\text { Loading Factor } \\
(\mathbf{S L F}) \geq \mathbf{0 . 5 0}\end{array}$ & $\begin{array}{c}T \\
\text { value }\end{array}$ & $\begin{array}{l}\mathrm{CR} \geq \\
0.70\end{array}$ & $\begin{array}{l}\mathrm{VE} \geq \\
0.50\end{array}$ \\
\hline \multirow{3}{*}{$\begin{array}{l}\text { F5: } \\
\text { Culture } \\
\text { (family acceptance) }\end{array}$} & $\begin{array}{l}\text { Worried when my baby care does not match the } \\
\text { family's expectations (37). }\end{array}$ & .73 & 10.75 & \multirow{3}{*}{.74} & \multirow{3}{*}{.50} \\
\hline & $\begin{array}{l}\text { Sad if family doubts my ability to take care of a } \\
\text { baby (36). }\end{array}$ & .71 & 10.68 & & \\
\hline & $\begin{array}{l}\text { Worried if the baby is not in line with family } \\
\text { expectations (11). }\end{array}$ & .58 & 13.33 & & \\
\hline \multirow{3}{*}{$\begin{array}{l}\text { F7: } \\
\text { Economic factors } \\
\text { (Informational and } \\
\text { economic supports) }\end{array}$} & $\begin{array}{l}\text { I feel a heavy burden carrying out parental advice } \\
\text { in caring for babies ( } 53) \text {. }\end{array}$ & .74 & 13.04 & \multirow{3}{*}{.83} & \multirow{3}{*}{.63} \\
\hline & $\begin{array}{l}\text { I am stressed when parents advise about caring } \\
\text { for babies ( } 52) \text {. }\end{array}$ & .84 & 14.09 & & \\
\hline & $\begin{array}{l}\text { I feel stressed with the current economic } \\
\text { conditions (51). }\end{array}$ & .62 & 14.26 & & \\
\hline \multirow{2}{*}{$\begin{array}{l}\text { F8: } \\
\text { Social Support } \\
\text { (Emotional and } \\
\text { appraisal support) }\end{array}$} & $\begin{array}{l}\text { My weakness in caring for a baby by mother } \\
\text { in-laws (58). }\end{array}$ & .57 & 6.54 & \multirow{2}{*}{.50} & \multirow{2}{*}{.30} \\
\hline & Confident in caring for babies (57). & .50 & 7.73 & & \\
\hline
\end{tabular}

Table 2 illustrates the compatibility of the external factor models to predict postpartum blues.

Table 3: Compatibility Test of Statement Items Internal and External Factors in Predicting Postpartum Blues $(\mathrm{n}=501)$.

\begin{tabular}{|c|c|c|c|c|c|}
\hline Variable & $\begin{array}{c}\text { Variable Indicators } \\
\text { (Internal and External Factors) }\end{array}$ & $\begin{array}{l}\text { Standardized } \\
\text { Loading Factor } \\
(\mathbf{S L F}) \geq \mathbf{0 . 5 0}\end{array}$ & $\begin{array}{c}T \\
\text { value }\end{array}$ & $\begin{array}{l}\mathrm{CR} \geq \\
0.70\end{array}$ & $\begin{array}{l}\mathrm{VE} \geq \\
0.50\end{array}$ \\
\hline \multirow{9}{*}{ Postpartum blues } & Internal factor (Mother's role and tasks) & & & \multirow{9}{*}{.92} & \multirow{9}{*}{.62} \\
\hline & F1 (skin to skin, communication, rooming in) & .72 & 9.46 & & \\
\hline & F2 (Breastfeeding) & .89 & 11.44 & & \\
\hline & F3 (Physical adaptation) & .85 & 15.53 & & \\
\hline & F4 (Responsiveness) & .70 & 9.03 & & \\
\hline & External factor (culture, social, economic support) & & & & \\
\hline & F5 (family acceptance) & .70 & 10.16 & & \\
\hline & F7 (informational and economic) & .91 & 13.44 & & \\
\hline & F8 (emotional and appraisal) & .72 & 10.56 & & \\
\hline
\end{tabular}

Table 3 displays internal and external factors. Statement items from internal and external factors were combined and analyzed again in predicting postpartum blues. Conformity test results of the statement items of the two factors were declared valid and can be relied upon to predict postpartum blues with criteria indicators (standard loading values .50, t values 1.96, CR .70, and VE .50).

Based on the degree of suitability of the model with absolute measure and incremental fit measure, 32 items were declared suitable in describing empirical data of postpartum blues. The results of the measurement of the model's suitability with the indicator criteria (absolute measure value: $\mathrm{RMSEA}=.074$ (good fit), GFI .80 (marginal match), and incremental fit measure $(\mathrm{NFI}=.93($ good match); NNFI $=$. $94(\operatorname{good}$ fit $)$, and CFI $=.89($ marginal fit $))$.
The results of the analysis of the statements in each of the items indicate that social, emotional, and appraisal support were not reliable but when in the analysis of all items obtained reliable and valid (values .50 , $\mathrm{t}$ values 1.96, CR .70, and VE .50). This outcome indicated mothers' failure to interact with their babies (bonding attachment). 


\section{Parallel test}

Parallel tests were conducted on the maternal blues scale constructed using the Kennerley model's maternity blues scale. This test aimed to determine the correlation between the two scales in measuring postpartum blues. The results obtained demonstrated that the two scales have a significant relationship ( $\mathrm{P}$ $<.01$, illustrating that the two scales represent the same data. The correlation between the two scales was .30. The magnitude of the correlation reflects the difference between the two scales in showing the occurrence of postpartum blues. The maternal blues scale that was constructed describes the affective domain in interacting with infants (bonding attachment), while the Kennerley model's maternity blues scale describes the condition of the affective domain with a coefficient of 0.85 (72-84 items), which is parallel with the new maternal blues scale ( 54 items) having a total value of items according to Cronbach's alpha as follows: F1: 0.882, F2:0.854, F3: 0.796, F4: 0.621, F5: 0.701, F5: 0,754, F8: 0.5.

Next, a correlation test was conducted between internal factors (the role and tasks of mothers) and external factors (i.e., supporting sources including cultural, social, and economic support) from the maternal blues scale that was developed. The results revealed that these two factors have a significant relationship $(\mathrm{P}<.01)$. The correlation between internal and external factors is strong (>.6).

\section{Diagnostic test}

This measurement was carried out on internal and external factors from the maternal blues scale that was developed. This measurement aimed to identify the presence of postpartum blues. It can also serve as a screening tool for predicting postpartum blues, as shown in Figures $\mathbf{2}$ and $\mathbf{3}$.

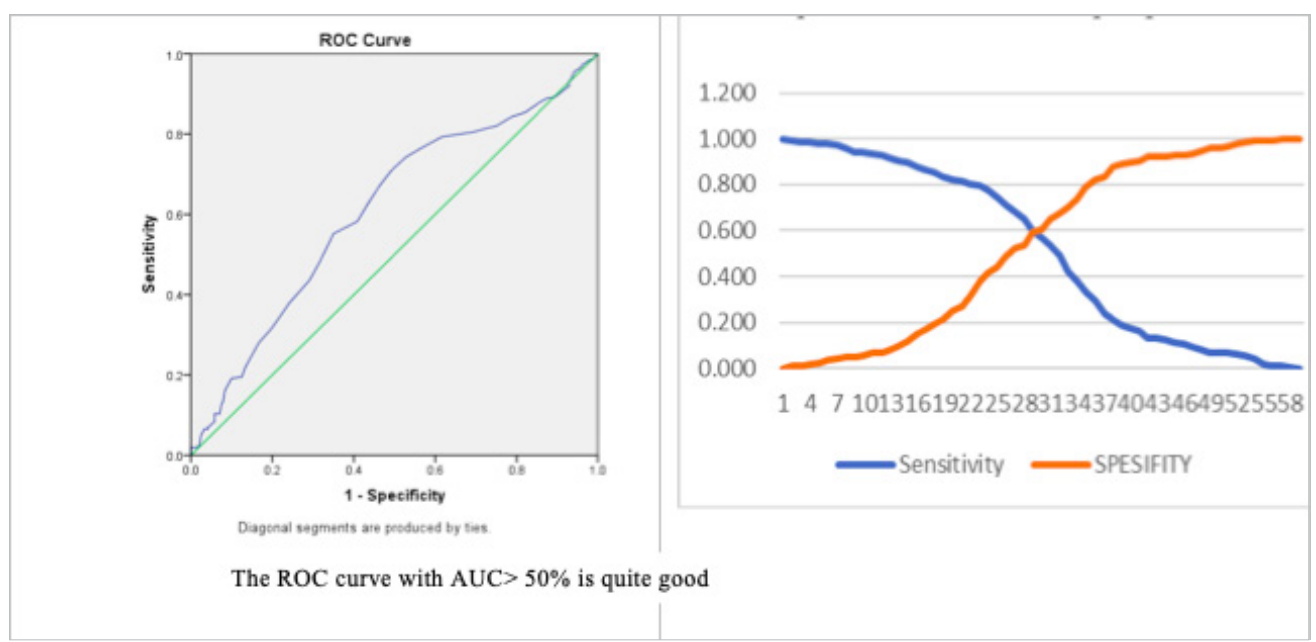

Figure 2: The Sensitivity and Specificity of Internal Factors Maternal Blues Scale

Figure 2 shows the results of the measurement of diagnostic tests on internal factors of the maternal blues scale. The Area Under the Curve (AUC) value is 61\% (95\% CI $55.7 \%-65.6 \%) \mathrm{p}<.05$. Based on confidence intervals, internal factors (the role and tasks of the mother) can predict the incidence of postpartum blues around $55.7 \%$ to $65.6 \%$ accuracy. The maternal blues scale that was developed could predict postpartum blues of $61 \%$ of 100 postpartum maternal population. Based on the intersection of the sensitivity and specificity curve, the internal factor score obtained in predicting postpartum blues was 53 , with a sensitivity of $60.2 \%$.

Figure 3 shows the results of the measurement of diagnostic tests for external factors from the maternal blues scale that was developed. The Area Under the Curve (AUC) value is 76.9\% (95\% CI 72.9-80.9\%) p <0.05. Based on confidence intervals, external factors (supporting sources including culture, social, and economic support) can predict postpartum blues events around $72.9 \%$ to $80.9 \%$ accuracy. The maternal blues scale that was developed could predict postpartum blues of 100 postpartum maternal population by $76.9 \%$ accuracy. The intersection of the sensitivity and specificity curves yielded an external factor score of 19 with a sensitivity of $77.3 \%$. Thus, the external factors described the risk factors for the occurrence of postpartum blues. 


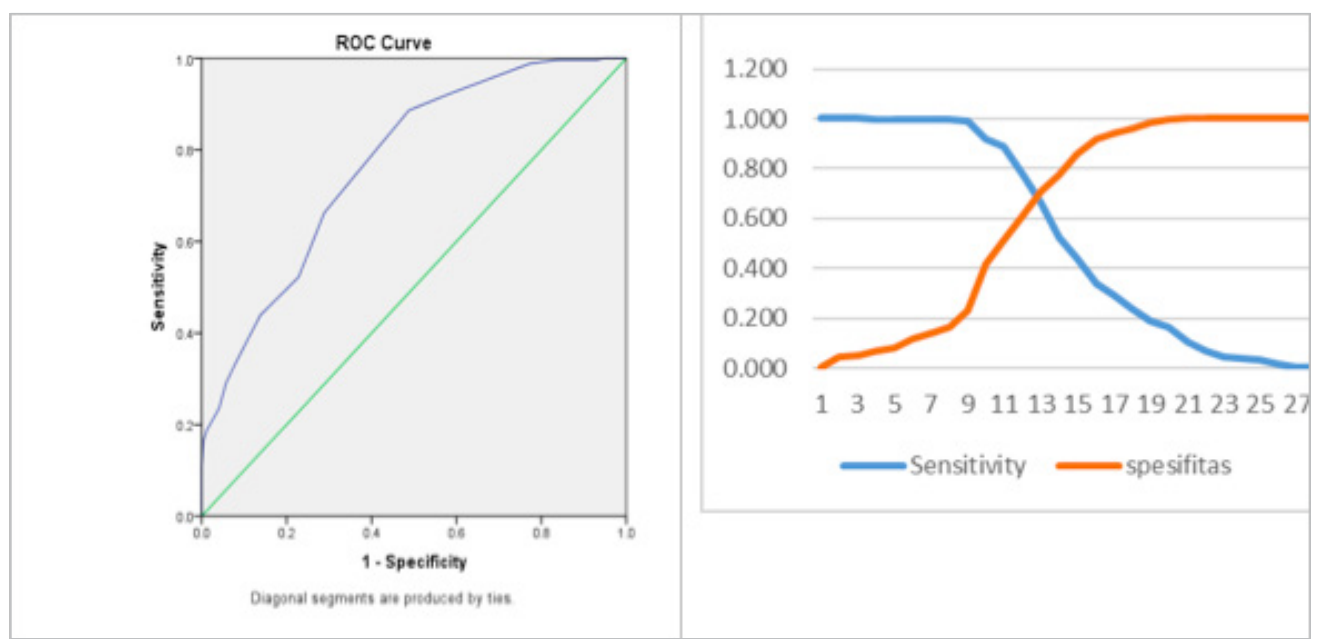

The ROC curve with AUC> $50 \%$ is quite good

ROC: receiver operating characteristic; AUC: area under the curve

Figure 3: Sensitivity and Specificity of External Factors Maternal Blues Scale

Table 4. The Comparison between Suryani's Model Instrument to Kennerley's Model in Measuring the Maternal Blues Scale $(n=120)$

\begin{tabular}{|c|c|c|c|c|c|}
\hline \multirow{2}{*}{$\begin{array}{l}\text { Suryani's Maternal } \\
\text { Blues Scale }\end{array}$} & \multicolumn{2}{|c|}{ Kennerley's Maternity Blues Scale } & \multirow{2}{*}{$\mathbf{p}$} & \multirow{2}{*}{ OR } & \multirow{2}{*}{ IC $95 \%$} \\
\hline & Blues & No Blues & & & \\
\hline Blues & $\begin{array}{c}51 \\
94.4 \%\end{array}$ & $\begin{array}{c}46 \\
69.7 \%\end{array}$ & \multirow{2}{*}{0.001} & \multirow{2}{*}{7.391} & \multirow{2}{*}{ 2.061-26.511 } \\
\hline No Blues & $\begin{array}{c}3 \\
5.6 \%\end{array}$ & $\begin{array}{c}20 \\
30.3 \%\end{array}$ & & & \\
\hline
\end{tabular}

$\mathrm{p}:<0.05$

According to Kennerly's maternity blues scale, all respondents who displayed maternal blues (94.4\%) also showed maternal blues when using Suryani's maternal blues scale. In comparison, of all respondents who were not characterized as having postpartum blues using Kennerly's maternity blues scale, 69.7\% were found to have the blues when using Suryani's maternal blues scale. These findings reveal a significant correlation between Kennerly's maternity blues scale and Suryani's maternal blues scale (.001). Suryani's maternal blues scale has a 7.391 times greater chance of finding maternal blues cases than Kennerly's maternity blues scale.

The diagnostic test value is: Sensitivity: a: $(\mathrm{a}+\mathrm{c})=51 / 54=0.94$;

Specificity: d: $(b+d)=20 / 66=0.30$, Positive predictive value $(\mathrm{PPV}): \mathrm{a}:(\mathrm{a}+\mathrm{b})=51 / 97=0.52$ Negative predictive value $(\mathrm{NPV}): \mathrm{d}:(\mathrm{c}+\mathrm{d})=$ $20 / 23=0.86$.

Likelihood ratio positive $(\mathrm{LR}+)=$ Sensitivity: $(1-$ Specificity $)=0.94 / 0,7=1.34$

Likelihood ratio negative (LR-) = (1-Sensitivity): Specificity $=0.06 / 0.30=0.2$.

\section{Discussion}

This study produced a maternal blues scale that measures postpartum attachment bonding to predict postpartum blues. The result of study identified 32 items that are valid and reliable in describing the affective state of postpartum blues through bonding attachment. The study also identified factors related to postpartum blues, both internal (maternal roles and tasks) and external (supporting sources in terms of culture, social, and economic support). Both subscales (internal and external factors) were used as a whole in this maternal blues scale, but the analysis process was done separately.

The roles and duties of mothers that are expressed as internal factors can describe the affective domain conditions of postpartum blues in terms of skin-to-skin contact, rooming in, breastfeeding, physical adaptation, and responsibility. The use of the compatibility of the mother's role and task factors through postpartum bonding 
attachment behavior to predict postpartum blues is in accordance with previous research. Bonding attachment in the postpartum period begins at birth through skin-toskin contact, breastfeeding, rooming in, and communication. ${ }^{24}$ Maigun Edhborg, Nasreen, and Kabir (2011) observed that depression inhibited the mother's interaction with her baby as the response decreased, limiting interaction with infants. At times, the bonding attachment process is hampered, resulting in an angry attitude when interacting and possibly leading to injuring a baby. Changes in the affective domain in interacting with infants occur when postpartum blues progress to the point of severe depression..$^{25}$ Previous measurements involving mothers' roles and duties through mother and baby interactions have not been used to measure postpartum blues. The results of the current study can enrich approaches for predicting postpartum blues (as shown in Table 3)

As with external factors (i.e., supporting sources including cultural, social, and economic support) are items that can predict the occurrence of postpartum blues. This statement is proven based on the indicators of the value of validity and reliability obtained. Family acceptance of infants was one of the cultural factors in this study that affected the condition of the affective realm of the mother in interacting with the baby. The presence of an unwanted or family-approved baby may stem from the sex of the baby, a marriage that is not approved by both families, or an unmarried pregnancy. ${ }^{26}$ Cultural traditions in Indonesia include marriage involving the blessing of both parents. Moreover, some ethnicities still emphasize one sex of the child as qualifying to be the family successor and impose restrictions on activities and prohibitions for postpartum mothers. Such factors can influence a woman to refuse to have children. Recognizing this problem can be a source of support for changes in the affective domain in interacting with babies that describe postpartum blues.

Gjerdingen, Froberg, and Fontaine (1991) stated that social support was one factor that could affect the physical and mental health of the mother. The most critical support is emotional support and information support in the types of help, assistance, and mentoring in areas such as housework. Support can be obtained from the husband or the people around him, including parents or parentsin-law. ${ }^{27}$ The type of social support that affects mothers who experience postpartum depression in Asian countries includes informational and emotional (affection) support and approval. ${ }^{24}$ The results of the current study agree with these findings

Family economic factors can also serve as predictors of postpartum blues. This assertion is in accordance with the previous studies. The complex problem experienced by Indonesian people is due to economic factors, especially low income. ${ }^{18}$ This factor affects the condition of the mother's emotional affective domain. ${ }^{18}$ Economic problems can be found in any ethnicities in Indonesia. Economic problems and their effects on the mother during the perinatal period are not only found in Indonesia but also occur in other ASEAN countries. For example, in India and Malaysia, the problem of low family income triggers postpartum depression. ${ }^{28}$

For social support and approval, the analysis of each of these items appeared to indicate that they were not reliable, but when all items were compiled and analyzed in order to predict the postpartum blues, that variable was shown to be valid and reliable. Important information that this study found was that the social support involving emotional, appraisal, informational, economic, and cultural factors combined are vital considerations in exploring the failure of mothers to interact with their infants as described by postpartum blues on the part of the mother. This result is in line with a previous study that demonstrated the significant influence of social support on the failure of bonding attachment and postpartum blues for mothers. ${ }^{29}$ The findings of the current study show that Suryani's maternal blues scale has 7.391 times the likelihood of finding maternal blues cases compared with Kennerly's maternity blues scale due to including these factors in the measured items.

Previous measurements such as cultural, social, and economic support have not been used in measuring instruments to explore the affective domain in interacting with infants in predicting postpartum blues. This study purports to be able to predict postpartum blues. Thus, the results of the current study promise to add a variety of ways to predict postpartum blues. 


\section{Conclusion}

The maternal blues scale can predict postpartum blues through an exploration of the affective domain when mothers interact with infants. This scale was constructed from two factors, internal (the role and duties of the mother) and external (supporting resources in the form of cultural, social, and economic support), that are related to the occurrence of postpartum blues. The development of these factors yielded 32 statement-based items that can predict postpartum blues having validity and reliability that meet the necessary indicators. The maternal blues scale that has been developed can therefore be declared suitable as a scale to predict postpartum blues. The results of this study that it provide an instrument to predict postpartum blues. This scale is consequently recommended as a postpartum assessment tool that can be used by nurses and midwives in hopes of decreasing the risk of postpartum depression and increasing the health of mothers and babies.

\section{Research Limitations}

This study had two limitations. First, the characteristics of the population did not reflect the ethnic diversity of all ethnicities in Indonesia. The scale still requires the development of demographic factors from other provinces in Indonesia. Second, the scale needs a broader study to explore cultural factors in predicting postpartum blues to be able to describe the overall cultural traits that exist in Indonesia.

\section{Acknowledgments}

We are grateful to the University of Indonesia that funded this study under scheme Pitta 2018 and the Jakarta I Health Polytechnic that facilitated the completion of this study. Likewise, we are thankful for the postpartum mothers in the South Jakarta DKI Community Health Centers who participated in the study.

\section{References}

1. Castle J. Early detection of postpartum depression: screening in the first two to three days. J Lancaster Gen Hosp [Internet]. 2008;3(4):147-9. Available from: http:// jlgh.org/JLGH/media/Journal-LGH-MediaLibrary/Past\%20Issues/Volume\%203\%20-\%20 Issue\%204/V3n4_Castle.pdf.

2. Jessica G, Gray R. Epidemiology of maternal mental health disorders. In: Martin CR, editor. Perinatal Mental Health: A Clinical Guide. first. London: M\&K Publishing; 2012. pp. $1-11$.

3. Ismail RI. Ante partum depression and husband's mental problem increased risk maternity blues. Med J Indones. 2006;15(2):74-80.

4. Manurung S, Lestari TR, Suryati B, Miradwiyana B, Karma A. Effectiveness of music therapy on prevention of postpartum blues in primipara mothers in the midwifery room of Cipto Mangunkusumo General Hospital, Jakarta. Bull Heal Syst Res. 2011;14(1):17-23.
5. Edhborg M, Matthiesen S, Lundh W, Widstrom M. Some early indicators for depressive symptoms and bonding 2 months postpartum - a study of new mothers and fathers. Arch Womens Ment Heal [Internet]. 2005;8:221-31. Available from: https://link. springer.com/article/10.1007/s00737-0050097-5

6. Klempner LG. Perspectives on risk factors, screening, and diagnosis. In: Stone SD, Menken AE, editors. Perinatal and Postpartum Mood Disorder: Perspectives and Treatment Guide for the Health Care Practitioner. New York: Springer Publishing Company; 2008. pp. 1-213.

7. Belsky J, Fish M, Isabella R. Continuity and discontinuity in infant negative and positive emotionality: family antecedents and attachment consequences. Dev Psychol [Internet]. 1991;27(3):421-31. Available from: https://doi.org/10.1037/00121649.27.3.421\%0A
8. Benoit D. Infant-parent attachment Definition, types, antecedents, measurement and outcome. Paediatr Child Health (Oxford) [Internet]. 2004;9(8):541-5. Available from: https://www.ncbi.nlm.nih.gov/pmc/articles/ PMC2724160/

9. Parfitt Y, Ayers S. The effect of postnatal symptoms of post-traumatic stress and depression on the couple's relationship and parent-baby bond. J Reprod Infant Psychol [Internet]. 2009;27(2):12742. Available from: http://dx.doi. org/10.1080/02646830802350831

10. Bornstein MH, Suwalsky JTD, Breakstone DA. Emotional relationships between mothers and infants: Knowns, unknowns, and unknown unknowns. Dev Psychopathol [Internet]. 2012;24(1):113-23. Available from: https:// www.ncbi.nlm.nih.gov/pubmed/22292998

11. Mantis I, Mercuri M, Stack DM, Field TM. Depressed and non-depressed mothers' touching during social interactions with their infants. Dev Cogn Neurosci [Internet]. 2018;35:57-65. Available from: https://doi. org/10.1016/j.dcn.2018.01.005 
12. Corrigan CP, Kwasky AN, Groh CJ. Social support, postpartum depression, and professional assistance: a survey of mothers in the Midwestern United States. J Perinat Educ [Internet]. 2015;24(1):48-60. Available from: http://doi.org/10.1891/1058-1243.24.1.48

13. Mercer RT. Becoming a mother versus maternal role attainment. J Nurs Scholarsh [Internet]. 2004;36(3):226-32. Available from: https:// doi.org/10.1111/j.1547-5069.2004.04042.x

14. Emmanuel EN. Maternal role development: the influence of maternal distress following childbirth. Midwifery [Internet]. 2011;27(2):265-72. Available from: https:// doi.org/10.1016/j.midw.2009.07.003

15. Klainin P, Arthur DG. Postpartum depression in Asian cultures: a literature review. Int J Nurs Stud [Internet]. 2009;46(10):1355-73. Available from: https://doi.org/10.1016/j. ijnurstu.2009.02.012

16. Bina R. The impact of cultural factors upon postpartum depression: a literature review. Health Care Women Int [Internet]. 2008;29(6):568-92. Available from: https:// doi.org/10.1080/07399330802089149

17. Rodrigues M, Nandita D. Gender, poverty, and postnatal depression: a study of mothers in Goa, India. Am J Psychiatry 2002; [Internet]. 2002;159(5):43-7. Available from: https://doi. org/10.1176/appi.ajp.159.1.43

18. Andajani-Sutjahjo S, Manderson L, Astbury J. Complex emotions, complex problems: understanding the experiences of perinatal depression among new mothers in urban Indonesia [Internet]. Vol. 31, Culture, Medicine and Psychiatry. 2007. pp. 101-22. Available from: https://doi.org/10.1007/ s11013-006-9040-0
19. Moslemi L, Tadayon M, Montazeri S, Tabari M, Gholamitabar,G. Prevalence and several effective factors on maternity blues. HealthMed [Internet]. 2012;6(7):2299-303. Available from: https://www.researchgate.net/ publication/282567893_Prevalence_and_ several_effective_factors_on_maternity_blues

20. Faisal-Cury A, Menezes PR, Tedesco JJA, Kahalle S, Zugaib M. Maternity blues: prevalence and risk factors. Span J Psychol [Internet]. 2008;11(2):593-9. Available from: https://www.ncbi.nlm.nih.gov/ pubmed/18988444

21. Cohen RJ, Swerdlik ME. Psychological Testing and Assessment: An Introduction to Tests and Measurement. 7th Edition. The McGraw-Hill Companies. Philadelphia : The McGraw-Hill Companies; 2010. 1-759 p.

22. Kaplan RM, Saccozzo DP. Psychological Testing Priciples, Applications and Issues. 6thedition . Lee J, Thomson Wadsworth. Philadelphia: Thomson LearningTM; 2005. pp.1-770.

23. Dahlan MS. Penelitian Diagnostik: Dasar-dasar Teoretis dan Aplikasi dengan Program SPSS dan Stata. 1stEdition. Aulia Novianty, editor. Salemba Medika. Jakarta: Salemba Medika; 2009. pp.1-152.

24. Edhborg M, Nasreen HE, Kabir ZN. Impact of postpartum depressive and anxiety symptoms on mothers' emotional tie to their infants 2-3 months postpartum: population-based study from rural Bangladesh. Arch Womens Ment Health [Internet]. 2011;14(4):307-16. Available from: https://www.ncbi.nlm.nih.gov/ pubmed/21626173
25. Moore ER, Anderson GC, Bergman N, Dowswell T. Early skin-to-skin contact for mothers and their healthy newborn infants. Cochrane Database Syst Rev [Internet]. 2014;16(5):1-118. Available from: https:// www.ncbi.nlm.nih.gov/pmc/articles/ PMC3979156/

26. O'Connor S. Child Neglect and Child Abuse. In: Perinatal Mental Health: a Clinical Guide. Philadelphia: M\&K Up Date; 2012. pp. 491-8.

27. Gjerdingen DK, Froberg DG, Fontaine P. The effects of social support on women's health during pregnancy, labor and delivery, and the postpartum period. Fam Med. 1991;23(5):370-5.

28. Manjunath NG, Venkatesh G, Rajanna. Postpartum blue is common in socially and economically insecure mothers. Indian J Community Med [Internet]. 2011;36(3):231-3. Available from: https:// dx.doi.org/10.4103/0970-0218.86527.

29. Ohara M, Okada T, Aleksic B, Morikawa M, Kubota C, Nakamura Y, et al. Social support helps protect against perinatal bonding failure and depression among mothers: a prospective cohort study. Sci Rep [Internet]. 2017;7(9546):1-8. Available from: https:// dx.doi.org/10.1038/s41598-017-087683.2008;23(3):323-8 


\section{The feasibility of a public-private mix program on pulmonary tuberculosis screening in Penang: A pilot study}

Wei Shuong Tang, Mei Wai Chan, Fei Ping Kow, Ranjini A/P Ambigapathy, Justen Han Wei Wong, Vasantha Thiruvengadam, Umarazina bt Abd Kadir, Anita Jain, Ramesvari Pararajasingam Pillai

Tang WS, Chan MW, Kow FP, et al. The feasibility of a public-private mix program on pulmonary tuberculosis screening in Penang: A pilot study. Malays Fam Physician. 2021;16(1);75-83. https://doi.org/10.51866/oa1096

\section{Keywords:}

pulmonary tuberculosis, feasibility study

\section{Authors:}

Chan Mei Wai

(Corresponding author)

MBBS (UM), FRACGP

RCSI\&UCD Malaysia Campus

Georgetown, Penang

email: chanmw@rcsiucd.edu.my

Tang Wei Shuong

MBBS (UM), Master in Family

Medicine (UM)

Jalan Perak Health Clinic

\section{Kow Fei Ping}

MBBS (Manipal, India) Master in

Family Medicine (UM)

Jalan Angsana Health Clinic

\section{Ranjini A/P Ambigapathy} MBBS (UM), Master in Family Medicine (UM)

Sungai Dua (Timur Laut) Health Clinic

\section{Justen Wong Han Wei}

M.D. (UPM), Master in Public Health

(UM)

North East District Health Office

\section{Vasantha Thiruvengadam} MBBS (Manipal, India),

Master in Public Health (UM) North East District Health Office

\section{Abstract}

Background: The low detection rate of tuberculosis (TB) cases in Malaysia remains a challenge in the effort to end TB by 2030. The collaboration between private and public health care facilities is essential in addressing this issue. As of now, no private-public health care collaborative program in pulmonary tuberculosis (PTB) screening exists in Malaysia.

Aim: To determine the feasibility of a collaborative program between private general practitioners (GPs) and the public primary health clinics in PTB screening and to assess the yield of smearpositive PTB from this program.

Methods: A prospective cohort study using convenient sampling was conducted involving GPs and public health clinics in the North-East District, Penang, from March 2018 to May 2019. In this study, GPs could direct all suspected PTB patients to perform a sputum acid fast bacilli (AFB) direct smear in any of the dedicated public primary health clinics. The satisfaction level of both the GPs and their patients were assessed using a self-administered client satisfaction questionnaire. IBM SPSS Statistical Software was used to analyze the data.

Results: Out of a total of 31 patients who underwent the sputum investigation for PTB, one $(3.2 \%)$ was diagnosed to have smear-positive PTB. Most of the patients (>90\%) and GPs (66.7\%) agreed to continue with this program in the future. Furthermore, most of the patients $(>90 \%)$ were satisfied with the program structure.

Conclusion: It is potentially feasible to involve GPs in combating TB. However, a more structured program addressing the identified issues is needed to make the collaborative program a success.

\section{Introduction}

Tuberculosis (TB) remains one of the top 10 causes of death globally. ${ }^{1}$ The World Health Organization (WHO) has pledged to end the TB epidemic by 2030. ${ }^{2}$ Despite the global decline of the disease burden, the moderate rate of decline reported in 2015 at $2 \%$ per year $^{2}$ is too low to achieve the predetermined milestones of the End TB Strategy. ${ }^{1}$ Hence, the Stop TB Partnership has recommended that countries should strive to achieve an annual case decline rate of $10 \%$ in $2025 . .^{2}$ In order to accelerate progress, the Global Plan articulates three people-centered targets called 90-(90)90 targets (reach $90 \%$ of all people who need TB treatment, including $90 \%$ of people in key populations, and achieve at least $90 \%$ treatment success). ${ }^{3}$ The Global Plan proposes to achieve the $90-(90)-90$ targets by 2025 at the latest to meet the goal of ending TB by $2030 .^{3}$
Finding the "missing people" remains a major challenge in TB control. ${ }^{2}$ In 2018, only 7 million TB cases were documented globally, in contrast to estimated TB cases of 10 million people. ${ }^{1}$ Such figures indicate that 3 million people were not diagnosed, treated, or officially registered by national TB programs. ${ }^{2}$ A systematic review linked health care delay to deferred diagnosis and treatment of tuberculosis, including that caused by seeking traditional healers or practitioners 5 and private general practitioners first. ${ }^{5,6}$ Moreover, many private general practitioners are delinked from the country's tuberculosis control efforts, which also contributes to the discrepancy between reported and estimated cases.

The collaboration between the private and government sectors plays a vital role in achieving effective TB control, especially in countries where a large proportion of careseeking entails private providers. Hence, 


\author{
Umarazina bt Abd Kadir \\ M.D.(UKM) Master in Public Health \\ (UM) \\ North East District Health Office
}

\begin{abstract}
Anita Jain
M.D. (India), Master in Family

Medicine (UKM)

Jalan Macalister Health Clinic
\end{abstract}

Ramesvari Pararajasingam Pillai M.D. (UNIMAS), Master in Family Medicine (UKM)

Jalan Perak Health Clinic the involvement of all related health care personnel in TB care through the publicprivate mix (PPM) approach is a crucial element of the WHO End TB Strategy. ${ }^{8}$ Evidence has shown that PPM programs had improved case detection, treatment outcome, and management of TB among countries that adopted this approach. ${ }^{?}$

Malaysia is considered a country with an intermediate incidence rate of $\mathrm{TB}$ with 93 per 100,000 population in $2018 .^{10}$ In 2014, the estimated incidence rate for Malaysia was 103 per 100,000 population, while actual detected cases were 81 per 100,000 population. Potentially, about 6,000 cases remained undetected in the country. ${ }^{11}$ Based on the National Strategy Plan (NSP) for TB, the estimated annual underrepresentation of TB cases is $13.49 \%$ (95\%CI: 10.39-15.34). ${ }^{11}$ It is crucial to close the gap between estimated incidents and identified patients. Therefore, enhanced case detection is a key strategy in the NSP for TB (2015-2020). ${ }^{11}$ Accordingly, the NSP plans to increase case notification of all forms of TB from 79 per 100,000 population in 2015 to 100 per 100,000 population in $2020 .^{11}$

Patients can choose to receive medical care from private or government health facilities in Malaysia. Public health facilities are government-funded institutions where patients pay a nominal fee. ${ }^{12}$ In comparison, in private health facilities, patients must bear the full cost of health care services. ${ }^{12}$ When a private general practitioner suspects a patient might have pulmonary tuberculosis (PTB), the patient can either be subjected to a sputum test or chest radiography at a private facility or be referred to a government primary health clinic for further investigation. However, in the current referral system, patients who are referred to government facilities must register at the facility and be re-examined by a doctor before having further investigation performed involving the diagnosis of PTB. This time-consuming referral process may be a factor in noncompliance with the management plan. Thus, both financial and time factors may become roadblocks for a symptomatic patient to seek PTB investigation. The situation is even more challenging when patients are not fully convinced of the possibility of a diagnosis of PTB or its severity if left untreated due to lack of symptoms.

Besides issues from patients, deferment in the diagnosis and treatment of $\mathrm{TB}$ in Malaysia could reflect low awareness of the disease among private general practitioners (GPs) 13 or be due to limited access to chest radiography and sputum examination in private health clinics compared to hospitals and government health clinics. ${ }^{13}$

In view of the importance of public-private collaboration to fill the gap on the issues that patients and general practitioners may face in Malaysia, this study aims to look into the feasibility of a collaboration program with general practitioners for PTB screening and assess the yield of smear-positive PTB from this program.

\section{Methodology}

\section{Study design and participants}

This investigation comprised a prospective cohort study conducted from March 2018 to May 2019 in selected private primary health clinics in the North-East District, an urban district in Penang, Malaysia. The inclusion criterion was a private primary health clinic with solo practice. Practitioners in group practices were excluded from this study.

A total of 11 private GPs were invited via convenience sampling to participate in this study. A participant information sheet was distributed to the GPs, and written consent was obtained from all participants.

\section{Program development}

The researchers initiated this program with the permission of the district health officer. Meetings were conducted involving the district health officer and the researchers. Initial program development included discussions regarding the flow of the intervention pathway. The relevant parties involved, such as the laboratory assistants and nurses, were invited to give opinions during the development of the pathways.

The researchers informed the participating GPs about the flow of the intervention pathways. All participating GPs were provided with a poster to be displayed at their respective clinics, standard national TB investigation forms, a client satisfaction questionnaire, and sputum containers. The displays were used to create TB awareness among the patients who visited the selected clinics. 


\section{Program overview}

Figure 1 shows the interventional pathway and the conventional pathway. In this program, the participating GPs were given the authority to order a sputum acid fast bacilli (AFB) test from laboratories at public primary health clinics. During the study period, all Malaysians who presented any of the symptoms suggestive of PTB: cough ( $\geq 2$ weeks), night sweat/ fever/ loss of weight ( $\geq 1$ month), or hemoptysis were offered to have their early morning sputum checked at the nearest public primary health clinic. The GPs provided each patient a signed TB investigation form, an awareness pamphlet on TB, a leaflet on the correct technique for sputum collection, and a sputum container. The laboratory assistant gave the patient a new sputum container once the patient sent their previous sputum container to the laboratory at a public primary health clinic. Three consecutive days of sputum were collected and tested for AFB. In this program, patients bypassed the conventional pathway in that they were not required to register and be re-examined by doctors in public primary health clinics. Furthermore, the patients saved time and money by not performing the investigations in private laboratories, hospitals, or clinics. Lastly, the patients rated their experience in this program on the client satisfaction questionnaire.

The laboratory assistants informed the researchers regarding the results of the tests. The researchers in turn disclosed the results to the respective GPs via email or phone call. The GPs gave all patients a date to review their results, and patients were allowed to decide on the referral site for further PTB management if the result was smear-positive for the sputum AFB.

Before the program began, a briefing on the flow of this interventional pathway was given to all laboratory assistants and nurses involved in the public primary health clinic.

At the end of the study, the researchers conducted interviews with all the GPs, and the GPs recorded their experience with the program on the client satisfaction questionnaire.

\section{Study Instrument}

\section{Patients}

The researchers used two instruments to collect data from the patients. The first instrument was the standard national TB investigation form. This form was used widely in the public primary clinic to order an investigation for sputum AFB. The sociodemographic characteristics of the patients were obtained from this investigation form.

The second instrument was the selfadministered client satisfaction questionnaire. The researchers developed a self-administered client satisfaction questionnaire based on example of online customer/client satisfaction questionnaires and modified this tool to suit the current study. It consisted of 5 items that assessed the participants' satisfaction regarding this program. A 5-point Likert scale was used to rate the extent of satisfaction for each item.

Face validation was conducted, and amendment was done based on feedback. The researchers conducted forward and backward translation to the Malay language and the questionnaire was pilot-tested on 10 subjects who were not part of the study population.

\section{General practitioners}

The same self-administered client satisfaction questionnaire (with item 5 removed) was used to assess the level of satisfaction among the GPs. At the end of the study, the researchers conducted interviews to gather information from the GPs on sociodemographic characteristics, barriers that the GPs identified, and suggestions to improve the program.

\section{Program evaluation}

Program implementation was evaluated using the following measures: satisfaction scoring from the GPs/ patients and the number of patients screened as positive for sputum AFB.

Ethical consideration

The study was approved by the Medical Research Ethics Committee, Malaysia (NMRR17-2120-37648) on October 27, 2017.

\section{Data analysis}

The data were entered into Microsoft Excel and imported into IBM SPSS Statistical Software, version 25 for analysis. Descriptive statistics were used to define the sociodemographic profile of the participants. Numerical variables such as mean and standard deviation for age were also displayed. The categorical variables such as sex were displayed as actual numbers 
Figure 1 The flow comparing the interventional pathway with the conventional pathway

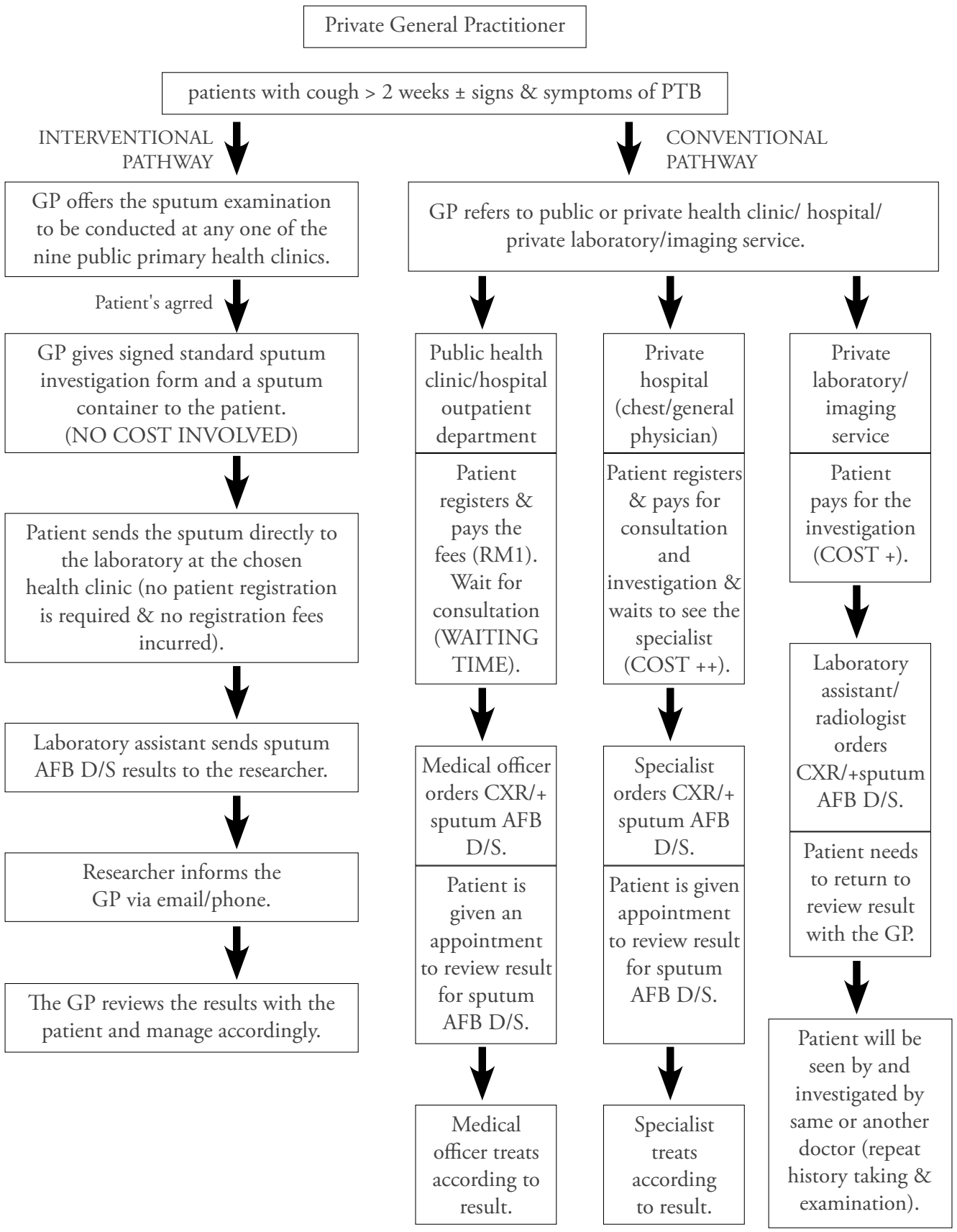

Sputum AFB D/S = sputum acid fast bacilli direct smear, CXR = chest radiograph, $\mathrm{GP}=$ general practitioner

and percentages.

The GPs' and patients' satisfaction scores for this program were analyzed. A 5-point Likert scale with 1 defined as very dissatisfied/strongly disagreed/very unlikely whereas 5 defined as very satisfied/strongly agreed/very happy was used to evaluate participants' satisfaction on the following questions:

i. Overall, how satisfied are you with the sputum investigation arrangement? ii. Based on your experience with this arrangement, how likely are you to recommend this to your friends who may need to send sputum for investigation for tuberculosis?

iii. Based on your experience with this arrangement, would you agree that this arrangement should be continued in the future?

iv. Based on your experience with this arrangement, do you recommend this 
arrangement to be extended to other private general practitioners?

v. Do you feel happy when you are called back to review your results?

A score of 1 or 2 was re-categorized as disagreed/dissatisfied/unlikely, while a score of 4 or 5 was re-categorized as agreed/satisfied/likely. A score of 3 was neutral.

Barriers and suggestions gathered about improving the program were used in the discussion session.

\section{Results}

Eleven eligible GPs were invited to participate in this study. Of these, only nine GPs agreed and consented to the study.

Table 1 shows the sociodemographic characteristics of the nine participating GPs. Nearly half of the participating GPs were senior, having more than 40 years of experience in practicing as a doctor and as a GP.

Table 1. Sociodemographic characteristics of the participating general practitioners $(N=9)$

\begin{tabular}{|l|c|}
\hline Sociodemographic characteristics & Frequency (percentage) \\
\hline Numbers of years in practice & $0(0)$ \\
$\mathbf{1 - 1 0}$ & $5(55.6)$ \\
$\mathbf{1 1 - 2 0}$ & $0(0)$ \\
$\mathbf{2 1 - 3 0}$ & $0(0)$ \\
$\mathbf{3 1 - 4 0}$ & $4(44.4)$ \\
$\mathbf{4 1 - 5 0}$ & \\
\hline Numbers of years as general practitioner & $1(11.2)$ \\
\hline $\mathbf{1 - 9}$ & $4(44.4)$ \\
$\mathbf{1 0 - 1 9}$ & $4(44.4)$ \\
\hline
\end{tabular}

Out of nine GPs, only five GPs sent their patients to the public primary health clinic to perform a sputum AFB investigation.

Table 2 shows the sociodemographic characteristics of the patients who sent in their sputum sample. A total of 31 patients sent a sputum sample. The mean age of the participating patients was $52.4( \pm 16.85)$. From the total number of patients, one was diagnosed to have smear-positive PTB.

Table 2. Sociodemographic characteristics of the participating patients $(\mathrm{N}=31)$

\begin{tabular}{|l|c|}
\hline Sociodemographic characteristics & Frequency (percentage) \\
\hline Gender & $14(45.2)$ \\
Male & $17(54.8)$ \\
Female & $\mathbf{5 2 . 4 ( 1 6 . 8 5 )}$ \\
\hline Age in years (mean $\mathbf{\text { SD}}$ ) & $2(6.5)$ \\
$1-20$ & $6(19.4)$ \\
$21-40$ & $13(41.9)$ \\
$41-60$ & $10(32.2)$ \\
$61-80$ & \\
\hline Results of sputum AFB smear & $1(3.2)$ \\
Positive & $30(96.8)$ \\
Negative & \\
\hline
\end{tabular}

Table 3 and Table 4 contain feedback from the GPs and patients collected from the clients' satisfaction questionnaire. Most of the patients were satisfied with the arrangement (90.3\%), agreed to recommend this arrangement to others $(90.3 \%)$, agreed to continue this program $(93.5 \%)$, or agreed to extend this program to other GPs. The responses from the GPs varied. Only one-third of the GPs were satisfied with the arrangement. Two-thirds of the GPs agreed to recommend this arrangement to others $(66.7 \%)$, agreed to continue this program $(66.7 \%)$, or agreed to extend this program to other GPs. 
Table 3. Responses on the "clients' satisfaction questionnaire" from general practitioners $(\mathrm{N}=9)$

\begin{tabular}{|l|c|c|c|}
\hline Statements & $\begin{array}{c}\text { Agreed/Satisfied/ } \\
\text { Likely } \\
\text { Frequency } \\
\text { (percentage) }\end{array}$ & $\begin{array}{c}\text { Neutral } \\
\text { Frequency } \\
\text { (percentage) }\end{array}$ & $\begin{array}{c}\text { Disagreed/ } \\
\text { Dissatisfied/ } \\
\text { unlikely } \\
\text { Frequency } \\
\text { (percentage) }\end{array}$ \\
\hline $\begin{array}{l}\text { Overall, how satisfied are you with the } \\
\text { sputum investigation arrangement? }\end{array}$ & $3(33.3)$ & $4(44.5)$ & $2(22.2)$ \\
\hline $\begin{array}{l}\text { Based on your experience with this } \\
\text { arrangement, how likely are you to } \\
\text { recommend this to your colleagues who } \\
\text { may need to send patients for sputum } \\
\text { investigation for tuberculosis? }\end{array}$ & $6(66.7)$ & 0 & $3(33.3)$ \\
\hline $\begin{array}{l}\text { Based on your experience with this } \\
\text { arrangement, would you agree that this } \\
\text { arrangement should be continued in the } \\
\text { future? }\end{array}$ & $6(66.7)$ & 0 & $3(33.3)$ \\
\hline $\begin{array}{l}\text { Based on your experience with this } \\
\text { arrangement, do you recommend this } \\
\text { arrangement to be extended to other } \\
\text { private general practitioners? }\end{array}$ & $6(66.7)$ & 0 & $3(33.3)$ \\
\hline
\end{tabular}

Table 4. Responses on the "clients' satisfaction questionnaire" from patients ( $\mathrm{N}=31)$

\begin{tabular}{|l|c|c|c|}
\hline Statements & $\begin{array}{c}\text { Agreed/Satisfied/ } \\
\text { Likely } \\
\text { Frequency } \\
\text { (percentage) }\end{array}$ & $\begin{array}{c}\text { Neutral } \\
\text { Frequency } \\
\text { (percentage) }\end{array}$ & $\begin{array}{c}\text { Disagreed/ } \\
\text { Dissatisfied/ } \\
\text { unlikely } \\
\text { Frequency } \\
\text { (percentage) }\end{array}$ \\
\hline $\begin{array}{l}\text { Overall, how satisfied were you with the } \\
\text { sputum investigation arrangement? }\end{array}$ & $28(90.3)$ & $2(6.5)$ & $1(3.2)$ \\
\hline $\begin{array}{l}\text { Based on your experience with this } \\
\text { arrangement, how likely are you to } \\
\text { recommend this to your friends who may } \\
\text { need to send sputum for investigation for } \\
\text { tuberculosis? }\end{array}$ & $28(90.3)$ & $1(3.2)$ & $2(6.5)$ \\
\hline $\begin{array}{l}\text { Based on your experience with this } \\
\text { arrangement, would you agree that this } \\
\text { arrangement should be continued in the } \\
\text { future? }\end{array}$ & $29(93.5)$ & 0 & $2(6.5)$ \\
\hline $\begin{array}{l}\text { Based on your experience with this } \\
\text { arrangement, do you recommend this } \\
\text { arrangement to be extended to other } \\
\text { private general practitioners? }\end{array}$ & $29(93.5)$ & 0 & $2(6.5)$ \\
\hline $\begin{array}{l}\text { Do you feel happy when you are called } \\
\text { back to review your results? }\end{array}$ & $28(90.3)$ & $1(3.2)$ & $2(6.5)$ \\
\hline
\end{tabular}

\section{Discussion}

Most patients $(90.3 \%)$ provided positive feedback on the program. In other words, the patients were satisfied and happy with the program. Similar feedback was observed in other studies. ${ }^{14,15}$ In 2017, a populationbased cross-sectional survey was carried out in Pakistan examining the satisfaction levels of TB patients about the New Funding Mechanism (NFM) of the PPM model ${ }^{14}$ in which private health providers were given financial incentives to support their consultation time during the course of treatment. The study recruited 576 patients, all of whom went through a "patient satisfaction survey tool." A total of $82 \%$ of the patients were satisfied with the PPM program. ${ }^{14}$ However, only one-third of the GPs were satisfied with the arrangement. Similar findings were observed in a study in Delhi, India. ${ }^{15}$ In comparison, the current study used a "referral model" (suspected TB patients were referred to the public primary health clinic for investigation of $\mathrm{TB}$ ) to facilitate the diagnosis 
of PTB. Like the previous studies, the GPs who participated in the current study were not satisfied with such an arrangement because some of their patients felt that it was still troublesome despite the minimal cost involved. Based on the feedback, a model that involves a porter system where transportation of sputum samples is arranged may increase the uptake of the test among eligible patients. Supporting this suggestion, an innovative PPM model in Vietnam that offered onsite TB testing or a similar porter system revealed positive results in reducing the gaps and delays in testing. ${ }^{16}$

Among the nine GPs in this study, only five referred patients to participate in this program. In general, private health clinics differ in their respective patient profiles, clinic locations, or business models. These differences might contribute to the readiness of the GPs to send eligible patients for investigation via this program. Hence, the process of mapping the GPs is an important step to identify suitable GPs to participate before the start of such a program. ${ }^{5}$ During this mapping process, GPs with larger practices or locations with a higher TB burden or poor access to health services may be prioritized.

The number of patients who participated in this program was not very encouraging. Out of 31 patients, one patient $(3.2 \%)$ was diagnosed as having sputum positive PTB. Compared to similar studies of the PPM program,, 917 case detection numbers are low. In general, engaging all care providers through a PPM program could increase the case detection up to four-fold and promise an excellent treatment outcome.18 In 2014, a systematic review of PPM for TB care and control identified 78 studies on 48 programs in 16 countries. ${ }^{9}$ Of the 78 studies, 41 studies reported an increase in case detection numbers or rates to some extent. ${ }^{9}$ A study in Ho Chi Minh City assessing case detection after implementing a PPM program reported that case detection increased $18 \%$ compared to pre-PPM program and was higher compared to a district with no PPM program. ${ }^{17}$ However, PPM is not equally effective in all high-burden countries. PPM will perform well in countries where the private and other sectors are influential in the health system. ${ }^{18}$ Malaysia is a country with an intermediate burden of TB, and only $5 \%$ of the country's TB patients have been under the care of private health providers. ${ }^{5}$ These factors might have contributed to the low case detection in the current study.
The lower numbers for participation might be attributed to the poor compliance of the GPs or patients with the suggested diagnostic algorithm. The number of tests offered was low. During the interview session with the GPs, the decision regarding PTB screening is not only based on duration of cough, ${ }^{19,20}$ but doctors also look at other supportive symptoms, such as the presence of hemoptysis, night sweats, and fever. This practice is slightly different from that of the government health clinics, where any patients with two weeks of cough will be subjected to sputum examination with or without chest $\mathrm{X}$-ray.

The current study had several identified limitations. First, this investigation was a pilot feasibility study that only involved nine selected GPs in the North-East District in Penang. Thus, the low case detection cannot be generalized to the study population. Second, no documentation was recorded on the number of patients that refused to join the program. As a result, we are not able to compare the effectiveness of this PPM program with other programs. Third, in this study, the researchers excluded non-Malaysians due to the local fee-related regulation. In Malaysia, a research investigation by Liew SM et al. ${ }^{21}$ reported that among patients who were diagnosed with PTB, $14.2 \%$ were non-Malaysians. Another study similarly reported that immigrants who stayed in a high-TB-intensity environment might worsen PTB infection progression. ${ }^{22}$ Fourth, the client satisfaction questionnaire was not validated. Lastly, an interview was carried out to assess the GPs' opinions but lacked proper statistical analysis. A future study should look into this aspect using qualitative research methods.

The strength of this study is that it represents a pioneer collaboration in line with the PPM approach for sputum AFB direct smear screening in Malaysia. This study can be further expanded to involve more GPs in the area with some adjustment to the arrangements, especially in terms of implementing the suggested porter system to transfer the specimens from the involved GP clinics and looking into the possibility to facilitate $\mathrm{TB}$ screening among immigrants. This pilot study thus acts as a vanguard for other researchers or stakeholders to develop a more structural approach involving GPs in the efforts to screen and treat TB earlier, with the eventual goal of eliminating TB. 
In conclusion, it is potentially feasible to have the PPM program for TB screening in Penang, Malaysia. However, more efforts are needed to look into patients' preferences, the dynamics of private practice, and the role of private health workers in the care of TB to develop a more effective PPM program in Malaysia.

\section{Funding}

This research was funded by the North-East District Health Office, Ministry of Health.

\section{Competing interest}

The authors declared that there were no competing interests.

\section{Acknowledgements}

We would like to express our appreciation to all the general practitioners and patients who participated in the study. We would also like to thank the laboratory assistants and nurses who assisted in this study. We are also grateful to Dr. Chew So-Phia, Dr. Shaik Husseinudin B. Babu Ali, and Mr. Lee Mean Yeit for their input in the preparation of the manuscript.

\section{How does this paper make a difference to general practice?}

- This investigation comprises a pilot study carried out on the Public-Private Mix (PPM) approach in the screening of PTB in Malaysia.

- In view of the modest detection rate, a more structural approach addressing the patient preferences, private sector dynamics, and the rationale for engaging all care providers should be carried out to make the PPM program a success.

\section{References}

1. Global tuberculosis report 2019. Geneva: World Health Organization; 2019. [cited 2020 Jun 30]. Available from: https://www. who.int/tb/publications/global_report/en/

2. World Health Organization. The end tb strategy. Geneva: World Health Organization; 2014. [cited 2019 Oct 14]. Available from: https://www.who.int/tb/strategy/end-tb/en/

3. World Health Organization. The global plan to end tb 2016-2020: the paradigm shift. Geneva: World Health Organization;2015. [ cited 2020 May 15]. Available from: http://www.stoptb.org/assets/documents/ global/plan/GlobalPlanToEndTB_ TheParadigmShift_2016-2020_ StopTBPartnership.pdf

4. Marahatta SB, Yadav RK, Giri D, et al. Barriers in the access, diagnosis and treatment completion for tuberculosis patients in central and western Nepal: A qualitative study among patients, community members and health care workers. PloS ONE. 2020 Jan [cited 2020 May 20];15(1). Available from: https://doi. org/10.1371/journal.pone.0227293
5. United Nations Office for Project Services. Stop tb field guide: Finding missing people with tb by engaging the private sector. Geneva: Stop TB Partnership; 2018. [cited 2019 Sep 4]. Available from:https:// stoptb-strategicinitiative.org/wp-content/ uploads/2019/03/STOFG_10.pdf

6. Storla DG, Yimer S, Bjune GA. A systematic review of delay in the diagnosis and treatment of tuberculosis. BMC public health. 2008;8(1):15

7. Regional Office for South-East Asia, World Health Organization. Ending tb in the SouthEast Asia region: Regional strategic plan 20162020. India: World Health Organization, Regional Office for South- East Asia; 2016. [cited 2019 Sep 16]. Available from: https:// apps.who.int/iris/handle/10665/250292
8. World Health Organization. Early detection of tuberculosis: An overview of approaches, guidelines and tools. Geneva: World health Organization; 2011. [cited 2019 Sep 12]. Available from: https://apps.who. int/iris/bitstream/handle/10665/70824/ WHO_HTM_STB_PSI_2011.21_eng.pdf? sequence $=1$

9. Lei X, Liu Q, Escobar E, et al. Publicprivate mix for tuberculosis care and control: A systematic review. Int J Infect Dis. 2015;34:20-32.

10. World Health Organization. Tuberculosis country profiles: Malaysia. Geneva: World Health Organization; 2018. [cited 2019 Sep 16]. Available from: https://www.aidsdatahub. org/resource/malaysia-tuberculosis-countryprofile-2018

11. Disease Control Division (TB/Leprosy Sector) Ministry of Health Malaysia. National strategic plan for tuberculosis control (20162020). Putrajaya: Ministry of Health Malaysia; 2016. Report no: KKM/BI/5000/2018. 
12. Kananatu K. Healthcare financing in Malaysia. Asia Pac J Public Health. 2002;14(1):23-8.

13. Liam CK, Tang BG. Delay in the diagnosis and treatment of pulmonary tuberculosis in patients attending a university teaching hospital. Int J Tuberc Lung Dis. 1997;1(4):326-32.

14. Ali SM, Anjum N, Naureen F, et al. Satisfaction level of tuberculosis patients regarding their access to tb care and prevention services, delivered through a public-private mix model in Pakistan. Healthcare (Basel). 2019 [cited 2020 Jan 20];7(4):119. Available from: https://www. mdpi.com/2227-9032/7/4/119 DOI: 10.3390/healthcare7040119

15. Arora VK, Sarin R, Lönnroth K. Feasibility and effectiveness of a public-private mix project for improved TB control in Delhi, India. Int J Tuberc Lung Dis. 2003;7(12):1131-8
16. Thu TD, Kumar AMV, Ramaswamy G, et al. An innovative public-private mix model for improving tuberculosis care in Vietnam: How well are we doing? Trop Med Infec Dis. 2020;5(1):26.

17. Ouy HT, Lan NT, Lönnroth K,et al. Publicprivate mix for improved TB control in Ho Chi Minh city, Vietnam: An assessment of its impact on case detection. Int J Tuberc Lung Dis. 2003;7(5):464-71

18. World Health Organization. Public-private mix for $t b$ prevention and care: A roadmap. Geneva: World health Organization;2018. [cited 2020 Jul 11]. Available from: https:// www.who.int/tb/publications/2018/ PPMRoadmap.pdf?ua=1

19. World Health Organization. Systematic screening for active tuberculosis-principles and recommendations. Geneva: WHO Document Production;2013. [cited 2019 Sep 16]. Available from: https://www.who.int/tb/publications/ Final_TB_Screening_guidelines.pdf
20. Ministry of Health Malaysia. Clinical practice guideline: Management of tuberculosis Malaysia. Kuala Lumpur: Ministry of Health Malaysia; 2012. [cited 2019 Dec 16]. Available from: http://www.moh.gov.my/moh/ attachments/8612.pdf

21. Liew SM, Khoo EM, Ho BK, et al. Tuberculosis in Malaysia: predictors of treatment outcomes in a national registry. Int J Tuberc Lung Dis. 2015;19(7):764-71.

22. Mohidem NA, Hashim Z, Osman M, et al. Demographic, socio-economic and behavior as risk factors of tuberculosis in Malaysia: A systematic review of the literature. Rev Environ Health. 2018;33(4):407-21. 


\section{Exploring women's perceptions and experiences of menopause among East Coast Malaysian women}

Nurul Najmi Mohamad Ishak, Nurjasmine Aida Jamani, Siti Roshaidai Mohd Arifin, Azwanis Abdul Hadi, Karimah Hanim Abd Aziz

Mohamad Ishak NN, Jamani NA, Mohd Arifin SR, et al. Exploring Women's Perceptions and Experiences of menopause among East Coast

Malaysian Women. Malays Fam Physician. 2021;16(1);84-92. https://doi.org/10.51866/oa1098

\section{Keywords:}

Menopause, experience,

Malaysia, women

\section{Authors:}

Nurjasmine Aida Jamani

(Corresponding author)

MD, M. Med (Fam Med), IBCLC

Department of Family Medicine

Kulliyyah of Medicine, International

Islamic University Malaysia

Pahang, Malaysia

email: minaida@iium.edu.my

Nurul Najmi Mohamad Ishak

MBBS

Department of Family Medicine

Kulliyyah of Medicine, International

Islamic University Malaysia

Pahang, Malaysia

Siti Roshaidai Mohd Arifin

$\mathrm{PhD}$ (Midwifery), MNSc,

BHSc, RN, RM

Department of Special Care Nursing Kulliyyah of Nursing International Islamic University Malaysia

Pahang, Malaysia

\section{Azwanis Abdul Hadi}

MBChB, M.Med (Fam Med)

Deparment of Family Medicine

Kulliyyah of Medicine, International

Islamic University Malaysia

Pahang, Malaysia

\section{Abstract}

Background: Menopause signifies the beginning of a non-reproductive phase from the reproductive period. Although it is considered a natural life transition, recent studies have indicated that a woman's menopausal experience may impact her quality of life. While studies have examined Malaysian women's knowledge and awareness of menopause, they have focused on the prevalence of menopausal symptoms and sociocultural aspects. These investigations also used a quantitative design that may have limited the information regarding the nature and experience of menopause.

Objectives: This study explores women's perceptions and understanding of their menopausal experience.

Methods: A total of 20 menopausal women were recruited using purposive sampling through social media in the state of Pahang, Malaysia. In-depth semi-structured interviews were used to explore how they perceived their menopausal experience. The data were then analyzed using thematic analysis.

Results: Three themes that emerged from the findings included perceptions of menopause, biopsychosocial changes and help-seeking behavior. For many Muslim women, menopause was perceived as a time for them to engage in religious commitment more than they had before.

Conclusion: The study findings uncovered a knowledge gap and a lack of support for women impacted by menopause. Muslim women regarded their menopause phase as a time for them to engage in religious duty fully. These results indicate the need for a psychosocial intervention and educational program to ensure women a better transition throughout their menopausal phase.

\section{Introduction}

Menopause comes from the Greek word "meno," meaning month, and "pausia," which means stop or halt. ${ }^{1}$ Menopause signifies the end of menstruation due to the loss of ovarian follicular activity resulting in reduced estrogen and progesterone levels. ${ }^{2}$ This phenomenon marks the beginning of a non-reproductive phase following the reproductive phase. During this phase, women might face a struggle in coping with menopausal symptoms. Symptoms such as hot flushes, fatigue, joint and muscle pain, headache, urinary problems, depression, and mood swings are commonly reported.

While menopause is considered a natural life transition, recent studies have shown that women's menopausal experience may impact their quality of life.,4 For example, some women have experienced negative mood and depressive symptoms during the menopausal transition. ${ }^{5}$ Moreover, researchers have reported that common menopausal symptoms such as sleep disturbance and cognitive problems negatively impacted women's work and relationship. ${ }^{6}$

Previous studies have indicated that menopausal women preferred to seek help from informal sources, such as friends and relatives, rather than healthcare providers, suggesting that women perceive menopause as a natural event. ${ }^{4,7}$ Evidence revealed that a lack of knowledge regarding treatment available for menopause resulted in not seeking help from formal sources such as healthcare providers. For example, Alshogran et $\mathrm{al}^{8}{ }^{8}$ found that most of the participants in their study did not know the roles, benefits, and risks of hormone replacement therapy (HRT).

Similarly, other studies reported that most menopausal women were uncertain about how long their menopausal symptoms might last and were not aware of hormone replacement therapy. ${ }^{6,9}$ Although some women revealed a sufficient understanding of the immediate effects of menopause, they exhibited a lack 
Karimah Hanim Abd Aziz $\mathrm{MPH}, \mathrm{DrPH}$

Department of Community Medicine Kulliyyah of Medicine, International Islamic University Malaysia Pahang, Malaysia of knowledge of the long-term consequences and reflected a negative attitude towards therapy. ${ }^{10}$ Furthermore, Stanzel et al.'s review of 19 studies $^{11}$ indicated that self-management strategies for menopausal symptoms were influenced by culture where menopause was considered a normal condition. Inadequate health-related knowledge about and awareness of menopause as evidenced in the above studies resulted in poor treatment-seeking behaviour. ${ }^{9,12}$

Studies found several barriers that hindered menopausal women from seeking help, including low menopause-related health literacy, perceived low priority for seeking help for symptoms, limited availability of health services and cost, financial issues, and considering menopause a part of the normal aging process., ${ }^{4,13}$ Some evidence revealed that many menopausal women appeared to "normalize" their menopausal symptoms or viewed menopause as a natural event and commonly sought menopause-related information from family and friends as a result. $^{4,14}$

While women often felt isolated, they were reluctant to talk openly about menopause or consult a healthcare professional. ${ }^{6}$ Some women felt dissatisfied with the care they had received for menopause and its treatment and considered the information and support available to them insufficient. ${ }^{6,11}$ Perceptions of menopause as a normal life phase also contributed to non-help-seeking behavior in the majority of women across countries and cultures. ${ }^{4,6}$

Although a few studies have evaluated women's knowledge and awareness of menopause in Malaysia, ${ }^{15-18}$ most studies focused on the prevalence of menopausal symptoms and sociocultural aspects. These studies also used a quantitative design that might have limited the information on the nature and experience of menopause. Furthermore, the use of quantitative approaches (e.g., cross-sectional design and self-reported questionnaire) in the majority of these studies limited further explanation of Malaysian women's experience of menopause.

A comprehensive exploration of women's experience of menopause is essential. The information sought could be applied by healthcare providers to evaluate, enhance, and promote future menopause education programs. In particular, this study's findings will form the basis for future interventions for menopausal women in Malaysia.

Thus, this study explores menopausal experience in postmenopausal women, their knowledge and perceptions toward menopause, self-help strategies in managing menopause, and the barriers to seeking help or treatment.

\section{Method}

\section{Theoretical Framework}

Evidence shows that the experience of menopausal symptoms is influenced by individual, cultural, social, and psychological factors. ${ }^{19,20}$ Thus, it seems relevant to apply the self-regulation model to explain women's cognitive representations of menopause and how they cope with their experienced symptoms. ${ }^{21}$

According to this theory, behavior is guided by a motivational system of setting goals, developing and enacting strategies to achieve those goals, evaluating progress, and revising goals and actions accordingly. Self-regulation models are commonly used to explain healthrelated behaviors adopted to improve health, such as avoiding sources of stress, obtaining informal sources of health information, seeking medical care, adhering to prescribed medication, and performing regular physical exercise. $^{22}$

The basic element of the model is the concept of feedback. In the case of menopause, a woman who understands that menopause is a condition requiring certain behavioral changes will search for information about the outcomes of her behaviors and move toward the desired outcome. This model also emphasizes selfcontrol, willpower, and the role of emotions in motivating and guiding behavior.

\section{Study design and setting}

This study is a qualitative research design using purposive sampling involving 20 women who had reached menopause in Kuantan, Pahang. Accordingly, the women selected in this study presented particular characteristics that enable a detailed exploration and understanding of menopause in Malaysia.

Purposive sampling is a vital sampling method in a qualitative study that entails 
identifying and selecting individuals or groups of individuals who are knowledgeable or have experienced a phenomenon of interest based on the selection criteria. ${ }^{23-24}$ In this study, women were purposely selected based on their age and years of menopause.

A qualitative method was used to explore the experience of menopause among these women since this approach offers the advantage of exploring women's experiences comprehensively through in-depth interviews, helping the researcher understand how menopausal women make sense of their lives and their experiences. Furthermore, this practice comprises the most frequent type of qualitative study done in all fields of practice, including the health sector.

In-depth interviews were chosen for this study as a more appropriate investigation tool for disclosing personal, sensitive information such as attitude and experience related to intimate issues compared to focus group discussion. ${ }^{25}$ In this case, menopause is considered a sensitive issue among Asian women; this study aimed to provide insight into how women interpreted their menopausal experience. ${ }^{26}$

\section{Sampling}

The participants were recruited through advertising on social media platforms such as Facebook, WhatsApp, and Instagram. Inclusion criteria and the researchers' contact details were included in the advertisement. The inclusion criteria were women who had experienced natural menopause within 5 years based on their recalled last menstrual period and symptoms of menopause. Women who had surgical menopause, premature menopause, and psychiatric illness were excluded.

Women who fulfilled the criteria and agreed to participate were given a date for the interview, which was determined based on the researchers' and respondents' availability. Data were collected for a period of 4 months, from May 2018 to August 2018.

Sample size is estimated based on the concept of saturation for qualitative research. Based on Dworkin ${ }^{27}$, a minimum of 5 participants and a maximum of 50 participants comprised an adequate sample size for using in-depth interviews. In this study, no new themes emerged after 15 respondents. Nevertheless, the researchers increased the recruitment of respondents up to 20 postmenopausal women to ensure data saturation was reached.

\section{Data collection}

Participants were invited for interviews at a time, date, and location that suited their convenience and preference. The semi-structured in-depth interviews were conducted using open-ended questions. The topic guide was developed based on the research questions that addressed menopausal knowledge, experiences, attitudes, and beliefs about menopause, along with the symptoms and ways of coping with menopause. We prepared an interview guide (Table 1), and the interview questions were established following a literature review. ${ }^{28-31}$ Two pilot interviews were conducted to refine the topic guide and evaluate and enhance the rigor of the interview sessions.

Interviews were conducted in either the Malay language or the English language. For this study, all interviews were conducted in the participants' houses. The participants provided written consent and brief sociodemographic information before the interview sessions. Confidentiality and anonymity were maintained. Each interview session was conducted only once for each participant, and each lasted for 45 to 60 minutes. The data from the interviews were audio-recorded and transcribed verbatim.

\section{Data analysis}

The data from this study were manually analyzed using thematic analysis as described by Braun and Clarke. ${ }^{32}$ During analysis, the transcript was first read to encourage data immersion, after which codes were determined by highlighting words or phrases from the text to capture key concepts.

Notes were made concerning first impressions of the data, and the codes were sorted into categories based on links. These categories organized the codes into meaningful clusters, facilitating deriving themes. The advantage of this analysis method is the ability to gain direct information without imposing preconceived categories. However, it may fail to identify key categories. Once all investigators agreed that the categories were saturated, the recruitment process was finalized. 
Table 1. Topic Guide

\begin{tabular}{|c|c|}
\hline $\begin{array}{l}\text { Women's experience during } \\
\text { menopause }\end{array}$ & Questions \\
\hline $\begin{array}{l}\text { Experiences of women during } \\
\text { menopause }\end{array}$ & $\begin{array}{l}\text { 1. Can you tell me about your life after cessation of menses? } \\
\text { 2. Could you tell me what symptoms have you encountered during } \\
\text { menopause? } \\
\text { 3. Can you tell me how menopause affects your general health? }\end{array}$ \\
\hline $\begin{array}{l}\text { Effect of menopause on } \\
\text { women's quality of life? }\end{array}$ & 1. Can you tell me how menopause affects your life in any way? \\
\hline Coping with the symptoms & $\begin{array}{l}\text { 1. How do you deal/cope with menopausal symptoms? } \\
\text { 2. What kind of assistance have you needed? Why did you choose it? }\end{array}$ \\
\hline Help-seeking & 1. Can you tell me why you didn't see your health practitioner? \\
\hline
\end{tabular}

We used maximum variance among participants where the participants had different levels of education and social background to ensure credibility. Furthermore, a member checking process entailed setting appointments to visit the participants in their homes. The participants read the polished content of the transcripts and the quotations cited. Rich, thick description was used to provide many perspectives about a theme to allow the results to be richer and realistic.

\section{Ethical Approval}

This study was approved by the International Islamic University Malaysia Research Ethics Committee with the project code IREC2018-069. All participants received verbal and written information before signing the informed consent form. All were informed about confidentiality and the right to withdraw their consent to participate in this study. Personal details have been changed to ensure that the participants are not identifiable.

\section{Results}

\section{Demographic characteristics}

In this study, 20 menopausal women between the ages of 49 and 61 years participated voluntarily, as shown in Table 2.

Most participants were Malays, were married, and had 3 or more children. Half of them were employed and had secondary education. Most had their menopause within the previous 3 years.

Table 2. Descriptive characteristics of participants

\begin{tabular}{|c|c|c|c|c|c|c|c|c|}
\hline No & Pseudonym & $\begin{array}{c}\text { Age at } \\
\text { interview }\end{array}$ & Race* & $\begin{array}{c}\text { Marital } \\
\text { status }\end{array}$ & Parity & $\begin{array}{c}\text { Years of } \\
\text { menopause }\end{array}$ & $\begin{array}{c}\text { Education } \\
\text { level }\end{array}$ & Occupation \\
\hline 1 & S & 58 & M & Divorce & 1 & 3 & Primary & Housewife \\
\hline 2 & H & 54 & M & Married & 5 & 1 & Secondary & Therapist \\
\hline 3 & A & 57 & M & Married & 4 & 1 & Tertiary & Staff nurse \\
\hline 4 & WH & 52 & M & Married & 6 & 2 & Secondary & Housewife \\
\hline 5 & RM & 58 & M & Married & 3 & 4 & Secondary & Community nurse \\
\hline 6 & AS & 54 & M & Single & 0 & 1 & Secondary & Food staller \\
\hline 7 & Z & 56 & M & Married & 5 & 3 & Secondary & Frozen food retailer \\
\hline 8 & HS & 59 & M & Married & 4 & 4 & Tertiary & Pensioner \\
\hline 9 & N & 49 & M & Single & 0 & 1 & Tertiary & Consultant \\
\hline 10 & ZD & 54 & M & Divorce & 6 & 4 & Secondary & Cleaner \\
\hline 11 & C & 54 & C & Married & 3 & 4 & Secondary & Housewife \\
\hline 12 & F & 53 & M & Married & 4 & 2 & Primary & Food staller \\
\hline 13 & ZK & 56 & M & Married & 4 & 3 & Primary & Clerk \\
\hline 14 & NG & 53 & M & Divorce & 0 & 2 & Tertiary & Procurement analyst \\
\hline 15 & NS & 55 & M & Married & 2 & 3 & Tertiary & Housewife \\
\hline 16 & RO & 54 & M & Married & 3 & 3 & Tertiary & Business-woman \\
\hline 17 & AM & 58 & M & Divorce & 7 & 5 & Primary & Housewife \\
\hline 18 & NJ & 49 & M & Married & 5 & 2 & Secondary & Housewife \\
\hline 19 & L & 61 & C & Married & 4 & 3 & Secondary & Housewife \\
\hline 20 & PM & 57 & I & Married & 2 & 5 & Secondary & Housewife \\
\hline & & & & & & & & \\
\hline
\end{tabular}

* Note: M-Malay, C-Chinese I- Indian 


\section{Menopausal women's experiences}

Three themes were identified to explain the women's experiences with menopause: perception of menopause, biopsychosocial changes, and help-seeking behavior. The following discussion presents details about the themes and selected quotations from the interviews.

\section{Theme 1: Perception of menopause}

The findings indicated that the participants perceived menopause as a negative element in their lives, indicating the beginning of growing old and a phase involving health deterioration. One of them mentioned:

"Since menopause, I always get sick. I easily get fever, cough and flu. It's almost two years I felt like this. This year, almost every month I need to go to the clinic for being unwell. I fainted last year. I have done my medical checkup, and everything was told to be normal. I don't know why it happened. My general health has not been good since menopause. Before this, I seldom fall sick."

\section{(ZK, 56, Malay)}

However, some women perceived menopause as a positive event, marking the end of the reproductive phase. One woman commented:

"When we have reached menopause, we don't need to think about pregnancy. We don't need to worry during intercourse like taking pills, etc. (laughing)." (RO, 54, Malay)

Menopause was also perceived as a time for religious commitment. Another participant expressed her thoughts as follows:

"We couldn't perform prayer or fasting during menses. Now, we can perform prayer, reciting Quranic verses, and fast comfortably during menopause. At the premenopausal time, we got a certain time to recite the Quran. But, when we reached menopause, every time and every second, we can recite the Quran. No more obstacles compared to those days. I can't say it's an obstacle as it is a natural process of women as God gave us a break from religious duty during menses. We can do religious duty better after menses stopped. It's not proper to call it an obstacle. We are enjoying our lives now." (NS, 55, Malay)

\section{Theme 2: Biopsychosocial changes}

This study's findings validate the changes that women experience during menopause. Some participants reported experiencing physical or somatic symptoms. One of them mentioned:
"I felt pain in my entire body. Sometimes I felt pain over my legs (pointed to both legs). The whole body is in pain, including the muscles. This condition happened since menopause. People said once you reached menopause, you are prone to all the diseases. Back then, I got muscles spasm and had met a doctor. The doctor said it was because of stress. The doctor also asked about my job. Basically, all of these are symptoms of menopause." (RO, 54, Malay)

Furthermore, most experienced psychological and emotional changes that affected their daily lives. For example, one woman asserted:

"In terms of emotions, I do feel terrible. However, there is a time I do feel much better. Previously back then I was not too emotional, and I was able to control it. But now, I realized that I've changed. I'm a bit sensitive. Sometimes, I felt very bad-tempered. Even though it was not so bad, but I could feel that I had changed. Before this, I could accept this as natural, but when I was in menopausal state, I easily felt sensitive, sad, and easily get irritated." (NS, 55, Malay)

\section{Theme 3: Help-seeking behavior}

Help-seeking behavior relates to the behavior that equipped the participants with ways to cope with the symptoms and negative experience of menopause. None of the participants sought professional help. Instead, some used alternative remedies, lifestyle changes, and spiritual practice to overcome these symptoms. Some of the examples they mentioned included the following:

"Nowadays, I feel much better when taking supplements. I consumed various type of supplements every day to boost up my estrogen level and for the skin; for instance primrose oil, calcium tablets as well as vitamin C. I also took 'jamu' (Malay traditional herbs) in a capsule form like 'X'(herb's brand name)." (RO, 54, Malay)

"Mmm... when something irritates me, I keep quiet for a while. By doing this, I could soothe my feelings. I felt much better if I took a rest, zikr (remembrance of God). " (H, 54, Malay)

At the same time, the barriers some of these women reported in terms of seeking treatment involved a lack of knowledge about the availability of treatment and their belief that menopause is a natural course of events for all women. Among the ideas mentioned were these thoughts:

"I don't have any idea about the treatment as well as health services for menopause. I always 
get treatment for my sickness but never heard about it. I never know that menopause has a treatment." (S, 58, Malay)

"I felt not necessary to get treatment. Every woman will experience menopause when the right time comes. I think we need to take milk and supplements when menopause." (A, 57, Malay)

\section{Discussion}

The study findings identified that the women interviewed had different perceptions and underwent varied experiences of menopause. Three major themes were derived from the findings: perception of menopause, biophysical changes, and help-seeking behavior.

\section{Perception of menopause}

The study found that menopause was perceived as an aging process and involved health deterioration. This result is comparable with other studies. ${ }^{29-31}$ The participants believed that reaching menopause is the final road of life, and they accept it wholeheartedly. Nonetheless, aging has been related to a phase that involves deteriorating health and body function, disability, being dependent, and being a burden to others. ${ }^{29}$ Most of the women highlighted changes in facial appearance, skin texture, and body image. They viewed menopause negatively as a time, when growing older, in which all their beauty, youth, and femininity would diminish. ${ }^{33}$ However, this perception also reflects the idea that women tend to embrace menopause as part of a natural process that all women will go through.

Nevertheless, most of the women in our study perceived menopause as a positive experience. They viewed menopause optimistically as a phenomenon that ended the miseries of the reproductive phase, such as menstrual problems and pregnancy, as other studies have reported. ${ }^{31,34,35}$ Bad menstrual experiences, such as cyclical period pain, heavy menses, and fear of pregnancy, finally came to an end upon reaching menopause.

Interestingly, most of the women in this study perceived menopause as a time for them to engage in religious duty, especially among Muslims. This emerging subtheme had not been included in any existing model reviewed. One previous study mentioned that spirituality and religiosity might help women to cope and overcome the menopause life phase better. ${ }^{36}$
The participants generally viewed menopause as bringing an opportunity for them to concentrate more on religious duty that they could not perform during menstruation. Previously, they were bound to their duty towards their family's needs and occupational scope. As they reached menopause, most of them were already retired, allowing them more time to perform religious obligations.

\section{Biopsychosocial changes}

In this study, we found that the participants' most commonly reported symptoms were somatic and psychological. The most common physical symptoms that the women in the study experienced involved musculoskeletal problems, including joint pain, bone-related pain, and body aches, followed by vasomotor symptoms, especially hot flushes and tiredness. This result is comparable with previous studies in other Asian countries ${ }^{37,38}$ and studies done in Malaysia. ${ }^{39,40}$

On the contrary, several studies in Asian and Western countries have reported a higher occurrence of vasomotor and urogenital symptoms than our study participants indicated. ${ }^{41-43}$ The difference in the prevalence of symptoms could be due to estrogen fluctuations that happen mostly in the perimenopausal period as well as psychosocial factors, lifestyle, and culture. Variations in results may also be the result of enormous methodological variation across studies. Additionally, physical symptoms such as tiredness and musculoskeletal problems may coincide with the aging process. ${ }^{44}$

\section{Help-seeking behavior}

Our study findings noted that none of the participants sought treatment for their menopausal symptoms. This outcome could be attributed to a lack of knowledge regarding menopause and its treatment. Huang et al. ${ }^{45}$ reported that about $46 \%$ of Asian women had never read, heard, or seen any information about hormone replacement treatment (HRT). In comparison, European women were more likely to be aware of the availability of HRT. ${ }^{45,46}$

Most of the women in this study preferred natural remedies, supplements, or herbal medication to ease their menopausal symptoms, which is similar to Huang et al.'s findings. ${ }^{45}$ Religious activities, such as performing prayers and reciting the zikr 
(remembrance of God), were also found to be helpful in easing menopausal symptoms. It could be possible that these women did not seek treatment because they considered menopause part of the aging process and a natural occurrence; hence, they tended to embrace it better.

\section{Strengths and limitations of the study}

One strength of this study is that the participants belonged to different socioeconomic backgrounds. Furthermore, the study findings provided a deep understanding of women's perceptions and experiences relating to menopause. However, this study also has some limitations.

In this study, most of the participants were mostly Malay Muslims, limiting the application of these findings to the whole Malaysian population. Health records were not accessed, nor was any investigation undertaken to confirm menopausal status.

\section{Conclusion}

This study's results uncovered a knowledge gap and a lack of support for women impacted by menopause. Muslim women regarded their menopause phase as a time to fully engage in religious duty. Such findings highlight the need for psychosocial intervention and educational programs suited to individuals' cultural and spiritual aspects to support women during this phase of life. Primary healthcare practitioners must be aware of the need for a health promotion program conducted within their healthcare setting to increase women's and families' knowledge of menopause to promote help-seeking behavior and lead to better postmenopausal health for this group of women. ${ }^{7,11}$

\section{Conflict of Interest}

The authors declare no conflict of interest.

\section{Acknowledgment}

We would like to thank all participants who were involved in this study.

\section{Funding}

This research did not receive any specific grant from funding agencies in the public, commercial, or not-for-profit sectors.

\section{How does this paper make a difference to general practice?}

- This study creates and increases awareness that menopausal symptoms are prevalent among Malaysian women and can impact a women's life quality.

- The findings and conclusion stress the importance of educating perimenopausal and menopausal women to seek help in managing their menopausal symptoms.

\section{References}

1. Marahatta RK. Study of menopausal symptoms among peri and postmenopausal women attending NMCTH. Nepal Med Coll J. 2012;14(3):251-255.

2. Goodman NF, Cobin RH, Ginzburg SB, Katz IA, Woode DE. American Association of Clinical Endocrinology medical guidelines for clinical practice for the diagnosis and treatment of menopause. Endocr Pract. 2011;17 (Suppl 6):1-25.
3. Taebi M, Abdolahian S, Ozgoli G, Ebadi A, Kariman N. Strategies to improve menopausal quality of life: a systematic review. J Edu Health Promot. 2018;7(93):1-10.

4. Stanzel KA, Hammarberg K, Fisher J. "Not everybody is an internet person": Barriers for menopause-related health literacy among immigrant women from the Horn of Africa nations. Health Promot J Austr. 2020;00:1-8.
5. Campbell KE, Dennerstein L, Finch S, Szoeke CE. Impact of menopausal status on negative mood and depressive symptoms in a longitudinal sample spanning 20 years. Menopause J North Am Menopause Soc. 2017;24(15):490-496.

6. Currie H, Moger SJ. MenopauseUnderstanding the impact on women and their partners. Post Reprod Health. 2020;25(4):183190. 
7. Hofnie-Hoëbe K, Weightman A, Shatona M, Kelson M. Information sources consulted by women in African countries to manage menopausal symptoms: a systematic review and meta-analysis. Open Journal of Nursing, 2018;(8): 317-338

8. Alshogran OY, Mahmoud FM, Alkhatatbeh MJ. Knowledge and awareness toward menopause and hormone therapy among premenopausal women in Jordan. Climacteric. 2020; (11):1-8.

9. Mustafa GN, Sabir JM. Perception and experience regarding menopause among menopaused women attending teaching hospitals in Erbil city. Glob J Health Sci. 2012;4(3):170-178.

10. Herbert D, Bell RJ, Young K, Brown H, Coles JY, Davis SR. Australian women's understanding of menopause and its consequences: a qualitative study. Climacteric. 2020; 23 (6):622-628.

11. Stanzel KA, Hammarberg K, Fisher J. Experiences of menopause, self-management strategies for menopausal symptoms and perceptions of health care among immigrant women: a systematic review. Climacteric. 2018;21(2):101-110

12. Joseph L, Varghese AP. Prevalence of menopausal symptoms and perceptions about menopause among postmenopausal women attending Gynaecology OPD at GMC Idukki, India. Int J Reprod Contracept Obs Gynecol. 2017;6(2):413-441.

13. Ghazanfarpour M, Khadivzadeh T, Latifnejad Roudsari R, Mehdi Hazavehei SM. Obstacles to the discussion of sexual problems in menopausal women: a qualitative study of healthcare providers. J Obstet Gynaecol. 2017;37(5):660-666.

14. Faccio E, Solarino M, Vitelli R, and Cipolletta S. Normalisation versus medicalisation of sexual disturbances during menopause: a qualitative research in the Italian context. Sexuality \& Culture. 2018; 22(2), 445-461.

15. Abdullah B, Moize B, Ismail BA, Zamri M, Mohd Nasir NF. Prevalence of menopausal symptoms, its effect on quality of life among Malaysian women and their treatment seeking behaviour. Med J Malaysia. 2017;72(2):9499.
16. Hassan SS, Thiruchelvam K, Ahmed SI, Clavarino AM, Mamun AA, Kairuz T. Psychological health and menopause-specific quality of life of Malaysian women with type 2 diabetes. Asian J Psychiatr. 2016; 23:56-63.

17. Diah NM. The knowledge of menopause and its treatment among Orang Asli in Gombak. Int Res J Soc Sci. 2013;2(8):1-4.

18. Diah NM. Exploring a sensitive issue: menopause experience among urban Malay women in Malaysia. 2007 [proceeding]

19. Quiroga A, Larroy C, Gonzalez-Castro P. Climacteric symptoms and their relation to feminine self-concept. Climacteric 2017;20(3):274-279.

20. Schneider HPG, Birkhäuser M. Quality of life in climacteric women. Climacteric 2017;20 (3):187-194.

21. Leventhal H, Leventhal EA, Contrada RJ. Self-regulation, health, and behavior: a perceptual cognitive approach. Psychology \& Health 1998;13:717-733.

22. Pimenta F, Ramos MM, Silva CC, Costa PA, Maroco J, Leal I. Self-regulation model applied to menopause: a mixed-methods study. Climacteric.2020 23(1), 84-92.

23. Meriam S B, Tisdell EJ. Designing your study and selecting a sample. In Qualitative Research-A Guide to Design and Implementation 2016 (pp. 95-98).

24. Palinkas LA, Horwitz SM, Green CA, Wisdom JP, Duan N, Hoagwood K. Purposeful sampling for qualitative data collection and analysis in mixed method implementation research. Adm Policy Ment Health.2015;42(5):533-544.

25. Powell RA, Single HM. Methodology matters-v focus groups. International Journal for Quality in Health Care, 1996.8(5), 499-504.

26. Hakimi S, Simbar M, Tehrani F. Perceived concerns of Azeri menopausal women in Iran. Iranian Red Crescent Medical Journal. 2014; 16(5), 1-7.
27. Dworkin SL. Sample size policy for qualitative studies using in-depth interviews. Arch Sex Behav. 2012;41(6):1319-1320.

28. Gill P, Stewart K, Treasure E, Chadwick B. Methods of data collection in qualitative research: interviews and focus groups. Br Dent J. 2008; 204(6), 291-295.

29. Sakdiah MH, Sulaiman H, Zulkefli NA. Views on ageing: a qualitative study among malay middle-aged women in urban setting in Malaysia. Int J Heal Sci Res. 2015;5(April):248-256.

30. Wong LP, Nur Liyana AH. A survey of knowledge and perceptions of menopause among young to middle-aged women in federal territory, Kuala Lumpur, Malaysia. J Univ Malaya Med Cent. 2007;10(2):22-30.

31. Mahadeen AI, Halabi JO, Callister LC. Menopause: a qualitative study of Jordanian women's perceptions. Int Nurs Rev. 2008;55:427-33.

32. Braun V, Clarke V. Using thematic analysis in psychology. Qualitative Research in Psychology, 2006 3(2), 77-101.

33. Anderson D, Posner N. Relationship between psychosocial factors and health behaviours for women experiencing menopause. Int J Nurs Pract. 2002;8:265-273.

34. Brown L, Brown V, Judd F, Bryant C. It's not as bad as you think: menopausal representations are more positive in postmenopausal women. J Psychosom Obstet Gynecol. 2018;39(4):281-288.

35. Im E-O, Lee SH, Chee W. "Being conditioned, yet becoming strong": Asian American Women in Menopausal Transition. J Transcult Nurs. 2011;22(3):290-299.

36. Strezova A, O’Neill S, O'Callaghan C, Perry A, Liu J, Eden J. Cultural issues in menopause: an exploratory qualitative study of Macedonian women in Australia. Menopause. 2017;24(3):308-315.

37. Shea JL. Chinese women's symptoms: relation to menopause, age and related attitudes. Climacteric. 2006;9(1):30-9. 
38. Li L, Wu J, Pu D, Zhao Y, Wan C, Sun L, et al. Factors associated with the age of natural menopause and menopausal symptoms in Chinese women. Maturitas. 2012;73(4):354360 .

39. Dhillon HK, Singh HJ, Shuib R, Hamid AM, Mohd Zaki Nik Mohamad N. Prevalence of menopausal symptoms in women in Kelantan, Malaysia. Maturitas. 2006;54(3):213-221.

40. Syed Alwi SA, Lee PY, Awi I, Malik PS, Md Haizal MN. The menopausal experience among indigenous women of Sarawak, Malaysia. Climacteric. 2009;12(6):548-556.
41. Chuni N, Sreeramareddy CT. Frequency of symptoms, determinants of severe symptoms, validity of and cut-off score for Menopause Rating Scale (MRS) as a screening tool: a cross-sectional survey among midlife Nepalese women. BMC Women's Health. 2011;11(30):1-9.

42. Yanikkerem E, Koltan SO, Tamay AG, Dikayak S. Relationship between women's attitude towards menopause and quality of life. Climacteric. 2012;(15):552-562.

43. Ali S, Tarin AU, Bhatti R. Average age of menopause and its climacteric symptoms in women of Multan city. Pakistan Journal Medical Health Sciences. 2015;9(1):262-4.
44. Rahman SASA, Zainudin SR, Mun VLK. Assessment of menopausal symptoms using modified Menopause Rating Scale (MRS) among middle age women in Kuching, Sarawak, Malaysia. Asia Pac Fam Med. 2010;9(1):5.

45. Huang KE, Xu L, I NN, Jaisamrarn U. The Asian Menopause Survey: knowledge, perceptions, hormone treatment and sexual function. Maturitas. 2010;65(3):276-283.

46. Genazzani AR, Schneider HP, Panay N, Nijland EA. The European Menopause Survey 2005: women's perceptions on the menopause and postmenopausal hormone therapy. Gynecol Endocrinol. 2006;22(7):369-375. 


\section{Prevalence of musculoskeletal pain in two primary care clinics in a mid-sized town's urban population in Malaysia}

Esha Dasgupta, Jasmine Li Lin Yap, K. Kirosa Kunjunee, Xin Ying Choong, Wan Wen Soh, Meroshini Sundaran, Swan Sim Yeap, Keen Sang Tai

Dasgupta E, Yap JLL, Kunjunee KK, et al. Prevalence of Musculoskeletal Pain in Two Primary Care Clinics in a Mid-Sized Town's Urban Population in Malaysia. Malays Fam Physician. 2021;16(1);93-102. https://doi.org/10.51866/oa1102

\section{Keywords:}

Musculoskeletal pain,

Disability, Primary care clinic

\section{Authors:}

\section{Tai Keen Sang}

(Corresponding author)

MBBS, FRCP

Senior Lecturer, International

Medical University, Clinical Campus

Seremban, Negeri Sembilan

Malaysia

Email: keensangtai@imu.edu.my

\section{Esha Dasgupta}

MBBS, FRCP, FRCPI

Professor of Medicine, International Medical University, Clinical Campus Seremban, Negeri Sembilan Malaysia

\section{Jasmine Yap Li Lin}

Medical student, International Medical University, Clinical Campus Seremban, Negeri Sembilan Malaysia

\section{K. Kirosa Kunjunee Medical student, International Medical University, Clinical Campus Seremban, Negeri Sembilan Malaysia}

\section{Choong Xin Ying}

Medical student, International Medical University, Clinical Campus Seremban, Negeri Sembilan Malaysia

\section{Abstract}

Objective: This study assesses the prevalence of musculoskeletal (MSK) pain in patients attending primary care clinics in a medium-sized town in Malaysia and examines the interventions given for the symptoms and the level of the associated disabilities.

Method: This investigation comprises a cross-sectional descriptive study of all patients visiting two primary care clinics aged 18 years and above. Patients presenting with joint pain answered a questionnaire assessing demographic data, disabilities (measured by the Stanford HAQ-DI), and treatment options.

Results: Of 1,074 patients surveyed, 202 (18.8\%) had MSK complaints. The mean age of those with MSK pain was 56.1 years. Incidence increased with age, reaching $78.8 \%$ of those over 48 years of age. The knee was the most common site of MSK pain (52.2\%), with 20.3\% requiring referral for specialist assessment. The median HAQ score was 0.375 and $89.6 \%$ of those surveyed had mild disability.

Conclusion: MSK pain is a common problem among patients visiting primary care clinics. The most common site of MSK pain was the knee. On formal assessment, the majority of these patients exhibited mild disability. A significant proportion of patients still required specialist referral. This finding would suggest a need for further training on the management of MSK disease at the primary care level to avoid over-burdening the secondary care services.

\section{Introduction}

Rheumatic diseases contribute a significant burden to the population's health. In 2017, the Global Burden of Disease study found that musculoskeletal (MSK) disorders ranked fifth in terms of disability-adjusted life years (DALYs) per 100,000 population worldwide. $^{1}$ MSK disorders are the leading global contributor to disability, causing pain and limiting mobility and dexterity. ${ }^{2}$ Moreover, the prevalence of MSK disorders increases with age $^{2}$; thus, with an aging population worldwide ${ }^{3}$, the burden of MSK disorders can be expected to increase. In Malaysia, MSK disorders also ranked fifth in terms of DALYs per 100,000 population, similar to the global results. ${ }^{1}$ Like the rest of the world, Malaysia has an increasingly aged population, and the proportion of the population over the age of 65 is expected to rise from $10.5 \%$ in $2019^{4}$ to $14.5 \%$ in $2040 .^{5}$

In Malaysia, MSK pain was found to be the seventh most common complaint in a primary care setting, comprising $5.9 \%$ of the reasons for encounter (RFE), with back and knee pain representing the most commonly affected sites. ${ }^{6}$ In another study, $6.5 \%$ of visits to primary care clinics involved MSK pain, of which the back, knee, and shoulder were the most common complaints.?

In surveys carried out in Canada, the USA, and Western Europe, the prevalence of physical disabilities caused by a MSK disorder has been estimated at $4-5 \%$ of the adult population., The figures for functional disability are much higher. For example, in a study from Lebanon, the proportion of lifetime functional disability due to MSK problems was as high as onethird of the subjects. ${ }^{10}$ The prevalence is higher in women and increases with age. ${ }^{11}$ In a community-based study from Australia, 53.9\% of women and $37.6 \%$ of men aged between 65-74 experienced impairment of their activities of daily living (ADL) as measured by a Health Assessment Questionnaire score of $>0 .{ }^{12}$ In individuals over 85 years old, the proportion of those with impaired ADL rose to $89.6 \%$ in women and $73.2 \%$ in men. Accompanying the pain and disability was 


\author{
Soh Wan Wen \\ Medical student, International \\ Medical University, Clinical Campus \\ Seremban, Negeri Sembilan \\ Malaysia
}

\section{Meroshini Sundaran \\ Medical student, International \\ Medical University, Clinical Campus \\ Seremban, Negeri Sembilan \\ Malaysia}

\section{Yeap Swan Sim}

MB ChB, MD, FRCP

Consultant Rheumatologist, Subang Jaya Medical Centre, Subang Jaya Selangor, Malaysia also a reduction in the quality of life in people with MSK pain. In Malaysia, no previous surveys have evaluated the effect of MSK pain on the subjects' daily functioning/associated disabilities.

Therefore, this study was carried out in a medium-sized town in Malaysia to determine the prevalence and pattern of MSK pain in a primary care setting, the interventions given for the symptoms, and the level of associated disability in two primary care clinics.

\section{Materials and Methods}

\section{Population sampled}

A cross-sectional study was conducted in the public primary care clinics of Klinik Kesihatan Seremban (KKS) and Klinik Kesihatan Seremban 2 (KKS2) in Seremban, Malaysia, from June 2014 to January 2015. The inclusion criteria were all patients aged 18 and above presenting with a complaint of MSK pain on the day of the clinic visit. Of the approximately 32 patients per clinic, 1-2 patients decided not to participate. Thus, the refusal rate was around $6 \%(2 / 32)$.

\section{Study design}

The study staff went to the above clinics once a week, at which time all patients attending the clinic on those days were asked about their presenting complaint for that visit. Patients with MSK pain were asked whether they would like to participate in the study by completing the questionnaire while waiting to see the doctor. If they agreed, formal consent was made before the patients received the forms for self-completion. All the forms returned were fully completed.

The patients were asked to complete the survey instrument, which was a two-part questionnaire (see Appendix One). The first part was further divided into three sections: section A-questions about the respondent's general characteristics and personal details, section B-data on the MSK pain for that particular clinic visit, and section C-the interventions performed for the MSK pain, by both the patient and the attending doctor. A body chart indicating the names of body parts was used to assess the site of the MSK pain, and participants were asked to make tick marks against all the body parts that were painful. The second part of the questionnaire was the validated Stanford HAQ 20-Item Disability Scale (HAQ-DI) to assess a patient's level of functional ability. ${ }^{13}$ The HAQ-DI, which comprises 20 items in eight categories (dressing, arising, eating, walking, hygiene, reaching, gripping, and outside activity), is measured on a four-point ordinal scale from 0 to 3: 0 without any difficulty, 1 with some difficulty, 2 with much difficulty, and 3 unable to do. The highest score in each category is averaged into a disability index on a scale from 0 (no disability) to 3 (complete disability). The score is the average of the eight category scores, with a range of 0 to 3. From the original studies, scores of 0 to 1 are generally considered to represent mild to moderate difficulty; 1 to 2 , moderate to severe disability; and 2 to 3 , severe to very severe disability. ${ }^{13}$ For the purposes of our analysis, we classified those with scores of 1 and below $(\leq 1)$ to have mild disability, those with scores above 1 and up to 2 as having moderate disability, and those with scores above $2(>2)$ to have severe disability. The questionnaire was available in English and Malay. The scale has a Malay translation ${ }^{14}$ and has been found to be a sensitive, reliable, and valid instrument for the measurement of functional status in rheumatoid arthritis patients in Malaysia. ${ }^{15}$

The following information was obtained from the study population: the patients' sociodemographic data; the presence of MSK pain; the sites of MSK pain and the number of such sites; the interventions tried by the patients, including self-administered analgesia, massage, physiotherapy and/or complementary medicine (acupuncture and traditional herbal medicine); the number that required specialist referral; and an assessment of the degree of disability as measured by the Stanford HAQ 20-Item Disability Scale.

\section{Data analysis}

Data were analyzed using the Statistical Package for Social Sciences (SPSS) version 19 (IBM Corp., Armonk, NY, USA). The Shapiro-Wilk test for normality was used to check that the data were normally distributed. The mean and standard deviations were calculated for the numerical data, and categorical comparisons were analyzed using a chi-square test. A p-value of $<0.05$ was taken to be statistically significant. 


\section{Consent and Ethical Approval}

All subjects provided signed informed consent prior to inclusion in the study. This study was approved by the Joint Committee of the Research and Ethics Committee of the International Medical University [ID No. CScl Sem6(16)2014] and conducted in accordance with the ethical standards laid down in the 2013 Declaration of Helsinki.

\section{Results}

In all, 1,074 patients were approached in the KKS and KKS2 clinics. A total of 202 complained of symptoms of MSK pain and went on to complete the study questionnaires. Therefore, from this study, 202/1,074 (18.8\%) patients presented with a complaint of MSK pain to the primary health clinics.
Table 1 shows the patients' sociodemographic characteristics. Most of the respondents presenting with a complaint of musculoskeletal pain were female $(\mathrm{n}=114 ; 56.4 \%)$. The female-to-male ratio was found to be $1.3: 1$, with a mean age of $56.1 \pm 15.7$ (one standard deviation [SD]) years. Within the different ethnic groups, Indian patients had the highest proportion of MSK pain complaints (39.1\%), followed by Malays (31.7\%), Chinese (27.2\%), and others (2.0\%). Approximately $50 \%$ of patients with MSK pain were employed, while $47.5 \%$ stated that they had "no income." Patients with "no income" were further questioned to ensure that they had no regular income from any employment, including self-employment. Of those who had income, all earned less than RM4000 per month (approximately USD900). The prevalence of MSK pain complaints increased with age, as shown in Figure 1, reaching $78.8 \%$ in those over 48 years of age.

Table 1: Sociodemographic characteristics of patients studied.

\begin{tabular}{|c|c|}
\hline & Number of patients, $\mathrm{N}=202(\%)$ \\
\hline Age (years) $($ mean $\pm S D)$ & $56.1 \pm 15.7$ \\
\hline $\begin{array}{l}\text { Gender } \\
\text { Male } \\
\text { Female }\end{array}$ & $\begin{array}{c}88(43.6) \\
114(56.4)\end{array}$ \\
\hline $\begin{array}{l}\text { Ethnicity } \\
\text { Malay } \\
\text { Chinese } \\
\text { Indian } \\
\text { Others }\end{array}$ & $\begin{array}{c}64(31.7) \\
55(27.2) \\
79(39.1) \\
4(2.0)\end{array}$ \\
\hline $\begin{array}{l}\text { Marital Status } \\
\text { Single } \\
\text { Married } \\
\text { Divorced } \\
\text { Widowed }\end{array}$ & $\begin{array}{c}37(18.3) \\
158(78.2) \\
2(1.0) \\
5(2.5)\end{array}$ \\
\hline $\begin{array}{l}\text { Occupation } \\
\text { Employed/Self-employed } \\
\text { Unemployed/Retired } \\
\text { Housewife } \\
\text { Student }\end{array}$ & $\begin{array}{c}102(50.5) \\
57(28.2) \\
36(17.8) \\
7(3.5)\end{array}$ \\
\hline $\begin{array}{l}\text { Monthly Income } \\
\text { No income } \\
\text { Less than RM1000 } \\
\text { RM1001-4000 } \\
\text { RM4001-8000 }\end{array}$ & $\begin{array}{c}96(47.5) \\
30(14.9) \\
69(34.2) \\
7(3.5)\end{array}$ \\
\hline
\end{tabular}




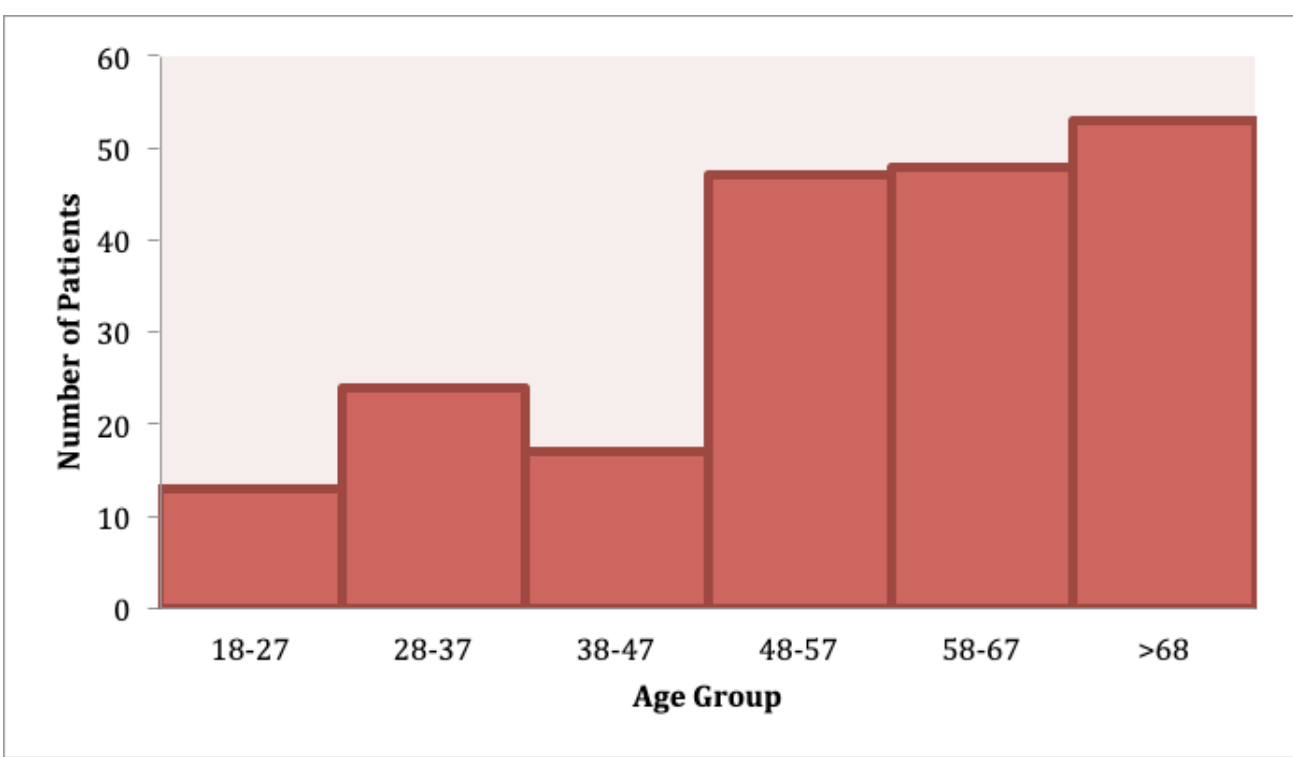

Figure 1: Number of patients with MSK pain in different age groups

The average number of painful sites per patient was $1.58 \pm 0.87$, with the majority $(59.9 \%)$ of the patients reporting MSK pain at only one site, followed by those with pain at two and three different sites $(28.7 \%$ and $5.9 \%$, respectively). Patients with MSK pain at four or more sites were found to be fewer in number, comprising only $5.5 \%$. The knee was found to be the most common site of MSK pain, accounting for $52.5 \%$ of the presenting complaints. The other sites of MSK pain complaints, in decreasing order of frequency, were the shoulder (17.3\%), ankle (17.3\%), back $(16.8 \%)$, hand $(15.8 \%)$, foot $(10.9 \%)$, wrist $(8.9 \%)$, elbow $(7.5 \%)$, neck $(5.9 \%)$, and hip (5.0\%).
Table 2 lists the interventions tried by patients prior to visiting the clinic, broken down by ethnicity. Most of the patients $(77.7 \%)$ had tried self-treatment before seeking medical help. Self-medication by oral analgesics was the most popular self-intervention tried by patients $(\mathrm{n}=91)$, followed by massage $(\mathrm{n}=76)$, while a smaller number used complementary medicine $(\mathrm{n}=29)$. No statistically significant association was noted between particular ethnicities and massage or oral analgesic use. However, for complementary medicine, we found that those of Chinese ethnicity appeared to have used this modality more commonly than Malays or Indians $(\mathrm{p}<0.05)$. Overall, 26.8\% (42/157) of the patients used more than one modality of self-intervention.

Table 2: Self-care practice by respondents in managing MSK pain by ethnicity.

\begin{tabular}{|l|c|c|c|c|}
\hline & Malay & Chinese & Indian & \multicolumn{1}{c|}{ Statistics } \\
\hline Massage & $28(36.8 \%)$ & $22(28.9 \%)$ & $26(34.2 \%)$ & $\chi^{2}=1.84, \mathrm{df}=2, \mathrm{p}=0.40$ \\
\hline Oral analgesics & $28(30.8 \%)$ & $27(29.7 \%)$ & $36(39.6 \%)$ & $\chi^{2}=0.35, \mathrm{df}=2, \mathrm{p}=0.84$ \\
\hline Complementary medicine & $7(24.1 \%)$ & $14(48.3 \%)$ & $8(27.6 \%)$ & $\chi^{2}=7.13, \mathrm{df}=2, \mathrm{p}=0.03$ \\
\hline
\end{tabular}

Following their visits to the clinic, $20.3 \%$ of patients were referred for a specialist opinion, and $12.4 \%$ were referred for physiotherapy.

The burden of disease disability was calculated using the Stanford-HAQ-DI. The median HAQ-DI score was 0.375 , with a mode of zero. Of the total, $89.6 \%$ of the patients presented with mild disability, 9.4\% exhibited moderate disability, and only $1 \%$ reported severe disability.

\section{Discussion}

Seremban is the state capital of Negeri Sembilan, one of the smaller states in Malaysia. The town covers an area of 948 $\mathrm{km}^{2}$, with a population of 555,935 in 2010. ${ }^{16}$ Seremban has four public primary care clinics. This study was done in two of the bigger clinics, which would be representative of the patients seen in public clinics in Seremban. However, the ethnic mix in the clinics showed an over-representation of Indians, 
who comprised $39.1 \%$ of the study sample, and an under-representation of Malays, who represented $31.7 \%$ of the patients. The general Malaysian population in 2010 was composed of $50.1 \%$ Malays, $22.6 \%$ Chinese, $11.8 \%$ indigenous, and $6.7 \%$ Indians, with "other" races numbering $8.9 \% .{ }^{17}$ The ethnic breakdown of Seremban in 2010 is similar to the general population-Bumiputera (Malay $\&$ indigenous) $56.3 \%$, Chinese $26.2 \%$, and Indians $17.0 \% .{ }^{16}$ Nevertheless, we feel that this ethnic breakdown is likely to be representative of the patients attending public (non-fee paying) clinics in Malaysia, as other studies have shown a higher proportion of Indian patients attending public clinics. ${ }^{18}$

The overall prevalence of MSK pain in our study was $18.8 \%(202 / 1074)$ in patients attending public clinics in Seremban. This finding is a marked increase compared to two previous studies of MSK pain presenting to primary care clinics in Malaysia, where only $5.9 \%$ and $6.5 \%$ had MSK pain, ${ }^{6,7}$ respectively. This difference might be a consequence of an aging population. In a previous populationbased Malaysian study from a semi-rural area, the prevalence of MSK pain was $21.1 \%{ }^{19}$ in the community, a finding very similar to this study. Thus, another hypothesis could be that people are more ready to seek medical assessment for their MSK pain nowadays that in the earlier studies. Compared to neighboring countries in the region, the prevalence of MSK pain was $23.6 \%$ in rural Indonesia and $31.3 \%$ in urban Indonesia, $17.6 \%$ in rural Thailand, and $28.4 \%$ and $16.2 \%$, respectively, in rural and urban areas in the Philippines. ${ }^{20-23}$ In Australia, musculoskeletal complaints accounted for $14.1 \%$ of patients' reasons for encounter (RFE) in general practice. ${ }^{24}$

This study recorded a slight preponderance of females $(56.4 \%)$ with MSK pain, which would be in keeping with previous studies showing that more females suffer from MSK pain. 919 Within the various ethnic groups, Indian females had the highest levels of MSK pain, which is in keeping with the previous study from Malaysia. ${ }^{7}$ In a laboratory model of pain, Malaysian females were found to have lower pain thresholds compared to males, but there was no difference between ethnic Malays, Chinese, or Indians. ${ }^{25}$ The most common site of MSK pain was the knee, in $52.5 \%$ of patients. This finding contrasts with the other studies in Malaysia that indicated back pain as the most common site of MSK pain. ${ }^{6,719}$ The majority of the respondents, $77.7 \%$, reported having tried to relieve their musculoskeletal pain on their own before seeing a doctor. Some of the modalities used included massaging the affected area, over-the-counter pain medication, acupuncture, and usage of complementary medicine. The Malaysian Community Oriented Programme for Control of Rheumatic Diseases (COPCORD) survey found that $58.8 \%$ of those with MSK pain self-medicated, with $17.7 \%$ using complementary medicine. ${ }^{19}$ That survey's results showing $17.7 \%$ using complementary medicine in the community is very similar to our study's finding of $14.5 \%$ (29/202) patients. However, there is a difference between the COPCORD study and our study in the usage of complementary medicine by different ethnic groups. In the COPCORD study, $21.8 \%$ of the Malays had tried complementary medicine compared to only $10.0 \%$ of the Chinese. ${ }^{19}$ In contrast, our study showed that the Chinese were more likely to use complementary medicine, with $48.3 \%$ utilizing it compared to only $24.1 \%$ of the Malays. One possible reason for the difference may be that the COPCORD study had more young subjects (only 12.6\% of the study population was over age 55), whereas our study's subjects had an average age of 56.1 years. One study demonstrated that Chinese who were older were more likely to have health beliefs suggesting that traditional Chinese medicine has fewer side effects and may possibly cure the underlying problem, compared to taking "Western" medicine. ${ }^{26}$ In a survey of the Malaysian Chinese public, $94 \%$ had sought traditional Chinese medicine, and $90 \%$ believed that it is acceptable to combine traditional Chinese medicine and modern medicine. ${ }^{27} \mathrm{~A}$ general survey of the Malaysian population found that the lifetime use of complementary medicine was $69.4 \%$, $88.9 \%$ of which were biological-based (herbs, vitamins, and supplements) therapies. ${ }^{28}$ This study of 6,947 respondents noted no difference in complementary medicine use when comparing educational level or working status. Thus, it may be that our results would be applicable to the wider population.

In this study, $20.3 \%$ of respondents from primary care were referred to Hospital Tuanku Jaafar, the main public hospital in Seremban, for further management. This outcome is similar to the Australian general practice data showing a referral for specialist care in 16.1 per 100 patient encounters. ${ }^{24}$ 
The Stanford 20-item HAQ has two core measurement scales: the disability index (HAQ-DI) and the pain scale, as well as its assessment of global health status. ${ }^{13}$ This 2-page HAQ is one of the most frequently used instruments for evaluating functional status and has established itself as a valuable, effective, and sensitive tool for the measurement of health status. ${ }^{29}$ Although initially developed for patients with arthritis, this instrument has also been used in normal aging populations, making it relevant for use in our study population, as not all those with MSK pain have been diagnosed with arthritis. ${ }^{29}$ With a median score of 0.375 , our patients would be considered to have mild disability, comparable with average scores that have been reported in a population-based study of $0.49 .{ }^{29}$

This study has several limitations that may reduce its widespread applicability. First, although the overall number of patients approached in the clinic was reasonable, we only obtained a sample size of 202 . However, we feel that it is an adequate number to determine the prevalence of patients with MSK pain attending the clinic. The higher proportion of Indians and those with low income reflects the population attending non-fee paying clinics. These limitations should be addressed in future studies having a larger sample encompassing patients across socioeconomic groups and including both rural and urban populations. In addition, for further studies, questionnaires in Tamil may be required to ensure that the data is accurately captured for the Indian population. However, some of our results, such as more MSK pain in females and those of Indian ethnicity, have agreed with other studies in Malaysia, which would suggest that this study has some external validity in terms of MSK pain prevalence.

\section{Conclusion}

This study assessed the prevalence of MSK pain among patients visiting two primary care clinics in an urban setting located in Seremban, Malaysia. MSK pain was a common complaint in those attending these clinics. Among patients with MSK pain, the majority exhibited mild disability, as measured by the Stanford HAQ 20Item Disability Scale. A significant proportion of these patients still required specialist referral, which suggests a need for further training on the management of MSK disease at the primary care level to avoid over-burdening the secondary care services.

\section{Competing interests and funding}

We do not have any competing interests for this study. This study was funded by the International Medical University, Malaysia.

\section{Acknowledgments}

We would like to thank the clinic directors for their permission to conduct research at their Centres and the International Medical University, Malaysia, for its support. We would also like to acknowledge the invaluable advice and assistance of Professor CL Teng, Department of Primary Care Medicine, International Medical University, Seremban, Negeri Sembilan, Malaysia, in the planning, development, and conducting of this study.

\section{Ethics Approval}

This study was approved by the Joint Committee of the Research and Ethics Committee of the International Medical University [IDNo.CSc/ Sem6(16)2014].

\section{References}

1. Institute for Health Metrics and Evaluation/ Global Health Data Exchange/Viz Hub. Available from: https://vizhub.healthdata.org/ gbd-compare/

2. World Health Organization/Home/ Newsroom/Fact sheets/Detail/Musculoskeletal conditions, dated 29 November 2019. Available from: https://www.who.int/newsroom/fact-sheets/detail/musculoskeletalconditions
3. United Nations DoEaSA: World Population Ageing 2009. 2010, New York.

4. Department of Statistics Malaysia/ Current Population Estimates, Malaysia 2018-2019. Available from: https://www. dosm.gov.my/v1/index.php? r=column/ cthemeByCat\&cat=155\&bul_id=aWJZRkJ4 UEdKcUZpT2tVT090Snpydz09\&menu_id =L0pheU43NWJwRWVSZklWdzQ4TlhUU T09\#: :text=The $\% 20$ composition $\% 20$ of $\% 20$ the $\% 20$ population, $70.0 \% 20$ per $\% 20$ cent $\% 20$ in $\% 202019$
5. Department of Statistics Malaysia/Population Projected (Revised) 2010-2040, dated 4 November 2016. Available from: https://www. dosm.gov.my/v1/index.php?r=column/pdfPrev \&id=Y3kwU2tSNVFDOWp1YmtZYnhUeV BEdz09

6. Mimi O, Tong SF, Nordin S, et al. A comparison of morbidity patterns in public and private primary care clinics in Malaysia. Malaysian Family Physician 2011;6(1):19-25. 
7. Zailinawati AH, Teng CL, Kamil MA, et al. Pain morbidity in primary care-preliminary observations from two different primary care settings. Med J Malaysia 2006;61(2):162-7.

8. Reynolds DL, Chambers LW, Badley EM, et al. Physical disability among Canadians reporting musculoskeletal diseases. J

Rheumatol 1992;19:1020-30

9. Woolf AD, Pfleger B. Burden of major musculoskeletal conditions. Bull World Health Organ 2003;81(9):646-56.

10. Slim ZN, Dowli A, Chaaya M, et al. Coping and disability: evidence from a developing country. Int J Rheum Dis 2011;14(1):61-67.

11. Fejer R, Ruhe A. What is the prevalence of musculoskeletal problems in the elderly population in developed countries? A systematic critical literature review. Chiropr Man Therap 2012;20: 31

12. March LM, Brnabic AJ, Skinner JC, et al. Musculoskeletal disability among elderly people in the community. Med J Aust. 1998;168(9):439-442.

13. Bruce B, Fries JF. The Stanford Health Assessment Questionnaire (HAQ): a review of its history, issues, progress, and documentation. J Rheumatol 2003;30:167-8.

14. ePROVIDE. Available from: https://eprovide. mapi-trust.org/instruments/health-assessmentquestionnaire

15. Hussein H, Mustafa R, Quek KF, et al. Cross-cultural adaptation and validation of the Malay health assessment questionnaire for use in rheumatoid arthritis. Int J Rheum Dis 2008;11:237-240.
16. Citypopulation.de. Available from: https:// www.citypopulation.de/en/malaysia/admin/ negeri_sembilan/0505_seremban/

17. The World Factbook, Malaysia. Available from: https://www.cia.gov/library/ publications/the-world-factbook/geos/my.html

18. Shahrir M, Shahdan M, Shahid M, et al. Multicentre survey of rheumatoid arthritis patients from Ministry of Health Rheumatology Centres in Malaysia. Int J Rheum Dis 2008;11:287-92.

19. Veerapen K, Wigley RD, Valkenburg $\mathrm{H}$. Musculoskeletal pain in Malaysia: a COPCORD Survey. J Rheumatol 2007;34:207-13

20. Darmawan J, Valkenburg HA, Muirden KD, et al. Epidemiology of rheumatic diseases in rural and urban populations in Indonesia: a World Health Organization-International League Against Rheumatism COPCORD Study, Stage I, Phase 2. Ann Rheum Dis 1992;51:525-8.

21. Chaiamnuay P, Darmawan J, Muirden KD, et al. Epidemiology of rheumatic disease in rural Thailand: a WHO-ILAR COPCORD study. J Rheumatol 1998;25:1382-7.

22. Manahan L, Caragay R, Muirden KD, et al. Rheumatic pain in a Philippine village-a WHO-ILAR COPCORD study. Rheumatol Int 1985;5:149-53.

23. Dans LF, Tankeh Torres S, Amante CM, et al. The prevalence of rheumatic diseases in a Filipino urban population: a WHOILAR COPCORD study. J Rheumatol 1997;24:1814-9.
24. Britt H, Miller GC, Henderson J, et al. General practice activity in Australia 2015-16. General practice series no. 40. Sydney: Sydney University Press, 2016. Available from: <purl. library.usyd.edu.au/sup/9781743325131>

25. Gupta E, Zailinawati AH, Lim AW, et al. Are Indians and females less tolerant to pain? An observational study using a laboratory pain model. Med J Malaysia 2009;64(2):111-3.

26. Lai DW, Surood S. Chinese health beliefs of older Chinese in Canada. J Aging Health 2009; 21(1):38-62.

27. Chew KS, Tan TW, Ooi YT. Influence of Chinese cultural health beliefs among Malaysian Chinese in a suburban population: a survey. Singapore Med J 2011;52(4):252-6.

28. Siti ZM, Tahir A, Farah AI, et al. Use of traditional and complementary medicine in Malaysia: a baseline study. Complement Ther Med 2009;17(5-6):292-299.

29. B, Fries JF. The Stanford Health Assessment Questionnaire: dimensions and practical applications. Health Qual Life Outcomes 2003;1:20. 


\section{Appendix One: Questionnaires Used}

\section{Questionnaire for Prevalence of Musculoskeletal Pain}

All questions contained in this questionnaire are strictly confidential.

\begin{tabular}{|l|l|l|l|}
\hline Part A & Socio-Demography \\
\hline Name(Last, First, M.I.): & Gender: $\square \mathrm{M} \square \mathrm{F}$ & Age: \\
\hline Marital status: & $\square$ Single $\square$ Married $\square$ Divorced $\square$ Widowed \\
\hline Ethnicity: & $\square$ Malay $\square$ Chinese $\square$ Indian $\square$ Others \\
\hline Occupation: & $\begin{array}{l}\square \text { Pensioner } \square \text { Professional } \square \text { Self-employed } \square \text { Skilled manual/ } \\
\text { Clerical } \square \text { Unskilled manual } \square \text { Housewife } \square \text { Unemployed } \quad \square \\
\text { Student }\end{array}$ \\
\hline
\end{tabular}

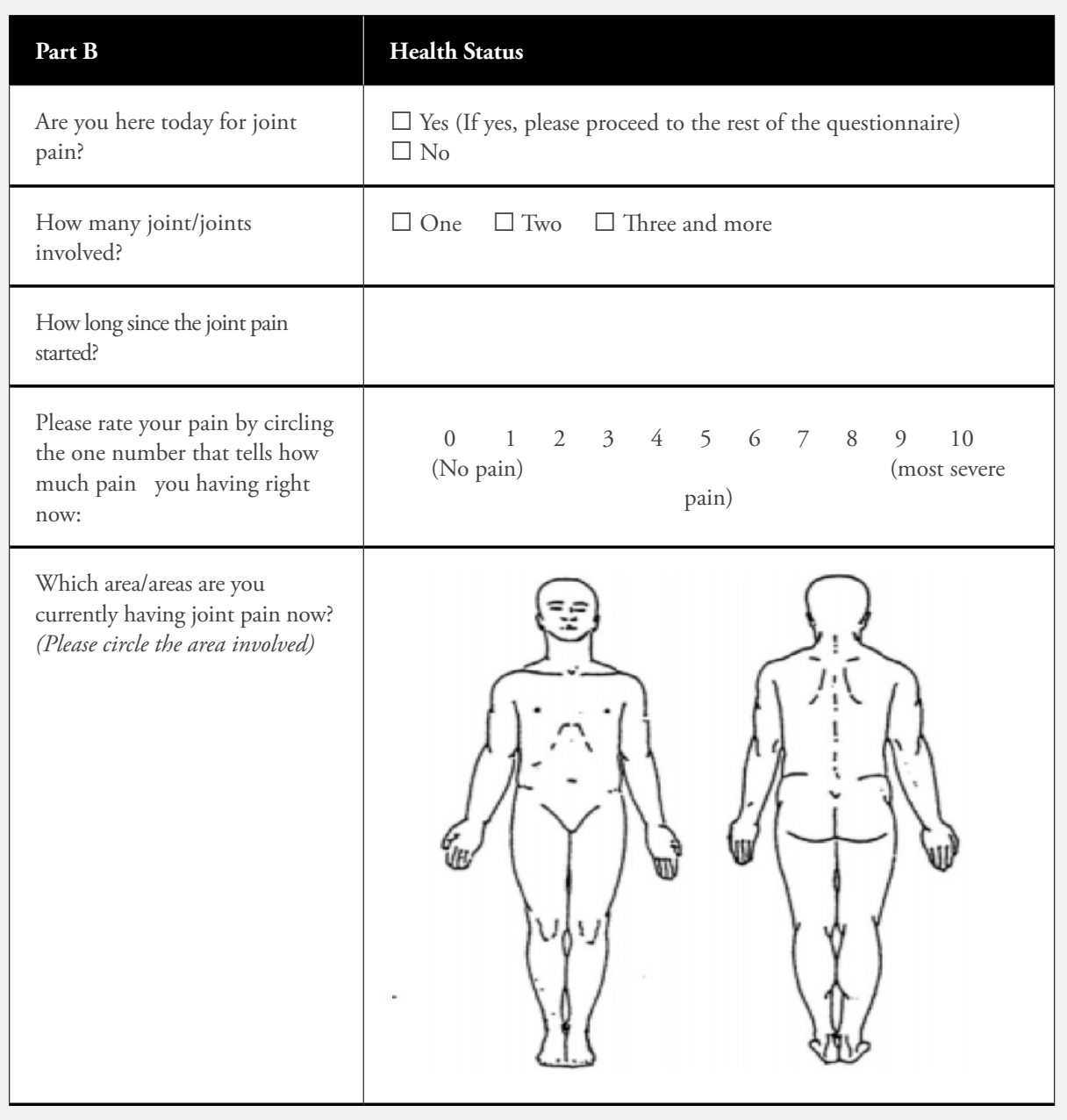

\begin{tabular}{|l|l|} 
Part C & Intervention for joint pain \\
\hline $\begin{array}{l}\text { How do you manage the joint } \\
\text { pain? }\end{array}$ & $\begin{array}{l}\square \text { Massage } \square \text { Analgesic tablet } \square \text { Acupuncture } \\
\square \text { Traditional Herbal } \square \text { Physiotherapy } \\
\square \text { Others: }\end{array}$ \\
\hline
\end{tabular}




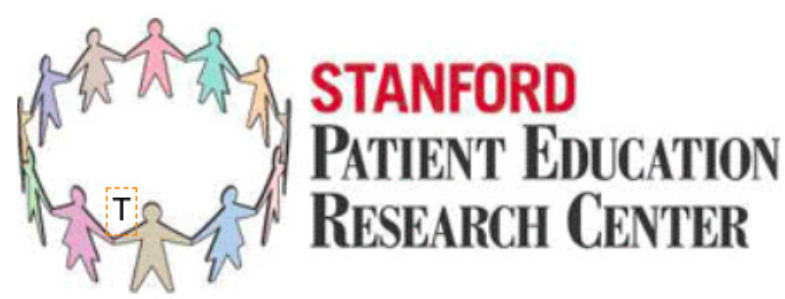

\section{Stanford HAQ 20-Item Disability Scale}

Please check $(\checkmark)$ the one best answer for your abilities over the past week

\begin{tabular}{|c|c|c|c|c|}
\hline At this moment, are you able to & $\begin{array}{l}\text { Without } \\
\text { ANY } \\
\text { difficulty }\end{array}$ & $\begin{array}{l}\text { Without } \\
\text { SOME } \\
\text { difficulty }\end{array}$ & $\begin{array}{l}\text { Without } \\
\text { MUCH } \\
\text { difficulty }\end{array}$ & $\begin{array}{c}\text { UNABLE } \\
\text { to do }\end{array}$ \\
\hline
\end{tabular}

\section{DRESSING \& GROOMING}

1. Dress yourself, including shoelaces and buttons?

2. Shampoo your hair?

$\begin{array}{llll}\square & \square & \square & \square \\ \square & \square & \square & \square\end{array}$

\section{ARISING}

3. Stand up from an armless straight chair?

4. Get in and out of?

$\square \quad \square$

$\square \quad \square \quad \square$

EATING

5. Cut your meat?

6. Lift a full cup or glass to your mouth?

7. Open a new milk carton?

$\begin{array}{llll}\square & \square & \square & \square \\ \square & \square & \square & \square \\ \square & \square & \square & \square\end{array}$

\section{WALKING}

8. Walk outdoors on flat ground?

9. Climb up five steps?

$\square$ $\square$

$\square$ $\square \quad \square$

$\square$

Please check any AIDS OR DEVICES that you usually use for any of the above activities:

$\square$ Devices used for dressing $\quad \square$ Built up or special utensils $\square$ Crutches

(button hook, zipper pull, etc) $\square$ Cane $\square$ Wheelchair

$\square$ Special or built up chair

$\square$ Walker

Please check any categories for which you usually need HELP FROM ANOTHER PERSON

$\square$ Dressing and grooming $\quad \square$ Arising $\quad \square$ Eating

$\square$ Walking

\section{HYGIENE}

10. Wash and dry your body?

11. Take a tub bath

12. Get on and off the toilet?

$\begin{array}{lll}\square & \square & \square \\ \square & \square & \square \\ \square & \square & \square\end{array}$


Please check $(\checkmark)$ the one best answer for your abilities over the past week

At this moment, are you able to

$\begin{array}{cccc}\text { Without } & \text { Without } & \text { Without } & \\ \text { ANY } & \text { SOME } & \text { MUCH } & \text { UNABLE } \\ \text { difficulty } & \text { difficulty } & \text { difficulty } & \text { to do }\end{array}$

\section{REACH}

13. Reach and get down a 5-pound object (such as a bag of sugar) from just above your head?

14. Bend down to pick up clothing from the floor

\section{GRIP}

15. Open car doors?
16. Open previously opened jars?
17. Turn faucets on and off?

$\begin{array}{llll}\square & \square & \square & \square \\ \square & \square & \square & \square \\ \square & \square & \square & \square\end{array}$

\section{ACTIVITIES}

18. Run errands and shop?

19. Get in and out of a car?

20. Do chores such as vacuuming or yard work?

$\square$

$\square$

$\square$

$\square$

$\square$

Please check any AIDS OR DEVICES that you usually use for any of the above activities:

$\square$ Raised toilet seat $\quad \square$ Bathtub bar $\quad \square$ Long-handled appliances for reach

$\square$ Bathtub seat $\quad \square$ Long-handed appliances in the bathroom

$\square$ Jar opener (for jars previously opened)

Please check any categories for which you usually need HELP FROM ANOTHER PERSON
$\square$ Hygiene
$\square$ Gripping and opening things
$\square$ Reach
$\square$ Errands and chores 


\title{
Malaysian clinical practice guidelines for management of diabetic foot: A synopsis for the primary care physician
}

\author{
Tharumaraja Thiruselvam, Aminudin Che-Ahmad, Ping Foo Wong, Afiza Hanun Ahmad@ \\ Hamid, Mohd Idham Hasan, Mohd Yazid Bajuri, Gurmeet Singh Sewa Singh, Vijiya Mala \\ Valayatham, Siti Norzalilah Abdul Majid, Hafizan Mohd Taji, Masfiza Abdul Hamid, \\ Ainol Haniza Kherul Anuwar, Mohd Aminuddin Mohd Yusof \\ Tharumaraja T, Che-Ahmad A, Wong PF, et al. Malaysian clinical practice guidelines for management of diabetic foot: A synopsis for the primary care \\ physician. Malays Fam Physician. 2021;16(1);103-113. https://doi.org/10.51866/cpg0001
}

\section{Keywords:}

diabetic foot, diabetic foot ulcer, diabetic neuropathy, screening, risk stratification

\section{Authors:}

Tharumaraja Thiruselvam (Corresponding author) MBBS(DU), MMed (Ortho) (USM) Department of Orthopaedics Hospital Kulim, Kedah Email: tharu64maraja@yahoo.com.au

Aminudin Che Ahmad MD (USM), MS Ortho (UKM) Department of Orthopaedics Traumatology \& Rehabilitation Pusat Perubatan Universiti Islam Antarabangsa Malaysia, Pahang Malaysia

Wong Ping Foo

MBBS (IMU), Dr Fam Med (UKM)

Klinik Kesihatan Cheras Baru

Kuala Lumpur, Malaysia

Afiza Hanun Ahmad@Hamid MD (UKM) M. Med Family Medicine (USM)

Klinik Kesihatan Hutan Melintang Perak, Malaysia

\section{Abstract}

Diabetic foot requires careful attention and coordinated management by a dedicated team. Screening, prevention, adequate assessment, and appropriate referral are crucial to prevent complications. Multimodal treatment and rehabilitation are recommended to ensure a better quality of life and reduction of amputation rate in people with diabetic foot.

\section{Introduction}

Diabetic foot is defined as infection, ulceration, or destruction of tissues of the foot associated with neuropathy and/or peripheral arterial disease (PAD) of people with diabetes mellitus (DM). ${ }^{1}$

According to the Malaysian National Health and Morbidity Surveys, the prevalence of diabetes has been increasing from $11.6 \%$ in 2006 to $15.2 \%$ in 2011 and further to $17.5 \%$ in 2015. The prevalence increased across age groups from 5.5\% among those 18 to 19 years of age to a peak of $39.1 \%$ among those 70 to 74 years of age. ${ }^{2}$ Overall, the cost of management of type 2 DM (T2DM) in 2011 was RM1.40 billion, which corresponded to $9.21 \%$ of the entire Ministry of Health $(\mathrm{MoH})$ budget. $^{3}$

The high prevalence of diabetes in adults increases the risk of foot problems, mainly due to neuropathy and/or PAD. ${ }^{4} \mathrm{Up}$ to $50 \%$ of people with DM are asymptomatic of diabetic peripheral neuropathy (DPN) 5 and about one million amputations are performed on people with diabetes each year worldwide. ${ }^{1}$ Diabetic foot requires careful attention and coordinated management, preferably by a multidisciplinary foot care team.

\section{Methods of Clinical Practice Guidelines Development}

The evidence-based Clinical Practice Guidelines (CPG) on Management of Diabetic Foot (Second Edition) were developed by a multidisciplinary Development Group from the $\mathrm{MoH}$ and Ministry of Education, guided by a multidisciplinary Review Committee. A systematic review method was used, starting with a protocol including objectives and clinical questions. Then a systematic literature search was carried out primarily using the Medline and Cochrane Systemic Review databases. The reference lists of all retrieved literature and guidelines were also searched to identify relevant studies. Experts in the field were also contacted for further relevant studies. References were also made to other existing CPGs on diabetic foot.

All literature retrieved were appraised using Critical Appraisal Skill Programme checklist, presented in evidence tables, and further discussed in each Development Group meeting. All statements and recommendations formulated were agreed upon by both the Development Group and Review Committee. Where evidence was insufficient, the recommendations were made using the expert opinion of the teams. The CPG was largely based on the findings of systematic reviews or meta-analyses and clinical trials, with local practices taken into consideration. 


\author{
Mohd Idham Hasan \\ MBBS (UQ), MS Ortho (UKM) \\ Foot Ankle (KKM) \\ Department of Orthopaedics \\ Hospital Putrajaya, Putrajaya \\ Malaysia
}

\section{Mohd Yazid Bajuri}

MD (UKM), MS Ortho (UKM)

Department of Orthopaedics \&

Traumatology, Pusat Perubatan

Universiti Kebangsaan Malaysia

Kuala Lumpur, Malaysia

Gurmeet Singh s/o Sewa Singh

MBBS (DU), MS Ortho (UKM)

Department of Orthopaedics

Hospital Pulau Pinang, Pulau Pinang

Malaysia

Vijiya Mala Valayatham

MBBS (UM), MRCP(UK)

Department of Medicine, Hospital

Putrajaya, Putrajaya, Malaysia

\section{Siti Norzalilah Abdul Majid}

MBBS(UM), MRehabMed (UM)

Department of Rehabilitation

Medicine, Hospital Rehabilitasi

Cheras, Kuala Lumpur, Malaysia

\section{Hafizan Mohd Tajri}

MBBCh (Ireland), MSurg (UKM)

Department of General Surgery

Hospital Kuala Lumpur, Kuala Lumpur

Malaysia

\section{Masfiza Abdul Hamid}

BPharm (USM)

Department of Pharmacy

Hospital Sultanah Bahiyah

Kedah, Malaysia

\section{Ainol Haniza Kherul Anuwar}

DDS (UGM), MCOH (UM)

Faculty of Dentistry, Universiti Malaya

Kuala Lumpur, Malaysia
The level of evidence was based on the US/ Canadian Preventive Services Task Force Level of Evidence, while the grading of recommendation used the principles of Grading Recommendations, Assessment, Development, and Evaluation (GRADE). The writing of the CPG followed strictly the requirement of Appraisal of Guidelines for Research and Evaluation (AGREE) II.

On completion, the draft of the CPG was reviewed by external reviewers and posted on the $\mathrm{MoH}$ Malaysia official website for any interested parties to give feedback. The draft was finally presented to the Technical Advisory Committee for CPG, and the Health Technology Assessment and CPG Council $\mathrm{MoH}$ Malaysia for final review and approval. The manuscript was then written based on the approved CPG as mentioned in Supporting Information section.

\section{Diagnosis and Assessment}

All people with diabetes should be assessed for diabetic foot at risk. They should be screened, diagnosed, investigated, classified, and stratified to ensure optimal management. Assessment of DPN should be performed at diagnosis and repeated annually. ${ }^{6}$ Early detection of diabetic foot at risk and appropriate interventions will minimize complications and healthcare costs. ${ }^{7}$

\section{History Taking}

Proper management of diabetic foot is initiated by good history taking, which includes general (risk factors for diabetic foot), medical (underlying concurrent medical condition), and individual diabetic foot history (vascular or neuropathic symptoms). Predictors for increased risk of foot ulceration in diabetes include a previous history of ulceration or lower extremity amputations and a longer duration of diabetes. ${ }^{8}$ Refer to the Diabetic Foot Assessment Form for full history taking on diabetic foot.

\section{Physical Examination}

Physical assessment is an important step in the screening and diagnosing of diabetic foot problems, including complications. This includes proper inspection and palpation of the foot.

\section{- Skin}

Skin changes due to vascular insufficiency may be present, for example, skin atrophy, nail atrophy, diminished pedal hair, prolonged capillary refill time ( $>2$ seconds), and reduced skin temperature.

\section{- Neurological}

A monofilament test and vibration perception are used to assess DPN, which is a major independent risk factor for diabetic foot ulceration. It may involve large fiber nerves (for touch, vibration, position perception, and muscle control), small fiber nerves (for thermal perception, pain, and autonomic function), or both. The commonly used screening tools are:

\section{Semmes-Weinstein Monofilament Examination}

A Semmes-Weinstein monofilament examination (SWME) is easy to perform and widely available locally. The examination uses a 5.07/10-g monofilament which exerts a buckling force when it bends. Inability to sense touch or pressure (>3 out of 10 sites) indicates loss of protective sensation. SWME should be combined with another modality in the screening of peripheral neuropathy. Refer to Figure 1.

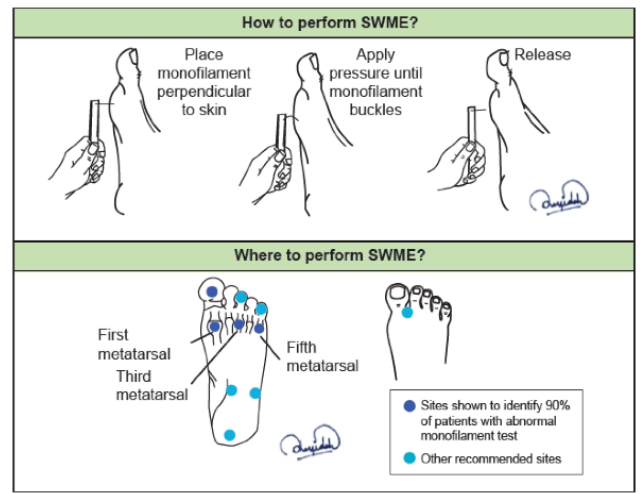

Figure 1. Semmes-Weinstein monofilament examination (SWME)

\section{Tuning Fork Test}

A tuning fork is used to detect the loss of vibration sense. The most commonly used tuning fork is $128 \mathrm{~Hz}$. Refer to Figure 2.

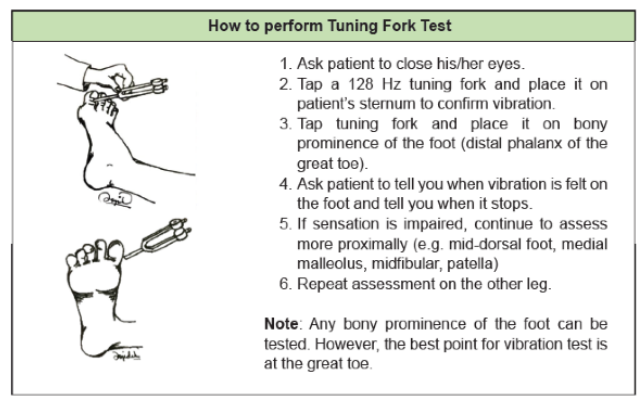

Figure 2. Tuning fork examination 
Mohd Aminuddin Mohd Yusof MD (UKM) MPH (Epid) (UM) Malaysia Health Technology Assessment Section (MaHTAS) Medical Development Division Ministry of Health Malaysia Purrajaya, Malaysia
Neuropathy should be assessed with 10-g monofilament and one other modality (e.g. pin prick, vibration sense with $128 \mathrm{~Hz}$ tuning fork, etc.). These increase the sensitivity of detecting peripheral neuropathy by $87 \% .^{6}$

\section{- Vascular}

Vascular assessment includes mandatory palpation of the femoral, popliteal, posterior tibial, and dorsalis pedis artery pulses. Critical limb ischemia is defined as rest pain with ulcers or tissue loss attributed to arterial occlusive disease. It is associated with substantial loss of limb and life. ${ }^{9}$

Palpation of foot pulses should be the initial screening method for PAD. Among the tests that can be used to exclude PAD are ${ }^{1}$ :

- Ankle-brachial index (normal value 0.9-1.3)

- Toe-brachial index (normal value $\geq 0.75$ )

- Continuous wave Doppler (presence of triphasic waveforms)
Thus, screening for DPN and PAD should be performed on all patients with diabetes at diagnosis and repeated at least annually. Those with DPN and PAD should be referred appropriately. Refer to Algorithm A.

\section{- Musculoskeletal}

Musculoskeletal complications in diabetic foot include ulcers, infections, and deformities (e.g. Charcot neuroarthropathy).

Conventional radiography may be helpful in diabetic foot for initial imaging to detect osteolysis, arterial calcification, gas shadow, malalignment, and peri-articular fragmentation.

Refer to the Diabetic Foot Assessment Form for the full physical examination of diabetic foot.

\section{Diabetic Foot Assessment Form ${ }^{10}$}

\begin{tabular}{|c|c|c|}
\hline \multicolumn{3}{|c|}{$\begin{array}{l}\text { DATE: } \\
\text { PERSONAL DATA }\end{array}$} \\
\hline \multirow{2}{*}{\multicolumn{3}{|c|}{$\begin{array}{l}\text { NAME: } \\
\text { IDENTIFICATION CARD NUMBER:- }\end{array}$}} \\
\hline & & \\
\hline $\begin{array}{l}\square \quad \text { Newly diagnosed (on admission) } \\
\square \text { High blood sugar: } \\
\square \text { Symptomatic: } \\
\square \text { Others: } \\
\square \text { Known case of Diabetes Mellitus } \\
\text { (DM) } \\
\text { Duration: } \\
\text { Date of diagnosis: __ years } \\
\text { Type of DM: } \\
\square \text { Type } 1 \\
\square \text { Type } 2 \\
\square \text { Others: }\end{array}$ & $\begin{array}{l}\text { Treatment: } \\
\square \quad \text { Never sought medical treatment } \\
\square \text { Self-treated } \\
\square \text { Traditional/alternative treatment } \\
\text { Current medical treatment: } \\
\square \quad \text { Nil } \\
\square \quad \text { Diet alone } \\
\square \text { Medication: } \\
\square \text { Oral Anti-Diabetic Agents: } \\
\quad \square \text { Insulin: } \\
\square \text { Combined: }\end{array}$ & $\begin{array}{l}\text { Other medical condition: } \\
\square \text { Ischemic Heart Disease } \\
\square \text { Stroke } \\
\square \text { Hypertension } \\
\square \text { Hyperlipidemia } \\
\square \text { Others: } \\
\text { Complications: } \\
\square \text { Peripheral Arterial Disease } \\
\square \text { Neuropathy } \\
\square \text { Nephropathy } \\
\square \text { Others: }\end{array}$ \\
\hline
\end{tabular}

\begin{tabular}{|l|c|c|c|c|c|}
\hline \multirow{2}{*}{} & \multicolumn{2}{|c|}{ Right } & \multicolumn{2}{c|}{ Left } & \multirow{2}{*}{ Description } \\
\cline { 2 - 6 } & Yes & No & Yes & No & \\
\hline Paresthesia (Pins \& Needles) & & & & & \\
\hline Claudication/Rest pain & & & & & \\
\hline Foot ulcer & & & & & \\
\hline Amputation & & & & & \\
\hline Orthosis/Prosthesis & & & & & \\
\hline \multirow{2}{*}{ Footwear } & Indoor & \multicolumn{2}{|c|}{ Outdoor } & \\
\hline & \multicolumn{2}{|c|}{} & & \\
\hline
\end{tabular}


(Kindly $\checkmark$ the appropriate box)

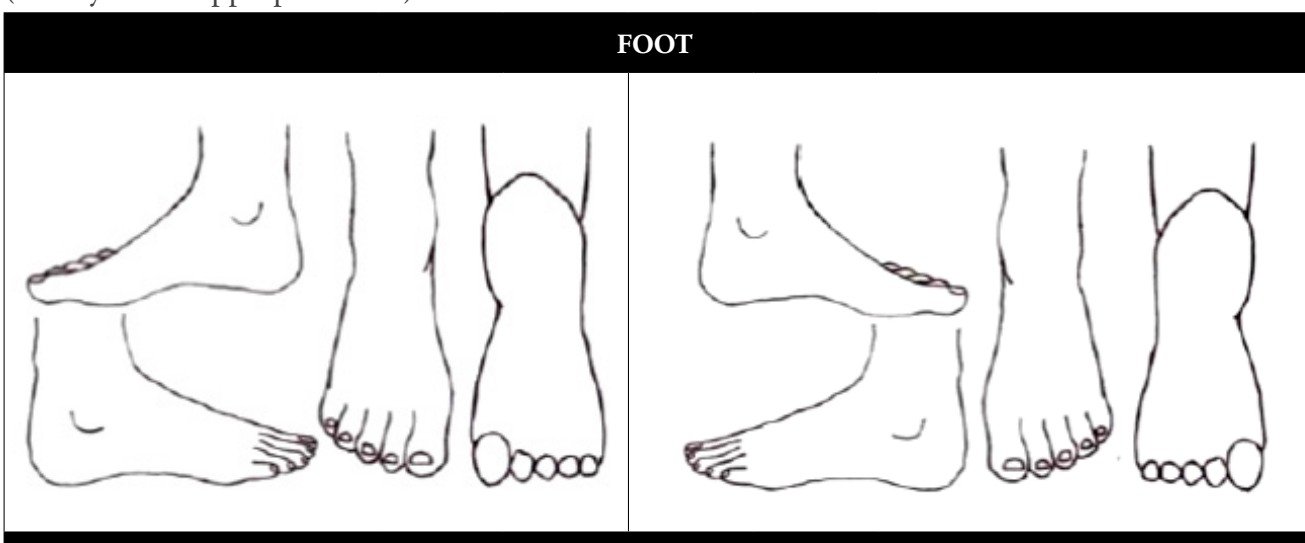

\begin{tabular}{|c|c|c|c|c|c|}
\hline \multicolumn{6}{|c|}{ GENERAL EXAMINATION } \\
\hline & \multicolumn{2}{|c|}{ Right } & \multicolumn{2}{|c|}{ Left } & \multirow{2}{*}{ Description } \\
\hline & Yes & No & Yes & No & \\
\hline \multicolumn{6}{|l|}{ Skin condition } \\
\hline \multicolumn{6}{|l|}{ Corn/callosity } \\
\hline \multicolumn{6}{|l|}{ Ulcer } \\
\hline \multicolumn{6}{|l|}{ Bunions } \\
\hline Lesser toe deformities & & & & & \\
\hline Charcot joints & & & & & \\
\hline
\end{tabular}

\begin{tabular}{|l|c|c|c|c|c|}
\hline \multirow{2}{*}{} & \multicolumn{2}{|c|}{ Right } & \multicolumn{2}{c|}{ Left } & \multirow{2}{*}{ Description } \\
\cline { 2 - 6 } & Yes & No & Yes & No & \\
\hline Muscle wasting & & & & & \\
\hline Presence of proprioception & & & & & \\
\hline $\begin{array}{l}\text { Abnormal monofilament test } \\
\text { (>3/10 ) }\end{array}$ & & & & & \\
\hline Presence of vibration perception & & & & & \\
\hline
\end{tabular}

\begin{tabular}{|l|c|c|c|c|c|}
\hline \multirow{2}{*}{} & \multicolumn{2}{|c|}{ Right } & \multicolumn{2}{c|}{ Left } & \multirow{2}{*}{ Description } \\
\cline { 2 - 6 } & Yes & No & Yes & No & \multirow{2}{*}{ D } \\
\hline Atrophic skin changes & & & & & \\
\hline Dystrophic nail & & & & & \\
\hline Absence of hair & & & & & \\
\hline Abnormal temperature gradient & & & & & \\
\hline Capillary refill $>3$ seconds & & & & & \\
\hline
\end{tabular}

\begin{tabular}{|l|c|c|c|c|c|c|c|}
\hline \multicolumn{7}{|c|}{ PALPABLE PULSE } \\
\hline $\begin{array}{l}\text { ++ (Normal) } \\
+\begin{array}{l}\text { (Weak) } \\
-(\text { Absent) }\end{array}\end{array}$ & \multicolumn{3}{|c|}{ Right } & \multicolumn{3}{c|}{ Left } & \multirow{2}{*}{ Description } \\
\cline { 2 - 7 } & ++ & + & - & ++ & + & - & \\
\hline Dorsalis pedis artery (DPA) & & & & & & & \\
\hline Posterior tibial artery (PTA) & & & & & & & \\
\hline Popliteal artery (PA) & & & & & & & \\
\hline Femoral artery (FA) & & & & & & & \\
\hline
\end{tabular}


(Kindly $\checkmark$ the appropriate box)

\begin{tabular}{|c|c|c|c|}
\hline & Right & Left & \multirow[t]{2}{*}{ Description } \\
\hline Brachial (mmHg) & & & \\
\hline Dorsalis pedis $(\mathrm{mmH}$ & & & \\
\hline Posterior tibial (mmF & & & \\
\hline $\mathrm{ABI}$ & & & $\begin{array}{l}\text { Use either DPA or PTA, whichever is } \\
\text { higher }\end{array}$ \\
\hline \multicolumn{4}{|c|}{ RISK STRATIFICATION } \\
\hline Low risk & \multicolumn{2}{|c|}{ Moderate risk } & High risk \\
\hline \multicolumn{4}{|c|}{ MANAGEMENT PLAN } \\
\hline $\begin{array}{l}\text { Referral: } \\
\square \text { Orthopedic } \\
\square \text { Vascular } \\
\square \text { Endocrine } \\
\square \text { Primary Care } \\
\square \text { Others: }\end{array}$ & $\begin{array}{l}\text { Follow-up: } \\
\square \text { 3-monthly } \\
\square \text { 6-monthly } \\
\square \text { Yearly } \\
\square \text { Others: }\end{array}$ & & $\begin{array}{l}\text { Foot care education checklist: } \\
\square \text { Foot hygiene } \\
\square \text { Nail care } \\
\square \text { Footwear advice } \\
\square \text { Routine foot check } \\
\square \text { Emollient use } \\
\square \text { Wound care } \\
\square \text { Recognizing active foot problems } \\
\text { (e.g. infection/erythema/ulcer) } \\
\square \text { Things to avoid (e.g. massage/ soak/ } \\
\text { reflexology/self-treatment) }\end{array}$ \\
\hline $\begin{array}{l}\text { Assessed by } \\
\text { Name: }\end{array}$ & Signature: & & Date: \\
\hline
\end{tabular}

\section{Risk Stratification}

A patient's current risk of developing a diabetic foot or requiring amputation is assessed using a practical risk stratification, as shown in Table $\mathbf{1}$.

Table 1. Diabetic foot risk stratification ${ }^{4}$

\begin{tabular}{|c|c|}
\hline Diabetic foot risk & Findings \\
\hline Normal & No abnormalities \\
\hline Low Risk & Callus alone \\
\hline Moderate Risk & $\begin{array}{l}\text { Any of the following: } \\
\text { - deformity } \\
\text { - neuropathy } \\
\text { - non-critical limb ischemia }\end{array}$ \\
\hline High Risk & $\begin{array}{l}\text { One of the following: } \\
\text { - previous ulceration } \\
\text { - previous amputation } \\
\text { - on renal replacement therapy } \\
\text { - neuropathy and non-critical limb ischemia } \\
\text { - neuropathy with callus and/or deformity } \\
\text { - non-critical limb ischemia with callus and/or deformity }\end{array}$ \\
\hline Active Diabetic Foot Problem & $\begin{array}{l}\text { Any of the following: } \\
\text { - ulceration } \\
\text { - infection } \\
\text { - critical limb ischemia } \\
\text { - gangrene } \\
\text { suspicion of an acute Charcot neuroarthropathy, or an } \\
\text { unexplained hot, red, swollen foot with or without pain }\end{array}$ \\
\hline
\end{tabular}




\section{Classification}

The University of Texas Classification ${ }^{11}$ is the preferred classification for diabetic foot and is useful to decide on the further management of the diabetic foot (refer Table 2). Refer to Algorithm B.

Table 2. University of Texas classification of diabetic foot ulcers

\begin{tabular}{|c|c|c|c|c|}
\hline STAGE & GRADE 0 & GRADE I & GRADE II & GRADE III \\
\hline STAGE A & $\begin{array}{c}\text { Pre- or post-ulcerative } \\
\text { lesion completely } \\
\text { epithelialized }\end{array}$ & $\begin{array}{c}\text { Superficial wound, } \\
\text { not involving tendon, } \\
\text { capsule, or bone }\end{array}$ & $\begin{array}{c}\text { Wound } \\
\text { penetrating to } \\
\text { tendon or capsule }\end{array}$ & $\begin{array}{c}\text { Wound } \\
\text { penetrating to } \\
\text { bone or joint }\end{array}$ \\
\hline STAGE B & With infection & With infection & With infection & With infection \\
\hline STAGE C & With ischemia & With ischemia & With ischemia & With ischemia \\
\hline STAGE D & $\begin{array}{c}\text { With infection } \\
\text { and ischemia }\end{array}$ & $\begin{array}{c}\text { With infection } \\
\text { and ischemia }\end{array}$ & $\begin{array}{c}\text { With infection } \\
\text { and ischemia }\end{array}$ & $\begin{array}{c}\text { With infection } \\
\text { and ischemia }\end{array}$ \\
\hline
\end{tabular}

\section{Prevention}

Patient education should be an integral part of the management of diabetic foot. It should be given at least annually and more frequently in higher-risk patients. Glycemic control (with minimization of hypoglycemia) should be individualized.

Patients should be advised on appropriate footwear according to the foot risk. Its importance increases with a higher risk of developing diabetic foot ulcer. Recommendations of footwear according to foot risk status are shown in Table 3. ${ }^{12}$

Table 3. Footwear advice ${ }^{12}$

\begin{tabular}{|l|l|}
\hline Risk status & \multicolumn{1}{c|}{ Actions } \\
\hline All foot at risk & $\begin{array}{l}\text { - Advise the use of footwear that fits, protects, and accommodates the shape of } \\
\text { the feet (with socks). }\end{array}$ \\
\hline Moderate or high risk & $\begin{array}{l}\text { - Prescribe footwear with: } \\
\text { custom-made in-shoe orthoses or insoles for people with a foot deformity } \\
\text { or pre-ulcerative lesions } \\
\text { - off-loading orthoses or insoles for people with healed plantar foot ulcer } \\
\text { Review prescribed footwear periodically to ensure it still fits, protects, and } \\
\text { supports the foot }\end{array}$ \\
\hline Foot ulceration & \begin{tabular}{l} 
Advise the wearing of footwear at all times, both indoors and outdoors \\
\hline
\end{tabular} \\
\hline
\end{tabular}

Patients with diabetic foot should be referred early for preventive surgery if all other modalities have failed. It should be performed by orthopedic surgeons trained in the procedures to prevent ulceration or re-ulceration in diabetic patients with foot deformity e.g. restricted ankle dorsiflexion, equinus contracture, claw toe, hammer toe, or mallet toe.

\section{Treatment}

\section{- Pharmacotherapy}

Appropriate analgesia should be considered in painful diabetic foot. In neuropathic pain, adjuvants are used at all steps of the analgesic ladder. ${ }^{13}$ Examples of adjuvants are antidepressants (e.g. amitriptyline or duloxetine) and anticonvulsants (e.g. gabapentin or pregabalin). ${ }^{14}$
Antibiotics should not be used unless there are local or systemic symptoms of infection. Local treatment including surgical debridement is important to be considered as part of the management. Antibiotic used for treatment should be based on the most recent culture and sensitivity report. ${ }^{15}$

In diabetic foot, antibiotics should be given according to the disease severity, care setting, patient's preference, clinical situation and medical history. If more than one regimen is appropriate, the regimen with lowest cost should be selected. For moderate and severe infections, broad spectrum antibiotics are used initially until culture and sensitivity results are available. Antibiotics should not be given for $^{4}$ :

- prevention of infections in diabetic foot

- >14 days for the treatment of mild soft tissue infection in diabetic foot 


\section{- Wound Management}

\section{Wound Dressings}

Advanced wound dressings may be offered in diabetic foot ulcer; refer to Table 4.

Table 4. Types of wound dressing in diabetic foot ${ }^{16}$

\begin{tabular}{|c|c|c|c|c|c|c|}
\hline No. & Types of dressing & Advantages & Disadvantages & Indications & Contraindications & $\begin{array}{l}\text { Review } \\
\text { intervals }\end{array}$ \\
\hline \multicolumn{7}{|c|}{ Basic wound contact dressings } \\
\hline 1. & $\begin{array}{l}\text { Gauze/basic absorbent } \\
\text { with paraffin or } \\
\text { similar (antiseptics or } \\
\text { antibiotics) }\end{array}$ & $\begin{array}{l}\text { - Reduces } \\
\text { adherence of } \\
\text { dressing to the } \\
\text { wound } \\
\text { - Widely available }\end{array}$ & $\begin{array}{l}\text { - Minimal exudate } \\
\text { absorption } \\
\text { - Requires } \\
\text { secondary } \\
\text { dressing }\end{array}$ & All wounds & Allergy & Daily \\
\hline \multicolumn{7}{|c|}{ Advanced wound dressings } \\
\hline 1. & Hydrogel & $\begin{array}{l}\text { - Provides moist } \\
\text { environment } \\
\text { - Acts as enzymatic } \\
\text { debridement } \\
\text { - Promotes } \\
\text { granulation }\end{array}$ & $\begin{array}{l}\text { Requires } \\
\text { secondary } \\
\text { dressing }\end{array}$ & $\begin{array}{l}\text { - Sloughy } \\
\text { wound } \\
\text { - Dry } \\
\text { wounds }\end{array}$ & $\begin{array}{l}\text { - Highly exudative } \\
\text { wounds } \\
\text { - Allergy }\end{array}$ & $1-2$ days \\
\hline 2. & Alginate & $\begin{array}{l}\text { - Forms gel } \\
\text { on wound } \\
\text { and maintain } \\
\text { moisture } \\
\text { - Acts as cavity } \\
\text { filler } \\
\text { - Absorbent in } \\
\text { exudative wounds } \\
\text { - Promotes } \\
\text { hemostasis } \\
\text { - Low allergenic }\end{array}$ & $\begin{array}{l}\text { Requires } \\
\text { secondary } \\
\text { dressing } \\
\text { Gel can be } \\
\text { confused with } \\
\text { slough or pus in } \\
\text { wound }\end{array}$ & 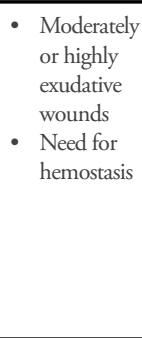 & $\begin{array}{l}\text { - Dry wounds } \\
\text { - Allergy }\end{array}$ & $2-3$ days \\
\hline 3. & Hydrofibre & $\begin{array}{l}\text { - } \text { Maintains } \\
\text { moisture } \\
\text { - Longer wear time } \\
\text { - Non-traumatic } \\
\text { upon removal } \\
\text { - Reduces risk of } \\
\text { maceration } \\
\text { - Can be used on } \\
\text { infected wounds }\end{array}$ & $\begin{array}{l}\text { - Not helpful for } \\
\text { dry wounds } \\
\text { - Requires } \\
\text { secondary } \\
\text { dressings }\end{array}$ & $\begin{array}{l}\text { Moderately } \\
\text { or highly } \\
\text { exudative } \\
\text { wounds }\end{array}$ & Allergy & $2-5$ days \\
\hline 4. & Foam & $\begin{array}{ll}\text { - } & \text { Maintains } \\
& \text { moisture } \\
\text { - Highly absorbent } \\
\text { - } \text { Cushioning } \\
\text { property }\end{array}$ & Limited size & $\begin{array}{l}\text { Moderately } \\
\text { or highly } \\
\text { exudative } \\
\text { wounds }\end{array}$ & $\begin{array}{l}\text { Dry wounds } \\
\text { - Wounds that } \\
\text { need frequent } \\
\text { review }\end{array}$ & $2-3$ days \\
\hline 5. & Hydrocolloid & $\begin{array}{l}\text { - Maintains } \\
\text { moisture } \\
\text { - Cleans and } \\
\text { debrides by } \\
\text { autolysis } \\
\text { - Easy to use } \\
\text { - Waterproof }\end{array}$ & $\begin{array}{l}\text { Induces peri-wound } \\
\text { maceration }\end{array}$ & $\begin{array}{l}\text { Mildly to } \\
\text { moderately } \\
\text { exudative } \\
\text { wounds }\end{array}$ & $\begin{array}{ll}\text { - Dry wounds } \\
\text { - Infection } \\
\text { - Highly exudative } \\
\text { wounds }\end{array}$ & $2-3$ days \\
\hline 6. & Silver & 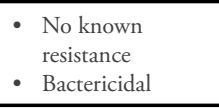 & $\begin{array}{l}\text { Some silver dressings } \\
\text { discolor the wound }\end{array}$ & $\begin{array}{l}\text { Infective } \\
\text { wounds }\end{array}$ & Allergy & $3-5$ days \\
\hline 7. & Others & $\begin{array}{l}\text { Not widely used - so } \\
\text { dressings (cultured ep }\end{array}$ & $\begin{array}{l}\text { e may be used in } s \\
\text { lermis, growth factor }\end{array}$ & $\begin{array}{l}\text { ialized centers } \\
\text { tem cells, etc.) }\end{array}$ & g. collagen, matrix, & regenerative \\
\hline
\end{tabular}

\section{Adjuvant Therapy}

Adjuvant therapy may be offered in delayed wound healing in diabetic foot with good vascularity.

- Negative pressure wound therapy is a procedure in which a vacuum dressing is used to promote wound healing. It is used for clean exudative wounds with poor granulation. ${ }^{17}$

- Maggot debridement therapy is used for the debridement of wounds with necrotic tissue. It shows better wound closure (>50\% of wound area) after 10 days compared with autolytic debridement with hydrogel in diabetic foot ulcer. ${ }^{18}$ 
- Hyperbaric oxygen therapy is used to increase oxygenation and antimicrobial effect that can improve the healing of chronic ulcers. ${ }^{19-21}$

\section{Revascularization}

Revascularization should be offered in diabetic patients with PAD. Surgical debridement by trained healthcare providers should be considered in diabetic foot ulcer that fails to respond to non-surgical debridement, or is deep and infected at presentation.

\section{Rehabilitation}

Off-loading should be offered to people with plantar diabetic foot ulcer. Those with diabetic foot who have had amputation should be referred for rehabilitation.

Algorithms A and B summarize the management of diabetic foot.

Algorithm A. Screening of diabetic foot

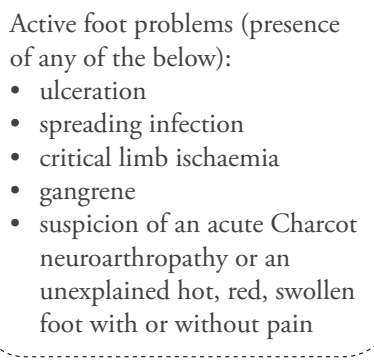

- spreading infection

- critical limb ischaemia

- gangrene

- suspicion of an acute Charcot neuroarthropathy or an unexplained hot, red, swollen foot with or without pain

r.

\section{All people with diabetes}

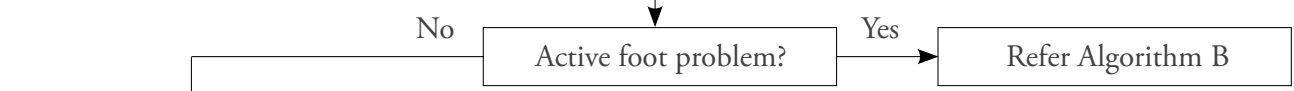

Previous history of ulceration, amputation, or on renal replacement therapy?

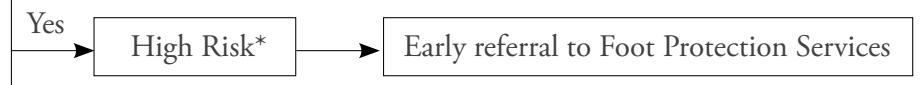

skin

- neurological

- vascular

- musculoskeletal
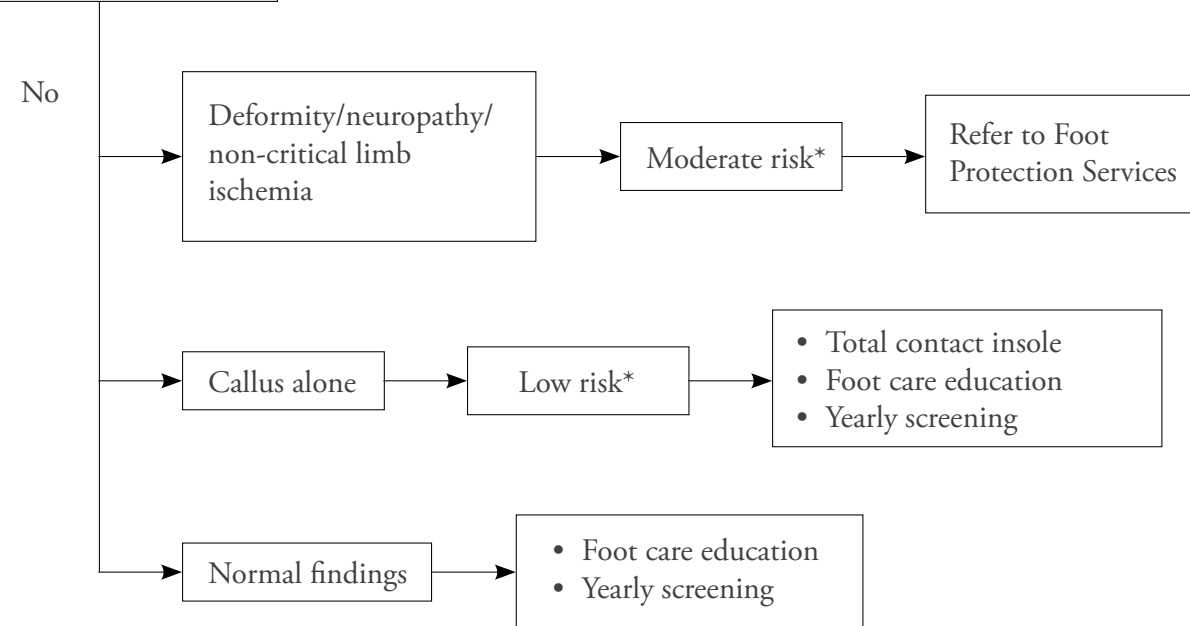

* Refer to Table 1 on diabetic foot risk stratification. 
Algorithm B. Active foot problems (with risk stratification)

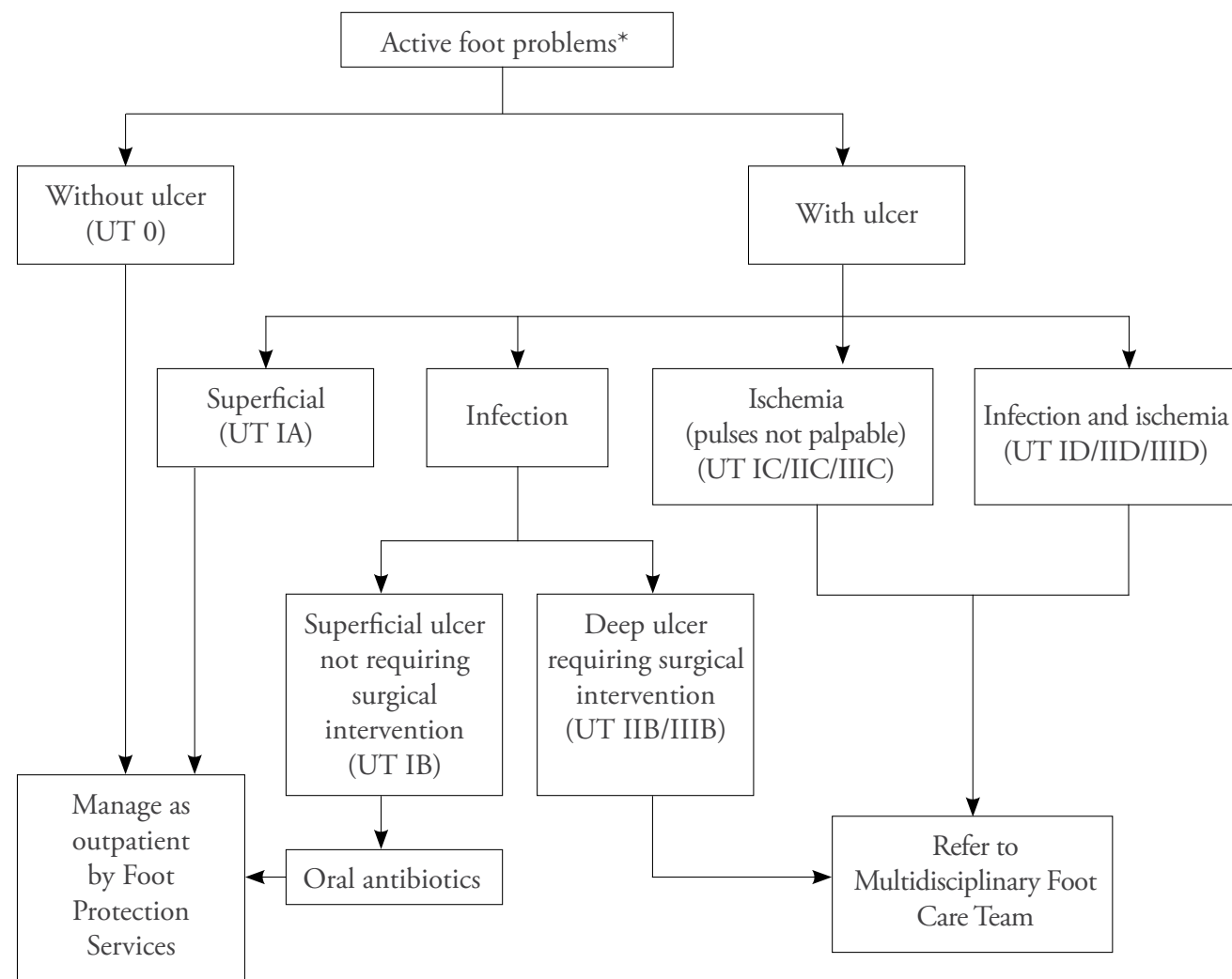

* Refer urgently for admission if patients present with general illness (e.g. sepsis or diabetic emergencies) irrespective of foot problems.

* UT $=$ University of Texas

\section{Referral}

People who are at moderate or high risk of developing a diabetic foot problem are referred to multidisciplinary professionals in the field of podiatry, diabetology, biomechanics and orthoses, and wound care. ${ }^{4}$ People with a limb-threatening or life-threatening diabetic foot problem should be referred urgently and managed under specialist care. Examples of such conditions include ulceration with fever or any signs of sepsis, critical limb ischemia, deep-seated soft tissue or bone infection, and gangrene.

The recommended referral schedule for diabetic foot is shown in Table $\mathbf{5}$.

Table 5. Recommended referral schedule

\begin{tabular}{|l|l|} 
Diabetic foot risk & \multicolumn{1}{c}{ Findings } \\
\hline Normal/Low risk & No referral needed-yearly review at primary care \\
\hline Moderate risk & Referral within 3 months to foot protection services \\
\hline High risk & Early referral within 2 weeks to foot protection services \\
\hline Active diabetic foot problem & Urgent referral within 24 hours to multidisciplinary foot care team \\
\hline
\end{tabular}


The referral should be addressed to:

1. The Foot Protection Service, which provides prevention and treatment of simple active diabetic foot problems in the community that do not require admission. The team should be led by a Family Medicine Specialist or physician with special training in diabetic foot problems and supported by podiatrist, diabetic team (including diabetic educator), wound care team, and rehabilitation services.
2. The multidisciplinary foot care service, which manages active or complicated diabetic foot problems in the hospital. The team is led by an orthopedic surgeon and/ or physician. Subsequent referral to other specialties is made according to the main problem presented by the patient.

\section{Monitoring and Follow-up}

Frequency of monitoring of patients with diabetic foot depends on risk stratification as shown in Table 6 below:

Table 6. Frequency of Monitoring for Diabetic Foot

\begin{tabular}{|c|c|c|c|c|}
\hline \multirow{2}{*}{ Risk } & \multirow{2}{*}{ Low risk } & \multirow{2}{*}{ Moderate risk } & \multicolumn{2}{|c|}{ High risk } \\
\cline { 4 - 5 } & & & No immediate concern & Immediate concern \\
\hline Frequency & Annually & $3-6$ months & $1-2$ months & $1-2$ weeks \\
\hline
\end{tabular}

\section{Supporting Information}

Details of the evidence supporting the above statements can be found in Clinical Practice Guidelines on the Management of Diabetic Foot (Second Edition) 2018, available on the following websites: http://www.moh.gov. my (Ministry of Health Malaysia) and http:// www.acadmed.org.my (Academy of Medicine). Corresponding organization: CPG Secretariat, Health Technology Assessment Section, Medical Development Division, Ministry of Health Malaysia; contactable at htamalaysia@ moh.gov.my.

\section{References}

1. Bakker K, Apelqvist J, Lipsky BA, et al.; International Working Group on the Diabetic Foot. The 2015 IWGDF guidance documents on prevention and management of foot problems in diabetes: development of an evidence-based global consensus. Diabetes Metab Res Rev. 2016;32 Suppl 1:2-6.

2. Tahir A, Muhammad FMY, Abdul AAG, et al (eds.). National Health and Morbidity Survey: Non-Communicable Diseases, Risk Factors and other health problems. Institute for Public Health. 2015.

3. Feisul IM, Azmi S, Mohd Rizal AM, et al. What are the direct medical costs of managing Type 2 Diabetes Mellitus in Malaysia? Med J Malaysia. 2017;72(5):271-277.

4. National Institute for Health and Care Excellence. Diabetic Foot Problems: Prevention and Management. London: NICE; 2015.

5. Pop-Busui R, Boulton AJ, Feldman EL, et al. Diabetic Neuropathy: A Position Statement by the American Diabetes Association. Diabetes Care. 2017;40(1):136-154.
6. Malaysian Endocrine \& Metabolic Society and Ministry of Health Malaysia. Management of Type 2 Diabetes Mellitus (5th Edition). Kuala Lumpur: MEMS \& MOH; 2015.

7. Ministry of Health Malaysia. Management of Diabetic Foot. Kuala Lumpur: MoH; 2004

8. Crawford F, Cezard G, Chappell FM, et al A systematic review and individual patient data meta-analysis of prognostic factors for foot ulceration in people with diabetes: the international research collaboration for the prediction of diabetic foot ulcerations (PODUS). Health Technol Assess.

2015;19(57):1-210

9. Slovut DP, Sullivan TM. Critical limb ischemia: medical and surgical management. Vasc Med. 2008;13(3):281-291.

10. A Che-Ahmad, NF Mustafa, N Alias, et al.Evaluation of foot at risk among diabetic patients using diabetic foot assessment protocol in Malaysia. IIUM \& MOH, 2012. (unpublished document)
11. Lavery LA, Armstrong DG, Harkless LB. Classification of diabetic foot wounds. J Foot Ankle Surg. 1996;35(6):528-531

12. vanNetten JJ, Lazzarini PA, Armstrong DG, et al. Diabetic Foot Australia guideline on footwear for people with diabetes. J Foot Ankle Res. 2018;11:2.

13. Ministry of Health Malaysia. Pain as the 5th Vital Sign Guidelines: 2nd Edition. Kuala Lumpur: MoH; 2013.

14. Ministry of Health Malaysia. Pain Management Handbook. Kuala Lumpur: MoH. 2013

15. Pharmaceutical Services Division, Ministry of Health Malaysia. National Antibiotic Guideline (Second Edition). Petaling Jaya: $\mathrm{MoH} ; 2014$

16. Ministry of Health. Wound Care Manual. Kuala Lumpur: MoH; 2014 
17. Dumville JC, Hinchliffe RJ, Cullum N, et al. Negative pressure wound therapy for treating foot wounds in people with diabetes mellitus. Cochrane Database Syst Rev. 2013;(10):CD010318

18. Ministry of Health Malaysia. Maggot debridement therapy. Kuala Lumpur: $\mathrm{MOH}$; 2008.
19. Kranke P, Bennett MH, Martyn-St James $M$, et al. Hyperbaric oxygen therapy for chronic wounds. Cochrane Database Syst Rev. 2015;(6):CD004123.

20. MohdYazid B, Ayesyah A, Nurhanani AB, et al. The Physiological, Biochemical and Quality of Life Changes in Chronic Diabetic Foot Ulcer after Hyperbaric Oxygen Therapy. Med \& Health. 2017;12(2): 210-219.
21. Nik Hisamuddin NAR, Wan Mohd Zahiruddin WN , Mohd Yazid B , Rahmah S Use of hyperbaric oxygen therapy (HBOT) in chronic diabetic wound - A randomised trial. Med. J. Malaysia, 2019 Oct;74(5):418-424. 


\title{
A rare cause of acute urinary retention in a young man: A median raphe penile cyst
}

\author{
Mohd. Nazli Kamarulzaman, Azhani Chik, Hamid Ghazali \\ Kamarulzaman MN, Chik A, Ghazali H. A rare cause of acute urinary retention in a young man: A median raphe penile cyst. Malays Fam Physician. \\ 2021;16(1);114-116. https://doi.org/10.51866/cr1016
}

\section{Keywords:}

median raphe cyst of the

penis, acute urinary retention

\section{Authors:}

Mohd. Nazli Kamarulzaman

(Corresponding author)

Urology Unit, Department of Surgery

Kulliyyah of Medicine, International

Islamic University Malaysia

Kuantan, Pahang, Malaysia

Email:

*nazlikamarulzaman@gmail.com

\section{Azhani Bt Chik}

Department of Surgery, Department of Surgery, Kulliyyah of Medicine International Islamic University Malaysia, Kuantan, Pahang Malaysia

\section{Hamid Ghazali}

Department of Urology, Hospital Tengku Ampuan Afzan, Jalan Tanah Putih, Kuantan, Pahang, Malaysia

\section{Abstract}

Background: A penile median raphe cyst is an uncommon congenital lesion that is formed due to failure of the median raphe to close completely during embryo development. The majority of the cysts are asymptomatic and often go unnoticed. Here, we report acute urinary retention as a very rare complication of a penile median raphe cyst.

Case presentation: A 21-year-old single man presented with a sudden onset of acute urinary retention of one days' duration. Urethral catheterization was done at the Emergency Department and this drained $800 \mathrm{ml}$ of urine. On further questioning, he claimed that he had had a painless nodule at the glans penis since childhood. The swelling increased in size in the past week causing discomfort. He denied any history of genitalia trauma or recent sexual intercourse. On examination, there was a bluish lesion over the ventral aspect of the glans penis measuring about $3 \times 2 \mathrm{~cm}$. The lesion was later excised and histopathology revealed a median raphe cyst of the penis.

Conclusion: A penile median raphe cyst is a rare lesion. Acute urinary retention caused by this lesion is very rare.

\section{Introduction}

Congenital lesions in the genitalia area commonly present during early childhood. However, some can manifest later in adulthood and pose a diagnostic challenge to the clinician. Congenital median raphe cysts are relatively rare and are often ignored by the patient until they become complicated.

A median raphe cyst often presents as a small yellowish solitary papule lesion. ${ }^{1}$ Thus, it almost always goes unnoticed. At the time of presentation, this lesion commonly has some form of complications such as pain, increase in size, change in color, or difficulty in passing urine. ${ }^{1-2}$ Rapid increase in size will obliterate the urethral lumen and may cause difficulty in urination. It is very rare for this lesion to cause the complete closure of the urethral canal that leads to acute urinary retention.

\section{Case presentation}

A 21-year-old single man presented with acute urinary retention of one days' duration. The onset was sudden when he awoke in the morning. Urethral catheterization was performed in the Emergency Department and this drained $800 \mathrm{ml}$ of urine.

On further questioning, he claimed that he had had a painless lesion at the glans penis since childhood. The swelling increased in size in the past week causing discomfort. It was tolerable, and therefore he did not seek any medical treatment. He denied any other urinary symptoms or urethral discharge. He also denied any history of genital trauma or recent sexual intercourse.

On examination, we noted a small lesion over the ventral aspect of the glans penis, measuring about $3 \times 2 \mathrm{~cm}$ in size (Figure 1A). It was wellcircumscribed, bluish in color, but no punctum or signs of inflammation were seen. It was tender on palpation. Before the excision of the lesion, we removed the urethral catheter and re-examined the lesion. Without the catheter in situ, we noted that the urethral opening was completely obscured (Figure 1B). Thus, we postulated that he had developed urinary retention secondary to this lesion at the glans penis.

Our initial diagnosis was penile hemangioma complicated with thrombosis or intralesional rupture. Intraoperatively, we noted that the lesion was well-circumscribed and enclosed within a thin layer of capsule (Figure 1C). The urethral mucosa was not involved. We proceeded with excision of the lesion followed by meatoplasty. The postoperative period was uneventful and the urethral catheter was able to be removed on Day 3 after the operation. The histopathology result revealed a median raphe 
cyst of the penis with hemorrhagic features within the lesion (most likely caused by recent bleeding). During his first follow-up 6 weeks after the operation, uroflowmetry showed very good results with a peak flow of $30 \mathrm{ml} / \mathrm{s}$ and no significant residual urine in the urinary bladder.

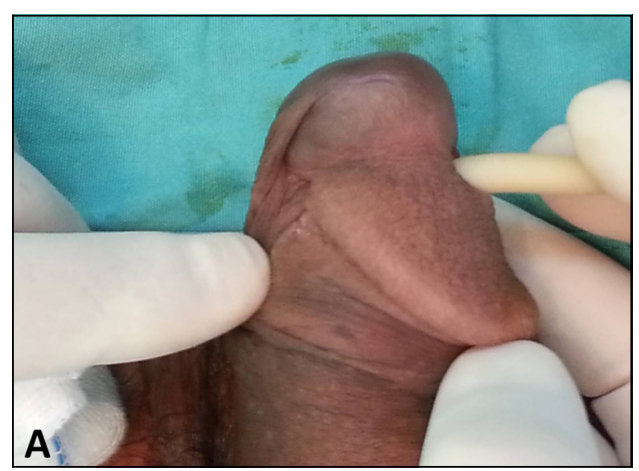

Figure 1A: A well-circumscribed small lesion over the ventral aspect of the glans penis, bluish in color, no signs of inflammation.

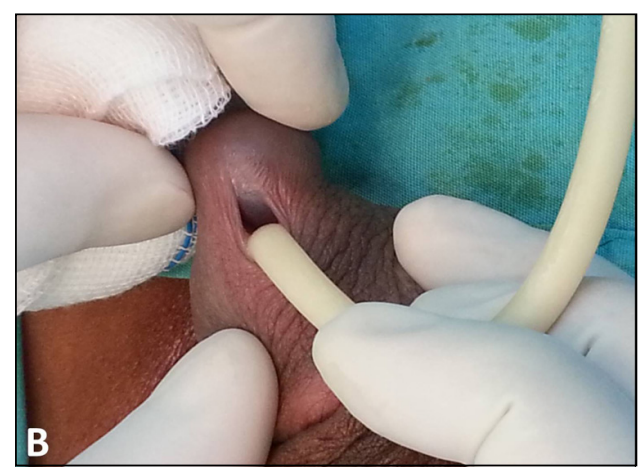

Figure 1B: The urethral opening was completely obscured by the lesion at the glans penis.

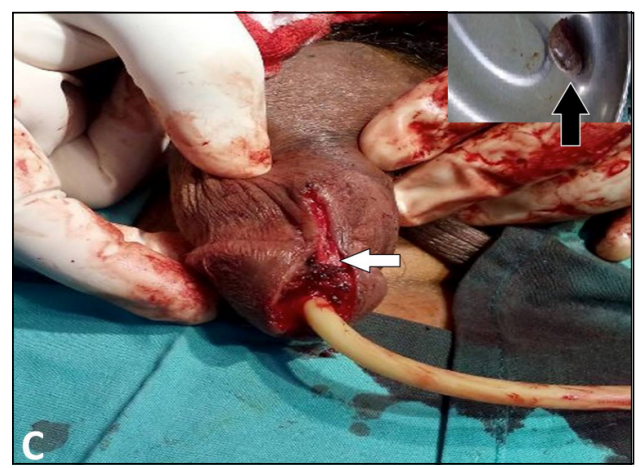

Figure 1C: The excised lesion was wellcircumscribed and enclosed within a thin layer of capsule (black arrow). Meatoplasty was done after the lesion was removed (white arrow).

\section{Discussion}

A median raphe cyst is an uncommon embryogenic developmental defect of the male genitalia. It was first described by Mermet in 1895. ${ }^{1}$ It is also known by several other names, including parameatal cyst, mucous cyst of the penis, and apocrine cystadenoma of the penile shaft. ${ }^{1}$ It can be found anywhere from the urethral meatus to the perineum and varies in size. The pathogenesis is postulated to be related to the fusion of the genitoperineal raphe at the midline. Therefore, the cyst development can be anywhere from the penis shaft to the perineum, with the most common site being at the penile shaft. ${ }^{2-4}$

The largest series of median raphe cysts were reported by Nishida et al. ${ }^{5}$ They reviewed 225 case reports from 1913 to 2010 and found that $83 \%$ of the cysts were solitary. ${ }^{5}$ There were six cases reported as pigmented median raphe cysts forming bluish discoloration of the lesion. ${ }^{5}$ The pigmented cysts were confirmed by the presence of melanin pigments in the histopathology analysis. ${ }^{5}$ In our case, the change in color was not caused by the presence of melanin pigment. Instead, the presence of hemorrhagic features in histology findings suggested that minor trauma could have caused the change in its color.

Median raphe cysts typically present as yellowish smooth papules that usually go unnoticed until trauma or infection occurs, giving rise to pain especially during erection or intercourse. ${ }^{1-4}$ In this case, the nodule mimicked a hemangioma, possibly due to the presence of intracystic hemorrhage. Yoshimoto et al. ${ }^{6}$ described a case of a blue-purple median raphe cyst of the penis that closely resembled our case, which was explained by the possibility of hemorrhage within the cyst. This patient had also received an initial diagnosis of hemangioma. ${ }^{6}$ However, a difference is that a history of zipper trauma occurring several years previously was apparent in the report by Yoshimoto et al. ${ }^{6}$ but not elicited in our case. We postulated that early morning erection possibly induced hemorrhagic changes in our case, as he denied a recent history of genitalia trauma or sexual intercourse.

The majority of penile median raphe cysts are asymptomatic and observation alone would suffice. However, with acute urinary retention as described above, intervention is needed to ease the symptoms. In this age group, the common causes of acute urinary retention include urethral stricture, urethral stone, and urethral trauma. ${ }^{7}$ The mainstay of treatment for a median raphe cyst is surgical excision. However, there is a variant of the condition which presents as elongated tracts known as 
canals. In this condition, videodermatoscopy is used in diagnosis. With a cystic lesion, simple removal would be sufficient, whereas the canal type needs to be excised fully to prevent a recurrence. ${ }^{4}$ To date, the best treatment option is surgical excision of the cyst as it gives the best cosmetic and functional outcome. ${ }^{2}$

\section{References}

1. Syed MMA, Amatya B, Sitaula S. Median raphe cyst of penis: a case report and review of the literature. J Med Case Rep. 2019;13:214223. doi:10.1186/s13256-019-2133-5

2. Alphones S, Phansalkar N, Manoharan P. Median raphe cyst of penis: A startling diagnosis for the unaccustomed clinician. Urol. Ann. 2019;11(3):314-316. doi:10.4103/ UA.UA_92_18

3. Ishida M, Iwai M, Yoshida K, Kagotani A, Okabe H. Pigmented median raphe cyst of the penis with consideration of the possible mechanism of melanocytic colonization: A case report. Oncol Lett. 2014;7(2):342-344. doi:10.3892/ol.2013.1719
4. LaCarrubba F, Tedeschi A, Francesconi L, Micali G. Canal versus cysts of the penile median raphe: advancing diagnostic methods using videodermatoscopy. Pediatric Dermatol. 2010;27(6):667-669. doi:10.1111/j.15251470.2010.01333.x

5. Nishida H, Kashima K, Daa T et al. Pigmented median raphe cyst of the penis. Cutan Pathol. 2012;39(8):808-810. doi:10.1111/j.1600-0560.2011.01862.x

6. Yoshimoto S, Ichinose M, Udagawa A, Matsumoto H, Shimizu S, Danino AM. Case of a rapidly growing blue-purple median raphe cyst of the penis. Ann of Plast Surg. 2002;48(1):108-109. doi:10.1097/00000637200201000-00021
7. Abdullahi M, Yunusa B, Mashi SA, Aji SA, Alhassan SU. Urinary retention in adults male patients: Causes and complications among patients manage in a teaching hospital in north western Nigeria. Open J Urology. 2016;6(7): 114-121. doi:10.4236/ oju.2016.67020. 


\section{Facial nerve palsy in otitis externa: A red flag?}

Aliyya Badaruddin, May May Choo

Badaruddin A, Choo MM. Facial nerve palsy in otitis externa: A red Flag?. Malays Fam Physician. 2021;16(1);117-120. https://doi.org/10.51866/cr1108

\section{Keywords:}

necrotizing otitis externa,

malignant otitis externa,

facial nerve palsy

\section{Authors:}

\section{Aliyya Badaruddin}

(Corresponding author)

MB, BCh, BAO, MOphthal

Department of Ophthalmology

University of Malaya Medical Centre

Kuala Lumpur, Malaysia

Email: aliyyabadaruddin@gmail.com

\section{Choo May May}

FRCS

Department of Ophthalmology University of Malaya Medical Centre Kuala Lumpur, Malaysia

\section{Abstract}

Otitis externa is an infection of the external auditory canal. It rarely results in facial palsy except in severe cases such as necrotizing otitis externa, which is a life-threatening invasive infection of the external auditory canal. Early recognition with prompt and appropriate treatment of necrotizing otitis externa is crucial to prevent more sinister complications. Here we report a case of an elderly gentleman who presented with otitis externa and developed facial palsy a month later. We identified possible problems that may have led to the complication so that such an occurrence can be prevented in the future.

\section{Introduction}

Facial palsy is an uncommon complication of otitis externa. It is more commonly seen in necrotizing otitis externa (NOE) with skull base osteomyelitis, especially if comorbidities are present. ${ }^{1}$ Here we report a case of an elderly diabetic patient who presented with otitis externa and subsequently developed facial palsy. We identified the possible problems that may have led to this complication.

\section{Case Report}

A 65-year-old man presented with right otalgia and otorrhoea for a duration of 2 days. He described the pain as excruciating and as sufficiently bad to disturb his sleep and disrupt some of his daily activities. He was diagnosed

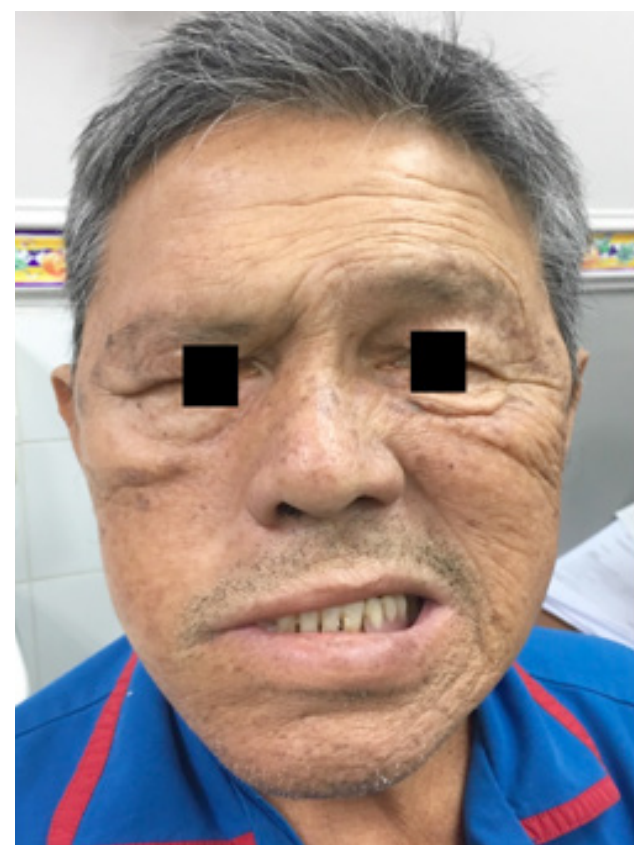

Figure 1: Right lower motor neurone facial palsy with right acute otitis externa by a general practitioner and completed 2 courses of oral antibiotics in addition to topical antibiotic. However, the pain did not resolve.

Four weeks later he developed facial asymmetry with drooling of saliva and was urgently referred to a neurologist to rule out a central cause. On examination, he had right lower motor neuron facial palsy with loss of right nasolabial fold, drooping of the corner of the forehead wrinkles (Figure 1).

$\mathrm{He}$ was then referred to the otorhinolaryngology team who discovered right severe otitis externa with granulation tissue in the external auditory canal. Right ear toileting and swab were performed, which

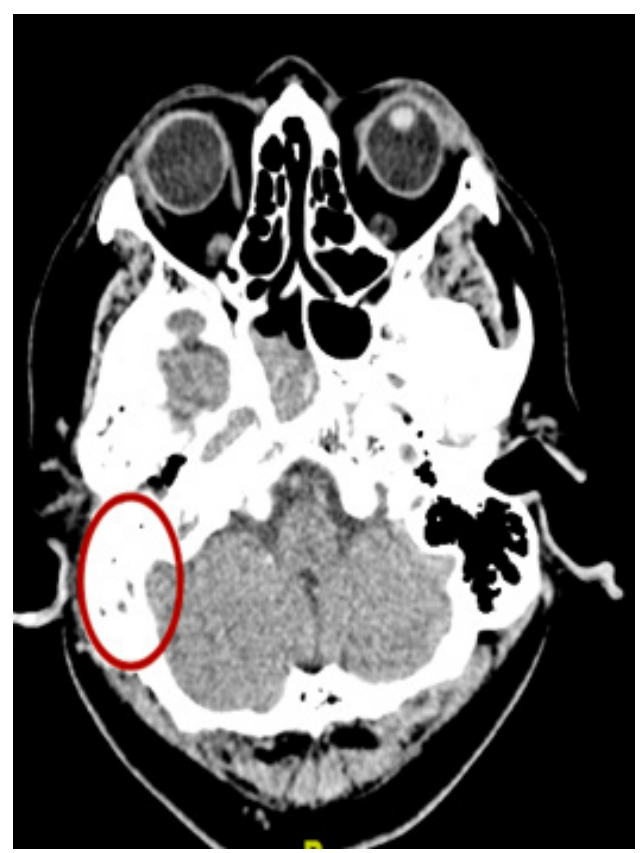

Figure 2: CT brain showing right mastoiditis and base of skull erosion mouth, right lagophthalmos and loss of right 
revealed Candida albicans. He was started on clotrimazole ear spray. He underwent High Resolution Computed Tomography of the temporal bone, which showed right mastoiditis and base of skull erosion (Figure 2). A biopsy ruled out malignant tumors. A subsequent Magnetic Resonance Imaging (MRI) showed enhancement at the right mastoid with no intracranial metastases (Figure 3). A final diagnosis of right necrotizing otitis externa with base of skull osteomyelitis and secondary facial palsy was made. He was started on intravenous ceftazidime $1 \mathrm{~g}$ every 8 hours, intravenous dexamethasone $8 \mathrm{mg}$ (in tapering doses) and underwent mastoidectomy (Figure 4).

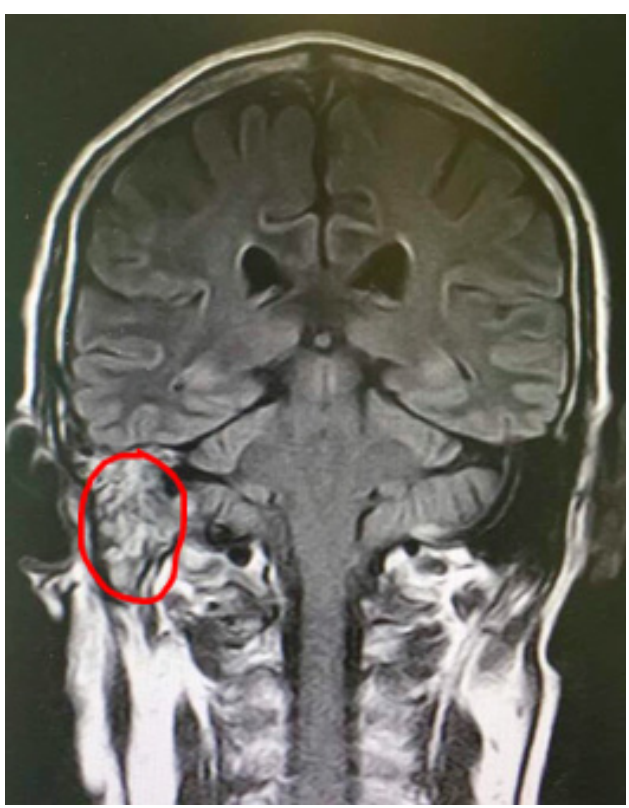

Figure 3: MRI brain/neck showing right mastoiditis

\section{Discussion}

Facial palsy is a rare complication of otitis externa. Previous studies have reported on facial palsy occurring in necrotizing otitis externa, especially in immunocompromised individuals such as diabetic patients. ${ }^{2,3}$ Diabetics have an increased $\mathrm{pH}$ in cerumen which predisposes them to infection such as Pseudomonas aeruginosa. The endarteritis and microangiopathy in diabetics leads to hypoperfusion in the subcutaneous tissue. ${ }^{1,4,5}$

Necrotizing otitis externa (NOE) associated with skull base osteomyelitis is an uncommon, rapidly spreading, life-threatening invasive infection of the external auditory canal (EAC) and the lateral skull base. ${ }^{1}$ Granulation tissue in the external auditory canal is a
Ophthalmic examination revealed right lagophthalmos with good Bell's reflex. There was mild punctate epithelial erosion. He was prescribed with lubricants and taping the right eye when asleep. The patient has had underlying diabetes for the past 8 years, which was not well-controlled with oral metformin $1 \mathrm{~g}$ and gliclazide $80 \mathrm{mg}$ twice daily. His random blood sugar was $13.0 \mathrm{mmol} / \mathrm{L}$ and $\mathrm{HbA} 1 \mathrm{C}$ $8 \%$. He was referred for optimization of sugar control while in the ward. Subcutaneous Insulatard $10 \mathrm{U}$ was added after which his blood sugar has been within normal range. There was gradual improvement of his facial palsy following rehabilitation including physiotherapy.

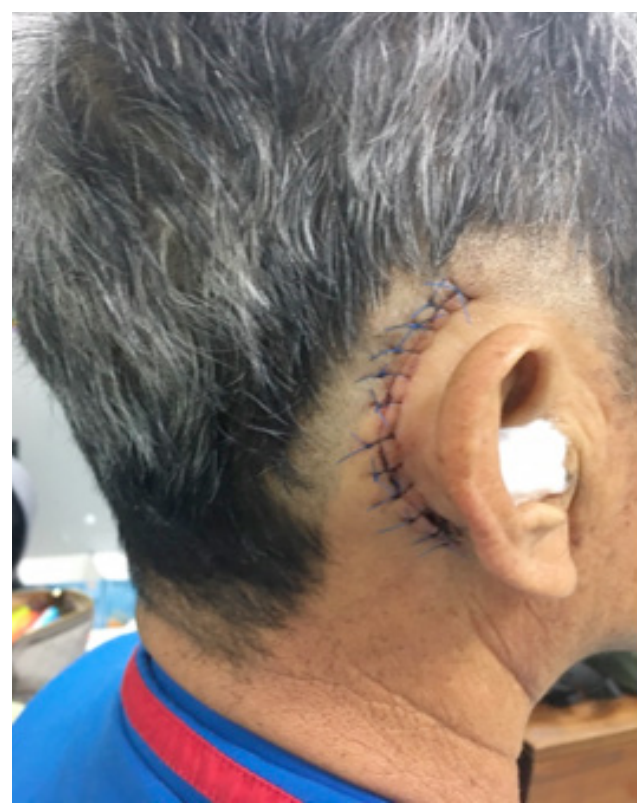

Figure 4: Right cortical mastoidectomy scar

pathognomonic finding of NOE. ${ }^{6}$ The disease may spread through the fissures of Santorini to the adjoining skull base, causing periostitis, osteomyelitis and cranial nerve palsies. ${ }^{1}$ It is very important to identify the disease and treat it early as it can cause more sinister complications such as meningitis, brain abscess and death. Treatment of NOE includes immunosuppression, local treatment of auditory canal and long-term antibiotic therapy (approximately 6-8 weeks). ${ }^{1,3}$ The role of surgery in NOE is limited; mastoidectomy is performed if mastoid air cells are involved and in persistent otalgia, a transection of $\mathrm{CN} \mathrm{V}$ and CN IX has been reported. ${ }^{3,7}$ Strict glycemic control is mandatory. ${ }^{3}$

Acute otitis externa (AOE) and NOE may have similar presentation in the beginning. However, 
in NOE the pain is so excruciating that it may disturb one's sleep and in later stages it can cause complications such as osteomyelitis of the skull with cranial nerves involvement or death from disseminated septic thrombo-emboli of the brain. Examination of NOE may show granulation tissue in EAC at the bone-cartilage junction. Imaging studies to confirm $\mathrm{NOE}$ include Computed Tomographic (CT) and bone scanning. Unlike AOE, NOE requires long-term intravenous antibiotic therapy. ${ }^{3,8}$ EAC cholesteatoma is an inflammatory lesion of the temporal bone with CT findings of soft tissue mass in EAC and adjacent bone erosion.'

There are several mechanisms thought to cause facial palsy in NOE. The primary mechanism is direct involvement of the nerve by toxins from the pathogens. Infection may spread through Santorini fissures to the base of the skull, causing bone destruction before spreading medially, thus triggering facial palsy. ${ }^{2,3}$ When facial palsy appears late in the disease, it may be due to silent mastoiditis, which may only be diagnosed with brain imaging. The presence of facial palsy indicates a poorer prognosis due to the deep penetration along the base of the skull. This may put other cranial nerve palsies at high risk and, due to the poor perfusion of the diseased area, a longer intravenous antibiotic treatment is required. ${ }^{3,10}$

Here we present a case of right facial palsy in a patient who was initially diagnosed with acute otitis externa which did not show improvement despite being treated with topical and oral antibiotics. We identified the possible causes that may have led to the complication of facial palsy. Firstly, when the patient initially presented with otalgia and otorrhoea, it is important to identify the causes and to start appropriate treatments. Ear secretions should be cultured prior to starting medications as early treatment with appropriate antimicrobials may achieve good cure rates and reduce the associated morbidity/mortality. ${ }^{1}$ Furthermore, the pattern of cultures may change after treatment has been initiated. ${ }^{3}$ If the infection is not responsive to antibiotics, a fungal infection should be considered. More importantly, early suspicion of NOE should be made if the symptoms remain persistent despite multiple courses of antibiotics. Hence, it is important to perform a good otoscopic examination and look for the presence of granulation tissue, especially in severe otalgia cases, for which a prompt referral to the otorhinolaryngology team should be made. ${ }^{1,10}$ Treating NOE with oral antibiotic alone as an outpatient is often inadequate; instead a long-term intravenous antibiotic is required. ${ }^{1,3}$

When patients with otitis externa went on to develop facial palsy, subsequent management of the problem may have been delayed by unnecessary referrals. This patient with lower motor neuron facial palsy associated with otalgia and otorrhoea was referred to the neurologist prior to seeing the otorhinolaryngology team, as it is crucial to exclude NOE. This, however, may have caused a delay in the treatment if the patient was not referred to the appropriate team promptly and may have resulted in more serious complications, including death. Therefore, a thorough examination must be performed to look for the causes of facial palsy in the ears, mastoid region, oral cavity, eyes, scalp, parotid glands and a complete neurological examination must be performed too before making a referral.

All patients with comorbidities including diabetes should be managed with a holistic approach. Treatment should not just focus on the otitis externa but also on any underlying health issues. The patient's sugar control should have been managed concurrently with the otitis when his case was first presented, as diabetic patients are more susceptible to a wide range of diseases including NOE. Medical experts should be involved earlier to co-manage any underlying comorbidities. In this case, if NOE had been diagnosed earlier during his initial presentation at the primary care level, the complication of facial nerve palsy may have possibly been avoided. A prompt referral and treatment in NOE cases may avoid other more serious complications including death.

\section{Conclusion}

Facial nerve palsy in otitis externa is an uncommon complication that may be prevented with proper management. This includes early recognition of the disease, early referrals, appropriate treatments and optimizing the comorbidities. Necrotizing otitis externa must be suspected in otitis externa cases in elderly diabetic patients who do not respond to oral antibiotic treatments.

\section{Funds Declaration}

No funds were received for this case report. 


\section{Patient Consent}

Written informed consent was obtained from the patient for this case report and its accompanying images.

\section{Disclosure of interest}

The authors report no conflicts of interest.

\section{How does this paper make a difference to general practice?}

- It creates awareness among clinicians and health staff of the need to recognize and differentiate necrotizing otitis externa (NOE) from acute otitis externa.

- It describes a case commonly encountered in a general-practice setting which may have been overlooked as a mild case but was ultimately discovered to be more complicated.

- A high index of suspicion for NOE is important when dealing with otitis externa not responding to topical/oral antibiotics.

\section{References}

1. Kumar SP, Ravikumar A, Somu L, Ismail NM. Malignant otitis externa: an emerging scourge. Journal of Clinical Gerontology and Geriatrics. 2013;4:128-131.

2. Walton J, Coulson C. Fungal malignant otitis externa with facial nerve palsy: tissue biopsy aids diagnosis. Case Rep Otolaryngol. 2014;2014:192318

3. Handzel O, Halperin D. Necrotizing (malignant) external otitis. Am Fam Physician. 2003; 68:309-312.

4. Singh A, Khabori M, Hyder J. Skull base osteomyelitis: diagnostic and therapeutic challenges in atypical presentation. Otolaryngol Head Neck Surg. 2005;133:121-125.
5. Illing E, Zolotar M, Ross E, Olaleye O, Molony N. Malignant otitis externa with skull base osteomyelitis. J Surg Case Rep. 2011;2011(5):6

6. Roberts JR. Malignant externa otitis: disastrous for diabetics. Emergency Medicine News. 2004;26:24-26.

7. Chandler JR. Pathogenesis and treatment of facial paralysis due to malignant external otitis. Ann Otol Rhinol Laryngol. 1972;81:648-658.

8. Cohen D, Friedman P, Filon A. Malignant external otitis versus acute external otitis. J Laryngol Otol. 1987;101: 211-215.
9. Heilbrun ME, Salzman KL, Glastonbury CM, et al. External auditory canal cholesteatoma: clinical and imaging spectrum. Am J Neuroradiol. 2003; 24: 751-756.

10. Cohen D, Friedman P. The diagnostic criteria of malignant external otitis. J Laryngol Otol. 1987;101:216-21. 


\title{
A life-threatening condition-ruptured ectopic pregnancy with negative urine pregnancy test: A case report
}

\author{
Fadzilah Mohamad, Ahmad Shuib Yahya, Aneesa Abdul Rashid, Navin Kumar Devaraj, \\ Abdul Hadi Abdul Manap
}

Mohamad F, Yahaya AS, Abdul Rashid A, et al. A life-threatening condition—ruptured ectopic pregnancy with negative urine pregnancy test: A case report. Malays Fam Physician. 2021;16(1);121-123. https://doi.org/10.51866/cr1117

\section{Keywords:}

ectopic pregnancy, negative

urine pregnancy test, ruptured

ectopic, reproductive women

\section{Authors:}

Fadzilah Mohamad

(Corresponding author)

MB BCH BAO (Ire), MMed Family

Medicine (UPM)

Department of Family Medicine

Faculty of Medicine \& Health

Sciences, Universiti Putra Malaysia

Selangor, Malaysia

Email: ilafadzilah@upm.edu.my

\section{Ahmad Shuib Yahya}

MBBCh (Ain Shams University),

MMed Obstetrics and Gynaecology

(USM)

Department of Obstetrics and

Gynaecology, Faculty of Medicine

\& Health Sciences, Universiti Putra

Malaysia, Selangor, Malaysia

\section{Aneesa Abdul Rashid}

MB BCH BAO (Ire), MMed Family

Medicine (UKM)

Department of Family Medicine

Faculty of Medicine \& Health

Sciences, Universiti Putra Malaysia

Selangor, Malaysia

\section{Abstract}

Ectopic pregnancy is an extra-uterine pregnancy and is a potentially life-threatening condition that can lead to death from intra-peritoneal hemorrhage. This case reports a rare occurrence of ruptured tubal pregnancy in which the patient presented early with abdominal pain and a negative urine pregnancy test but subsequently presented again with evidence of intra-peritoneal hemorrhage. A negative urine pregnancy test is often used to rule out pregnancy, but it is not $100 \%$ sensitive. Complete assessment is critical in this important diagnosis in order to plan for the appropriate emergency management.

\section{Introduction}

The incidence of ectopic pregnancy (EP) is $2 \%$ with a mortality rate of 0.5 per 100,000 live births. ${ }^{1}$ The most common site is the fallopian tube $(96 \%)$. EP is among the leading causes of maternal mortality and morbidity. ${ }^{1}$ Failure to diagnose may result in intra-peritoneal hemorrhage, shock, and death. Ruptured EP is a gynecological emergency. It should be suspected in women of reproductive age presenting with an acute abdomen. A positive urine pregnancy test (UPT) with a negative ultrasound finding of intrauterine gestational sac will increase the suspicion of EP. However, pregnancy is usually excluded when the UPT is negative and thus results in a missed diagnosis of EP. This case report illustrates how EP was missed at the primary care level, resulting in a life-threatening intra-peritoneal hemorrhage.

\section{Case Report}

A 33-year-old woman, para 1+2, presented to a primary care clinic with two days history of dull localized left lower abdominal pain. It was associated with vaginal bleeding that was thought to be her usual menses. She had an irregular menstrual cycle, and her last menstrual period was five weeks ago. She was previously on injectable contraception. Her last injection was five months ago. She had histories of dilatation and curettage for her previous miscarriages. During the first visit, no UPT was done. She was treated for dysmenorrhea and discharged home.
Three days later, she presented again for worsening abdominal pain. Her pain score was $6 / 10$. The pain radiated to the right lower abdomen. She remained afebrile and there was no vaginal bleeding. Her vital signs were stable. Abdominal examination was unremarkable except for tenderness in the lower abdomen. Transabdominal ultrasound (TAS) showed no evidence of an intrauterine gestational sac. Urinalysis was normal. UPT was negative. She was once again discharged home.

She presented to the emergency department two days later with severe generalized abdominal pain. It was associated with vomiting, abdominal distension, and dyschezia. She was tachycardic (120 beats per minute) but her other vital signs were normal. Examination revealed a distended and guarded abdomen with cervical motion tenderness. UPT was positive. She was referred to the gynecology team for suspected ruptured EP. Transvaginal ultrasound (TVS) showed an empty uterus with a $5 \times 4 \mathrm{~cm}$ left adnexal complex mass and free fluid collection in the pelvic cul-de-sac. An emergency diagnostic laparoscopy was done. Intra-operationally, the left fallopian tube was disrupted, and a left salpingectomy was performed. Postoperatively, she recuperated well.

\section{Discussion}

The classic clinical triad of EP includes abdominal pain, amenorrhea, and vaginal 


\author{
Navin Kumar Devaraj \\ MD (UPM), MMed Family Medicine \\ (UM) \\ Department of Family Medicine \\ Faculty of Medicine \& Health \\ Sciences, Universiti Putra Malaysia \\ Selangor, Malaysia
}

\section{Abdul Hadi Abdul Manap}

MD (UPM), MMed Family Medicine (UPM)

Department of Family Medicine

Faculty of Medicine \& Health

Sciences, Universiti Putra Malaysia

Selangor, Malaysia bleeding. ${ }^{1}$ UPT is a mandatory test in all women of childbearing age presenting with these symptoms. It is a quick and easy qualitative test for beta human chorionic gonadotropin $(\beta-\mathrm{hCG})$. The sensitivity is $99 \%$ if the $\beta$-hCG level is greater than 25 IU/L. ${ }^{2}$ Lower levels of $\beta$-hCG may result in a false-negative reading. The incidence of EP with a negative UPT is $1.6 \% .^{3}$ In this case study, the first issue to be highlighted is the failure of the doctor to perform UPT during the patient's initial visit despite having symptoms suggestive of EP. The missed diagnosis led to mismanagement and delays in treatment. Errors of treatment and diagnosis are common medical negligence claims brought against medical professionals. ${ }^{4}$

Discontinuation of injectable contraception is known to delay the return of fertility, sometimes up to 18 months after the last injection. ${ }^{5}$ However, in this case, fertility returned right after discontinuation and this could also be the reason why the doctor missed this crucial diagnosis.

Another issue in this case was the falsenegative UPT that misled the doctor in ruling out EP. $\beta$-hCG is detectable in urine and serum within 16 days following the luteinizing hormone surge. ${ }^{6}$ In normal pregnancies, the serum $\beta$-hCG level doubles every 48 to 72 hours but in EP, it increases at a lesser rate. ${ }^{1}$ A study done among women with EP showed that the increment of $\beta$-hCG was only $75 \%$ after 48 hours compared to $124 \%$ in a viable pregnancy ${ }^{7}$ and it declined at the same rate or faster than those with complete abortion, such that the results could be interpreted as "normal" for a complete abortion. $^{7}$ A defect in the biosynthesis of $\beta-\mathrm{hCG}$ in an ectopic trophoblast may also cause a false-negative result. The trophoblastic tissue may have been inactive before it ruptured and could have resulted in premature clearance of $\beta$-hCG from the circulation. $^{3}$ A faulty strip could be another reason 8 but this unlikely in this case as no other inaccurate UPT results were reported in the clinic during that period.

The preferred diagnostic tool for EP is TVS. ${ }^{?}$ Once suspected, serial serum $\beta$-hCG should be measured. The absence of an intrauterine pregnancy with increasing $\beta$-hCG serum above the discriminatory zone suggests an EP. ${ }^{10}$ However, at the primary care level, these procedures are usually unavailable. The doctor needs to rely on history and clinical examination. TAS is widely available in primary care; however, it has little benefit in the early stages of EP as the diagnostic reliability of TAS is only $70 \%$ compared to $\geq 90 \%$ for TVS. $^{2}$ TAS may only be able to visualize the presence of free fluid and an empty uterus. ${ }^{2}$ Therefore, the ability to perform TVS should be recommended to be part of the Credentialing and Privileging program among the primary care doctors that may aid the diagnosis of EP.

Ruptured EP is a clinical diagnosis with clinical features such as sudden and persistent abdominal pain that may be accompanied by shoulder pain, peritonitis, or shock. ${ }^{1,10}$ In this case study, the patient had a compensated hemorrhagic shock as evidenced by tachycardia, normotension, and hemoperitoneum.

This report highlights the fallibility during the early presentation of EP. A comprehensive history should always be obtained, especially the menstrual, gynecological, and contraceptive history. EP must be excluded in all sexually active women with abdominal pain regardless of the presence of vaginal bleed. The patient's history of irregular menses, recent withdrawal of contraception, and two previous dilatation and curettage procedures were indicators toward a diagnosis of EP. Early detection can reduce the risk of tubal rupture and allows more conservative treatment to be employed. ${ }^{1}$

\section{Conclusion}

$\mathrm{EP}$ is a life-threatening condition that requires urgent recognition and treatment. Although UPT is a reliable tool for detecting pregnancy, a negative result does not rule out EP. It must be suspected in a sexually active woman presenting with abdominal pain, amenorrhea, and/or vaginal bleeding.

\section{Acknowledgment}

Written consent was obtained from the patient for the publication of this case report.

\section{Funding and Conflict of Interest}

This case report did not receive any funding. All authors declare no conflict of interest in this study. 


\section{How does this paper make a difference to general practice?}

- A flaw in the diagnostic workup of this case was that the exclusion of EP was solely based on the negative UPT result.

- EP should be suspected and UPT should be mandatory in all sexually active women with lower abdominal pain, amenorrhea, and/or vaginal bleeding.

- Negative UPT with high suspicion of EP should be managed as an emergency until proven otherwise. Thorough history and examination are important and would make a considerable impact on the management of EP.

- Having TVS at the primary care level may assist in the diagnosis of EP at an earlier stage.

- Timely referral of EP to tertiary centers may prevent life-threatening complications.

\section{References}

1. Vicken PS, Ellen W. Ectopic Pregnancy. Medscape. Updated Sep 28, 2017; Accessed 9 July, 2020. Available from: https://emedicine. medscape.com/article/2041923

2. Madani Y. The use of ultrasonography in the diagnosis of ectopic pregnancy: a case report and review of the literature. Medscape J Med. 2008;10(2):35. Accessed 29 Mar, 2020.

Available from: http://www.medscape.com/ viewarticle/568521

3. Paritakul P. Ruptured tubal pregnancy with a negative urine pregnancy test and serum beta human chorionic gonadotropin. Thai J Obstet Gynaecol. 2017;25(2):130-135. doi:10.14456/ tjog.2017.19

4. Powers E. Chapter 2: Why doctors get sued. In: Jha S, Ferriman E. Medicolegal Issues In Obstetric and Gynaecology. Springer International Publishing; 2018:9-13.
5. Kaunitz AM. Depot medroxyprogesterone acetate (DMPA) for contraception: Formulations, patient selection and drug administration. In: Post T, ed. UpToDate. UpToDate; 2020. Accessed 9 Jul, 2020. Available from: https://www.uptodate.com/ contents/depot-medroxyprogesterone-acetatedmpa-for-contraception-formulations-patientselection-and-drug-administration

6. Greene DN, Grenache DG; Education Committee of the Academy of Clinical Laboratory Physicians and Scientist. Pathology consultation on human chorionic gonadotropin testing for pregnancy assessment. Am J Clin Pathol. 2015;144(6):830-836. doi:10.1309/ AJCP7O7VAREDUYIJ

7. Silva C, Sammel MD, Zhou L, Gracia C, Hummel AC, Barnhart K. Human chorionic gonadotropin profile for women with ectopic pregnancy. Obstet Gynecol. 2006;107(3):605-610. doi:10.1097/01. AOG.0000198635.25135.e7
8. Brennan DF, Kwatra S, Kelly M, Dunn M. Chronic ectopic pregnancy--two cases of acute rupture despite negative beta hCG.J Emerg Med. 2000;19(3):249-254. doi:10.1016/ s0736-4679(00)00233-x

9. Elson CJ, Salim R, Potdar N, Chetty M, Ross JA, Kirk EJ on behalf of the Royal College of Obstetricians and Gynaecologists. Diagnosis and management of ectopic pregnancy. BJOG Int J Obstet Gynaecol. 2016;123(13):e15-e55. doi:10.1111/1471-0528.14189

10. Togas T. Ectopic pregnancy: Clinical manifestations and diagnosis. In: Post T, ed. UpToDate. UpToDate; 2020. Accessed Mar 27, 2020. Available from: https://www. uptodate.com/contents/ectopic-pregnancyclinical-manifestations-and-diagnosis 


\title{
Type 2 diabetes remission: How does it work?
}

\author{
Mohd Shahriman bin Ahmad Fuat, Faridah binti Mohd Zin, Zainab binti Mat Yudin \\ Ahmad Fuat MS, Mohd Zin F, Mat Yudin Z. Type 2 diabetes remission: How does it work?. Malays Fam Physician. $2021 ; 16(1) ; 124-128$. \\ https://doi.org/10.51866/cr1026
}

Keywords: diabetes mellitus, remission, therapeutic lifestyle change, metabolic syndrome

\section{Authors:}

Faridah binti Mohd Zin

(Corresponding author)

$\mathrm{PhD}$. Senior Lecturer

Department of Family Medicine

School of Medical Sciences

Universiti Sains Malaysia.

Kota Bharu, Kelantan

Email: faridahz@usm.my

Mohd Shahriman bin Ahmad Fuat

Department of Family Medicine Hospital Universiti Sains Malaysia Kota Bharu, Kelantan

Zainab binti Mat Yudin MMed, Lecturer

School of Dental Sciences Universiti Sains Malaysia Kota Bharu, Kelantan

\section{Abstract}

Type 2 diabetes mellitus (Type $2 \mathrm{DM}$ ) is a chronic disease which rise is closely linked to the obesity epidemic and which requires long-term medical attention to limit the development of its wideranged complications. Many of these complications arise from the combination of resistance to insulin action, inadequate insulin secretion, and excessive or inappropriate glucagon secretion. The increasing evidence of its remission state has been discussed in the literature. Here we report on a patient with metabolic syndrome who underwent a structured therapeutic lifestyle changes (TLC) therapy which eventually led to remission of Type 2 DM.

\section{Introduction}

Type 2 diabetes mellitus (Type $2 \mathrm{DM}$ ) is a non-communicable disease (NCD) which continues to grow in prevalence worldwide despite significant efforts to control and prevent it. In Malaysia, the 2019 National Health and Morbidity Survey (NHMS) reported that $18.3 \%$ of adults over the age of 18 and $20.8 \%$ of adults over the age of 30 suffered from diabetes. ${ }^{1}$ The pathophysiology of Type 2 DM was believed to be characterized by progressive, irreversible loss of pancreatic insulin secretion mediated by apoptosis of pancreatic $\beta$-cells. ${ }^{2,3}$ However, recent studies showed that weight loss can bring restoration of $\beta$-cells response, leading to diabetes remission. ${ }^{2}$ Although there is a growing body of theoretical evidence related to this remission state, only a handful of studies and cases covered in the literature specifically report the effectiveness of therapeutic lifestyle changes (TLC) in managing Type 2 DM. ${ }^{1}$ This study therefore looks at the ability to achieve a remission state through therapeutic lifestyle changes in a patient with Type 2 DM.

\section{Case History}

A 33-year-old female, who had underlying Type 2 DM, hypertension and hyperlipidemia, was referred to the obesity clinic for morbid obesity with a body mass index (BMI) of $41.8 \mathrm{~kg} / \mathrm{m}^{2}$. She was diagnosed with Type $2 \mathrm{DM}$ at the age of 22, after which she was started on oral hypoglycaemic agents. She was noncompliant to medications and had multiple hospital admissions for complication of uncontrolled blood sugar. Her initial HbA1c level at diagnosis in 2009 was $9.8 \%$ which worsened to $12.8 \%$ over the course of almost 10 years. Consequently, her liver transaminases and lipid profile became deranged. After failing to achieve glycemic control, she was started on insulin in 2013. Unfortunately, she continued to not comply to treatment until 2018 when she was admitted for severe diabetic ketoacidosis. Concurrently, her body weight reached 115 $\mathrm{kg}$ with BMI of $41.8 \mathrm{~kg} / \mathrm{m}^{2}$. Moreover, her effort tolerance was significantly reduced with New York Heart Association class 3, which disturbed her daily activities. After that, she became determined to change her lifestyle and agreed to be referred to the obesity clinic at Hospital Universiti Sains Malaysia in December 2018. She was given extensive counseling and an intensive therapeutic lifestyle intervention was planned. She received comprehensive dietary advice, was set up with a personalized exercise regime, and attended individual and group behavioral therapy sessions for six months. On further examination, it was found she had a strong family history of Type $2 \mathrm{DM}$, she worked as a teacher at a secondary school, and denied any history of over-the-counter drug or traditional medication intake. Table $\mathbf{1}$ and $\mathbf{2}$ outline the treatment received and the progress of the parameters measured respectively. 
Table 1. Summary of treatment received, challenges and patient adherence to plan

\begin{tabular}{|c|c|c|c|}
\hline & $\begin{array}{l}\text { Management } \\
\text { recommendation/advised }\end{array}$ & Patient's adherence/preference & Challenges \\
\hline $\begin{array}{l}\text { Dietary } \\
\text { intake }\end{array}$ & $\begin{array}{l}\text { Intensive calorie restriction and } \\
\text { counting. } \\
\text { Referral to dietitian. } \\
\text { Aim for less than } 2000 \mathrm{kcal} \\
\text { per day. } \\
\text { Regular fasting twice a week } \\
\text { (depending on patient's } \\
\text { preference). } \\
\text { Stop consumption of sweet } \\
\text { drinks and encouraged to } \\
\text { drink unlimited amounts of } \\
\text { low-calorie fluids such as water, } \\
\text { coffee and tea. } \\
\text { Low carbohydrate diet. }\end{array}$ & $\begin{array}{l}\text { Strict calorie counting as } \\
\text { advised by dietitian (calories } \\
\text { needed per day: } 1600 \mathrm{kcal} \text { ). } \\
3 \text { main meals daily for } 5 \text { days } \\
\text { per week. } \\
14 \text { hours fasting } 2 \text { times a week } \\
\text { (Monday and Thursday). } \\
\text { Stop consumption of sweet } \\
\text { drinks. } \\
\text { Stopped snacking in between } \\
\text { meals. }\end{array}$ & $\begin{array}{l}\text { Initially, during the } \\
\text { first } 2 \text { months of the } \\
\text { TLC regime, she had } \\
\text { mild hypoglycemic } \\
\text { episodes, but these } \\
\text { did not recur after the } \\
\text { 2-month mark. }\end{array}$ \\
\hline $\begin{array}{l}\text { Physical } \\
\text { activities }\end{array}$ & $\begin{array}{l}\text { Exercise therapy clinic: } \\
\text { Referral to exercise therapy } \\
\text { specialist. } \\
\text { Aerobic and resistance exercise. } \\
\text { Daily exercise, started with } \\
\text { light exercise e.g. brisk walking, } \\
\text { jogging, then stepped up } \\
\text { to running, } 90 \text { minutes per } \\
\text { session. } \\
\text { Advised to gradually increase } \\
\text { her exercise duration rather } \\
\text { than intensity. (resistance } \\
\text { exercise) } \\
\text { Encouraged to join group/ } \\
\text { aerobic exercise therapy e.g. } \\
\text { aero-dance and group hiking. }\end{array}$ & $\begin{array}{l}\text { She began with light exercise } \\
\text { such as walking. } \\
\text { Stepped up the frequency, } \\
\text { intensity and duration every } \\
2-3 \text { weeks. } \\
\text { Attend group exercise, } \\
\text { especially aero dance, } 4-5 \text { times } \\
\text { per week. } \\
\text { Frequency of exercise: daily } \\
\text { - Intensity: moderate } \\
\text { - Duration: } 60-90 \text { minutes } \\
\text { per session. }\end{array}$ & \\
\hline $\begin{array}{l}\text { Behavioral } \\
\text { Therapy }\end{array}$ & $\begin{array}{l}\text { Regular monthly follow-up } \\
\text { with individual and group } \\
\text { therapy. } \\
\text { Motivational interview } \\
\text { counseling for at least } 15 \\
\text { minutes at every visit. } \\
\text {-Behavioral change support } \\
\text { approach using the 5As model } \\
\text { (ask, advise, assess, assist, } \\
\text { arrange). } \\
\text {-Emotional support approach. } \\
\text {-Re-emphasized that obesity is } \\
\text { a result of maladaptive eating } \\
\text { patterns and exercise habits. } \\
\text { Emphasized the important role } \\
\text { of CBT in managing weight } \\
\text { loss such as focusing on the } \\
\text { aim, weight self-monitoring, } \\
\text { calorie-counting diary, and } \\
\text { increasing physical activity. }\end{array}$ & $\begin{array}{l}\text { Motivational interview } \\
\text { approach: } \\
\text { - Empowerment, shared } \\
\text { decision making. } \\
\text { - Emotional and empathy } \\
\text { support. } \\
\text { - Adherence to diet and } \\
\text { physical therapy. } \\
\text { - Avoid maladaptive eating } \\
\text { habit. } \\
\text { - Implement diabetes self-care } \\
\text { such as meal planning, } \\
\text { planned physical activity, } \\
\text { blood glucose monitoring, } \\
\text { taking diabetes medicines, } \\
\text { and managing episodes of } \\
\text { illness. }\end{array}$ & \\
\hline
\end{tabular}

*Shared decision making was implemented during each visit 
Table 2. The progress of the parameters measured

\begin{tabular}{|c|c|c|c|c|c|c|c|c|}
\hline${ }_{\text {Parameters }}$ Visit & $\begin{array}{c}\text { Dec } \\
2018\end{array}$ & $\begin{array}{c}\text { Jan } \\
2019\end{array}$ & $\begin{array}{c}\text { Feb } \\
2019\end{array}$ & $\begin{array}{c}\text { Mar } \\
2019\end{array}$ & $\begin{array}{c}\text { Apr } \\
2019\end{array}$ & $\begin{array}{c}\text { Jun } \\
2019\end{array}$ & $\begin{array}{c}\text { Aug } \\
2019\end{array}$ & $\begin{array}{c}\text { Dec } \\
2019\end{array}$ \\
\hline Weight (kg) & 115 & 108 & 104 & 99 & 96.3 & 94 & 83.4 & 79 \\
\hline HbA1c (\%) & 12.6 & 9.4 & - & - & 4.6 & - & 5.0 & 5.3 \\
\hline $\begin{array}{l}\text { Lipid profile } \\
\text { TC (mmol/L) } \\
\text { TG }(\mathrm{mmol} / \mathrm{L}) \\
\text { LDL }(\mathrm{mmol} / \mathrm{L}) \\
\mathrm{HDL}(\mathrm{mmol} / \mathrm{L}) \\
\end{array}$ & $\begin{array}{l}7.6 \\
3.2 \\
4.8 \\
0.8\end{array}$ & - & - & - & $\begin{array}{l}5.3 \\
1.8 \\
2.2 \\
1.2 \\
\end{array}$ & - & $\begin{array}{c}4.46 \\
0.88 \\
3.01 \\
1.5 \\
\end{array}$ & - \\
\hline $\begin{array}{l}\text { Renal Function } \\
\text { Sodium }(\mathrm{mmol} / \mathrm{L}) \\
\text { Potassium }(\mathrm{mmol} / \mathrm{L}) \\
\text { Urea }(\mathrm{mmol} / \mathrm{L}) \\
\text { Creatinine }(\mu \mathrm{mol} / \mathrm{L}) \\
\end{array}$ & $\begin{array}{l}139 \\
4.4 \\
4.7 \\
66 \\
\end{array}$ & - & - & - & - & - & - & $\begin{array}{l}136 \\
4.8 \\
4.9 \\
64 \\
\end{array}$ \\
\hline $\begin{array}{l}\text { Liver function } \\
\text { AST (U/L) } \\
\text { ALT (U/L) } \\
\text { ALP (U/L) } \\
\end{array}$ & $\begin{array}{l}28 \\
73 \\
79 \\
\end{array}$ & - & - & $\begin{array}{l}18 \\
74 \\
13 \\
\end{array}$ & - & - & - & $\begin{array}{l}15 \\
67 \\
15 \\
\end{array}$ \\
\hline $\begin{array}{l}\text { Assessment of DM } \\
\text { complications }\end{array}$ & \multicolumn{2}{|c|}{$\begin{array}{c}\text { ECG: normal } \\
\text { Funduscopy: normal } \\
\text { Urine protein: trace. } \\
\text { Mild hypoglycemia } \\
\text { episode during first } 2 \\
\text { months of therapy } \\
\end{array}$} & \multicolumn{2}{|c|}{$\begin{array}{c}\text { Foot examination: } \\
\text { normal } \\
\text { No hypoglycemia } \\
\text { symptom. }\end{array}$} & \multicolumn{2}{|c|}{$\begin{array}{l}\text { Urine protein: } \\
\text { negative }\end{array}$} & \multicolumn{2}{|c|}{$\begin{array}{l}\text { ECG: normal } \\
\text { Funduscopy: normal }\end{array}$} \\
\hline $\begin{array}{l}\mathrm{OHA} / \text { insulin regimen } \\
\text { (units) }\end{array}$ & $\begin{array}{c}\text { IR } 24 \\
\text { TDS } \\
\text { IN } 30 \\
\text { ON } \\
\text { MXTR } \\
\text { 1gm } \\
\text { OD }\end{array}$ & $\begin{array}{l}\text { IR } 14 \\
\text { TDS } \\
\text { IN } 24 \\
\text { ON } \\
\text { MXTR } \\
\text { 1gm } \\
\text { OD }\end{array}$ & $\begin{array}{l}\text { IR } 14 \\
\text { TDS } \\
\text { IN } 20 \\
\text { ON }\end{array}$ & $\begin{array}{c}\text { IR } 10 \\
\text { TDS } \\
\text { IN } 20 \\
\text { ON }\end{array}$ & $\begin{array}{c}\text { IR } 8 \\
\text { TDS } \\
\text { IN } 16 \\
\text { ON }\end{array}$ & $\begin{array}{c}\text { IR } \\
-/ 6 / 6 \\
\text { IN } 8 \\
\text { ON }\end{array}$ & \multicolumn{2}{|c|}{ Treatment ceased } \\
\hline
\end{tabular}

Abbreviations:

TC: total cholesterol, TG: total triglycerides, LDL: low-density lipoprotein, HDL: highdensity lipoprotein

AST: aspartate aminotransferase, ALP: alkaline phosphatase, ALT: alanine aminotransferase

OHA: oral hypoglycemic agent, IR: insulin regular, IN: insulin isophane, MTXR: metformin extended release

\section{Discussion}

This case illustrates the effectiveness of therapeutic lifestyle changes in eliminating the need for diabetic medication in a case of longstanding Type 2 Diabetes (Type 2 DM). The patient-centered care concept, as a core of the primary care principle, was utilized throughout the entire process. During each visit, the patient was given the opportunity to outline her preferences for her exercise regime and to discuss any dietary modifications. The practice of shared decision making made the patient more likely to adhere to the treatment. The first official report on the remission of Type 2 DM was made following a bariatric surgery almost a quarter-century ago.,3 More recent research has proved that the diabetes remission state can be achieved by therapeutic lifestyle changes focusing mainly on a strict dietary regime achieving weight loss of approximately $15 \mathrm{~kg}{ }^{3}$ The underlying physiological changes were found to be a result of weight reduction improving the defects in both insulin secretion and hepatic insulin sensitivity of Type $2 \mathrm{DM}^{4}{ }^{4}$ Thus, recent practice involves the use of new exercise regimes, behavioral interventions, and psychosocial care - all considered essential components of the therapeutic lifestyle change (TLC) weight reduction strategy in the treatment of Type 2 DM. $^{4,5}$

Studies have shown that dietary intervention plays the most significant role in weight reduction; in fact, $70 \%$ of weight can be reduced by diet alone. ${ }^{6}$ Options include balanced lowcalorie, low-fat/low-calorie, moderate-fat/lowcalorie, and low-carbohydrate diets, as well as the 
obesity clinic. A multicomponent exercise regime should involve a comprehensive combination of aerobic and resistance training. Nevertheless, the patient's safety upon exercising - including their fitness and cardiovascular risk - should always be taken into consideration before prescribing an exercise regime. Other factors that can affect the structure and intensity of a prescribed exercise regime include existing medical conditions and age. ${ }^{1}$ Another study reported, in those with obesity and Type 2 DM, structured exercise interventions lasting at least 8 weeks can lower $\mathrm{HbA1C}$ by an average of $0.66 \%$ even without a significant change in body weight. ${ }^{11,12}$

Recently, behavioral therapy has been found to be a valuable addition for weight reduction programs. ${ }^{13,14,15}$ Among the recommended behavioral therapies, Cognitive Behavioral Therapy (CBT) is recognized as the first-line treatment to help patients to achieve a longterm involvement in sustainable and successful weight reduction programs. ${ }^{13,14}$ CBT helps in improving diet control, stress management, motivation to exercise, and coping skills, all of which lead to a higher chance of achieving the desired goal. ${ }^{13,14}$ However, due to the extensive nature of the CBT process, which requires 8 to 10 one-hour sessions, it is reasonable to regard motivational interview technique (MIT) as a better choice of behavioral therapy in the primary care setting. ${ }^{14,15}$ MIT is a client-centered approach that promotes behavioral change by exploring ambivalence in a nonjudgmental and supportive yet direct fashion. ${ }^{16,17}$ This feasible primary care technique has been shown to be an effective adjunct therapy to improve adherence to the weight reduction program. ${ }^{16,17}$ In our case, we applied MIT concept at each visit to improve and maintain motivation toward the prescribed regimens. The details of the therapy given are shown in Table $\mathbf{1}$.

Finally, after approximately 8 months of an intensive therapeutic lifestyle changes regimen and a series of regular follow-ups, the patient had fulfilled the criteria of diabetes remission. The remission state of diabetes is defined as when a patient achieves an HbA1c level below 6.5\% while also being able to discontinue all diabetic medications for at least 2 months. ${ }^{3}$ For this patient, her latest $\mathrm{HbA1c}$ level is $4.6 \%$, following which all the diabetic medications were ceased.

\section{Conclusion}

The present case shows that an intensive therapeutic lifestyle regimen can eliminate the need for diabetic medication; thus remission can be achieved in a Type 2 DM patient with obesity without recourse to drugs. A multidisciplinary approach delivered in a patient-centered manner is an effective strategy for achieving weight reduction through a therapeutic lifestyle regimen. Weight reduction with the concurrent increment in physical activities improves diabetic control. Hence, despite the growing medical interventions, therapeutic lifestyle changes should always be an important adjuvant in the treatment of Type 2 DM.

\section{Declaration of patient consent}

The authors certify that appropriate patient consent was obtained.

\section{Financial support and sponsorship}

Nil.

\section{Conflicts of interest}

There are no conflicts of interest to declare.

\section{Acknowledgement}

The author is grateful and acknowledges the valuable contributions of all the helpful coauthors in completing this case report.

\section{How does this paper make a difference to general practice?}

- It demonstrates the effectiveness of therapeutic lifestyles changes (TLC) in reducing insulin resistance, resulting in cessation of diabetic therapy while maintaining diabetic control, thus preventing the complications of Type 2 DM.

- This case illustrates the efficiency of the patient-centered approach in achieving the desired outcome in the management of a chronic medical problem. The shared decision making between the health provider and patient became the center of the behavioral changes process which in turn improved the patient's adherence to treatment and follow-up.

- The use of Motivational Interview Technique, which is feasible in a primary care setting, can promote a better long-term outcome, especially in the management of a noncommunicable disease. 


\section{References}

1. Institute for Public Health. The Fifth National Health and Morbidity Survey 2019 (NHMS IV 2019). Ministry of Health, Malaysia; 2019.

2. Buchwald H, Estok R, Fahrbach K, et al. Weight and type 2 diabetes after bariatric surgery: systematic review and meta-analysis. Am J Med. 2009;122: 248-256.

3. Lean MEJ, Leslie WS, Barnes AC, et al. Durability of a primary care-led weightmanagement intervention for remission of type 2 diabetes: 2-year results of the DiRECT open-label, cluster-randomised trial. Lancet Diabetes Endocrinol. 2019;7(5):344-355 doi:10.1016/S2213-8587(19)30068-3.

4. Lim EL, Hollingsworth KG, Aribisala BS, Chen MJ, Mathers JC, Taylor R. Reversal of type 2 diabetes: normalization of beta cell function in association with decreased pancreas and liver triacylglycerol. Diabetologia, 2011; 54: 2506-2514.

5. American Diabetes Association. Lifestyle management: Standards of Medical Care in Diabetes-2019. Diabetes Care 2019;42(Suppl. 1): S46-S60.

6. Franz MJ, Bantle JP, Beebe CA, Brunzell JD, Chiasson J-L, Garg A, Holzmeister LA, Hoogwerf B, Mayer-Davis E, Mooradian $A D$, Purnell JQ, Wheeler M. Evidence-based nutrition principles and recommendations for the treatment and prevention of diabetes and related complications (Technical Review). Diabetes Care 25: 148-198, 2002.
7. Briggs Early K, Stanley K. Position of the Academy of Nutrition and Dietetics: the role of medical nutrition therapy and registered dietitian nutritionists in the prevention and treatment of prediabetes and type 2 diabetes. J Acad Nutr Diet 2018; 118:34-353.

8. Ku M, Ramos MJ, Fung J. Therapeutic fasting as a potential effective treatment for type 2 diabetes: A 4-month case study. Journal of Insulin Resistance 2017; 1:5

9. Dansinger ML, Gleason JA, Griffith JL, Selker HP, Schaefer EJ. Comparison of the Atkins, Ornish, Weight Watchers, and Zone diets for weight loss and heart disease risk reduction: A randomized trial. JAMA. 2005; 293:43-53.

10. Physical Activity Guidelines Advisory Committee. 2018 Physical Activity Guidelines Advisory Committee Scientific Report. Washington, DC, U.S. Department of Health and Human Services 2018.

11. The American Diabetes Association: Physical activity/exercise and diabetes (Position Statement). Diabetes Care 27 (Suppl. 1): S58S62, 2004.

12. Boulé NG, Haddad E, Kenny GP, Wells GA, Sigal RJ. Effects of exercise on glycemic control and body mass in type 2 diabetes mellitus: a meta-analysis of controlled clinical trials. JAMA 2001; 286:1218-1227.
13. Wilson GT, Wilfley DE, Agras WS, Bryson SW. Psychological treatments of binge eating disorder. Arch Gen Psychiatry. 2010;67(1):94101.

14. Castelnuovo G, Pietrabissa G, Manzoni GM, Cattivelli R, Rossi A, Novelli M, Varallo G, Molinari E. Cognitive behavioral therapy to aid weight loss in obese patients: current perspectives. Psychol Res Behav Manag. 2017 Jun 6;10:165-173

15. Emmons KM, Rollnick S. Motivational interviewing in health care settings. Opportunities and limitations. Am J Prev Med. 2001;20(1):68-74. doi:10.1016/s07493797(00)00254-3.

16. VanWormer J, Boucher J. Motivational interviewing and diet modification: a review of the evidence. Diabetes Educ 30:404-419, 2004.

17. DiLillo VG, Siegfried NJ, West DS. Incorporating motivational interviewing into behavioral obesity treatment. Cogn Behav Pract 10:120-130, 2003 


\title{
Late-Onset Mirror Syndrome
}

\author{
Erinna Mohamad Zon, Nik Ahmad Zuky Nik Lah, Pek Sung Hoo
}

Zon EM, Nik Lah NAZ, Hoo PS. Late-Onset Mirror Syndrome. Malays Fam Physician. 2021;16(1);129-132. https://doi.org/10.51866/cr1099

\section{Keywords:}

Mirror syndrome, Ballantyne

syndrome, hydrops fetalis

\section{Authors:}

\section{Erinna Mohamad Zon}

(Corresponding author)

MD (USM), MMed O\&G (USM)

Department of Obstetrics \&

Gynaecology, School of Medical

Sciences, Universiti Sains Malaysia

Malaysia

Department of Obstetrics \&

Gynaecology, Hospital Universiti

Sains Malaysia, Malaysia

Email: erinna@usm.my

\section{Nik Ahmad Zuky Nik Lah} MD (USM), MMed O\&G (USM) Department of Obstetrics \& Gynaecology, School of Medical Sciences, Universiti Sains Malaysia Malaysia

\section{Hoo Pek Sung}

MD (UKM) MRCOG (UK)

Department of Obstetrics \&

Gynaecology, School of Medical

Sciences, Universiti Sains Malaysia Malaysia

\section{Abstract}

Mirror syndrome is a rare clinical condition in pregnancy associated with significant fetal mortality and maternal morbidity. It is characterized by a triad of complications: fetal hydrops, placenta oedema, and maternal oedema. We are reporting one case of late-onset Mirror syndrome in which the patient presented later in the gestation of 36 weeks due to excessive weight gain and clinical sign mimicking preeclampsia. Awareness of this disease is essential, as a failure of recognition will delay the treatment and cause higher maternal and perinatal morbidity and mortality

\section{Introduction}

Mirror syndrome is a rare clinical condition in pregnancy associated with significant fetal mortality and maternal morbidity. It is characterized by a triad of complications: fetal hydrops, placenta edema, and maternal edema. The reason for discussing this case is to highlight the high fetal mortality risk associated with this condition.

\section{Case Report}

A 29-year-old housewife in her third pregnancy at 36 weeks gestation was referred from a district hospital for severe preeclampsia when she presented with hypertensive crisis with headache and high proteinuria. Previously, she had been normotensive, non-proteinuric and all her antenatal follow-ups had been uneventful. Her serial ultrasound was completed and no gross abnormality was detected, with no evidence of fetal growth restriction. Four days before her presentation, she was noted to have an excessive weight gain of $7.5 \mathrm{~kg}$ in two weeks with prominent bilateral pedal edema and proteinuria and she was planned for blood pressure monitoring at a local clinic. During monitoring, the physician noted her blood pressure was high and she was referred to a tertiary center for severe preeclampsia. Assessment of the patient upon admission noted that she had anasarca, high blood pressure, and high proteinuria. Her uterus was larger than the gestational age. Ultrasound examination revealed a singleton fetus with breech presentation and generalized hydrops (scalp edema (Figure 1), pleural effusion, pericardial effusion, ascites (Figure 2), and generalized skin edema). The fetus also had cardiomegaly with atrioventricular cushion defect and a constricted right ventricular outflow (Figure 3). There was also a hyperplancentosis with a placenta thickness of $12.29 \mathrm{~cm}$ (Figure 4).
She was diagnosed with mirror syndrome and was started on magnesium sulfate infusion for the prevention of eclampsia. Her condition was stable, but the fetal prognosis was poor. The patient was then counseled for vaginal delivery with an induction of labor. She had an assisted vaginal breech delivery and a fresh stillbirth 3 $\mathrm{kg}$ female baby with edema and peeled skin was born (Figure 5). The placenta weight was $1.8 \mathrm{~kg}$ (Figure 6).

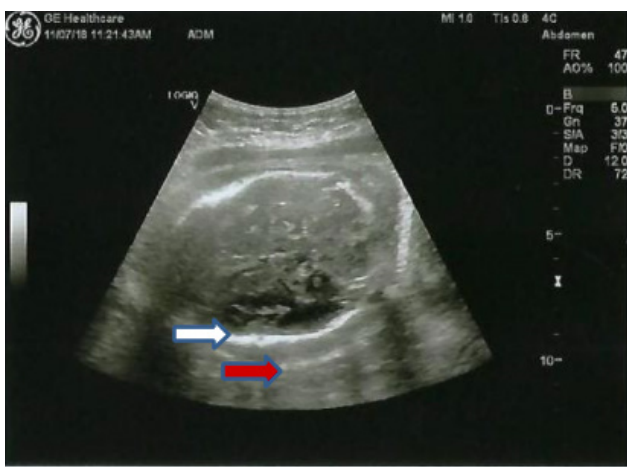

Figure 1: Transabdominal scan finding of scalp edema (white arrow: skull, red arrow: scalp). There was fluid collection in between these two structures.

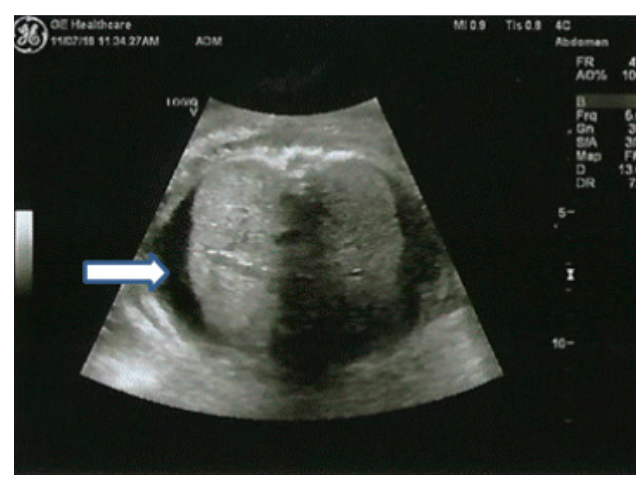

Figure 2: Transabdominal scan of fetal ascites (white arrow) and fluid accumulation in the abdominal cavity. 


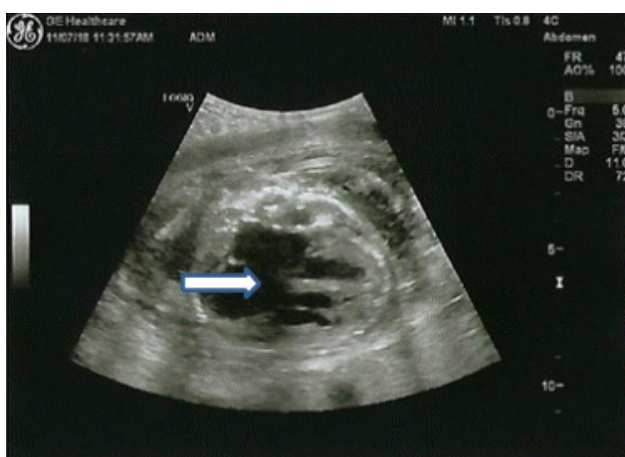

Figure 3: Transabdominal scan finding of cardiomegaly with atrioventricular cushion defect (white arrow).

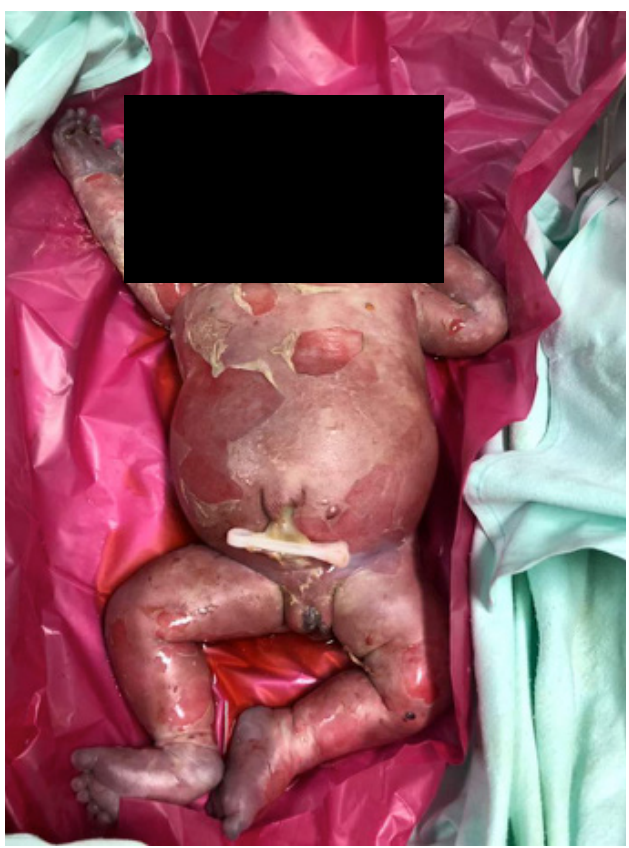

Figure 5: Hydrops fresh stillbirth with generalized skin edema and peeling of the skin.

She had massive primary postpartum hemorrhage secondary to uterine atony postdelivery which responded after a second-line uterotonic agent and insertion of a Bakri balloon tamponade. The massive primary postpartum hemorrhage required blood transfusion and was subsequently complicated with acute kidney injury. She was managed in the intensive care unit post-delivery and subsequently was transferred to the general ward.

She was nursed on a general ward for one week and discharged with antihypertension. At four weeks postpartum, she became normotensive, non-proteinuria, and her renal profile was normalized.

\section{Discussion}

Mirror syndrome, or Ballantyne syndrome, is

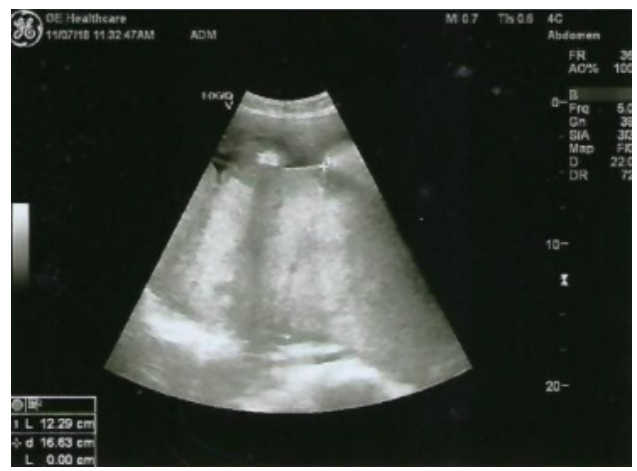

Figure 4: Transabdominal scan of hyperplacentosis (placenta thickness of $12.29 \mathrm{~cm}$ )

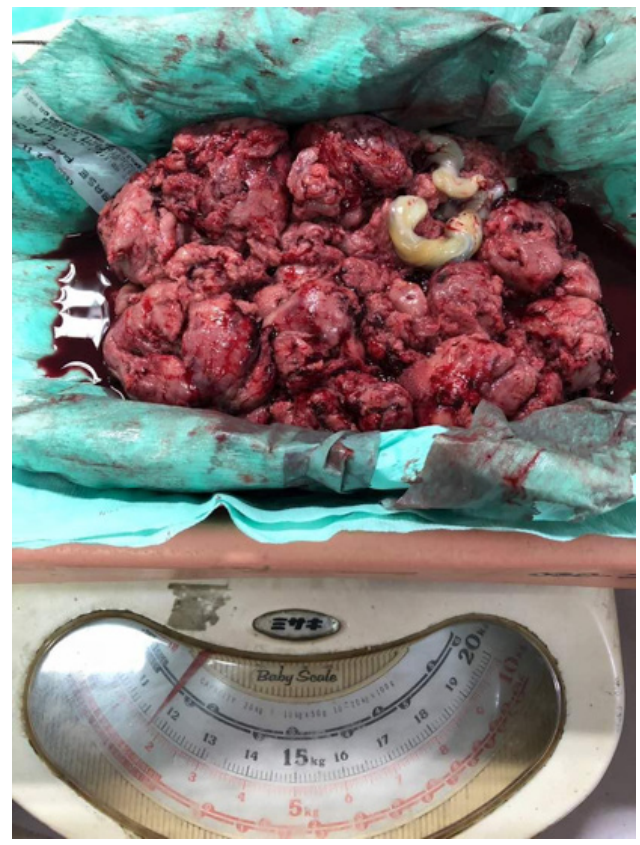

Figure 6: Placenta post-delivery weighing $1.8 \mathrm{~kg}$ which is more than a 1:6 ratio to fetal weight.

a rare clinical condition in pregnancy, which is characterized by fetal hydrops, placenta edema, and maternal edema. The syndrome mirrors the clinical fetal condition in the mother. The pathogenesis is unknown; however, a common hypothesis shared between mirror syndrome and preeclampsia is that a dysfunctional placenta releases anti-angiogenic factors into the maternal circulation. ${ }^{1}$ The incidence is about one case in 3,000 pregnancies; however, it could be under-reported as the clinical presentation is very similar to preeclampsia. ${ }^{2}$ In 1892 , John W. Ballantyne suggested that fetal hydrops was caused by Rhesus isoimmunization. However, a few years later, it was also found to be associated with mirror syndrome. In a retrospective study of 71 cases of fetal hydrops, mirror syndrome developed in $29 \%$ of the cases. ${ }^{3}$ A systematic review of associated fetal conditions, maternal presentation, and perinatal outcome concluded 
that mirror syndrome was associated with Rhesus isoimmunization (29\%), twin-twin transfusion syndrome (18\%), viral infection $(16 \%)$ and fetal malformations, fetal or placental tumors $(37.5 \%){ }^{4}$

The cause of fetal hydrops in our case is most likely due to a fetal heart abnormality leading to the development of mirror syndrome. The diagnosis was made late as it was not detected during follow-up. Ideally, all patients should be screened for fetal anomaly at 18 to 22 weeks gestation, as early detection of fetal anomalies at primary care would result in timely referral to an obstetrics and gynecology specialist for further management.

The presentation of mirror syndrome usually mimics preeclampsia. The onset of preeclampsia is generally after 20 weeks of gestation ${ }^{5}$ while in mirror syndrome, the onset ranged from 22.5 to 27.8 weeks of gestation. ${ }^{4}$ The presentation of mirror syndrome includes edema (80\%-100\%), hypertension $(57 \%-78 \%)$, and proteinuria $(20 \%-56 \%)$. The overall rate of intrauterine death was $56 \% .^{4}$ Maternal excessive weight gain with marked skin edema and uterine enlargement can also be distinguishable features in mirror syndrome. In contrast, elevated blood pressure and proteinuria can be present in both mirror syndrome and preeclampsia. ${ }^{5}$ Maternal symptoms disappeared 4.8 to 13.5 days after delivery. ${ }^{4}$

It is difficult to differentiate between preeclampsia and mirror syndrome from clinical assessment alone; however, hemodilution could be a main biological feature, differentiating mirror syndrome from usual preeclamptic syndromes. ${ }^{6}$ The hemoglobin, serum albumin levels, and uric acid are lower in mirror syndrome. The comparison between these conditions is summarized in Table $\mathbf{1}$

Table 1: Comparison between preeclampsia and mirror syndrome

\begin{tabular}{l|c|c|}
\hline \multicolumn{1}{|c|}{ Variable } & Mreeclampsia & Mirror syndrome \\
\hline Gestational age & More than 20 weeks of gestation & $16-34$ weeks of gestation \\
\hline Edema & Present & Markedly present \\
\hline Hypertension $(140 / 90)$ & Present & Not always present \\
\hline Proteinuria $(>300 \mathrm{mg} /$ day) & Present & Not always present \\
\hline Creatinine:urea ratio & Present & Not always present \\
\hline Thrombocytopenia & Present & Not always present \\
\hline Pulmonary edema & Present & Present \\
\hline Anemia & Hemoconcentration & Memodilution \\
\hline Placenta edema & Rare & Markedly present \\
\hline & Fetal & Polyhydramnios \\
\hline Hydrops & Rare & Present \\
\hline Amniotic fluid index & Oligohydramnios & Not always present \\
\hline Cardiac abnormality & Can be present & Present \\
\hline Intrauterine growth restriction & Usually present & Present \\
\hline Associated tumor & - & \\
\hline Fetal death & Not always present & \\
\hline
\end{tabular}

The fetal prognosis in established mirror syndrome is poor. The condition results in intrauterine fetal death in over $50 \%$ of cases. ${ }^{4}$ Case series add new evidence to support that early diagnosis of mirror syndrome, followed by fetal therapy and maternal clinical support, are critical for a good outcome. ${ }^{7}$ In those with an underlying correctable fetal anomaly or diseases such as fetal anemia and twin-to-twin transfusion syndrome, intervention during the antenatal period plays a vital role in the resolution of fetal condition and improves maternal and fetal outcome. The complications of mirror syndrome are pulmonary edema, acute respiratory distress syndrome, pericardial effusions, and renal failure. Pulmonary edema is the commonest complication and occurred in $21.4 \% .{ }^{4}$ In our case, the patient suffered from complications of mirror syndrome including severe preeclampsia, massive postpartum hemorrhage that required tamponade balloon institution, and blood transfusion. Following the 
complicated delivery, intrapartum, she had an acute renal injury and needed to be observed in the intensive care unit, and had hypertension in the early puerperium stage. Once the diagnosis of mirror syndrome is made, timely treatment is essential to achieve the best outcome for the mother. ${ }^{8}$

\section{Conclusion}

Early detection of the possible cause of fetal hydrops is very important and implementation of fetal therapy in a treatable cause, with consideration of early termination for other causes, may potentially decrease the risk of fetal mortality as well as maternal morbidity and mortality associated with mirror syndrome. Careful evaluation is needed to differentiate between preeclampsia and mirror syndrome because there may be a higher risk of maternal morbidity in mirror syndrome.

\section{How does this paper make a difference to general practice?}

- Excessive weight gain is commonly encountered during antenatal follow-up and should be investigated further.

- A fetal anomaly scan should be done at 18 to 22 weeks gestation to detect any structural anomalies in a primary setting with adequate ultrasound machine facilities and a skilled operator.

- Due to the similar clinical presentation of mirror syndrome and preeclampsia, it is crucial for early prompt recognition, identification of the cause, and early management of mirror syndrome. This will have an essential impact on maternal and fetal survival. Fetal therapy can be implemented in cases where the cause of mirror syndrome is treatable.

\section{References}

1. N. Graham, A. Garrod, P. Bullen, and A. E. P. Heazell, "Placental expression of antiangiogenic proteins in mirror syndrome: A case report," Placenta, vol. 33, no. 6, pp. 528-531, 2012, doi: 10.1016/j. placenta.2012.02.016.

2. S. Allarakia et al., "Characteristics and management of mirror syndrome: A systematic review (1956-2016)," J. Perinat. Med., vol. 45, no. 9. Walter de Gruyter GmbH, pp. 1013-1021, Dec. 20, 2017, doi: 10.1515/jpm-2016-0422.

3. G. Hirata, S. Aoki, K. Sakamaki, T. Takahashi, F. Hirahara, and H. Ishikawa, "Clinical characteristics of mirror syndrome: A comparison of 10 cases of mirror syndrome with non-mirror syndrome fetal hydrops cases," J. Matern. Neonatal Med., vol. 29, no. 16, pp. 2630-2634, 2016, doi: $10.3109 / 14767058.2015 .1095880$.
4. T. Braun et al., "Mirror syndrome: A systematic review of fetal associated conditions, maternal presentation and perinatal outcome," Fetal Diagn. Ther., vol. 27, no. 4, pp. 191-203, 2010, doi: $10.1159 / 000305096$.

5. S. F. Navarro-Perez, K. Corona-Fernandez, J. L. Rodriguez-Chavez, A. Bañuelos-Franco, and M. G. Zavala-Cerna, "Significant Clinical Manifestations in Ballantyne Syndrome, after a Case Report and Literature Review: Recognizing Preeclampsia as a Differential Diagnosis," Case Rep. Obstet. Gynecol., vol. 2019, pp. 1-7, 2019, doi: 10.1155/2019/2013506.

6. C. R. Mathias and C. Rizvi, "The diagnostic conundrum of maternal mirror syndrome progressing to preeclampsia - A case report," Case Rep. Womens Health, vol. 23, p. e00122, 2019, doi: 10.1016/j.crwh.2019.e00122.
7. A. Chimenea, L. García-Díaz, A. M. Calderón, M. M. D. Las Heras, and G. Antińolo, "Resolution of maternal Mirror syndrome after successful fetal intrauterine therapy: A case series," BMC Pregnancy Childbirth, vol. 18, no. 1, pp. 1-5, 2018, doi: 10.1186/s12884-018-1718-0.

8. H. Li and W. Gu, "Mirror syndrome associated with heart failure in a pregnant woman : a case report," Int J Clin Exp Med, vol. 8, no. 9, pp. 16132-16136, 2015. 


\title{
Aural polyp with facial asymmetry in an unfortunate infant
}

\author{
Farah Syahida Zubir, Jeyasakthy Saniasiaya, Haslinda Abdul Gani \\ Syahida Zubir F, Saniasiaya J, Abdul Gani H. Aural polyp with facial asymmetry in an unfortunate infant. Malays Fam Physician. 2021;16(1);133-135. \\ https://doi.org/10.51866/cr1070
}

\section{Keywords:}

rhabdomyosarcoma, temporal bone, facial palsy

\section{Authors:}

\section{Jeyasakthy Saniasiaya}

(Corresponding author)

Department of Otorhinolaryngology

Faculty of Medicine, University of

Malaya, Kuala Lumpur, Malaysia

Email: shakthy_18@yahoo.com

\section{Farah Syahida Zubir}

Department of Otorhinolaryngology

Hospital Tuanku Jaáfar, Seremban

Negeri Sembilan, Malaysia

Department of Otorhinolaryngology Faculty of Medicine, University of Malaya, Kuala Lumpur, Malaysia

\section{Haslinda Abdul Gani}

Department of Otorhinolaryngology Hospital Tuanku Jaáfar, Seremban

Negeri Sembilan, Malaysia

\begin{abstract}
Temporal bone rhabdomyosarcoma is an aggressive entity that simulates chronic otitis ear infection. It is the most common soft tissue sarcoma amongst pediatric patients. Herein, we would like to report a case of temporal bone rhabdomyosarcoma involving a 2-year-old boy who presented with a one-month history of otorrhea with facial asymmetry. Early treatment led to remission of this severe neoplasm.
\end{abstract}

\section{Introduction}

Rhabdomyosarcoma (RMS) is the third most common neoplasm in childhood, behind only neuroblastoma and nephroblastoma. ${ }^{1}$ Approximately $35 \%$ of all pediatric RMS cases occur within the head and neck, with orbit being the most common site. Involvement of the ear and the temporal bone region, albeit rare, have been reported amongst children. ${ }^{2}$ Clinical presentation of temporal bone RMS may resemble features of chronic suppurative otitis media, ${ }^{2}$ which may contribute to its delayed diagnosis. ${ }^{3}$ Advanced disease, however, will present with cranial nerve palsies and intracranial extension features. ${ }^{4}$

\section{Case Report}

A previously healthy 2-year-old-boy was referred to our center with a 1-month history of left otorrhea and facial asymmetry. According to his mother, the ear discharge was persistent despite being treated multiple times with ear drops and antibiotics. There were no signs of otalgia and the child remained afebrile. The mother, however, noticed left facial asymmetry two weeks later with no other signs of meningism or raised intracranial pressure. Besides that, the child was active and tolerating orally well.

Upon assessment, the child was comfortable under room air. Otoscopic examination revealed a polypoidal, fragile mass occupying the entire ear canal with purulent discharge. Facial asymmetry was lower motor neuron HouseBrackman Grade III. Besides that, other nose and throat examinations were unremarkable. The child was admitted and was commenced on intravenous Ceftriaxone and intravenous steroids. High-resolution computed tomography (CT) temporal bone revealed soft tissue density filling the entire left external and middle ear cavities with extensive erosion of ossicles, scutum, tegmen tympani, facial canal (both tympanic and mastoid segment) and mastoid air cells (Fig.1). Mastoid exploration was carried out, which revealed an extensive mass occupying the mastoid cavity and middle ear, causing erosion of the mastoid cortex, suprameatal and posterior meatal wall. Histopathological examination of the mass showed fragments of polypoidal tissue covered by squamous epithelium infiltrated by atypical cells exhibiting large hyperchromatic and pleomorphic cells with prominent nucleoli (Fig.2). These cells also express Desmin and Myogenin, negative for LCA, PanCK and S100 with proliferative index as high as $90 \%$, which is consistent with embryonal rhabdomyosarcoma. The parents were counselled and the child was referred to the oncology unit for chemoradiotherapy. The child underwent 23 fractions of radiotherapy under general anesthesia. Upon subsequent imaging and follow-up, the disease is stable with no evidence of recurrence.

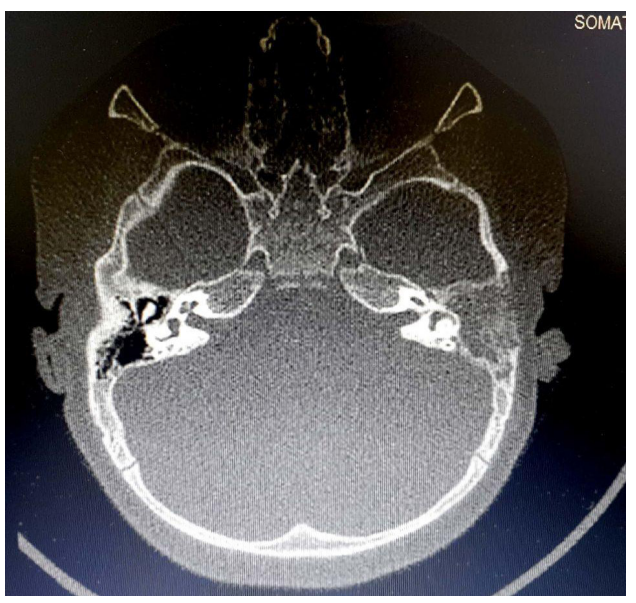

Figure 1. 


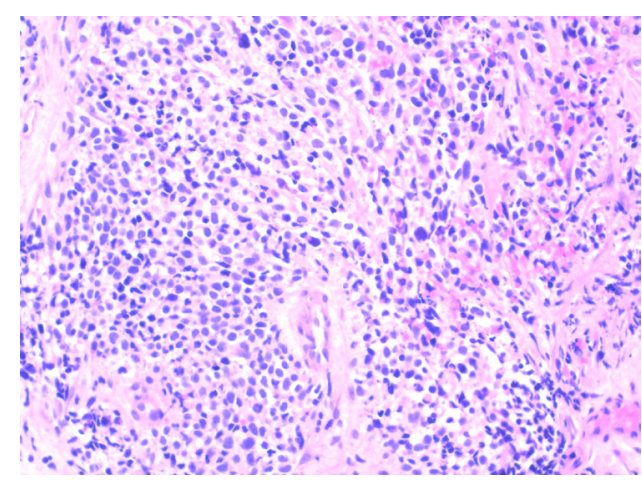

Figure 2.

\section{Discussion}

RMS is the most common soft-tissue malignancy seen in childhood. ${ }^{5}$ It may originate in any anatomical site, occurring predominantly in the head and neck regions, orbits, skull base, nasal cavity, and nasopharynx, where there is little or no musculoskeletal tissue. ${ }^{6}$ It has a bimodal age distribution, with the first peak between ages 3 and 5 years and the second peak between ages 14 and 18 years.

A retrospective study of children with temporal bone RMS found that the mean time between symptom onset and diagnosis was 7 weeks and the most common manifestation $(66 \%$ of patients) was otitis media unresponsive to treatment. ${ }^{8}$ According to Prat and Gray, who analyzed symptoms of RMS of the middle ear in 50 patients, $54 \%$ presented with polypoid masses in the external auditory canal, $40 \%$ with otorrhea, $30 \%$ with otorrhagia, $22 \%$ with otalgia, and $14 \%$ with facial nerve palsy. ${ }^{9}$ In our patient, he presented with unresolving otorrhea which may mimic chronic otitis media. However, it was when he developed facial asymmetry that a more serious explanation was suggested. Our initial differential diagnosis for this patient includes cholesteatoma, RMS and Langerhans cells histiocytosis (LCH).

Cholesteatoma in the pediatric population demonstrated an annual incidence of 2.9 per 100000 children. ${ }^{1}$ In parallel with increasing awareness of cholesteatoma, with the aid of otoscopic and endoscopic ear examination, children with congenital cholesteatoma are usually asymptomatic. Unlike RMS, cholesteatoma presents with a white mass behind an intact ear drum, or a deep retraction pocket with or without granulation and skin debris $^{2}$ Although facial nerve palsy can occur as a complication of cholesteatoma, it has been reported only in approximately 4.3\% of patients. ${ }^{3}$ In children with temporal bone RMS, though, the incidence is higher. Durve et al reported a case series in which 9 out of 14 (64\%) children with RMS of ear and temporal bone had facial nerve paralysis as part of their presentation. $^{4}$

It is a common practice in the treatment of children to perform imaging prior to biopsy so as to avoid unwarranted complications such as a torrential bleed from a vascular tumor. Temporal bone CT with contrast is the imaging of choice as it better delineates bony involvement. Magnetic resonance imaging (MRI) with contrast is most specific for diagnosing soft-tissue tumors and assessing meningeal invasion. ${ }^{8}$ The imaging characteristics for RMS and $\mathrm{LCH}$ are similar, but the primary site of involvement is different. ${ }^{10}$ According to Chevalier et al, the most common subsite of the temporal bone involved for LCH is mastoid while for RMS it is typically confined to the anterior part of the temporal bone. RMS demonstrates a homogeneous lesion with mild contrast enhancement in CT whilst on MRI it typically appears as a homogenous mass, isointense or minimally hyperintense relative to muscle on T1-weighted images and hyperintense relative to both muscle and fat on T2-weighted images, with postcontrast images showing enhancement of the tumor. ${ }^{11}$ As RMS does not arise from the bone, bony erosion is considered a poor prognostic sign.

RMS of the head and neck region falls into three categories: $51 \%$ of cases occur in the parameningeal region (nose, paranasal sinuses, middle ear and mastoid); $24.5 \%$ of cases present in the non-parameningeal region (parotid gland, oral cavity and larynx); and $24.5 \%$ of cases are in the orbit. RMS of the ear is rare, with only approximately $3 \%$ of patients presenting with the middle ear disease. In this case, RMS occupies the middle ear and mastoid. Histologically, RMS resembles normal skeletal muscle before innervation, and there are several pathologic subtypes of RMS: embryonal, botryoid, alveolar, pleomorphic, spindle cell, and anaplastic variants. ${ }^{12}$ The embryonal RMS comprises approximately $60-70 \%$ of RMS cases, ${ }^{13}$ which incidentally is our patient's histology. Embryonal subtypes have a better prognosis compared to other subtypes.

Complete surgical resection of the lesion may not only be technically difficult, but may result in significant cosmetic deformity ${ }^{14}$ Recent trends suggest that radical resection procedures are deemed redundant as the advent 
and advancement of chemoradiotherapy has dramatically improved the survival rate. ${ }^{2}$ Indeed, survival rates have improved so much that the International Society of Pediatric Oncology have been able to complete remission in $91 \%$ of patients with non-metastatic disease. ${ }^{15}$

\section{Conclusion}

Rhabdomyosarcoma of the temporal bone is an aggressive tumor which may mimic chronic otitis media. High index of suspicion is warranted in the context of persistent otitis media unresponsive to medical treatment. Immediate imaging followed by mastoid exploration is therefore recommended with presence of mass in external auditory canal with facial asymmetry. Early diagnosis and prompt management with multimodal therapy offers the best outcome amongst pediatric temporal bone rhabdomyosarcoma.

\section{How does this paper make a difference to general practice?}

- Presentation of otorrhea with facial asymmetry should alert physician of a more serious condition such as malignancy

- Persistent otorrhea with aural polyp in children should be investigated thoroughly, which should include biopsy and imaging

- In addition to histopathological investigations, immunohistochemical study is salient for accurate diagnosis

- Prompt investigation, diagnosis and management has revealed good prognosis

\section{References}

1. Stiller CA, Parkint DM. International variations in the incidence of childhood softtissue sarcomas. Paediatr Perinat Epidemiol. 1994;8(1):107-119.

2. Durve DV, Kanegaonkar RG, Albert D, Levitt G. Paediatric rhabdomyosarcoma of the ear and temporal bone. Clin Otolaryngol Allied Sci. 2004;29(1):32-37.

3. Alho O-P, Teppo H, Mäntyselkä P, Kantola $S$. Head and neck cancer in primary care: presenting symptoms and the effect of delayed diagnosis of cancer cases. Cmaj. 2006;174(6):779-784.

4. Ragab A, Abdulber Fakoury M, Kassouma J, Moustafa K, Al Salem FM. Botryoid rhabdomyosarcoma in mastoid and middle ear in a 4-year-old boy: A rare case report. Hamdan Med J. 2018;11(3):130.

5. Jan MMS. Facial paralysis: a presenting feature of rhabdomyosarcoma. Int J Pediatr Otorhinolaryngol. 1998;46(3):221-224.
6. Arita K, Sugiyama K, Tominaga A, Yamasaki F. Intrasellar rhabdomyosarcoma: case report. Neurosurgery. 2001;48(3):677-680.

7. Vlaški L, Vučković N, Dragičević D, Kljajić $\mathrm{V}$, Seničar S. Prolonged peripheral facial nerve paralysis in a child - think of temporal bone rhabdomyosarcoma: case report. Open Med. 2014;9(2):226-230.

8. Sbeity S, Abella A, Arcand P, Quintal MC, Saliba I. Temporal bone rhabdomyosarcoma in children. Int J Pediatr Otorhinolaryngol. 2007;71(5):807-814.

9. Prat J, Gray GF. Massive neuraxial spread of aural rhabdomyosarcoma. Arch Otolaryngol. 1977;103(5):301-303.

10. Chevallier KM, Wiggins RH, Quinn NA, Gurgel RK. Differentiating pediatric rhabdomyosarcoma and langerhans cell histiocytosis of the temporal bone by imaging appearance. Am J Neuroradiol. 2016;37(6):1185-1189.
11. Lee JH, Lee MS, Lee BH, et al. Rhabdomyosarcoma of the head and neck in adults: MR and CT findings. Am J Neuroradiol. 1996;17(10):1923-1928.

12. Vegari S, Hemati A, Baybordi $H$, Davarimajd L, Chatrbahr G. Embryonal Rhabdomyosarcoma in Mastoid and Middle Ear in a 3-Year-Old Girl: A Rare Case Report. Case Rep Otolaryngol. 2012;2012(Figure 2):1-3.

13. Vegari S, Hemati A, Baybordi $\mathrm{H}$, Davarimajd L, Chatrbahr G. Embryonal rhabdomyosarcoma in mastoid and middle ear in a 3-year-old girl: a rare case report. Case Rep Otolaryngol. 2012;2012.

14. Wiatrak BJ, Pensak ML. Rhabdomyosarcoma of the ear and temporal bone. Laryngoscope. 1989;99(11):1188-1192.

15. Maurer HM, Gehan EA, Beltangady M, et al. The intergroup rhabdomyosarcoma study-II. Cancer. 1993;71(5):1904-1922. 


\title{
Acute ptosis as a presentation of preseptal cellulitis leading to cerebral abscess in a patient with uncontrolled diabetes
}

\author{
Nor Roziah Razali, Yao Mun Choo \\ Razali NR, Choo YM. Acute ptosis as a presentation of preseptal cellulitis leading to cerebral abscess in a patient with uncontrolled diabetes. \\ Malays Fam Physician. 2021;16(1);136-138. https://doi.org/10.51866/cr1010
}

\section{Keywords:}

ptosis, preseptal cellulitis,

cerebral abscess, diabetes

\section{Authors:}

\section{Choo Yao Mun}

(Corresponding author)

MBBS (Hons)(Monash), MRCPCH

(UK)

Associate Professor, Department of

Paediatrics, Faculty of Medicine

University of Malaya, Kuala Lumpur

Malaysia

Email: yaomun@um.edu.my

\section{Nor Roziah Razali}

$M D$

Department of Emergency Medicine University Malaya Medical Centre Kuala Lumpur, Malaysia

\section{Abstract}

Acute ptosis due to preseptal cellulitis requires urgent medical attention, as the infection can extend posteriorly into the orbit, leading to significant visual and cerebral complications. We report a case of a 58-year-old woman with uncontrolled diabetes mellitus presenting with acute ptosis due to preseptal cellulitis. After initial resolution of fever with intravenous amoxicillin-clavulanate, she experienced a seizure due to cerebral abscess a week later and was treated with intravenous ceftriaxone. Preseptal cellulitis is usually treated on an outpatient basis with oral antibiotics, as it rarely extends posteriorly to cause cerebral complications. We wish to highlight the importance of admitting patients with preseptal cellulitis in patients with uncontrolled diabetes for intravenous antibiotics due to the potential for visual and cerebral complications.

\section{Introduction}

Acute ptosis is a medical emergency requiring urgent assessment. Ptosis results from dysfunction of the muscles that raise the eyelid or their nerve supply (oculomotor nerve for the levator palpebrae superioris and sympathetic nerves for the superior tarsal muscle). Preseptal cellulitis is one of numerous causes of acute ptosis, which can lead to posterior extension of the infection, causing meningitis and cerebral abscess.

\section{Case Report}

We report a case of a 58-year-old female with uncontrolled diabetes mellitus complaining of 3-day history of right eye ptosis, fever, rhinitis, and diarrhea. The right eyelids were inflamed, but the pupils and extraocular movements of the eye were normal. Visual acuity, cranial nerves, and neurological examination were unremarkable. Blood sugar was $19.9 \mathrm{mmol} / \mathrm{L}$ with $\mathrm{HbAlC}$ of $12.2 \%$. She was treated with intravenous amoxicillin-clavulanate for preseptal cellulitis with resolution of fever, rhinitis, and diarrhea. However, ptosis persisted, and she developed seizures one week later with new onset of pyrexia.

Clinically, nystagmus and lip-smacking were observed. Lumbar puncture showed biochemical meningitis with sterile cultures. Computed tomography revealed preseptal fluid collection with subdural collection, leptomeningeal enhancement, and a rim-enhancing lesion over the right frontal region consistent with preseptal cellulitis leading to partially treated meningitis complicated by cerebral abscess. She was treated with intravenous ceftriaxone for 8 weeks with complete resolution.

\section{Discussion}

Acute ptosis can be caused by the aponeurosis of the levator muscle, nerve abnormalities,trauma,i nflammation, or lesions of the lid (e.g.,preseptal cellulitis) or orbit. $^{1}$ Preseptal cellulitis describes an infection of the eyelid in which superficial periorbital soft tissues anterior to the orbital septum are affected and the orbital structures posterior to the septum are not affected. ${ }^{2}$ Two basic mechanisms operate in the formation of preseptal cellulitis. The first involves spreading of a local infection to the eyelid. In this process, the source of infection is penetrating trauma around the eyes or an infection of the skin or subcutaneous tissue, such as acute dacryocystitis, hordeolum, infected chalazion, severe conjunctivitis, impetigo, and erysipelas. Other causes include eye surgery or insect bites. In the second mechanism, the septicity originates from the focus of the infection, which is far from the orbit. ${ }^{3}$

Preseptal cellulitis typically presents with eyelid edema and erythema. The extent of infection is superficial and does not normally extend posteriorly into the orbit in a mild infection. In contrast, orbital cellulitis is recognized to cause cerebral complications. Visual acuity pupillary reactions, extraocular motility, and intraocular 
pressures are normal. Periorbital tissues may become infected as a result of trauma (including insect bites) or primary bacteremia. Differential diagnoses of preseptal cellulitis includes orbital cellulitis, adenoviral keratoconjunctivitis, allergic conjunctivitis, contact dermatitis, hordeolum, Kawasaki's disease, idiopathic orbital inflammation, thyroid eye disease, dacryocystitis, and dacryoadenitis. The Chandler Classification of Orbital Complications staging system ${ }^{4}$ is as follows:

- Stage I - Preseptal cellulitis

- Stage II - Inflammatory orbital edema

- Stage III - Subperiosteal abscess

- Stage IV - Orbital abscess

- Stage V - Cavernous sinus thrombosis.

The most common organisms are Staphylococcus aureus, Staphylococcus epidermidis, Streptococcus species, and anaerobes, which are bacteria that usually cause upper respiratory tract infections and external eyelid infections. Multiple factors can cause preseptal cellulitis, such as ocular trauma, paranasal sinusitis, upper respiratory tract infection, acute or chronic otitis media, and dental origin. Various antibiotic regimens have been used for the treatment of preseptal cellulitis, such as ampicillin, clindamycin, cephalexin, cefuroxime, ampicillin with sulbactam, and chloramphenicol. Preseptal cellulitis is usually treated on an outpatient basis with oral antibiotics. However, in immunocompromised patients, such as those with uncontrolled diabetes mellitus, prompt treatment with intravenous antibiotics is recommended. ${ }^{5}$

Preseptal cellulitis requires accurate diagnosis, as infection in immunocompromised patients can progress posteriorly into the orbit, potentially leading to significant visual and cerebral complications. Most complications are thought to be minimal, with the infection involving only the eyelid and superficial periorbital soft tissues without affecting the orbital structures, especially

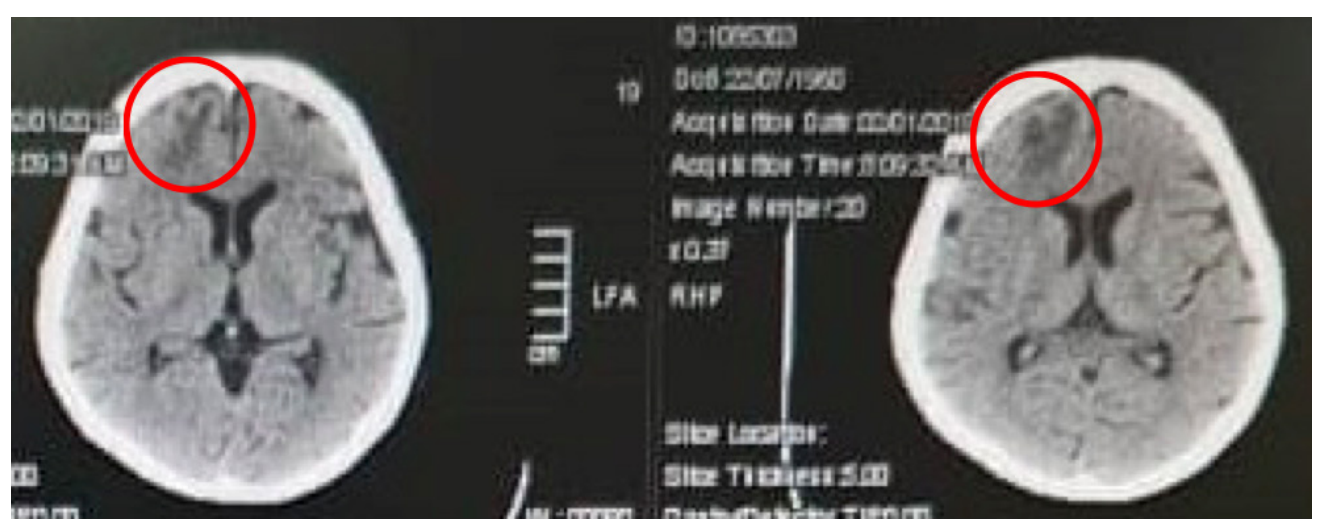

Figure 1: CT Brain showing preseptal fluid collection with subdural collection, leptomeningeal enhancement, and rim-enhancing lesion over the right frontal region if the condition is treated early during the course of infection. Prognosis is usually good with prompt diagnosis and treatment. However, complications can develop even with prompt treatment. Orbital extension and complications, such as orbital cellulitis, subperiosteal abscess, orbital abscess, or cavernous sinus thrombosis, can occur. ${ }^{6}$

Necrotizing fasciitis, a rare complication caused by $\beta$-hemolytic Streptococcus, can lead to necrosis and toxic shock syndrome. Central nervous system involvement with meningitis and cerebral abscess can occur after orbital extension. However, meningitis can occur even in the absence of significant clinical signs, leading to cerebral abscess.

Most case reports highlight septal cellulitis causing cerebral complications. In our case, this presentation of isolated unilateral ptosis was not typical of a neurogenic cause as the patient presented with preseptal cellulitis. Infections of the eyelids, nasolacrimal duct, conjunctiva, and corneal surface occur more frequently in people with uncontrolled diabetes. Administration of prompt intravenous antibiotics in immunocompromised patients, especially in the case of uncontrolled diabetes, is required in preseptal cellulitis due to the risk of hematogenous spread posteriorly, considering that some general practitioners may treat this condition on an outpatient basis with oral antibiotics. A CT scan is recommended in the case of marked eyelid swelling, fever, leukocytosis, suspected abscess, or no improvement after 24 hours on the proper antibiotics. ${ }^{4}$

In conclusion, acute ptosis caused by preseptal cellulitis in patients with uncontrolled diabetes mellitus requires diligent consideration of the possibility of intracranial infective extension causing meningitis and cerebral abscess. Cerebral abscess, though a rare complication of preseptal cellulitis, requires careful consideration in diabetic patients. 


\section{How does this paper make a difference to general practice?}

- This paper highlights the importance of recognizing preseptal cellulitis in a patient with uncontrolled diabetes and prioritizes administering intravenous antibiotics rather than oral antibiotics for immunocompromised patients.

- A CT scan is recommended in the case of marked eyelid swelling, fever, leukocytosis, suspected abscess, or no improvement after 24 hours on the proper antibiotics.

- Although septal cellulitis is known to cause cerebral complications, preseptal cellulitis can also lead to cerebral complications. Therefore, recognition of potential complications in an uncontrolled diabetic patient is important.

\section{References}

1. Carrie LM, David AC. Acquired ptosis: evaluation and management. American Academy of Ophthalmology [cited 10 August 2019]. Available from https://www.aao.org/ eyenet/article/acquired-ptosis-evaluationmanagement

2. Chaudhry IA,ShamsiFA. Outcome of treated orbital cellulitis in a tertiary eye care center in the Middle East. Ophthalmology. 2007;114(2):345-54.
3. Wald ER. Periorbital and orbital infections. Infect Dis Clin N Am. 2007;21(2):393-408.

4. Bae C, Bourget D. Periorbital cellulitis. [Updated 2020 Jul 21]. In: StatPearls. Treasure Island (FL): StatPearls Publishing; 2020. Available from: https://www.ncbi.nlm.nih.gov/ books/NBK470408.
5. Howe L., Jones NS. Guidelines for the management of periorbital cellulitis/abscess. Clin Otolaryngol. 2004;29:725-728.

6. Seongmu L,Michael T. Management of preseptal and orbital cellulitis. Saudi J Ophthalmol. 2011;25(1):21-29. 
